Florida International University

FIU Digital Commons

$11-9-2018$

\title{
Material Girls: Consumption and the Making of Middle Class Identity in the Experiences of Black Single Mothers in the Washington, DC Metropolitan area
}

Aysha L. Preston Ph.D.

Florida International University, apres032@fiu.edu

Follow this and additional works at: https://digitalcommons.fiu.edu/etd

Part of the African American Studies Commons, Family, Life Course, and Society Commons, Gender and Sexuality Commons, Race and Ethnicity Commons, Social and Cultural Anthropology Commons, and the Women's Studies Commons

\section{Recommended Citation}

Preston, Aysha L. Ph.D., "Material Girls: Consumption and the Making of Middle Class Identity in the Experiences of Black Single Mothers in the Washington, DC Metropolitan area" (2018). FIU Electronic Theses and Dissertations. 3856.

https://digitalcommons.fiu.edu/etd/3856

This work is brought to you for free and open access by the University Graduate School at FIU Digital Commons. It has been accepted for inclusion in FIU Electronic Theses and Dissertations by an authorized administrator of FIU Digital Commons. For more information, please contact dcc@fiu.edu. 


\section{FLORIDA INTERNATIONAL UNIVERSITY}

Miami, Florida

MATERIAL GIRLS: CONSUMPTION AND THE MAKING OF MIDDLE CLASS IDENTITY IN THE EXPERIENCES OF BLACK SINGLE MOTHERS IN THE WASHINGTON, DC METROPOLITAN AREA

A dissertation submitted in partial fulfillment of the requirements for the degree of DOCTOR OF PHILOSOPHY

in

GLOBAL AND SOCIOCULTURAL STUDIES

by

Aysha Louise Preston 
To: Dean John F. Stack

School of International and Public Affairs

This dissertation, written by Aysha Louise Preston, and entitled Material Girls:

Consumption and the Making of Middle Class Identity in the Experiences of Black Single Mothers in the Washington, DC Metropolitan Area, having been approved in respect to style and intellectual content, is referred to you for judgment.

We have read this dissertation and recommend that it be approved.

Alexandra Cornelius

Jean Muteba Rahier

Benjamin Smith

Vrushali Patil, Major Professor

Date of Defense: November 9, 2018

The dissertation of Aysha Louise Preston is approved.

Dean John F. Stack School of International and Public Relations

Andrés G. Gil

Vice President for Research and Economic Development and Dean of the University Graduate School

Florida International University, 2018 
(C) Copyright 2018 by Aysha Louise Preston

All rights reserved. 


\section{DEDICATION}

I dedicate this to my mother and grandmothers; who have taught me strength and determination in life and have made this moment possible. 


\section{ACKNOWLEDGMENTS}

I would like to thank my family for their continuous support as I embarked on this journey to complete the requirements for a $\mathrm{PhD}$. My mother, Monica Jones, has encouraged me to see this project through the finish line. My grandmother, Carolyn Preston, was always available to listen and share her positivity and light.

My friends, both from home and new friends made as a student at FIU have been a major system of support for me as I worked to complete this degree. My incoming cohort, Masonya Bennett, Abby Gondek, and Mariama Jaiteh made Miamiliving fun and enjoyable, while also being true friends and supporters as I continued through this program. Thank you for your understanding and for always being available to listen to my frustrations and rejoices. I would like to especially thank my partner, Jamil Bonnick, and my childhood friend, Yvonne Nash, for everything they have done over these past few years to help me reach my goals.

I would like to thank Florida International University for the generous financial support which allowed me to complete the requirements for this degree. I was fortunate to receive a Masters-level Teaching Assistantship through the African and African Diaspora Studies program and a Doctoral-level Teaching Assistantship through the Department of Global and Sociocultural Studies. Both opportunities provided me invaluable hands-on experience and covered my academic expenses for the first four years of my program. I also received funding from the Smithsonian Institution to conduct archival research for this dissertation at the National Museum of American History. There, my mentors, Omar Eaton Martinez, David Haberstich, and Vanessa Broussard assisted my archival research and helped me to prepare for a career in the museum field. 
I would like to thank my committee members. My dissertation chair, Dr. Vrushali Patil, was very understanding and supportive throughout this process. She provided timely suggestions and notes that helped me to produce this final manuscript. I thank Dr. Patil for her patience and guidance as a I conducted field research, worked on the dissertation, and began my professional career. I would also like to especially thank Dr. Jean Rahier, who from my first visit to Florida International University as a prospective student, welcomed me and provided guidance throughout my academic career. Dr. Rahier's continued support of my work has been paramount. Finally, thank you to Dr. Alexandra Cornelius and Benjamin Smith who have both inspired and reassured me as I worked to complete this dissertation and have been available to provide critical feedback, assistance, and encouragement throughout my time at FIU. 
ABSTRACT OF THE DISSERTATION

MATERIAL GIRLS: CONSUMPTION AND THE MAKING OF MIDDLE CLASS

IDENTITY IN THE EXPEREIENCES OF BLACK SINGLE MOTHERS IN THE

WASHINGTON, DC METROPOLITAN AREA

by

Aysha Louise Preston

Florida International University, 2018

Miami, Florida

Professor Vrushali Patil, Major Professor

This dissertation explores the ways in which black single mothers in the Washington, DC metropolitan area use material goods and consumption practices to inform their identities as members of the middle class. Black middle class women are challenging stereotypes surrounding single mother households, the idea of family, and class status in the United States, as more women overall are having children while single, delaying or deciding against marriage, and are entering the middle and uppermiddle classes as a result of advanced education and career opportunities. Because of these demographic and sociocultural shifts, the romanticized "nuclear family" which consists of a married heterosexual couple and their children is becoming less authoritative as a symbol of middle class status. Instead, the middle class is represented through lifestyle options such as home ownership, neighborhood selection, fashion choices, education, and leisure activities. In the Washington, DC metro area, black women are asserting their single status while employing strategies to raise their children and excel professionally in order to maintain a middle class lifestyle. 
In this dissertation I examine black women, who are both single mothers and nonpoor, as an understudied, but constructive group in the DC metro area. Through ethnographic field research, I explored their experiences in the home, workplace, and greater community by employing a mixed methods approach including participant observation, semi-structured interviews, and focus groups. I demonstrate the ways material goods and experiences shape their complex identifies against and in support of various stereotypes. This research is unique in its focus on the black middle class from a new perspective and contributes to scholarly literatures on class and identity formation, black womanhood and motherhood, and material culture. 


\section{TABLE OF CONTENTS}

CHAPTER

PAGE

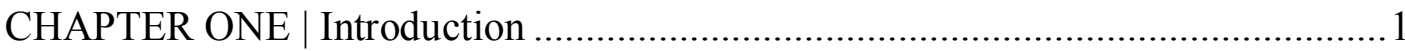

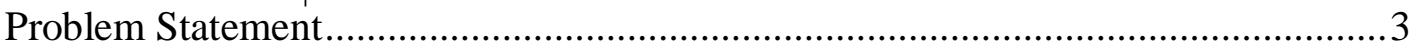

Defining: Black Middle Class Single Mothers ........................................................ 8

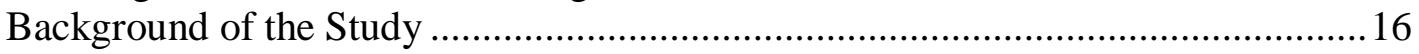

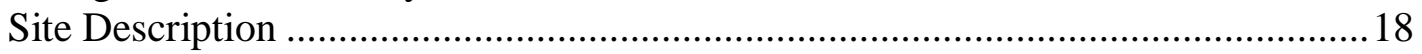

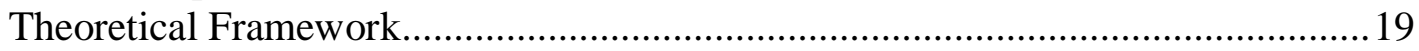

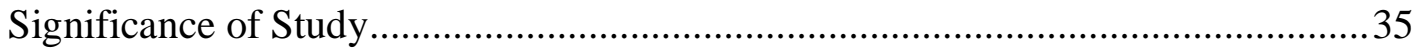

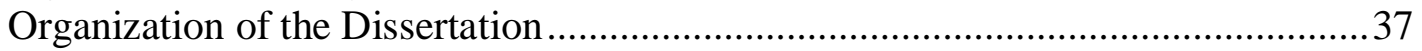

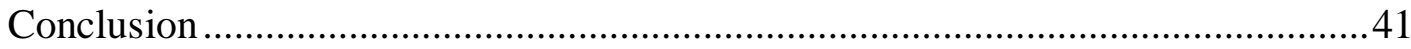

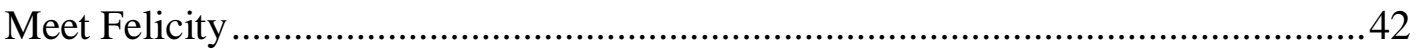

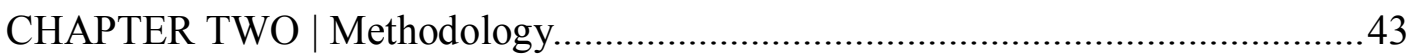

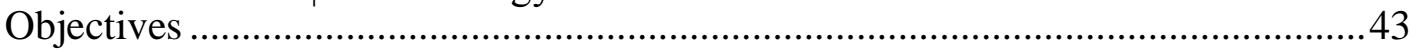

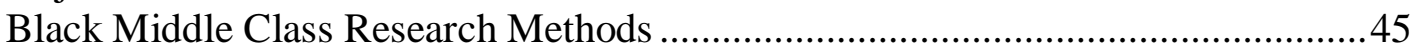

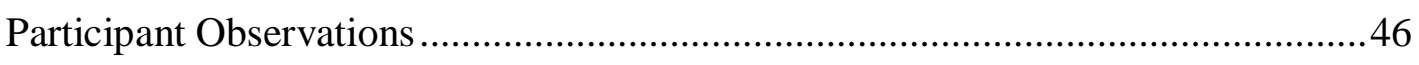

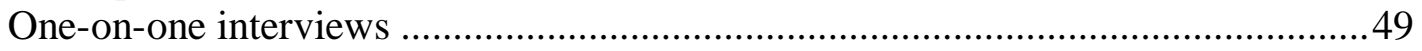

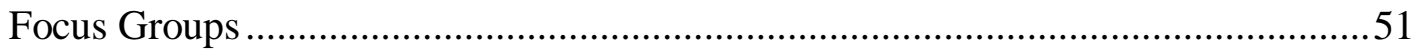

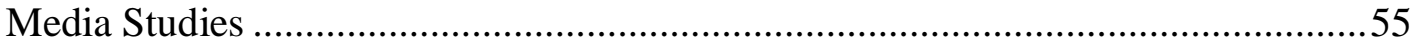

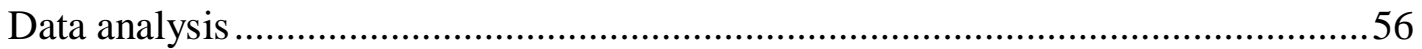

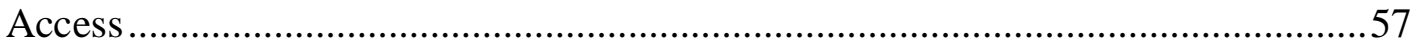

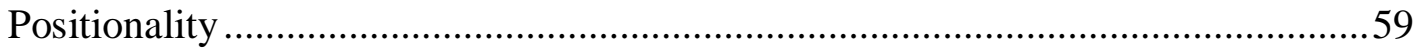

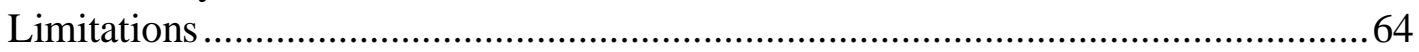

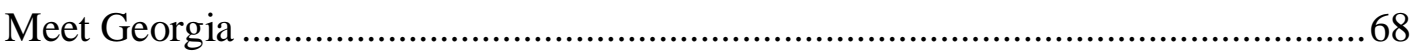

CHAPTER THREE | Chocolate City No More: The Displacement of African Americans and the Rapidly Changing Demographic in Washington, DC ............... 70

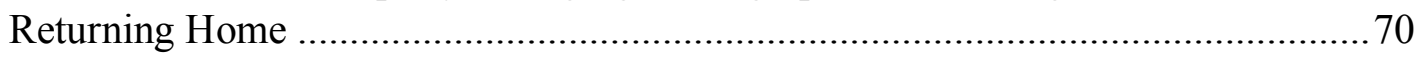

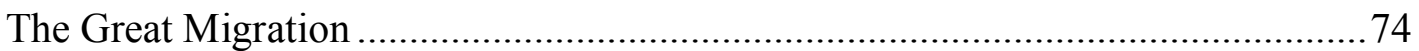

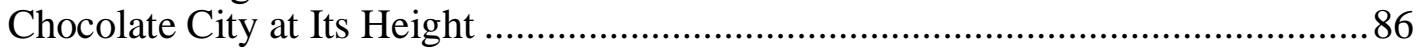

Drugs, Politics, and Scandals - The Great Decline..................................................97

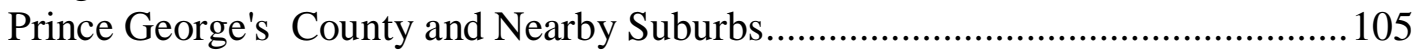

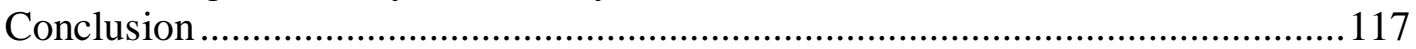

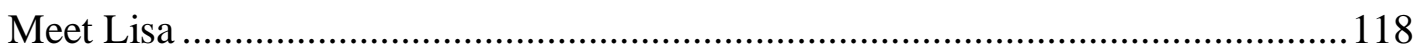

CHAPTER FOUR | It's Not Can I do it, But How Can I Do It?: Black Women,

Work, and Single Motherhood ............................................ 120

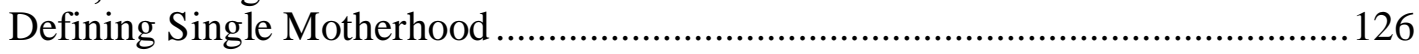

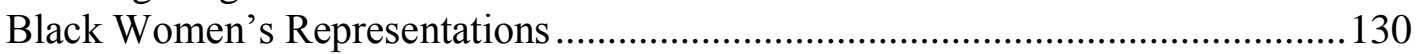

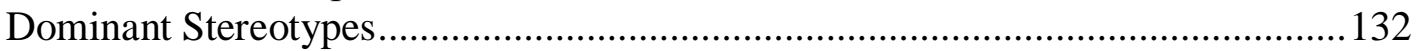

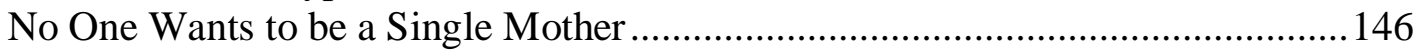




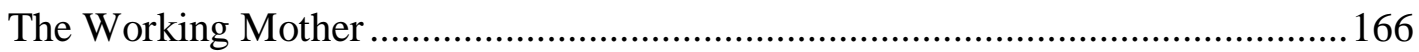

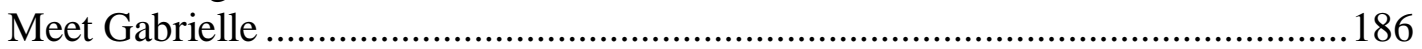

CHAPTER FIVE | Material Culture and Class in the DMV ................................188

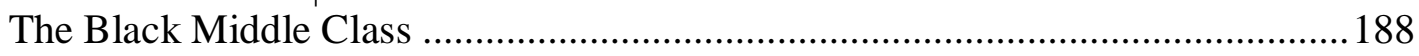

Status Symbols in the Black Middle Class ........................................................... 192

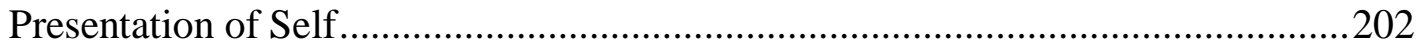

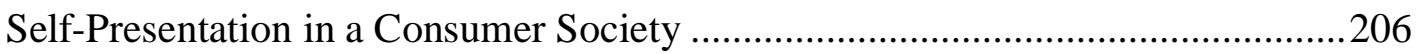

Respectability Politics in the Black Middle Class ...............................................211

Keeping Up With the Joneses: Conspicuous Consumption in the BMC ..............216

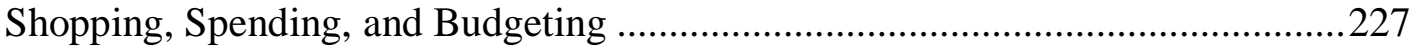

Immaterial Consumption and the Importance of Experiences .............................241

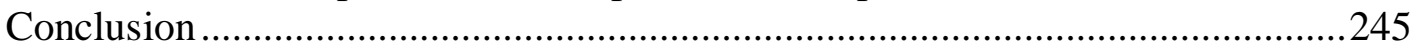

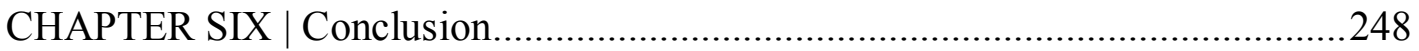

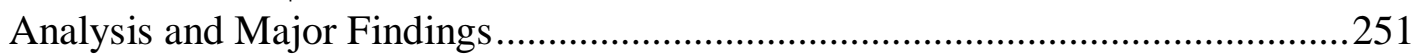

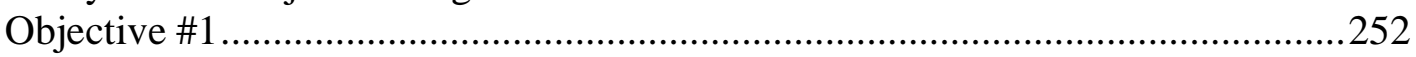

Connections to Larger Contemporary Issues....................................................260

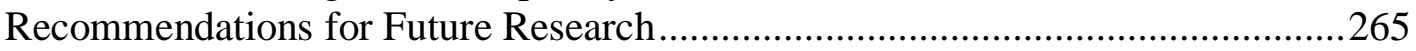

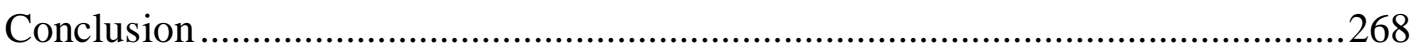

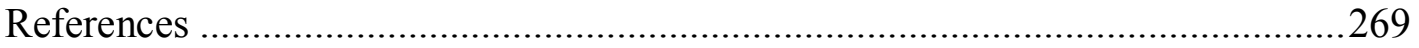

VITA 
CHAPTER ONE | Introduction

As I rose on the Saturday morning of May 19, 2018 to work on this dissertation, the most high-profile wedding of the year was taking place across the pond in London, England. Prince Harry, Duke of Sussex, of the Royal British family was marrying African American television star and daughter of a single mother, Meghan Markle. The royal wedding, due to its high-profile nature and unprecedented interracial union, sparked nonstop news commentary for several hours that morning, and for many weeks leading up to the big day. As the couple prepared to marry, the world yearned to learn as much as they possibly could about the bride-to-be. Markle's parent's divorce, and father's absence captured the media's attention and dominated the tabloids in the week before the wedding. It was one of the first times I could remember seeing such a high-profile wedding with a Black bride from a non-nuclear family.

Meghan's mother, Doris Ragland, quickly became the heroine in the news coverage. She was publicly recognized as being the primary caregiver for her only daughter, Meghan, and for overcoming the adversities related to single motherhood while Meghan was a child. As the sole member of Meghan's family to attend the wedding, Ms. Ragland was photographed smiling and with immense pride as she represented herself as Meghan's rock and stability over the years. Social media erupted with celebrations of the new "black Princess," and articles were published to encourage black women to remain open to love and marriage, just as Meghan had done. This wedding — although unrepresentative of average, everyday unions — was used as an opportunity to give black women hope. It was odd.

For decades, black women have been portrayed as unmarriageable and undesirable. Stereotypes related to our vocalism, strength, and ability to take charge, 
have promoted the idea that black women are not the ideal marriage candidates, or partners in general, despite black women's desires to marry (Chaney 2011; Perry 2013; Hill 2006). The lack of interest by black men, and men of all races for black women on dating apps and sites is striking (Lin and Lundquist 2013). Black men's decisions to accept and promote these negative stereotypes, has not served black women well, and has resulted in high levels of divorce, an increase in interracial marriage by black men, and high rates of never married black women. In 2016, the US Census American Community Survey reported that Blacks had the lowest levels of marriage percentage of all groups in the United States (U.S. Census Bureau 2016). According to the survey estimates, $50 \%$ of Whites over 15 year old were married, compared to $28 \%$ of Blacks. These percentages have remained consistent (more or less $5 \%$ ) for over 10 years. Black women, specifically, have the lowest rates of marriage compared to women of other races. Although black men and women have stated their desires for marriage, less than half of the black population has ever been married, and according to previous studies, "when they do, they get married later in life, experience marriages that are of a shorter duration, have a higher likelihood of divorce and are less likely to remarry after divorce" (Cherlin 1992; Glick and SungLing 1987; Chaney 2011).

Several factors impact these trends in black marriage and family formation. Black women, in response to or in rejection of the desire to marry have continued to advance their lives personally and professionally and have decided to become mothers without marriage. This decision has caused black women to be publicly criticized as unfit mothers who fail to provide stable homes for their children. In the 1990s, poor black women's decisions to become mothers were targeted as prenatal criminals for engaging in drug use while pregnant (Roberts 1997). Many had their children taken 
away after positive drug tests of crack-cocaine. Throughout this decade, black women were forced to make difficult decisions to simultaneously maintain their womanhood and motherhood.

The decline and delay of marriage, as women make strides professionally and gain higher levels of education, has resulted in an increase in single mother-led households. As the new normal, women are achieving their professional goals to enter or remain in the middle class while also tackling motherhood. Generally, white middle class women who opt out of or delay marriage and decide to parent solo are represented as progressive, liberal heroines who can successfully manage a career without sacrificing motherhood (Mannis 1999; Mechaneck, Klein, and Kuppersmith 1987). These women are typically regarded as forward-thinking individuals who consciously reject heteronormative gender roles and ideas of family formation. Black women, however, are not afforded this luxury. Instead, their decisions to parent solo — regardless of class status — are criticized as contributing to "social problems" present in the black community, such as lack of family values and poverty. Black single mothers are rarely portrayed as progressive, educated, working professionals. In fact, black single mothers are rarely portrayed as middle class — they are almost always represented as low-income. In a society where the terms of "family" are constantly in flux and where women of all races are able to work and make a living independent of a man as provider, black women are still condemned when stepping outside of the formerly well-respected nuclear family.

\section{Problem Statement}

Black middle class women are challenging the stereotypes surrounding single mother households, the idea of family, and class status in the United States. Today, more women of all ethnic groups are having children while single, delaying or 
deciding against marriage, and are entering the middle and upper-middle classes as a result of advanced education and career opportunities. Because of these demographic and sociocultural shifts, the romanticized 1950s American family structure consisting of a "nuclear" married heterosexual couple and their children is becoming less authoritative as a symbol of middle class status. The praised nuclear family model is based on white (upper-) middle class more or less imagined realities (Nicholson 1997; Sabourin 2003; Staples 1994; Thorne and Yalom 1982), and in recent years has been deconstructed as an untraditional family model for many groups. In fact, among African American women in the United States, they are having more children while unmarried and while employed and/or enrolled in college (Holland 2009). Nevertheless, despite the nuclear family model losing influence among several communities, such as black women and younger generations, it continues to be the idealized family formation that invisibilizes and displaces "alternative" family structures such as those shaped and adopted by - non-exhaustively - gay and lesbian parents, adoptive parents and single mothers.

Black motherhood has gained scholarly attention in recent years due to its unconventional organization and expectations. Scholarly research has focused on two competing extremes - the low-income 'single' mother and the middle/upper-class wife and mother. The first group of literatures often concentrate on unmarried black women who have children and are low-income, welfare-dependent, and unskilled/uneducated (Moller 2002; Holland 2009; Edin 2000; Darity Jr. and Myers Jr. 1983). Black single mothers of all socioeconomic backgrounds face challenges as primary caregivers and income earners for their families. As a larger demographic, single mothers have been researched as women who suffer from depression, face 
financial burdens while raising children, and other issues that may impact physical and mental health (Dill 1988; Jackson 1992; Mandara, Johnston, Murray, and Varner 2008; Sabia 2008). Black mothers who work are generally more satisfied with their lives than women who stay at home with their children, but experience similar levels of stress and face depression (Jackson 1992). Other research focuses on negative impacts single parenting can have on children and how children face the challenges of being raised by single mothers. Single mothers are unrealistically expected to do everything, even when they have assistance from extended networks. The life chances of children being raised by single mothers has been associated with negative incomes including poorer grades and greater behavioral problems (McLanahan and Percheski 2008). These literatures suggest that black single motherhood is not functional for the women or children involved, particularly because of the major strain caused by finances and the non-nuclear family structure. While these studies provide necessary insight into the challenges low-income black single mothers and their children face, they ignore the strengths and challenges of black women who make sufficient incomes to successfully maintain their households and care for their children.

The second group of literatures represent middle class families as consisting of women who exist in "traditional" domestic roles as primary caregivers in their nuclear family households (Barnes 2016; Lacy 2007; Patillo 1999). Black motherhood, however, is not bound to two extremes. There is a wide gap in social science literatures on the varying experiences of unmarried black women that few scholars have attempted to address. Those scholars who do recognize black single mothers as income-earning primary caregivers have investigated the social problems associated with single motherhood, including stress and lack of marriage (Jackson 1992; Holland 
2009). The literature largely ignores unmarried black women who fit in between the extremes, and decide to have children as employed, often college-educated members of the middle class.

Black middle class women are situated between competing notions of black middle class values and black womanhood (hooks 1992; Hill 2001; Johnson 2013). Whereas black middle class values embrace the patriarchal family structure and "traditional" Western forms of respectability, black womanhood has historically been built upon independence and self-reliance. The Strong Black Woman stereotype, which can be understood positively and negatively, asserts that black women are able to overcome all obstacles and emerge as strong and independent women who serve their families, workplaces, and communities (Barnes 2016). This complicates the identity-making processes of black women who uphold certain middle class consumer expectations (such as education and home ownership), but reject other expectations regarding family structure (such as marriage prior to childbirth). Black women, and black middle class single mothers included, have used material culture and consumption to display these competing values and expectations while also constructing their own identities within society. Material goods often display one's socioeconomic status, professional or group affiliation, and can be used to make bold statements in social and political movements. Black middle class single women, like the black women and men of various circumstances, use their buying power to create a collective identity and use their style as a way to best represent themselves (Goffman 1959; Fisher 1996). Studies have shown that black women spend up to $80 \%$ more on material goods that modify their appearance (cosmetics, skin care, hair care, etc.) than any other demographic (Fisher 1996; S. D. Smith 2009), but black women's 
consumer preferences and motives remain largely absent from consumer and consumption literatures. Black Americans account for a large demographic of key consumers in various industries, including automobiles, department retail stores, beauty, and technology innovation. In 2008, for instance, black women had become the largest target demographic for Toyota, because of their high levels of education, high incomes, and interest in purchasing dependable mid-priced automobiles (Brodesser-Akner 2008). It has been assumed that black women do not function as major consumers since they are largely unmarried, and thus lacking the financial security provided by dual incomes, they are uninterested in spending on expensive items (Brodesser-Akner 2008). Popular culture and other news reports, on black consumption in the beauty industry and in department and discount stores, reveal that black middle class women spend significant amounts on themselves and in their households (Fisher 1996; Compton 2005). Single mothers within this category may also purchase things to negate undesirable stereotypes often attributed to black single mothers and gain social membership (Lamont and Molnar 2001).

This research will build upon literatures of the black middle class, black family studies, and material culture and consumption. It is the first social scientific study that focuses on the consumption patterns of black single women, to reveal how they consume material goods to identify simultaneously as single mothers and members of the black middle class. The expression "black middle class single mother" is used frequently throughout this research. Before proceeding, I would like to clearly define my intentions for this expression, as it implies race, class, and status, which its own definitions are each equally complicated and evolving. 


\section{Defining: Black Middle Class Single Mothers}

In 1915, W.E.B. DuBois wrote, "In general, the Negro population in the United States is brown in color, darkening to almost black shading off in the other direction to yellow and white, and is indistinguishable in some cases from the white population" (DuBois 1915). DuBois's observation and understanding of blackness in the United States in 1915, in which race was determined by the "one drop rule," which concluded that any individual with a drop of blood from a black ancestor was legally black, resembles the over-simplified presentation of blackness in 2018. The Negro population, which has since adopted the terms African American and/or Black, consists of individuals across the spectrum of color and shade, culture and identities. At the time of DuBois' writing, much of the black population in the United States were direct descendants of enslaved people originally from West African countries. Today's black population is much more diverse, representing people across the Diaspora. With the passing of the 1965 and 1990 Immigration Acts, the migration of African and Caribbean peoples continues to rise (Pierre 2004), and as a result, the United States black population is more of a melting pot now than ever before and a representation of the diversity of blackness .

I have used the term 'black' throughout this dissertation to represent the selected research participants in this study. The US Census considers those who identify Africa as their region of origin to be black or African American (US Census Bureau 2017), and all of the participants of this research have all self-identified with these terms. These women identify as black and/or African American in US Census reporting, in other official documents, and in everyday conversation. In most instances, they use these terms interchangeably, and I have done the same throughout this paper. The influx of black immigrants from across the African diaspora who have 
migrated to the United States has destabilized and complicated the meaning of blackness in this country (Hintzen and Rahier 2003).

Notably, two of the 30 women participants were of Caribbean descent and the others identified as African American. Although these women were raised in Caribbean-American households, they both lived their entire lives in the United States -- and one lived exclusively in the Washington, DC metro area. Their proximity to African Americans and assimilation into the local "African American culture" prompted them to identify as African American and insist on being represented in this study. As Jemima Pierre demonstrated in her work, the process of "assimilation" or as she calls it, "Americanization" is different in context for Black/African immigrants and is produced with intents that may or may not be focused on assimilation into "Black America" specifically (Pierre 2004). In this research, one participant proudly proclaimed, "Iza Trini" in acknowledging her Trinidadian culture. She was born in the United States and raised in the Washington, DC metropolitan area surrounded by other Black Americans. She continued, 'But, they don't have 'Caribbean' on most forms, so I guess I'm African American." Census reports and other official documents widely ignore the varieties of ancestry present among individuals of African descent.

There is no single definition of 'the black community.' This community varies based on characteristics including place, ethnicity, nationality, income, and more. When the phrase "black community" is used in the Washington, DC area, in my experience and in the experiences portrayed by the women in this research project, the 'black community' refers to the diversity among people of the African Diaspora, most notably African Americans, Afro-Caribbean, Afro-Latinos, and some Africans. I specify that some Africans and not all Caribbean identify as members of the US black community because research has shown that (some) black immigrants actively 
differentiate themselves from Black Americans due to cultural differences and an array of negative associations (Pierre 2004; Sasso 2015). However, at certain times in DC, these subgroups also come together in specific spaces; such as festivals, most notably Georgia Avenue's Caribbean Day Festival, Howard University’s Homecoming week, and in restaurants and cultural spaces like Busboys and Poets. There is no shortage of diversity in this area. These subgroups are informed by their cultural heritage and dictates the ways individuals relate to things such as race, class, religion, and more. I have approached this dissertation with the primary focus on African Americans because of Washington, DC's long history of African American life and social mobility and because the majority of my research participants identify as such.

Despite the increasing black immigrant population in the area, the Washington, DC metropolitan area still has a significant African American population. In 1862, the city abolished slavery (prior to the Emancipation Proclamation of 1863) and offered African Americans the opportunity to secure paid work. This encouraged African Americans to stay in the area and for many to relocate to the area. Since then, African Americans from across the United States have continued to migrate to DC during and after the Great Migration in search of employment stability and educational opportunities. 


\begin{tabular}{|rr|}
\multicolumn{2}{|c|}{ District of Columbia } \\
\hline \multicolumn{1}{|c|}{ Estimate } \\
\hline \multicolumn{1}{|c|}{436,745} \\
\hline Total & \\
\hline American & 7,664 \\
\hline Subsaharan African & 20,288 \\
Ethiopian & \\
\hline African & 6,791 \\
\hline Nigerian & 6,120 \\
\hline Sudanese & 3,308 \\
\hline West Indian (except & 1,519 \\
\hline Jamaican & \\
\hline West Indian & 3,098 \\
\hline Haitian & 989 \\
\hline Trinidad and Tobagonian & 504 \\
\hline Barbadian & 367 \\
\hline Bahamian & 307 \\
\hline U.S. Virgin Islander & 303 \\
\hline British West Indian & 158 \\
\hline
\end{tabular}

Data from People Reporting Single Ancestry, Washington, DC. American Fact Finder, 2018

Although the research primarily focuses on African Americans, I understand that Washington, DC's black population extends beyond that subgroup and for years, has included a significant Caribbean, West African (mainly, Nigerian) and East African (Ethiopia) population, as evidenced by this chart (above) from the US Census. In fact, the Washington, DC metro area has the largest Ethiopian population outside of Africa (Schwartz 2016). Washington's former Caribbean Day festival once attracted thousands of Washingtonians and visitors each year to participate in the annual celebration of the city's rich Caribbean population. These subgroups and black immigrants bring with them different economic, cultural, ideological, and national contentions that occur in other national formations (Hintzen and Rahier 2003). Still, these subgroups and particularly second-generation black immigrants, form a 
cohesive larger group as black Americans. Schools, places of worship, and other common spaces are culturally diverse. Together we all form Washington's “black community." The city is very small, and the black communities intermingle constantly, without a specific area exclusive for any one diasporic subgroup; as a result, the black community expands. For that reason, I have included the two Caribbean women in this research project. One of the Caribbean women (she has a Jamaican parent and a Trinidadian parent by way of New York City) moved to the region because of its professional opportunities for black people. She did not distinguish the opportunities available to African Americans versus Black Caribbean or African immigrants; instead, there were opportunities that all Black Americans (immigrant or native-born). In Chapter 2, I further explain how Washington's “black community" came to be and how it formed a significant black, primarily African American, middle class.

I have included Caribbean middle-class blacks in my definition of the black middle class. The black middle class in the Washington, DC area today consists of African Americans, Caribbean, African, and other diasporic subgroups. Even among African Americans, the 'black community' can vary based on factors such as place, income, or education level. My understanding of a 'black community' as a metropolitan woman may differ from the representation of the 'black community' to an African American woman in New Orleans, Chicago, or Oakland. While this community, though large and multifaceted, shares many principles or characteristics (for example, the community's involvement in the church), other characteristics like food or music may vary. In this location and across the diaspora, definitions of black and blackness are continually shifting, disrupting popular discourse on what it means to be black (as if there is only one distinct definition) (Hintzen and Rahier 2003). 
Even with these differences, as a group of black Americans in the Washington, DC metro region who share similar histories, we are all members of a unique 'black community.' For this reason, and because of their own pronouncement of African American inclusion, I have included non-African American middle-class women in this research. I have interviewed women of Caribbean heritage who have identified themselves as members of the "black community" and also, at times, as African American. Future research on this topic could aim to explore the differences and similarities of women who are mothers across the African diaspora and how they might navigate as middle-class black women differently.

I have determined an annual salary of roughly $\$ 50,000-\$ 100,000$ as an indicator of middle-class for the purposes of this research. This salary range falls within the range of the median income in the area, which for Washington, DC is $\$ 102,000$ and for Prince George's County is $\$ 76,000$. Additionally, at the lowest end of this salary range, individuals have "tapped out" of the ability to receive public assistance. The State of Maryland uses the Federal Poverty Level to determine eligibility of individuals for public assistance. I have more than doubled the poverty level income for a family of three $(\$ 20,000)$ to $\$ 50,000$ as a realistic living wage in the research area. I have left this salary range purposefully wide because this work focuses on the ways the research participants self-identify with class. I also understand that salary is not the sole determinant of class, and that a combination of experiences, education, and lifestyle form one's class identity.

There is a sense that despite the wide gap in salaries, the women of this research relate to each other as mothers who each earn more than allowed to receive aid but too little to not be burdened by everyday expenses in a major metropolitan area. Also, it is important to note than most women in this research earned close to 
$\$ 100,000$, with less than five women earning less than $\$ 60,000$ annually. While this number may appear to many to be upper-middle class or not in the middle class at all, this area's high cost of living and the responsibilities of single motherhood made these "high" salaries feel very low to many of the women. I recognized that the DC area is known to have a large 'black' middle class without distinguishing between subgroups of black people. I would argue that in this area there are more similarities than differences between the African American middle class and non-African American middle class. Unlike other cities that may be segregated by national origin (like New York City or Miami, for example), in the DC area black people of different backgrounds share the same resources, live in the same neighborhoods, and participate in similar activities. For example, I referred to Raymond T. Smith's The Matrifocal Family when conducting scholarly research in preparation for my field research (R. T. Smith 1996). While Smith's research focused on black women in the Caribbean, many of the arguments overlapped with women who were sought after and included in my research. The women included in this research were diverse in a number of characteristics. At least one mother identified as lesbian, most women were religious in some capacity (Christian), while others were not religious at all. These differences were introduced in our conversations and, at times, deeply impacted the women's understanding of motherhood, family, and class. However, as this study is most concerned with their attitudes toward class specifically, the other aspects of their identity were not the focal points of my questions to participants.

To define the middle class, I include all white-collar positions, small business owners, and select service positions (those that require specific skills and/or training and 
produce higher incomes). I paid close attention to the lifestyles, neighborhoods, and habits of these women to determine if they were positioned within the DC metro region's understanding of the middle class.

In this research, "single" is used to describe a legally single, unmarried woman. I am aware of the complexities of this term, considering the expectation that some of the women I engage have romantic partners, are in consistent cohabitating unions, or do not consider themselves "single" mothers because of the parenting assistance they receive from extended networks. I am using the term, 'single,' because as legally unmarried women, they are likely subject to stereotypes and categorizations of single mothers as one homogenous group, despite how they identify themselves. The term 'single' as defined by the United States federal government, and for use in census records, public assistance, and so forth, as "the sum of never-married, widowed, and divorced people." The government defines single as a marital status and therefore does not include people who are in relationships or dating. Furthermore, according to the federal government, "'single' when used in the context of a 'singleparent family/household,' means only one parent is present in the home. The parent may be never-married, widowed, divorced, or married, spouse absent" (Census 2018). Single is also self-defined, in that women who are legally separated were also included in this study as they claimed their independence from the support of their husband or spouse and recommended that their experiences most closely aligned with those of the average "single mother."

For the purposes of this research, I have adopted the federal government's definition of single and single parent. The women who participated in this study were never-married, widowed, divorced, and separated from their spouse. Although several 
of them were in relationships, and some lived with their current partners, they were not legally married, and most importantly, self-identified as 'single' for their marital status. Additionally, a majority of the women who participated in this research were in communication with the father(s) of their child(ren). Despite the father's involvement in the child's life, as the primary parent in the household, the women of this research were defined as "single." Throughout this research, my aim is to center black women's experiences as single mothers and black middle class consumers outside of and in addition to the common representations of them in popular culture and past scholarly research.

And finally, each participant in this study were biological or adoptive mothers to their children. In some instances, the women cared for other children, nieces, nephews, other relatives, and children of family friends on a consistent or occasional instance and considered themselves as mother-figures. When I refer to "black middle class single mothers" I am referencing black women who are the legal guardian of the children in their household.

Background of the Study

My research interests came to me as a result of my personal experiences as a young student to a black middle class single mother. In 2009, my mother, younger brother, uncle, and two first-cousins helped me move into my dorm room at St. John's University in Queens, NY. I was moving four hours away from home to attend a \$50,000-a-year university and begin my life as an "adult." In the August heat and chaos of the move-in process — back and forth to the car with dollies and up several flights of stairs -- my mother, frustrated, sternly reminded me that none of this would have been possible without her. My father was not present during move-in day. He 
did not make the deposit to secure my enrollment or purchase the home goods that were needed for me to live without a parent in my new dorm. In a metaphor for my life, my mother provided me with everything.

At the time, I did not know that I would be constantly reminded of my mother's words throughout my college experience. As a student at St. John's, I was often asked about my father's involvement (both personally and financially) in my life. My response was often met with surprise and confusion by new friends and colleagues, as I disclosed that although I had a relationship with my father, my mother took full responsibility of all of my financial needs. It was not until this time, that I realized that black middle class single mothers were somewhat of a taboo outside of DC, or outside of what I was used to. From this time, I began to think critically about the black middle class, its meaning, and how women like my mother fit in. At home in Washington, I was surrounded by black single mothers who were professional and skilled working women. They were my mother's friends, my teachers, and they were the mothers of my friends. Black middle class single mother's "hidden" commonness interested me. While I never saw examples of my family on television, I knew that this group of women existed in the DC area, and assumed it existed in other areas as well.

As a graduate student, I decided to direct my attention to these women. I was interested in diversifying the narrative of what the black middle class looked like. Initially, I wanted to use the experiences of black single mothers to show that the black middle class was not monolithic. As my interests and research progressed, I decided that it was not enough to show that the black middle class was diverse, but that even within itself, marginalized groups like single mothers, adopt specific practices to assert and preserve their black middle class identities. My interests have 
developed into this study on identity formation, and the ways in which material things are used to represent, belong to, and ultimately identify with a class and race-based community.

\section{Site Description}

The Washington, DC metropolitan area serves as my research site for this study which explores the middle class experiences of black single mothers. Washington, DC and its suburbs are very unique in the opportunities it offers black women and young professionals, the large middle and upper-middle class present in the area, and the high rate of black single mothers. In Washington, DC, 50\% of all births are to unwed mothers; when considering the DC Black community, this number exceeds 70\% (US Census 2013). However, academic research lacks explanation on whether black non-poor single (never married and divorced) mothers actively plan for single parenthood thus disregarding the middle class ideal of the nuclear family, or if their consumption patterns are sufficient for middle class respectability. Several black women in the Washington, DC metro area rely on stable positions within the federal government and nonprofit organizations to keep themselves and their families in the middle class. As housing and rent prices continue to rise in DC, making it one of the country's most expensive places to live, black single mothers are forced to make competitive incomes to remain in the area and be the primary economic provider for their families.

Due to the extremely high cost of living in Washington, DC specifically, and the large influence of African Americans in nearby cities, my research site expands to the city's greater metropolitan area. In my fieldwork, I conducted research within and near "the beltway," which is the stretch of the 495 highway that locals use to 
determine one's proximity to the city. Put plainly, those "inside" of the beltway are very close to DC, while those "outside" of it, are not. Washington, DC and nearby Prince George's County, Maryland have played significant roles in the formation of the black middle class. Several cities within Prince George's County continue to top ranking lists of most affluent predominately black cities. The area's history and significance influenced my decision to conduct field research here.

Finally, Washington, DC is home for me. I lived between Washington, DC and Prince George's County, Maryland until leaving home for college. My family is still there, and it is the place I continue to visit for all major holidays and family events. My decision to conduct this research here was personal for me, as my experiences as a child of a single mother were shaped in this environment. The abundance of black middle class single mothers in this area shielded me in a way that I did not recognize until leaving home. It became clear to me that DC, because of its opportunities for black women, was unlike any other city in the United States, and because of this, I needed to return home to explore my community from with a new perspective.

\section{Theoretical Framework}

This research is framed within the context of four primary groups of literature: black feminist theory and intersectionality, family studies, material culture and consumption, and class identity formation.

Marriage and Motherhood from an Intersectional Black Feminist Perspective

We realize that the only people who care enough about us to work consistently for our liberation is us. Our politics evolve from a 
healthy love for ourselves, our sisters, and our community which

allows us to continue our struggle and work. - Black Feminist

Statement, Combahee River Collective, April 1977

In April 1977, the Combahee River Collective, a collective of Black feminists wrote a general statement on the politics of black feminism. This statement has become a primary text in black feminist studies, laying the groundwork for black feminist issues and beliefs. Black women's feminism, and specifically the theory of intersectionality is used to center the experiences of black women as mothers in this research project. Key texts that I have used to shape this research include Black Feminist Thought (Collins 2000), All the Women Are White, All the Blacks Are Men, But Some of Us Are Brave: Black Women's Studies (Hull, Scott, and Smith 1982), and Feminist Theory: From Margin to Center (hooks 1984). The authors of these texts each have different approaches in their writings, but the overlapping truth is that black women and our experiences must be defined by black women, and the issues facing black women must be brought to light and addressed by working to create change in every aspect of society.

Feminist scholar, author and activist, bell hooks' Feminist Theory: From Margin to Center (hooks 1984) is a pioneering text in the black feminist theory. This book was written largely in response to Betty Friedan's, The Feminist Mystique, which despite its popularity as the originating feminist text, completely ignores the oppressive experiences of black women and women of color. In this text, bell hooks criticizes the entire system in play in the United States, which privileges white men over everyone else. Additionally, in this text and in Feminism is for Everybody (2000), bell hooks intervenes in traditional feminist discourse by examining the ways 
race, gender, and class together influence black women's patriarchal subordination. She argues that feminism is "the movement to end all sexism, sexist exploitation, and oppression" and it can only be done if we redefine the feminist movement to include the oppressions of all, and collectively combat institutionalized oppression.

In Patricia Hill Collins’ pivotal text, Black Feminist Thought (Collins 2000), Collins asserts that black women are defined through the intersections of race, class, and sexuality. She affirms the notion that black women, out of oppression and misidentification, have created a self-defined worldview to validate their diverse experiences as black women that does not rely on or act in response to the experiences of white women. Collins brings attention to the ways that black women, as mothers, partners, and women, are defeminized and demonized in popular culture through media misrepresentations (music, hip hop culture, fiction novels, etc.) which reinforce historical understandings of black women as sexually promiscuous. From a black feminist perspective, Collins observes the agency black women project by resisting and negotiate controlling images and participating in the creation of new representations (Hill 2004).

In this perspective, Collins asserts that black motherhood cannot be analyzed by white perspectives because of key assumptions that all mothering occurs within the confines of a nuclear family where the mother has total responsibility for child-rearing, there are strict gender-roles of parental influence, and that 'good' mothers refer to 'stay-at-home' mothers (Collins 1994a). Her work, and the work of other black feminist scholars challenged the ideas of family disorganization put forth by Daniel Patrick Moynihan in 1965. Moynihan's report ignored the "demographic and socioeconomic reasons why many female-headed households are now and have always been a predictable and accepted form of household organization" in black 
communities in the US and broader African diaspora (Sudarkasa 2007). In My Mother Who Fathered Me (E. Clarke 1957), Edith Clarke sought to validate and expound the complex family formations, particularly of single independent working mother households, in Jamaica. She explains how inequalities have prevented Jamaican men from earning a stable, sufficient income that would allow for a wife to stay at home with children and resemble the idealized Western nuclear family (LaFont and Pruitt 1997). In addition, cultural norms suggest that the pressure to provide financially falls on the man, who as she notes, should not "propose marriage, unless he owns a house, and preferably, a bit of land" (Clarke 1957). Clarke and others positioned black women as the heads of households, and the stable parent figure necessary to raise a family.

Shirley A. Hill challenges the institution of marriage from the intersectional differences experienced by black women. She writes, "marriage is a quintessentially gendered institution, based on male domination, female subordination, legitimate children, property rights, and separate responsibilities for men and women" (Hill 2006). Hill understands marriage and motherhood as two separate entities that do not depend on one another in black communities and in the black feminist perspective. Like, Patricia Hill Collins, Shirley Hill acknowledges the rationale behind single mother households in the black community and black women's attitudes towards marriage (Hill 2006, 2005). Using the institution of slavery to ground her arguments, Hill calls attention to the ways in enslaved African Americans were denied the opportunity to marry and establish traditional “American” families. In her work, Hill draws attention to black women's agency in resisting marriage post-slavery, because "doing so would have undermined the strength of the maternal or female-centered families they had long relied on" (Hill 2006). 
Hill challenges revisionist scholarship, which highlighted the roles of male slaves in the family and inadvertently created "a more humane version of slavery" by looking closely at the histories of enslaved black women's responsibilities in the family and in the field. Black enslaved women were faced with workloads as difficult and cumbersome as men but were expected to take care of their physical homes on the plantation and to take care of the children. Scholars have drawn connections to the domestic responsibilities of enslaved black women to patriarchy, polygamy, and mother-child relationships which were all characteristics of pre-colonial African societies (Collins 2000; Hill 2006; Nobles 1974). As enslaved women and mothers, the dual responsibilities expected of black women became traditional practices within the black community.

Following Emancipation, newly freed African Americans sought to build strong families. "Once slavery ended they scrambled to reunite their families, but not necessarily their marriages" Hill explains (Hill 2006). Women fought to be reunited with their children, parents, siblings, and partners even in the absence of marriage. To newly freed people, family extended beyond the confines of marriage and there was an intense desire to rebuild and recreate family in their own terms (Schwalm 1997). Women prioritized their children as key members of the family dynamic. Today, black women continue to have children out-of-wedlock and often assume primary responsibility for their children.

The high rate of non-marital childbirth has gained attention as the latest obstacle facing the black family and community. This statistic is consistent with projected black marriage trends which first gained national attention in the midtwentieth century. The black family's unique single parent structure of the 1950s captured the attention of leading scholars across academic disciplines (Gunnar 
Myrdal, E. Franklin Frazier, Edith Clarke, St. Clair Drake and Horace Cayton) and politicians (Daniel Patrick Moynihan). Since then, scholars have offered expanded views that address the intersection of race, class, and gender in family studies (Collins 2000; Zinn 2000; Furstenberg 2007). Scholars have addressed the differences in family structure as results of factors pertaining specifically to black women's mate availability, education and economic level, and overall changing views on family (Catanzarite and Ortiz 2002; Chambers and Kravitz 2011).

Black women have been successful with high rates of college attendance. They have earned degrees to enter the professional workforce and subsequently gain access to the middle class, but they remain the least likely group to marry. Richard V. Reeves and Katherine Guyot of The Brookings Institution found that black women with college degrees are actually $15 \%$ less likely to be married than a white woman (Reeves and Guyot 2017). Black women have the lowest mate availability pool (black men have high incarceration rates, less college degrees, and enter interracial marriages at greater rates than black women (Holland 2009), and may decide to start a family without a husband. To compensate, they use their financial resources (for services such as childcare) and extended kin and community networks to aid in childrearing (E. Higginbotham and Weber 1992; Jackson 1992; Christopher 2012; Barnes 2016).

Black women's longstanding history with paid work outside of the home in addition to mothering has created an expectation of black women as income earners in black middle class families that does not exist traditionally in white middle class families (Collins 2000; Harley 2002). Black mothers have also differed from white mothers in their empowering practices of 'motherwork', which acknowledges the ways black women raise their children in a world plagued by racism and sexism, "to 
foster a meaningful racial identity" (Collins 1994b). Motherwork, in black families across socioeconomic backgrounds, allows black mothers to teach their children how to protect themselves and develop self-esteem. While many have positioned the black family as disorganized, unstable, and socially immobile (Drake and Cayton 1945; Moynihan 1965; E. F. Frazier 1948), more recent scholars have highlighted the strengths of black families and their functional family structures (Lacy 2007; Patillo 1999; Strmic-Pawl and Leffler 2011). Strengths, such as their close knit sense of community and reliance on extended family and friend networks in childbearing, challenge the claims that black families are disorganized (Miller-Cribbs and Farber 2008; Mendenhall, Bowman, and Zhang 2013; Stack 1975). Nevertheless, the white nuclear family is a middle class family that acts as a normative standard for all other families. Black families who attain middle class status and benefits, are thus overly represented as nuclear families.

Identity Formation Literatures

At its core, this research project is focused on identity, and how individuals form their own identities against long-standing stereotypes, misperceptions, and limited scholarship. Black middle class single women are the focus of this research. These women fit within separate, but intersecting cultures of the African diaspora, womanhood, the middle class, and single, non-married individuals within society. Brian Thomas succinctly defines culture in three facets. He explains:

"The increasing casual, theoretical, and political significance of "culture" is manifested in three, often conflated facets: first, as an individual society identity representing a mode of self-understanding and self-writing; second, as a collective identity in which forms of collective agency are normatively 
constructed and understood; and third, as an ascribed identity, as a way of picking out individuals in a social ontology, one deeply reflecting particular practices and policies (or practices of ascription)" (Thomas 2014).

In order to understand the significance of this research, one must understand the concept of identity and the ways in which identity is formed. Identity formation is discussed as mostly an internal process (Korobov 2015), but it relies on the presence of others (Svensson, Berne, and Syed 2018; Phinney 1990). Ethnic identities, like other social identities are socially constructed and involves others in complex processes. Ethnic identity formation scholars find that ethnic identities need to constantly be affirmed and reaffirmed by the individuals of the group, in order to not be defined by outsiders (Kibria 2000, Lyman and Douglas 1973). Both individual and collective identities form out of or in response to what others say they are or are not. Ylva Svensson discusses ethnic identity formation as a relational and interactive process which evolves based on the context. In particular, "individuals express their ethnic identity differently across different social relationships" whether, friends, family, work colleagues, or strangers (Svensson 2018, Kiang, Harter, and Whitesell 2007). People are active agents in interpreting, presenting, and constructing their ethnic identities in specific social contexts, but race, because of its dependence on outward physical characteristics allow others to activate race-based inferences stereotypes (Cosmides, Tooby, and Kurzban 2003). In most cases, race is projected onto the individual without the person being able to actively interpret or construct their identity. For instance, news reports show that black people, men specifically, do not always have the power to construct their own identities, for example, in interactions with police or figures of authority. In this context, race precedes other characteristics of identities. As a relational process, black men's identities have been 
pre-constructed and invalidated (Way and Roger 2015), often based on racist stereotypes that cause police to act irrationally which lead to death or incarceration. In this regard, identity formation is not always a choice of the individual but can be understood as both self-identified and ascribed external definitions by others (Goodyer and Oktikpi 2007).

Erving Goffman and Pierre Bourdieu's work on identity and class distinctions were used to inform and shape this research. In his The Presentation of Self in Society, Erving Goffman discusses how individuals use things and events to shape their identities. Goffman understands the self as an act, or the individual as an actor on stage (Goffman 1959). In everyday public life, we as individuals perform our best selves on the front stage. Our private inner workings of ourselves, as we prepare to go out into the public, or lounge without worry of being judged occurs backstage. For Goffman, identity is a high complex, highly crafted self-component that is shaped by others input and expectations. Individuals perform such identities to gain acceptance into different social groups.

Pierre Bourdieu theorizes about the making of class hierarchies and classbased identities in Distinction: A Social Critique of the Judgement of Taste (Bourdieu 1984). Bourdieu argues that taste, like identity, is not acquired completely individually, and is instead a collective preference that is acquired through socialization in particular contexts and fields (Bourdieu 1984). Fields are areas in which social conditioning occurs, such as the classroom, the office, the opera - that allow individuals to modify behavior and expectations to fit in with the present social scene. Tastes are created within these fields and are specific to social classes and impact consumption patterns. Bourdieu believes that consumption plays a major role in distinguishing social classes. Finally, he argues that individual tastes and 
preferences are important in determining how people participate and socialize in different fields (Bourdieu 1984; Allen and Anderson 1994). To Bourdieu, taste acts as a marker of capital. He writes:

Taste classifies, and it classifies the classifier. Social subjects, classified by their classifications, distinguish themselves by the distinctions they make, between the beautiful and the ugly, the distinguished and the vulgar, in which their position in the objective classifications is expressed or betrayed. (Bourdieu 1984).

Class, a derivative of tastes, then is based on groups of people who have been socially conditioned to have similar tastes and material conditions in life. Bourdieu argues that fashion and other material objects assist in the formation of social class identities and function as "symbolic capital" and are used to classify people based on things (Bourdieu 1990, Appleford 2015). These things are displayed in a number of ways, in one's home, as fashion, and now, on online platforms.

Bourdieu also argues that these material things and shared collective experiences, including tastes, fashion, and skills form a group's cultural capital. Cultural capital, he argues, exists in three forms: the embodied state (the mind), the objectified (things), and the institutionalized (institutions). In one example. Bourdieu brings attention to the unequal scholastic achievements to children of different social classes (Bourdieu 1986), recognizing that children of certain social classes receive better educational opportunities and advantages because of their parents' capital. Basic opportunities such as this becomes out of reach or more difficult to attain for other classes. Cultural capital thus creates a collective identity while simultaneously creating inequality among different groups. The concept of cultural capital is used to 
distinguish the haves and the have nots, and has led to anti-black racism and discrimination.

Individuals perform their class through social performances. These performances often require individuals to gain a number of skills, for instance playing an instrument or having knowledge in fine arts or finance and looking and behaving a certain way. People often have to purchase and adorn physical things in order to fit in with the ascribed identity. As members of an elite social class, one must be physically prepared to attend galas, balls, and high class charity events, perhaps, which require ball gowns and tuxedos. In a case such as this one, Bourdieu discusses the process of one going through the motions to perform such identity. All in all, every individual is performing to some degree, but some are able to perform more naturally than others as a result of cultural competency developed over extended periods of time.

Today's internet society has exemplified the way individuals represent and promote their identities. In the world of fast-paced social networks, people shape and reshape their online identities constantly to complement and at times, (propel) their in-person identities. In an arguably more concrete and direct way, social networks as digital social ecosystems, allow people to manage their identities. Certain websites allow users to create avatars, which act as a unique virtual representation of the users. These avatars wear styled clothing, hair, accessories, and more. In a deliberate way, the user creates the virtual version of themselves in the way they see themselves or, more often, as their idealized selves (Bozkurt and Tu 2016). The ability to craft oneself on the internet in a digital space, closely supports Goffman's theories on selfpresentation.

Material Culture (Things) 
This research heavily relies on the scholarly literature surrounding objects, which become things, or also known as material culture. Material is a collection of signs, objects, and things used to "mark identity in complex ways" and "is shaped by and shapes social identities like ethnicity, gender, race, age, class, religion, sexuality and status" (Wood 2014). Material culture is used to create complex, yet homogenous definitions of what it means to be a member of certain identity categories such as woman, Black, American, and middle class. Material culture is often defined as the objects individuals and groups of people use to represent and define their culture(s) (Miller 2012; Clarke 2001). It is the physical material or resource obtained and purchased by individuals to give meaning to specific aspects of one's life. Robin Bernstein argues that material culture "scripts human actions", that is particular things inform individuals how to behave. Scholars of "thing theory" such as Arjun Appadurai, argue that things, unlike objects, interact more closely with humans and illuminate social contexts (Appadurai 2006; Henare, Holbraad, and Wastell 2006). Bernstein suggests that, "A thing demands that people confront it on its own terms, thus a thing forces a person into an awareness of the self in material relation to the thing" (Bernstein 2009). Objects, which become things when interacted with humans, are obtained and purchased by consumers, passed down by generations, or made. The fascination with accumulating and purchasing objects that often are used to create meaning, has created an open consumer society in the United States, and has encouraged the consumption of new commodities and spectacles around the world (Appadurai 1990).

Material culture is not always concerned with spending. Objects can be acquired in various ways, passed down through lineages or self-made to reveal other aspects of individual lives. In fields dependent on material culture, scholars link the 
"relationship between human subjects and the objects they create as mutually constitutive" (Henare, Holbraad, and Wastell 2006). Meanings are attached to things which provide new, deeper understandings of social life. In museum studies, scholars no longer reference material culture, such as period dresses and textiles, as onedimensional examples of a time period, but often as "complex composites with multiple histories that should in turn be examined from multiple perspectives" (Petrov 2012). Material culture displayed in museums (and even objects not housed in museums but that are part of everyday life or ethnographic studies, for instance) can therefore tell many stories about various aspects of individual lives, groups, geographic spaces, and more and provides multidimensional analyses of social life (Petrov 2012; Brumfiel and Millhauser 2014; Francis 2009).

Class and Consumption

Members of the black middle class rely on material culture and consumption to distinguish themselves, create a collective group identity, and adhere to class expectations and trends (Lamont and Molnar 2001). Consumption can lead to membership in symbolic and literal communities. For example, scholars have found that the black middle class emphasize purchasing homes in neighborhoods that were close to the city, remodeled, and in up-and-coming gentrified areas (Moore 2008; Lacy 2007). Home ownership is one of the biggest indicators of middle class status, not only for the black middle class but for the larger American middle class in general. As consumption objects that signify wealth, homes and specific neighborhoods typically allow for members of the black middle class to live around like-minded individuals who also share their socioeconomic positions. In Washington, DC, the black middle class has created a gentrification around a "Black middle-class 
gentry instead of a white one" (Moore 2008), in specific suburbs. For Black residents in and around DC, this type of consumption may be the ultimate display of status and mobility.

Conspicuous consumption, which first gained popular attention in Thorstein Veblen's Theory of the Leisure Class (Veblen 1899), is the display of expensive goods and services, which blends material culture and hyper consumerism to create a self-expression based on possessions (Bourdieu 1984; Frijters and Leigh 2008). Specific items generally fall under the category of conspicuous consumption items, such as luxury goods, vintage items, oversized homes, and lavish parties (Frijters and Leigh 2008; Podoshen, Andrzejewski, and Hunt 2014; Lamont and Molnar 2001; Friedman and Ostrov 2008). Conspicuous consumption has had a negative history with black communities in the United States, particularly after E. Franklin Frazier's well-known critique of the black middle class' spending habits (Frazier 1957). Frazier argued that blacks were only interested in consuming as a way to rank themselves higher or in competition with other blacks of a lower or similar socioeconomic class. Today, scholars continue to expand on consumption as a status seeking motive (Friedman and Ostrov 2008), especially in black communities of varying socioeconomic classes (Baxter and Marina 2008; Lacy 2007; Dominguez 2015). Conspicuous consumption, when done correctly, seeks to reveal both high income and high status among individuals, despite the fact that many individuals of lower incomes and social classes also possess expensive things.

Consumerism scholars have agreed that the practice of consumption and act of consumption varies by class. Bourdieu's analysis of taste, and the creation of habitus, heavily relied on material goods. Daniel Miller's analysis of shopping as a task, highlights how material goods are used to communicate love and other feelings 
in relationships marked by class and gender (Miller 1998). Both scholars argue that material things are consumed based on the preferences of the dominant class (Miller 1998; Bourdieu 1984). For the women in my research, the have identified with nuclear middle class family consumption patterns, created their own identities through material goods, or some combination of both.

Consumerism is most well-known in the economics, marketing, psychology, and environmental studies fields (Kasser 2002). Within these fields, consumerism has been presented as the cause of modernity, the effect of modernity, and a crisis mainly facing individuals in capitalist societies. Sociologist and author of The Constitution of Society and The Consequences of Modernity, Anthony Giddens, writes about consumerism as "simultaneous cause and therapeutic response to the crisis of identifies emanating from the pluralization of communities, value and knowledge in "post-traditional society"' (Trentmann 2004). Like Pierre Bourdieu and Daniel Miller, Giddens relates consumerism to identity-formation in modern societies. This understanding of consumerism does not mirror the approach of consumerism by historian, Peter Stearns. Stearns defines consumerism as the acquisition of unnecessary material goods purchased for display. In Consumerism in World History, Stearns argues that consumerism "describes a society in which many people formulate their goals in life partly through acquiring goods that they clearly do not need for subsistence or for traditional display" (Stearns 2006). In Anne Friedberg's ethnographic work on shopping malls, Window Shopping, she argues that consumption facilitates "expressing- and revising- individual identity" (Friedberg 1994; Conroy 2003). These material based analyses of consumerism also align with Daniel Miller, who argues that consumerism encourages groups of people (social classes) to place their values and worth in their material objects (Miller 2012). While 
consumption can "become the negation of the alienability associated with the market, the state, science... and labor" (Miller 2012), it simultaneously acts as a link between individuals in these groups. He believes that consumption, with its emphasis on material objects, is greater than simple purchases. He recognizes these purchases as complex, active processes that involve individuals transforming goods for various meanings surrounding managing relationships, identity-making, and expectations (Trentmann 2004; Miller 1998).

Consumerism and material culture have emerged as a way for people to associate themselves in particular groups, such as women, as members of the middle class, or even as Americans. Consumerism "has created mass markets, industrialization, and cultural attitudes that ensure that rising incomes are used to purchase an ever-growing output" (Goodwin et al. 2008) among the consumer society. It has become a "means of status competition and a therapeutic quest for selffulfillment and gratification" (Archer and Blau 1993). Wealth is now associated with purchases and these purchases superficially reveal one's quality of life. Lifestyle now indicates ones social group membership and status through certain consumption practices in ways that old strict classifications of class and status did not allow (Mason 1998). Furthermore, acts of consumption have become acts of self-expression (Laan and Velthuis 2016). To certain groups, such as housewives, consumption can be regarded as a form of pleasure and/or work that express their titles. There is a clear division in consumerism studies that places men as public producers and women as private consumers (Conroy 2003). Women often consume for themselves and others (family and community) in ways that men do not. Women and gender studies scholars, along with scholars of other fields, provide evidence on how consumption impacts the lives of women and minorities as a necessary component of social 
mobility and equality in fields such as the university or the workplace (Waymer 2011; Baxter and Marina 2008; Fisher 1996; Podoshen, Andrzejewski, and Hunt 2014; Mukherjee 2006).

Significance of Study

I aim to complicate the common narrative of the black middle class and black single motherhood. There are few qualitative research studies that focus on black single mothers who are middle class (Marsh, Darity, Cohen, Casper, et al. 2007; Jackson 1992) and none, to my knowledge, that explore how black single mothers use material objects and objects of consumption to define themselves and their positions within society. Black women, and black single mothers included, are a richly diverse group of people, whose experiences cannot be reduced to a single image, characteristic, or class. It is my hope that this research contributes greatly to family and class studies. The varied experiences of black women should constantly be shared in order to promote a more complete view of the community.

Black women play pivotal roles in the society as consumers, yet, little research addresses their contributions to the rise of certain material goods. Although I am not a business student, I have employed research related to marketing and consumer studies to inform this research project. There is limited research on black women, generally, as consumers. I recognize the importance of black women consumerism and through this research and personal experience, have witnessed the importance of material goods to black women of varying socioeconomic backgrounds. I have used material culture and consumption as a lens to understand how black women assert themselves into the middle class. While my research is situated in Washington, DC, it relates to black middle class women and mothers in other metropolitan areas with large black populations. In this research four fundamental questions are addressed: 


\section{$\underline{\text { Research Questions }}$}

1. Are black middle class single women willfully challenging middle class, family, and gender expectations as single mothers against the dominant patriarchal nuclear family model?

2. How do black middle class women understand and interpret their roles as single mothers against the stereotype of black family dysfunctionality and the continuing black middle class ideal of the nuclear family structure?

3. What objects do single mothers use and acquire that consciously/unconsciously to position themselves as members of the middle class? How do they use these objects to create a deeper meaning and understanding of middle class identity and black single motherhood?

4. What are the challenges black single women face as single mothers and how are they meeting these challenges?

This research has the potential to inform policy decisions related but not limited to leave in the workplace, housing and urban development efforts, and gender pay equality. I have collected the experiences of these women to share with a larger audience. For many women who participated in this research, they did not find their experiences to be special, or out of the ordinary, but representative of several women in similar situations.

This study is not intended, by any means, to discredit the experiences of poor and low-income black single mothers. Nor is it intended to overlook the issue of fatherless black children in the United States. Despite marital status, thousands of young black children are raised without the influence and support of their fathers, which is directly correlated with black male incarceration. Additional research must also be conducted 
to draw connections between this demographic and social consequences of their children. This study is not intended to discredit the experiences of black single mothers who are not middle class and who may not benefit from the class based advantages of the women in this study.

\section{Organization of the Dissertation}

Chapter 2 contains a detailed record of the methods used in conducting this research. I will layout the plan for the research and the methods used to gather results. As this is a qualitative anthropological research project, I will include the ways I gained access to my research participants and how my positionality as a graduate student and child of a single mother contributed greatly to my ability to access single mothers in the area. I explain the specific phases of this research project and the tools used to analyze the data.

I look to other pivotal research studies on the black family and black middle class to conduct this research. Karyn Lacy's Blue Chip Black: Race, Class, and Status in the New Black Middle Class (Lacy 2007) and Riche J. Daniels-Barnes Raising the Race (Barnes 2016) guided me in shaping and designing this research project. I set out to conduct a research project that allowed me to gather the experiences of several middle class women, just as Lacy's and Daniels-Barnes' research had done, by creating inviting safe spaces for the women to participate. These studies used key anthropological methods, included participant observation and informal and formal structured interviews. In the methodologies chapter, I justify my decisions to employ these specific methods. My choices in designing this project were both systematic and unintentional, at times, a reaction to the presented circumstances. Keith Murphy best describes my process in designing my research: 
"ethnography, like designing, is inherently interventionist and always prospectively disruptive of the social worlds it touches. But rather than "recoil[ing] from direct intervention" (Hunt 2010, p. 37), as ethnographers are typically expected to do, a design-influenced framework encourages fieldworkers to expect to intervene and to work reflexively and creatively with that intervention as part of the ethnographic process (Murphy 2016).

Decisions to change the interview locations or volunteer my time as a babysitter to the participants in this study, for instance, were unplanned but necessary changes to the study that allowed me to understand the subject and participant better. I elaborate on these objectives and methods in the methodologies chapter.

In Chapter 3, I position Washington, DC as the site of this research. Washington, DC has long been referred to as "Chocolate City" because of its dense population of black people. For several years, it was crowned the "blackest" city in the United States, with more African Americans per capita than any other place in the country, and the first city to have an African-American majority (Tavernise 2011). During the Great Migration, millions of African Americans migrated north, with many settling in Washington, DC. DC's robust job offerings, small city charm, and educational opportunities made it an ideal place to relocate to gain a fresh start for African Americans. I will review the ways in which Washington, DC came to be a safe haven for African Americans during the Great Migration, its road to a becoming a black metropolis, and finally its decline as a combination of crime and gentrification in the 90 s to present-day.

Washington, DC and the surrounding areas are important to my research because of what its reputation implies for the research participants. As the seat of the 
federal government and "one of the most polarized cities, by income and education, in the country" (Morello and Keating 2011), women in this research are hyper aware of their appearance and the appearance of their children. There is an expectation, in the workplace and in the community, to uphold traditional values of Washington as a serious, political city, which has been shown over the years by Washington's black elite class.

Today, Chocolate City is much lighter, and has become "cappuccino city" as Derek S. Tyra refers to the changing demographics of DC in his ethnography of the historic Shaw/U Street neighborhood, Race, Class and Politics in the Cappuccino City (2017). As white millennials and established transplants have moved into the city, the costs of housing have risen and continues to push long-time African American residents out of the city and into nearby suburbs and less expensive Southern states. As a result, surrounding suburbs are critical to this research. A majority of my research participants lived in nearby Prince George's County, Maryland (PG County). Many women in my research were born in DC, or nearby and lived in PG County because of its convenience, its slighter cheaper cost of living, and because of the desired suburban lifestyle. Although many consider PG County as the place that African Americans were pushed into due to gentrification in the city, PG County has its own history. While DC was known for having the most African Americans per capita, Prince George's County has long been known as the wealthiest African American county in the United States.

In Chapter 4, I introduce black women as working professionals in the middle class and as single mothers in the Washington, DC area. Single parenthood is a complex situation that has been experienced in many ways by the women in this research. Some women are divorced, others never married, some are widowed. The 
bottom line for each of these women is that they assume the full responsibility as the primary legal guardian for their child(ren). In this chapter, I discuss the roles and responsibilities of single motherhood as black women work to be productive and competitive employees in the workplace in order to maintain their middle class status and lifestyles. This chapter reveals how race and class status impacts their lives as single mothers and impacts the opportunities available for their children (based on housing, school district, extra-curricular activities, etc.). I also explain how black single mothers understand their position as single mothers, whether intentional or as a result of unwanted circumstances.

Chapter 5 explores material culture and consumption and the ways in which things work to define the black middle class. I analyze the ways specific things resonate with black single mothers in the DC metropolitan area. Sociologist and anthropologist Pierre Bourdieu, attributed things and material culture to one's habitus, or "structuring structures" which are systems of power relations in place which shape one's worldview and determine actions and behaviors (Bourdieu 1977). As members of the middle class, black single mothers work hard to maintain and fit in with their perceived community. By both embracing and rejecting the subtle pressure to "keep up" with the latest trends and expectations of class in the DC metropolitan area, these women position themselves as middle class, despite their single marital status. This chapter will explore the ways in which these women acquire things, through online and department store shopping, and the reasons they feel enticed to participate in the society of spending. In this chapter, we will take a look at the status symbols, objects that suggest one's socioeconomic status present in the lives of black single middle class mothers and how these symbols compare to the black middle class as a whole. 
In Chapter 6, the final chapter of this dissertation, I conclude with the major findings of my research. I will provide brief summaries of each chapter and identify the ways this work contributes to the field. I will also discuss my recommendations for future research related to this work.

Conclusion

The social organization and family structure of the black middle and upper classes has become increasingly popular in mainstream media, nevertheless scholars continue to focus on the black lower classes, as witnessed by the hundreds of studies conducted on or about the black urban poor. The black middle class fails to receive the same high level of attention and representation in both popular and scholarly discourse. Black mothers are characterized as individuals of two extremes, single and poor or married and stable. It is time to recognize the black middle class as the complex entity it is, full of contradictions and affirmations. Popular culture theorists have begun to analyze the black middle class and consumption patterns present in television shows and movies, but there is more research to be done. Pier Dominguez, for instance, notes that these television programs showcase racialized gender performances of excess that many viewers may not experience in the same way (Dominguez 2015). My research aims to determine whether these popular race, class, and gender performances inform the real-life consumption patterns and identity formation of off-screen black middle class women and mothers. 


\section{Meet Felicity}

Felicity was beaming with joy as I walked into her newly purchased, and newly renovated home. The three-story townhome was located just minutes away from my mother's home in Maryland, in an area not far from the FedEx Field, home to the Washington Redskins. Felicity met me at the door as I arrived for our $8 \mathrm{pm}$ weeknight interview. "Please take off your shoes" she said with a smile as I entered the home. She purchased it the year before and had recently hosted a painting party with her close friends. Her place was simply decorated in black and white decor. It had a modern look, with her use of glass, oversized mirrors, and marble throughout the entryway.

Felicity is a federal government employee. As a teenager from Washington, DC, she took advantage of summer programs that allowed her to gain work experience in the local and federal government. She found an agency that supported her college attendance and allowed her to return to work each summer. After graduating, she was hired full-time at the agency, and now earns an annual salary of $\$ 100,000$. To support her personal interests and for additional income, she also works part-time at a non-profit organization, where she makes an additional $\$ 20,000$. She is 29.

Jade, her precious and energetic 3-year-old daughter, came running my way. She was so excited to have a guest. "Hi, Aysha!" she yelled as she ran around the living room, before being asked to return to the kitchen to finish her dinner. Felicity had two jobs, maintained a new home, and had a 3-year-old. After evidence of infidelity sufficed, she ended her long-term relationship with Jade's father. She never planned on being a single mother, but the circumstances required her to leave an unhealthy relationship and raise her child without her child's father in the home. She 
manages her finances, savings, and Jade's needs independently. Her finances are intact, her savings are plentiful, and her self-respect is like none other. Felicity is a single mother and she is unashamed.

CHAPTER TWO | Methodology

Objectives

Weeknights in my childhood home were always extremely systematic. My mother would pick up my younger brother from his daycare, and then pick me up from my after-care, where I had completed most of my homework, been fed a snack, and gone outside to play, until around 6pm. My mother would enter our house and head directly to the kitchen to begin cooking, most times without even removing her coat. She usually had food thawing out the night before or in the morning to make dinner quick and easily, saving more complicated meals for Sunday evenings. While she cooked, I helped my brother, who is seven years younger than I am, settle in. We would play games, or I would get back to my homework if it were not complete so that I could enjoy my "tv time." During this time, my mother also prepped our lunches for the next day, talked on the phone with her friends, yelled from the kitchen for us to complete our chores and get ready for the next day. It was a serious routine. When I decided to conduct this research, I was reminded of those busy weeknights, when my mother had three or more things to do at once - and, somehow, always got it done. It did not feel strange or rushed, it was just the way things worked Monday through Friday so that our lives would run smoothly. As a researcher, I took these moments of my childhood into consideration, and worked towards developing an effective and efficient method of data collection in order to work with the needs of my participants. 
I designed this research project with the subject, black single middle class mothers, as the primary focus and determinant for specific methods employed. In order to explore the experiences and behaviors of these women in the Washington, DC metropolitan area, I took into close consideration the women's relationship with the place, their availability to participate in such research, and components of the research that would most interest them. This research was designed by focusing on key concepts such as conspicuous consumption (E. Frazier 1957; Lamont and Molnar 2001; Podoshen, Andrzejewski, and Hunt 2014) respectability politics (E. B. Higginbotham 1993; Cooper 2017), the making of class and class status (Hunt and Ray 2012; Moore 2008), stereotypes and misrepresentations in popular culture (Mukherjee 2006; Warner 2015), and collective identities between mothers (Collins 1994a; A. D. Wilson 2014), in collaboration with my prior knowledge of my research group. I unpacked these concepts among my research group by employing a multidisciplinary qualitative research approach, which included participant observation, media studies, material evidence, interviews, and focus groups. I became a member of the place, relocating to Laurel, MD, a Prince George's County suburb, and constant presence in the lives of many of my research participants.

I carefully designed this research project with the objective of obtaining a representative collection of data that was relevant and comprehensive (Prod et al. 2009). I sought to make the research process easy and accessible for the benefit of the research participants. I aimed to be flexible in my approach, in order to gather the most useful information from my informants. I determined that accessible research methods would encourage a diverse research group, and thus, rich and varied data to ensure content validity. The methods selected were based on prior instrumentation in anthropology and sociology. The research methods selected supported my objective to 
gather information related to the experiences and perspectives of black middle class single mothers in the research area in order to explore common and alternate themes amongst the group.

\section{Black Middle Class Research Methods}

In addition to key primary texts in anthropology and sociology, I have referred to prominent anthropological studies on black socioeconomic classes and black family formations to design my field research plan (Patillo 1999; Patillo-McCoy 2000; Lacy 2007; Stack 1975; Graham 1999). Using the approaches of these groundbreaking texts, I relied heavily on the methods of participant observation, interviews, and community involvement/immersion.

Karyn Lacy’s Blue Chip Black: Race, Class, and Status in the New Black Middle Class (2007), focuses on the same physical location as this research. To analyze the black middle and upper-middle class, Lacy visited the homes of families (often with married parents) and conducted interviews related to their middle class activities, and decisions to live in specific neighborhoods. Lacy’s approach to understanding class, involved a combination of interviews and participant observation. She was able to see the research participants personal space (their homes) and allowed them to elaborate on why they purchased homes in specific neighborhoods and what that meant for their image. I recognized this approach as effective, yet simple, and one that I wanted to adopt in my own research. I believed that allowing individuals to discuss their things, in their own homes or while surrounded by such things, created an opportunity for open and honest discussions between myself and the interviewee. 


\section{Participant Observations}

In this research project, I relied heavily on participant observation to guide my research. Many qualitative researchers would argue that observation is the first step in research and gathering knowledge related to the problem, or group of focus (Timseena 2009). Participant observation is one of the primary methods of data collection in anthropological research (Geertz 1973, Stack 1975, Bourdieu 1984, Barnes 2015). In order to truly understand and learn about the people and culture, the researcher must insert him or herself into the field and frantically observe their surroundings. Timseena explains:

Its aim is to gain a close and intimate familiarity with a given group of individuals (such as a religious, occupational, or sub-cultural group, or a particular community) and their practices through an intensive involvement with people in their natural environment, usually over an extended period of time. (Timseena 2009)

This method applies to researchers in foreign settings of study, as well as, if not more so in familiar settings. As a researcher from the Washington, DC area and within the community of single motherhood, I was conscious of my need to observe my research area and participants more closely and through two lenses - as an insider and outsider. Taking into account Ite (1997) and Mandiyanike's (2009) argument that a graduate student conducting research at home "might face challenges and perils that could hinder the research" (Zhao 2017), I worked to acknowledge and respond to challenges as they arose. I understood that conducting research at home would provide benefits and challenges to my research and productivity. Using my closest research participants as a guide, I attempted to enter the world of single motherhood as both an 
observer and participant. I employed George Marcus' methods of multi-sited ethnography. Marcus urged researchers to be mobile and "follow the people," meaning to join participants as they were as well as the goods and services they produced (Marcus 1995). To better understand my physical research area and my participants, I took full advantage of various opportunities that allowed me to observe. While I would have preferred to meet each woman in her home, sometimes their schedules would not allow for it. I adapted my research site to expand from the homes of the women, to their workplaces, coffee shops, and co-working spaces. I followed the participants as needed to get to know them and understand their daily schedules as single mothers. Because of late working hours, busy weekends, or responsibilities with young children, it was necessary for me to meet some research participants at work or while on their lunch breaks. I found myself traveling all over the city, to meet mothers at the most convenient times and places for them. Although in these rare instances, I was unable to view and analyze their homes, I used other observations to draw conclusions. I paid special attention to the restaurant and location the woman wanted to meet or took notes on the state of her office if I were invited to her workplace. In workplace settings, I took notes on her interactions with other coworkers, office placement, and overall position in the office.

This method allowed me to collect data related to my research problem and the processes of my participants (Russel 2015). In addition to my personal interactions with the women of this research, I spent a lot of time navigating the city and nearby Maryland suburbs to understand the geography of my research site. I traveled across Washington, DC researching homes for sale and apartments for rent, to understand the expensive housing market and cost of living expenses. I also attended programs and events in the city, including an Inclusionary Zoning seminar to understand the benefits 
low-income and lower middle class families were offered in DC to compete with the high costs of living in the area. During this time, my mother purchased an additional property, a condominium in Prince George's County, Maryland. I accompanied her to view other homes to get a better understanding of the housing market in Prince George's County - the county where the majority of my research participants currently lived. I babysat for participants who needed additional assistance with childcare. I attended parties and events hosted by my participants. I engaged in children's birthday parties, family gatherings, and other typical family and friend events to gain as much knowledge as possible on my research site and research group. I found any possible opportunity to interact with single mothers broadly. There were no fixed boundaries between "home" and "field," (Zhao 2017), instead my home became the field, in which I were always a part of (Katz 1994). There were no specific areas, clubs, or events that I attended that were specifically for black middle class single mothers. Instead, single mothers across socioeconomic backgrounds, and mothers of varying marital statuses were often in each other's company. Consistent observation of these spaces helped me to distinguish the different roles of each of the women. I combined these ethnographic field research methods to fully observe my surroundings to better understand my research problem.

In some cases, I became an active and constant participant in the mothers' lives. This allowed me to have additional individual time with the participant and observe her interactions with her children, personal space, and things. I benefitted the most from these individual extended interactions. In my experiences, I found that mothers (single or not) did not spend their time primarily discussing their children, families, or material things exclusively. After accepting this, I realized that observing participants 
individually would offer me the greatest and most in-depth insight into their everyday life experiences.

One-on-one interviews

I prepared a set of guided questions to conduct in-depth one-on-one interviews with my research participants. These questions were developed to provide insight on the women's lives as mothers and their lifestyles as members of the middle class in the DC metro area. The interview was divided loosely into the three sections: participant's prior expectations of motherhood and family, representations of black women and black single mothers, and middle class lifestyles. The interviews also allowed room for the participants to speak openly and freely on other related topics that they felt important to my research and to their personal experiences as single moms.

Interviews are common methods that have become central to our society. Silverman reminds us that we live in an "interview society" where in addition to qualitative research, interviews are present in talk shows, reality shows, celebrity interviews, news programming, and more (Silverman and Marvasti 2008; Forsey 2010). It is a primary way that we come to understand social phenomena and individual's feelings towards specific topics. Interviews were selected as a primary method of data collection because of the quantity of information I would be able to gather, and because of its ease of use. Interviews also became incentives, unknowingly, to the research participants. Several of the women made comments suggesting that they felt honored to be interviewed, or never knew that their stories or voices were important enough for an individual interview. I felt that these comments made the interviews more genuine, as these women were humbled and appreciative of 
the opportunity to share their experiences and perspectives. Throughout the interviews, I engaged in "participant listening," which encourages researchers to listen deeply while interacting with participants through interviews or observations to observe one's values, beliefs, material conditions, and patterned behaviors (Forsey 2010).

The individual interviews were designed to last one hour. On average, the interviews lasted about 1 hour and 30 minutes. I expected the women to be busy, and unable to interview for long periods of time - some women conducted interviews at work or on their lunch breaks, so time was a major factor. Instead, the interviews tended to last as long as they needed. With the exception of one participant, whose daughter became injured during the interview and needed medical attention, no other women interrupted the interview to because it went over time. The interviews were formatted to receive open-ended responses, in which the participants took full advantage.

Overall, the individual interviews provided me with an abundance of information. Although the participants often made comments suggesting that they “didn't know" or "never thought about it," their responses revealed a lot about themselves. While I recognized the importance of accepting the research participant's accounts as valid I also understood that individual accounts of oneself could be unclear and/or contradictory (Hollway and Jefferson 2000). Unlike life outside of research, in informal and familiar settings, I did not challenge the participants responses, but listened and relied on the other research methods to provide counterexamples and deeper understanding. 


\section{Focus Groups}

Focus groups have been used as instruments to collect qualitative and quantitative data in several fields including consumer and market research and the social sciences. In market research, advertising companies and product developers use focus groups to gather data from target consumer audiences (David 2007). A significant component of my research focuses on tangible physical things and some intangible purchases (like trips, or classes), so I also approached my research participants as consumers. In order to understand how they related to specific products and experiences, I combined anthropological and sociological research and market research focus group approaches.

Focus groups are essentially guided group discussions that create an opportunity for individuals to share and compare experiences and preferences. As a way to test products and sales, companies use focus groups to gain customer feedback prior to the product being available publicly, or to gather more information on how to best sell the product. The focus group method is beneficial for such objective because they allow for exploration and discovery, context and depth, and interpretation (Morgan 1998). I sought to benefit from the strengths of this method in my research. I recognized that brands were often discussed in my conversations with participants as they pertained to socioeconomic status and class. They spoke about specific brands and things they liked and disliked about some of them. They referenced prices, material, quality, and other characteristics. As these in depth descriptions of brands continued throughout my individual discussions with the participants, I decided to use focus groups as a method to discuss common themes and expectations introduced during the research. 
Over the course of my field research, I conducted one 2.5 hour focus group. I invited seven participants with whom I had already conducted individual interviews. This number was selected based on previous research that found that:

The rationale for this range of focus group size stems from the goal that focus groups should include enough participants to yield diversity in information provided, yet they should not include too many participants because large groups can create an environment where participants do not feel comfortable sharing their thoughts, opinions, beliefs, and experiences (Onwuegbuzie, Dickinson, Leech, and Zoran 2009).

I selected these specific women because of various differences in occupation, number of children, and residential neighborhoods. Also, these women expressed interest in continuing our conversation with other women and were available at the proposed focus group date and time. I determined that a focus group would be a beneficial method for my specific research because of its efficient way of obtaining information from multiple participants simultaneously, its group dynamic, and for its likelihood of natural and unforeseen responses (Onwuegbuzie et al. 2009).

I conducted the focus group after having in-person one-on-one interviews with each participant. I emailed each woman and proposed a date, time, and specified expectations for the focus group. Upon email confirmation of five of the seven invited participants, I secured a location for the focus group. I used the unoccupied home of a family member (another single mother who also participated in the general research study, but who was not present for the focus group). At the time of the focus group, the home was only occupied by myself, the participants, their children (if they brought children along), and a hired babysitter. 
I called the event a "Mommy and Mimosas Brunch." While it was clearly stated to the participants, that it was a focus group, they also expected it to be a social event. I invited the mothers to bring their children, because as single mothers they may have been burdened with finding a babysitter otherwise. I quickly realized that in order to make the focus group work with my demographic, I would have to secure a babysitter to be available to watch the children in a different room while my participants were occupied with the focus group. Three mothers asked to bring their children along, but at the last minute one of the mother's shared that her children went to spend the day with their father and would not make it to the group.

I decided to make the event a brunch for moms, as a way to show appreciation to them, but to also create a relaxed research environment. I determined it was best to invite mothers who did not know each other as a way to protect confidentiality and encourage honest responses without judgment from friends or colleagues. It was also important that the women felt comfortable to share openly with one another, although they were strangers. By opening the event with brunch foods (waffles, eggs, yogurt, fruit, chicken wings, bacon, etc.) and mimosas, the women were able to relax and get to know each other briefly before my interference. Because discussions surrounding race, class, and motherhood in general can be very personal, it was crucial for these women to find some type of connection with one another as mothers prior to our open discussion. The success of the focus group relied heavily on the participants ability to interact (Freeman 2006). Although they did not know each other beforehand, this brief period of laid back interactions allowed the women to appear trusting and ready to openly discuss their perceptions, ideas, opinions, and experiences in front of the larger group (Krueger and Casey 2000, Onwuegbuzie et al. 2009). We discussed 
confidentiality in the space, and the women verbally agreed to keep the information shared within the contexts of the focus group private.

For the focus group, I prepared open-ended questions, showed a video, and prepared an activity based on material consumption. I opened the focus group by showing the promotional video to the "Real Housewives of Potomac" upcoming season as an entry point to discussing class and the realities/misperceptions of it in the DMV area. I followed up with a strikingly different video, the extended trailer to the documentary, "72\%" (2014), which opened the conversation up for discussions around the representations of black women in media and stereotypes surrounding black single mothers. I prepared a list of questions for any woman to answer. They did not speak in any particular order, and each chimed in when compelled. It operated as a guided discussion, with me asking large overarching questions, and the women adding their experiences and asking their own questions to one another. This dynamic and interactive experience is what prompted by decision to use focus groups as a method of research:

Focus groups aim to promote self-disclosure among participants, by explicitly capitalizing on group dynamics in discussions.

Participants are encouraged to question each other's responses, elicit clarification and explore caveats to their statements. The method seeks to promote a safe environment for self-disclosure through careful participant selection, sensitive questioning by a moderator and the prior establishment of clear ground rules for participation (Krueger 1994). (Freeman 2006). 
Towards the end of the brunch, I planned a short activity for the women. I printed a selection of items (cars, homes, fashion items, groceries, books, and more) on individual pieces of paper. Each of these items had a less expensive and a more expensive version. For instance, I provided two types of cars - a luxury brand car and an economy size mid-price range car). Using the list of objects provided, I asked the women to select the items that they attributed to the middle class. This provided me with clear examples on the varying definitions and expectations of middle class lifestyles by the women in the group. They provided reasoning for their selection. The women spoke about the importance or unimportance of such items in their immediate communities (location-based communities and social communities). They shared their relation to these items and offered explanations for why they agreed or disagreed with certain choices.

\section{Media Studies}

I recognized popular culture and the media as a major component of my research from very early on. I watch a lot of television, and as my field research progressed, I learned that my participants did as well. Already an avid television consumer, I began to watch network and cable shows from a critical lens, closely examining and questing how the writers, directors, and actors portrayed or represented black women. I paid close attention to representations of black mothers on screen. I relied on several articles related to the popular television shows and films that produce highly visible representations of black womanhood, including network shows like Scandal and Empire and cable television shows like Queen Sugar and The Real Housewives franchise. 
I took notes on the representations that these shows produced and spoke openly about these representations when the research participants introduced them in our interviews. It became imperative for me to focus on the media in this research, because it is one of the driving forces of the stereotypes and misrepresentations that these women challenge each day.

Data analysis

After collecting my data using the aforementioned methods, I utilized computer software to compile, organize, and analyze my data. I transcribed my interviews in two phases. First, I put the audio files into my computer video software "iMovie," and converted the videos to subtitles. Next, I hired a contracted writer/editor to assist in editing the transcripts for punctuation, spelling, and formatting. I produced two versions of the transcripts - one version with the original timestamps on Microsoft Excel so that I could revisit the interviews and locate the time a line was spoken, and the other a narrative version, for style and readability.

I input all of the transcripts, field notes, and memos, and reflections from social and television media into NVivo, a qualitative data analysis software. In NVivo, I developed codes and nodes for themes and individual interviewees. I began by creating codes based on common concrete characteristics between the women, such as age, number of children, marital status, and income. The next levels of coding were more complex, and included themes related to general stereotypes, shopping and spending patterns, and goals. I applied these codes to the full written text and audio available in the software. I used the software to organize the most common themes amongst my participants and to highlight and separate the contrasting accounts and experiences. NVivo was a beneficial tool because it could be adapted as my research 
continued. It produced useful information such as word maps and allowed me to create a key of all pertinent participant demographics.

To write and compile this dissertation, I used Scrivener, a paid word processor. Scrivener allowed me to organize this dissertation into smaller, more manageable chunks. The software creates binders for each chapter, monitored my writing progress, and organized notes and references. It allowed me to label sections of this paper by draft number, which was helpful in keeping my writing organized. Unlike other word processors, it allowed me to view multiple sections of the paper and supporting research simultaneously. It was extremely helpful in organizing such a long, complex document, and was the saving grace as an organized word processor.

Access

This research focuses on middle age black women, mostly African American, but also Afro-Caribbean, who are unmarried and assume primary responsibility of their children. The criteria for research participation was based on marital status, age, children, location, and income. In general, most of the research participants had 1-2 children, were located in DC surrounding suburbs, and made average incomes for the Washington, DC metropolitan area (between $\$ 65,000$ - $\$ 85,000$ annually).

My experiences and familiarity with the research site provided me with the full advantage of having personal relationships with several potential research participants. I personally knew and have been exposed to many single mothers throughout my life. When embarking on this project, however, it became extremely important for me to expand my research participants to include more than women who I had personal connections with to avoid selection bias. To do this, I used my 
immediate physical and digital social networks to connect with black middle class single mothers in the area.

Initially, I spread the news about my research topic, interests, and goals to my immediate family. I spoke with my mother, grandmother, aunts, male and female cousins, and close friends. It was quite easy for them to be interested in my work, because they were most concerned with my success as a doctoral student. They all brainstormed women who were single and who they considered middle class, and reported them to me through text messages, late night phone calls, and at family gatherings. My small tight-knit community wanted me to complete the requirements for the $\mathrm{PhD}$, and in order to do so they came together to provide me with contacts to other black middle class women. Conducting my research in my hometown became advantageous for me, as I was treated like the "little sister" or "play niece" completing her final paper to graduate. The overwhelming support and desire to help me track down women who were not relatives became serious pastimes of those closest to me.

My research project also interested my family and friends, initially, because of the subject matter. Those who are single mothers, were both honored and intrigued by my decision to conduct a research project specifically around the experiences of black middle class mothers. Because of this invested personal interest, they referred me to co-workers, friends, study mates, and extended family members who might have fit my proposed participant description. In my observations, the women took extreme pride in being contacted for this project. It became a selling-point of sorts, when I watched my participants reach out to other women by phone.

I reached out to women in my former community organizations, former workplaces, church, and online networks to form my starting participant sample. 
From our interactions, and often in the middle of our interviews, these women would think of other friends, family, and colleagues who they would like me to meet. If the person was a good fit, and timing worked out for the both of us, I would meet those women. The process of snowball sampling continued throughout my field research.

Positionality

A Self-Reflexive Approach

“...the new ethnographic project argues against the possibility of 'unbiased' scholarship, and views reflexivity as a tool to enhance awareness of our situatedness and, subsequently, to be more receptive to perspectives that approach the world from a different position.” (Saukko 2003).

As the daughter of a single mother, and a native of the Washington, DC metropolitan area, I entered the field with preconceived notions and my own personal understanding of single mother households and life in the middle class. In order to accept the biases, I brought to the field as a researcher closely tied to my research site and research participants, I sought to conduct a self-reflexive ethnography. Prior to the start of my research, and throughout my time in the field, I employed Foucault's concept of "technology of self" (Foucault 1982), which maintains that one completes an inventory of the discourses that have formed one's self (Saukko 2003) and remains self-aware and ethical. I became critically aware of my positionally as the child of a single mother, and how my life's experiences have influenced my approach to this work. Throughout the research I was hyper-aware of time, because it was something that I recognized as a major factor in my own life growing up. As a child, I watched 
my mother juggle multiple tasks at once, work late, prepare dinner, check homework, and more. My witnessing my mother's everyday experiences as a single mother and the immediate effects it had on myself and younger brother, heavily informed my research. At the same time, I understood that my personal experiences, although with a mother who fit my research participant description, were singular experiences that could not be applied to the group as a whole. By taking an inventory or creating an informal list of these conditions and biases, I engaged in critical self-analysis, which informed my decisions in the field as a researcher. Furthermore, I embraced the fact that I could never be truly neutral on the subject matter, but that I would work towards governing myself and actions as researcher in an ethical and honest manner (Saukko 2003). I applied this thinking to the development of my research project as it pertained to class and to family structures.

Insider vs. Outsider vs. Somewhere In-Between

As a researcher, I shared commonalities with my participants including gender, race, language, and class that traditionally categorize my position as an insider (Rubin 2012, Zhao 2017). In the introduction to each interview I conducted, I introduced myself as a student, a local, and a child raised by a single mother. This indication as a child of a single mother often evoked a positive response from the interviewee. Most women who did not know me personally prior to the interview, expressed a surprise, pride, or a sense of relief. My experiences as a child raised by a single mother in the same area as my research participants informed my decision to reveal this personal history about myself in our one-on-one interactions. From my experiences, black single mothers often face some form of prejudice. The introduction of my personal history created an invisible, leveled playing field. Instantly, the women seemed to 
understand that I, too, was raised by a single mother and am in no position to judge based on this particular characteristic. This information allowed the women I knew beforehand to compare their experiences to mine (some of them knew my mother) and allowed my new informants to feel comfortable sharing and asking questions. In interviews that often became two-way conversations, some women would ask me the same questions I asked them. They sought answers to how my mother did things, wanted to know how, as a single mother, she raised a child who would continue on to her doctoral studies, and were curious about my relationship with my father.

My experiences with the research subjects on a surface level, positioned me as an insider. Although I felt related to these women in some ways based on our characteristics, we were vastly different. The experiences these women shared amongst each other were experiences that I could not relate to due to age, relationship history, and motherhood. My personal history and connection to single motherhood, the area, and the black middle class, suggested that I was an insider, however, several times throughout my research I became aware of my position as an outsider. This presented a limitation to my participant observations.

Timseena's description of participant observation involves the researcher becoming one with the community:

Under such condition, the researcher must participate with the community or the subjects on which the research activity is associated. The researcher acts as a member of the community and collects information acting as if he/she were from the same cultural group where the study is going to be done and understand all phenomena occurring in the group. (Timseena 2009) 
This type of community membership was not possible for my research.

Although I felt connected to my research participants and the greater black middle class single mother community, I remained an outsider because I had not lived as a black single mother and could not do so unless experiences major life changes. Research participants would ask me about motherhood - whether I had any children or not - and would offer their unsolicited advice on my interactions with men and motherhood. This duality of being a product of the black single mother community, but not a member of the community itself, provided balance to my research efforts. I was able to nod and shrug in agreement to statements that I understood personally, or witnessed my own mother experience, but I could also genuinely ask questions surrounding topic in which I did not have prior knowledge about. My experiences as a young woman without children prompted these typically older black women with children to use their wisdom and expertise to "school me" and insist on the "real" single motherhood.

\section{Student Researcher}

My experiences as an insider/outsider in the community did not cause me to feel like an invasive researcher. My student status definitely prompted many women to dedicate their time to me, but in the interviews my student/researcher status felt nonexistent. I would always inform my participants that interviews would require approximately $1-1.5$ hours prior to our meeting. They would usually say they were busy and may have to keep their responses short, but they would almost always take up the full time - with most of our interviews exceeding 1.5 hours. As our interviews quickly became conversations, they spoke candidly and openly and often forgot about the time or my recording device. As a student, often perceived to be much younger 
than I am, my participants seemed to want to help me succeed, and therefore agreed to participate and supported me in other ways.

I also recognized my position as a researcher, which held a privileged position, as I was responsible for " deciding what questions to ask, directing the flow of discourse, interpreting interview and observational material, and deciding where and in what form it should be presented" (Mclafferty 1995). I attempted to reconcile this power dynamic by allowing the research participant to ask me questions openly. When questioned about my life, childhood, and experiences in the middle class, in DC, or with a single mother, I responded honestly - just as I expected them to do for this research. Although I sought to create shared spaces (Chattopadhyay 2013) where my participants and I engaged in mutual exchanges of information, I knew the space was unequal. I understood that ultimately it would be my interpretation of this research and ability to define the research problem and participates in the production of a final written comprehensive text that constituted my privileged position as a student researcher.

Throughout the field research, there were varying degrees of position and privilege. At times, my positions co-existed as both insider and outsider within the same research moment. The truth was that my complicated positions could not neatly fit into either category - insider or outsider. Instead, my role as researcher and daughter of a single mother departed from the traditional dichotomy of insideroutsider, and supported more recent scholarship on positions of in-betweenness (Zhao 2017; Botterill 2018; Chattopadhyay 2013). My positionality as an insider and outsider simultaneously aligned with Rose's notion of 'betweenness', which demonstrates that a researcher can be both separated from and related to the researched (Rose 1997). Rose argues that it is imperative to "situate knowledges" by 
acknowledging the power relationships in research and practicing transparency fully disclosing them in research. As humans and researchers with our own histories and lived experiences, we cannot come to any scenario without biases, power dynamics, and prior knowledge, but we can work to produce non-generalizing knowledges.

\section{Limitations}

Location

I proposed to document the experiences of black single middle class mothers in the DMV, which is the DC metropolitan area that includes the city of DC, Maryland suburbs, and Northern Virginia. During my field research, it became very difficult to locate and connect with mothers in Northern Virginia. I connected primarily with women in Maryland, and a few in DC. This has caused limitations in my research findings on the DC metropolitan area. My research has come to focus on women in DC and MD specifically and does not include the full "DMV" area as originally proposed.

\section{Meetups}

I originally proposed to participate in Meetup groups. Meetup.com in the online social network that allows individuals to create groups, or "meet ups" for similar and likeminded people to meet up in-person. The site is designed to form a social network on and off-line based on one's interests. There are meet up groups for knitting, dissertation writing, and single parents. There are several single parent meet-up groups in the DMV area. Unfortunately, however, I was unable to use the website as a resource to fulfill my research expectations. 
Initially, I planned to attend join the Meetup group, "Single Parents of the DMV" online and attend in-person events. Groups post events such as happy hours, bowling, park outings with children, and more. I hoped to attend these events to meet single mothers outside of my immediate network and invite them to participate in my research. I also hoped to use the Meetup group to observe how the mothers interacted with one another and presented themselves and their children. The meet-up groups were unsuccessful.

I connected with the organizer of the group, Sheila, who is also a single mother. She explained that most of the members in the group are inactive. She had planned several in-person meet ups in the past, but the confirmed members would never show up. She expressed her frustration with the $100+$ members of the group for not participating, but also empathized with them because of their schedules. As a single mother herself, she understood that often times things "come up" that may alter original plans, or that their busy schedules do not allow single parents to take time out for themselves to have a social group. It became clear to me that single parents joined these groups with the intent of finding time for themselves, but that intent was thwarted by the responsibilities and expectations of single parenthood.

\section{Shopping}

Another ineffective proposed research method was shopping with my research participants. In most of my one-on-one interviews, the mothers revealed that they in fact did not like to shop, did not have time to shop, or shopped online because of convenience. Many of their responses focused on shopping for household necessities like food and cleaning supplies. I expected to join the women in shopping excursions, but quickly learned that the items that these women consumed were often not purchased in a traditional store. 
Because the women shopped online, I was unable to accompany them on physical shopping trips. I did not feel it would be beneficial to accompany women to the grocery store, and it also felt highly impractical. My research participants were extremely busy, full-time working single mothers, and time was often an issue for them. I scheduled and rescheduled several meetings with the participants to accommodate their busy schedules. The idea to incorporate an aspect of my research that coordinated shopping times, when women would mention shopping at random times whenever they had a moment to do so, became unrealistic. Instead, I asked more direct questions about the women's shopping and consumption habits. I also interviewed women in their homes as often as I could, to be able to take understand the things they liked by observing first-hand the things they already owned.

Surprisingly, I discovered a new way to learn about the shopping habits and material focuses of my research group - Facebook. I was "Facebook Friends" with a number of my participants prior to our interviews and became friends with some of them after our initial meetings. As their "friend," I was allowed to view their posts. Online these women shared a lot of information about their newest purchases, trips, and other expenses. Although it was not initially planned, Facebook became a way for me to observe my participants without physically accompanying them to shop. The participants posted freely without my gaze as a researcher - which allowed them to engage in "self-curation" and performance of self online (Ibrahim 2016; Goffman 1959). Often times, the participants who I was connected with online presented themselves to be more concerned with their material goods than they expressed inperson.

Studies have found that online social networks can cause users to feel pressured in presenting themselves in positive, and even exaggerated ways (Djafarova and 
Trofilmenko 2017; Scott and Ravenscroft 2017; Ibrahim 2016). Young mothers are among the most active users of social media platforms, including sites such as Facebook and Instagram. They often use these online networks for several reasons: a sense of community, to learn from other mothers/advice, feeling of encouragement, and general self-esteem. The women in my research group also used social media to connect with a larger community of friends and colleagues, who did not use the platform exclusively for parenting reasons. In a 2017 study, Djafararova and Trofilmenko found that "mothers rarely discuss real problems or admit challenges they face daily" (Djafarova and Trofimenko 2017). When possible, I compared the experiences that were shared with me personally during our interviews with the images and experiences that were shared online.

My participants followed-up with additional anecdotes after our interviews. Few of them emailed me or texted me to share more experiences, or to clarify something they mentioned earlier. This level of interest and involvement revealed to me that they took my work seriously and spent time contemplating our conversations even after the interview had ended. These women expressed the most interest in reading my findings at the end of the project. 


\section{Meet Georgia}

Georgia sat at her dining room table as she prepared to share her story. We were connected through an email chain that was shared among black women in a local graduate program. She eagerly replied to my request searching for black middle class single mothers. As we sat at her dining room table, her children, two teens came in and out of the kitchen, and her partner, checked in to see if we needed anything.

Georgia, who is originally from Los Angeles, embraced all that the DMV had to offer. She relocated to the DC area in search of something new and for work opportunities that would better position her in her career goals. Unlike most mothers in this study, Georgia decided to become a mother at a young age, purposefully. She was aware of pregnancy complications in her family and wanted to make sure she could become a mother. She was not overly concerned with marriage, but prioritized motherhood early on. Georgia became pregnant with her boyfriend of many years and understood that marriage could come at a later date. They eventually broke things off. She now lives with and shares a life with her girlfriend and expects to marry soon. "I will always be a single mother," she says. Georgia recognizes women as the one constant figure in children's lives. While everyone else can come and go, as a mother she expects to always be present for her children.

She is one of the younger participants in this study. As a full-time graduate student and business owner, she is very busy. She is excellent with her finances but loves to embrace the finer things. Her brand of choice is Louis Vuitton, but she also loves Gucci. "Purses," she says, are her weakness. She enjoys purchasing luxury handbags because now, as a homeowner earning up to $\$ 100,000$ a year, she believes she can afford it. She also affirms that she deserves it. 
"This is not how I was raised," she says as she picks up her large Gucci bag that is sitting on her dining room table, "I was raised extremely poor growing up with my mother in California. So, coming from this perspective... I wanted to be able to provide. Being a single mother was never a deterrent, it just makes you work a little harder.”- Georgia, 36, December 22, 2016

Georgia's life experiences have taught her that hard work pays off. And now, she prefers the best for herself and her children. From food to clothes, she embraces her highly selective nature and is proud of her progress. Today, Georgia is working to complete a doctoral program, works full time, and continues to run a successful private counseling business. 
CHAPTER THREE | Chocolate City No More: The Displacement of African Americans and the Rapidly Changing Demographic in Washington, DC Returning Home

Washington, DC has historically been a city of refuge and opportunities for African Americans to start fresh and thrive in their efforts to create stable middleclass households and upwardly mobile communities. The opportunities available in the city attracted African Americans from across the country and provided African American women positions outside of domestic fields. Here, African American women have been able to build their own success, with higher education and decent work opportunities, dispelling the common notion that women must have men in the home in order to have financial stability. In this chapter, I explore the history of Washington, DC and how it rose to prominence as a black middle class center and how recent developments have forced Washington's black middle class to shift outside of the city. The women included in this research are both native Washingtonians and migrants who relocated to the area for school or work, in hopes of greater opportunities. As the city continues to change, these women find themselves working hard to maintain their established middle class lifestyles.

Row homes are to Washington, DC what Brownstones are to Brooklyn. My mother was raised in this style of house in Dupont Circle, NW, Washington, DC, and I have vivid memories of visiting friends in row homes - these massive, tall townhouses where, because of proximity, the neighbors become more like family than strangers. Today, as I roam the city the row homes and their inhabitants do not resemble what I recall from childhood, or even my teenage life a short 10 years ago. The city is not chocolate anymore. 
White nuclear families now occupy the once predominately African American areas of Dupont Circle, Shaw, and most notably the shopping district, Historic Georgetown. The housing market has skyrocketed in Washington, DC, and shows no evidence of slowing down. Based on 2015 findings by the US Census Bureau and the US Department of Housing and Urban Development, a family of four is estimated to make $\$ 110,000$ in the DMV, which refers to DC and specific Maryland, and Northern Virginia cities (US Department of Housing and Urban Development 2015, US Census Bureau 2015). The metro area had the highest median income based on US Census data in 2016 (Zou 2016). As a result of the high median incomes and consequent higher costs of living, African Americans are present in the city, but increasingly only between the hours of $9 \mathrm{am}$ and $5 \mathrm{pm}$, retreating to Maryland suburban neighborhoods after their workday and treacherous commute.

The outmigration of black residents of Washington, DC is the result of years of big development efforts in our most vulnerable areas. New residential and commercial spaces, including more restaurants, grocery stores, and better housing, have made their way into nearly every neighborhood in DC. As a result of gentrification, longtime residents are no longer able to afford to live in these areas. The term gentrification was first coined by British sociologist, Ruth Glass, in 1964. Glass argued that the city of London was undergoing a "mounting flow of consumption," which included the abundance of goods and an influx of new high rise buildings, cars, and affluent people (Glass 1964). In this pivotal text, she describes the changes of the city that created a new uniformity, including the introduction of cafes, bars, and luxury brand clothing stores coupled with long commuter rides and expensive social costs. Since its initial use, gentrification has become a major issue for cities in and outside of the UK and has become the subject of discussion in films (Spike Lee 1989) 
$\neg$, television shows (Issa Rae 2016; Spike Lee 2017) and music (Jay Z 2017).

Washington, DC is one of gentrification's latest and hardest hit victims. Urban sociologist, Sabiyha Prince's work on gentrification in DC explores the effects of gentrification on low income residents and ways progressive newcomers and forwardthinking organizations work to mitigate the harm introduced by the process (Prince 2014). In the recently published, "Race, Class, and Politics in the Cappuccino City" Derek S. Hyra replaces the misnomer of "chocolate" in his book's title and explores the causes of gentrification through the recent private revitalization and commercialization of the Shaw neighborhood in Washington, a former Black middle/upper-middle class enclave (2017).

It is fascinating to see the city experience massive changes in its population demographics, because African American life — music, arts, politics, and culture is so quintessentially the Washington, DC experience. It is difficult for native residents to envision the city without its African American influences and large population. This city once served as a refuge for African Americans by providing thousands with quality educational opportunities, stable careers in the federal government and private sectors, and home ownership, which aided their socioeconomic mobility. For women specifically, the city has consistently offered diverse employment opportunities. Women migrants during the Great Migration, for instance, were in search of economic opportunities and independence (Hine 1991), and DC was able to offer these things. Black women found domestic work in the households of Southern congressmen, in local politics and advocacy roles, and as typists, receptionists, and vital employees of the federal government (Ingle 1971). Placement in the federal workplace started off slow but remained steady. In 1923, the federal government employed 51,000 black employees (D. King 1995). The total full-time 
Black employees reached 389,000 in 1969 , and peaked at 414,000 in 1980 , which made up $17 \%$ of the total federal workforce. Educated black men and women found opportunities in the federal government after completing their studies at historically black colleges and universities. Today, the federal government has a higher proportion of women in senior level positions than the private sector and has drastically narrowed the gender pay gap (Federal Employment Survey 2014). Because of this, the federal government has long been a desired employer for black women. It continues to attract recent college graduates and emerging professionals who seek to situate themselves and build wealth in the growing city.

Washington, DC is also home to historically black, Howard University, and a wide selection of other predominately White colleges and universities in the metro area including the University of Maryland, George Washington University, Georgetown University, and more. Howard University, one of the most elite and prestigious historically black colleges and universities, has produced a large majority of the black middle class locally and nationally. As students at this institution, black men and women consumed material goods to represent themselves as members of the black bourgeoisie and as emerging professionals. In photographs from the Smithsonian National Museum of American History Archives Center's prized Scurlock Studio collection, one can clearly see the pride Howard University students took in their appearance and their emphasis on looking a particular way. Georgia Avenue in NW Washington was once known for its demographic of Howard University students and university-focused commercial businesses. It also served as the site of annual the DC Caribbean Day Parade (or DC Carnival). From 1993 to 2011, thousands of predominately black DC residents and tourists took over the street with costumes, floats, and music. The parade has been banned since then due to the 
organizers outstanding debts and violence associated with the parade. Now the street, with the exception of the small section of Howard University, caters to white affluent residents with upscale restaurants, and expensive high-rise apartments, similar to the neighborhoods Ruth Glass described.

In this chapter, I will review the major demographic shifts in the nation's capital and surrounding area. To provide context for this research project, I begin with the Great Migration and how the federal city of Washington, DC contributed to the promises of the Great Migration and ways it differed from other sought after Northern cities. I will continue the chapter with the rise of DC as a black metropolis, earning it the nickname, "Chocolate City" through the 1990s, until it began to face the black population decline as a result of gentrification, crime, and available housing opportunities outside of the city. I conclude this chapter by detailing the effects of gentrification in DC, including how it has impacted the black populations and growth in nearby Maryland suburbs, specifically Prince George's County, Maryland. This chapter aims to contextualize the research site of the DC metropolitan area. In order to understand the significance of black middle class single mothers in the DC metropolitan area, one must first understand the impacts of race, class, and gender historically in this area.

\section{The Great Migration}

Between 1915 and 1970, millions of African Americans moved from the US south to Northern and Western states. Historians and demographers vary on the exact number, but many estimate that roughly 6 million people made the brave and unpredictable journey (Wilkerson 2010; Lemann 1999) while others maintain that the figures were upward of 8 million (Gregory 2009). Scholars refer to this mass exodus 
of African Americans as "The Great Migration". This mass relocation can be further divided into two waves, referred to as the First (1915 - 1940) and Second (1940 1970) Great Migrations, with each wave occurring at the start of World Wars I and II. In an effort to secure greater opportunities for themselves and their families, African Americans fled their Southern cities and towns. The US south was wrought with extreme and brutal racist policies under Jim Crow, which resulted in limited economic growth. The North, West, and Midwest presented more promises of success and thus became highly desired and sought after locations. This relocation of African Americans dramatically changed the American landscape - redistributing the African American population from a mostly rural community to mostly urban within a generation (Gregory 2009).

The Great Migration was a strategic mass relocation of African Americans. African Americans organized with one another to make the transition as smooth and successful as possible. For most, it was a period of planning prior to making the journey, which involved strategically selecting a new destination, by gathering information on available jobs and coordinating with friends and family who had already migrated to the area (Wilkerson 2010; Boehm 2009). In other instances, African Americans faced extreme danger and decided to make the move north without any preparation beforehand. There is no single cause for The Great Migration as reasons greatly varied from escaping the Jim Crow south to following family and friends. Specific cities and states, however, became collectively decided migrant destinations. It is no coincidence than certain northern metropoles have large amounts of Blacks with roots in specific Southern cities and towns. For instance, African Americans from Florida, South Carolina, North Carolina, and Virginia had destinations in Pennsylvania, New Jersey, New York, and Boston, while those from 
Alabama, Arkansas, and Mississippi had destinations in Illinois, Michigan, and Wisconsin (Schomburg Center for Research in Black Culture 2005). Louisianans and Texans tended to be the largest group to migrate far west, to California and Washington.

Major cities that experienced an influx of African Americans during the Great Migration included New York City, Chicago, Philadelphia. African Americans also migrated far west to cities Los Angeles and San Francisco and to midwestern cities Detroit and St. Louis. The proliferation of industrial jobs in these areas were incentives for African American migrants (Wilson 2011). Consistently throughout the full span of the Great Migration, New York City experienced the highest influx of African Americans, with over 250,000 migrants by 1930 (Schomburg Center for Research in Black Culture 2005). New York City, particularly Harlem, was wellknown and attractive to black migrants because of its booming economy and arts scene. Famous black writers, musicians, and artists lived in Harlem. It was in many ways a black utopia and became the symbol of progress and promise to African Americans throughout the country. Migrants were hoping to find jobs that utilized the college degrees that were earned from historically black colleges in the South. Women hoped to find work outside of the domestic field and families hoped for physical safety by escaping the racist and violent South. Generally, African Americans worked towards building institutions and associations that would improve their lives (Prince 2014). New York City and other urban centers presented migrants with greater possibilities.

In an effort to find these new opportunities, African Americans selected cities that were metropolitan and important to the American economy. Detroit, Michigan and surrounding cities were home to a booming automobile industry that offered 
factory jobs to African American men and women (Tompkins Bates 2012). In the 1930s, the city also had the highest average of black male dentists of any of the other top black cities (R. Boyd 2013). Philadelphia and the other cities in the Northeast had industrial opportunities in shipbuilding, railroad, electric, battery industries and more semi-stable employment during World War II (Center 2018). Between 1940 and 1945, African Americans migrated west to the East Bay area of California to access "social and economic mobility associated with the region's expanding defense industry" (Lemke-Santangelo 1996). These cities, and the decision to migrate to other dominant cities is what made the migration truly "great," because it transitioned African Americans from predominately rural communities to a group of mostly urban people. African Americans became so densely populated in American cities in the North that there were enough people "to make a substantial impact on their social and political institutions" in these places (Gregory 2009). This transformation had greater implications because it called for changes across the entire country.

Southern migrants were not always welcomed with open arms when they emigrated from the South. In addition to white northerners questioning their relocation, migrants also had to face black native northerners who expressed concern in some areas. In his book, The Negro Family in Chicago, sociologist E. Franklin Frazier writes about the supposed unpreparedness of black migrants to large urban cities (Frazier 1939). The South was stereotypically presented to be slower and not as sophisticated as the North, which could have posed a problem for migrants to assimilate in their new cosmopolitan cities. Naturally, it was not the same experience for each migrant or their families. Some adjusted quite easily to their new environments, with the help of other more grounded migrants. Others found the 
transition to be far too difficult than their native communities, and made several migrations, moved back and forth, or eventually relocated to the South for good.

The Great Migration was as much as a family experience as it was an individual one. Black families who journeyed onward in the Great Migration defied common stereotypes regarding the dysfunction of black families. In 1965, at the end of the Second Great Migration, politician Daniel P. Moynihan published the groundbreaking report "The Negro Family: A Case for National Action" (Moynihan 1965). Moynihan criticized black families in US urban centers because of their overrepresentation of black single mother headed households. He argued that this family structure, among other factors like education and crime, were responsible for the failures and challenges of the black community. Leading up to this report and afterwards, black families were represented as unstable, yet those migrants who participated were all but unstable. Husbands and wives, relatives, and fictive kin collectively decided to uproot their families, and wholly depend on each other to make their transition into the North or West successfully.

Throughout the earlier periods of the exodus, African American men would typically move North first, before sending for their families. As targets for racial discrimination in the job markets and specifically targets for racially inflicted violence in the South, African American men found it easier to migrate North to start or continue their adult lives. After prevailing through the physical demands of the move and establishing employment and housing, they could then send for other members of their family to join, including wives, children, and extended relatives. As a result, African American men came to represent the leading force behind the migration. While men often migrated first to establish new homes in Northern and Western urban 
centers, black women played critical roles in the planning and execution of the migration.

Black Southern women made the difficult decision to migrate North for various reasons. Black women were accustomed to their lifestyles, homes, and settings in the South, but as family members, friends, and fictive kin moved North, others followed. Lisa Kristoff Boehm's Making a Way out of No Way explores the varied and tough decisions black women made regarding their migration North and West (Boehm 2009). By placing black women migrants as the primary subject and focus of her work, Boehm documents the factors that allowed these women to predominate this movement. Using oral histories as the primary method of data collection, Boehm learns that while moving North was understood to be dream-like, Southern natives did not make the decision lightly. For instance, black women had positive fond memories of their childhoods in the South that made the idea of uprooting themselves and their families particularly difficult (Boehm 2009).

Women utilized their organizing and leadership skills, which were often developed in the Southern church and within the family, to successfully execute the tedious, uncomfortable, and at times, dangerous move North (Lemke-Santangelo 1996). They established and maintained contacts with other friends and family members who had already migrated, as well as those who stayed in the South (Boehm 2009). They cared for children and searched for acceptable and comfortable housing in their new cities (Lemke-Santangelo 1996). Black women are important subjects for the study of and understanding of this monumental exodus. Census data shows that women actually made up the majority of migrants to cities in the North and West. Historian James Gregory estimated that in 1980 there were 100 women for every 91 men migrating north (Gregory 2009). These women often came with children, but a 
large number of them traveled solo, for a variety of reasons. Some sought a better use of their college educations, others wanted to escape domestic work, and those in the Cotton Belt wanted to leave the tumultuous work of sharecropping behind. By the time of the second great migration, black women were the majority of all migrants (Gregory 2009).

In the South, black women were accustomed to men working as primary breadwinners while they tended to more domestic responsibilities in and out of the home. In most Southern towns it was uncommon for a black woman to be an entrepreneur, a businessperson, or the primary earner in the household. Black women worked, but they also relied heavily on black men and their families for financial support. In the North, however, African American urban women were able to work outside of the home for better wages and look for "alternative work and an enhanced role in policy decisions (Boehm 2009).” The migration provided black women with the opportunities to be involved in previously unattainable fields such as health and medicine, technology, and administration. They were also exposed to other black women who owned their own businesses, such as beauty salons and restaurants (R. L. Boyd 2009; R. Boyd 2013; Boehm 2009). The Second World War, beginning in 1939, prompted African Americans to relocate to Western cities like Oakland, California to pursue wartime positions. In the California cities, women were able to work in the factories of Lockheed-Martin and Boeing during World War II, in stable production positions as "riveters" who built wartime supplies (Lemke-Santangelo 1996). Southern women were not accustomed to this type of work and the financial independence that it afforded, which provided them with new outlooks on their potential as women in the workforce. Unfortunately, most of them were laid off from factory jobs once the wars ended. Many of them found positions in the food and 
service industries in the West, while others were able to maintain their financial stability in the form of white-collar jobs in government agencies, banks, schools, and other industries.

Washington, DC was also impacted by the mass relocation of African Americans during the Great Migration. The federal city is unique because of its geographical location, which is situated below the Mason-Dixon line, and is therefore technically a Southern city. As the seat of the federal government, located on the border of the South and the North, it is unlike any other major city in the country. The city features the infrastructure of modern cities like New York and Chicago, but still has a small town charm. In 1907, the city's train station, Union Station opened. At the time, it was the largest railroad terminal in the world. Many migrants of the great migration traveled to DC by train and entered the city through this massive gateway. In many ways, the station introduced the migrants to the newness and fast-pace of the city.

Historians have found that most black people living in Washington, DC and surrounding border states like Maryland and Delaware did not leave their homes to migrate further north. Although a southern city by definition, DC came to be an area where migrants from Southern areas relocated. Washington, DC benefitted from its status as the federal city by not being subjected to many of the unjust racist practices of other Southern cities or states. Individuals and/or families fleeing the harsh realities of the South may have stopped in Washington, DC because not only was it the first city entry into the North, but also because of its highly stable employment opportunities for African Americans.

Washington, DC offered positions in the federal government to African American men and women. The highly populated black area included neighborhoods 
of black families, where black businesses thrived. Black businesses in fashion and beauty, medicine, and law existed across the city. As early as 1860, Elizabeth Keckly, a former slave and personal dressmaker to Mary Todd Lincoln, served as an example of the possibilities of black entrepreneurs early on. The wide range of opportunities available to blacks in this city, attracted African Americans from across the country to create a melting pot of black migrants. In my own family, my paternal grandparents were able to meet because of my grandfather's migration from Martinsville, VA and my grandmother's migration from Waterbury, CT. My maternal grandparents also met in Washington, DC, after my grandfather relocated south from Pittsburgh to Washington. I am able to trace my maternal grandmother's lineage to slavery in Washington, DC in the 1860s. Isabel Wilkerson, historian and author of the pioneering book, The Warmth of Other Suns (2010), family migration story is similar to my own. Wilkerson's parents were also able to meet and begin a family in Washington, DC after her parents migrated from Georgia and Virginia. Washington, DC, because of its solid African American base prior to the Great Migration as well as its social mobility opportunities, attracted several families and individuals during this time.

The brave migration North, in some regards, represented a 'survival of the fittest' mentality of black Southerners. The decision to uproot one's life from all that is known and familiar takes a special type of individual. Those who migrated were ambitious, organized, and educated risk-takers. Most of them had never visited their new homes prior to the big move and made the decision off of faith and strategy without knowing the promises that laid ahead. There is conflicting scholarship on the overall economic advantages of the Great Migration for Southern migrants. Many have argued that those individuals who took the leap to the urban metropolitan areas 
were better off financially by the end of the $20^{\text {th }}$ century than their counterparts who did not leave the South (Alexander et al. 2017, Tolnay 2001). Using census records, Gregory found that southern migrants in the north made incomes up to $70 \%$ more than the incomes of those in the South. In 1969, black women migrants (from the south to the north), made incomes that were $42 \%$ higher than their Southern counterparts (Gregory 2009). This situated the North as a place of prosperity, where blacks could have a fair shot to get ahead and work towards upward mobility. It was believed that Southerners benefitted tremendously from the systems in place in the North, more so than blacks who were native to northern areas. A recent study, however, found that overall Southern-born migrants fared no better overall than Southerners who did not migrate. At most, the Southern migrants benefitted more from lifestyle advantages such as arts and culture over economic advantages (Eichenlaub, Tolnay, and Alexander 2010). Southern born and Northern born African Americans differed in their relationships with the Northern cities. Southern born African Americans valued the opportunities available and took advantage of the programs and education offered without leaning exclusively on public programs in the North. Statistics gathered from the 1970 US Census showed that Southern-born women were slightly less likely to be on welfare in the Great Lakes states than Northern born women, and Southern born were employed 5\% more than Northern born black men (Gregory 2009). Southern migrants took full advantage of their migrations and took pride in working. They set out to make their lives better, even if that did not always result in greater financial freedom than was available in the South.

The Great Migration drastically reshaped the demographics of the United States, particularly in US cities. African Americans went from a 90\% Southern population prior to the migration to totaling $47 \%$ percent in cities in the North and 
West. The reshaping of African Americans as a predominately rural and southern group of people led to dramatic social policy changes throughout the North. As African American communities grew, "white flight" (Crowder and South 2008) - the phenomenon of white people leaving their neighborhoods and homes as the area became populated with diverse black and brown minorities — occurred, creating low-income ghettos and federally run housing projects. This occurred in cities like DC and the South side of Chicago, but recent gentrification efforts have reintroduced white residents to these areas.

The massive reconfiguration of Black American demographics led to cities that came to be known as black metropolises. These cities thrived with black-owned businesses and black community organizing. Cities such as Chicago and Philadelphia, and neighborhoods like Harlem became known for its black cultural influences. Through the great migration, African Americans used their experience as migrants or children of migrants to explore their talents in the fields of music, literature, sports, politics, and more. Additionally, black Americans worked hard to enter key industries in the US economy. The Washington, DC metropolitan area remains an area of interest for people of all races and backgrounds to seek opportunities. Deidre, a research participant and mother of three, moved from her rural town in North Carolina in her early twenties to benefit from all the area had to offer. Although she migrated years after "The Great Migration," she represents the more recent migrants, young, black, educated men and women who continue to recognize DC as a city full of promise and upward mobility.

"I wanted to study English and be a producer. A movie producer and I saw my life living in Maryland. I'm from North Carolina, let me say that. I saw my 
life living in Maryland, in some nice condo that overlooked water." - Deidre, December 23, 2016

After moving to the DC area, and returning home to North Carolina for a few years prior to her divorce, she has returned to Prince George's County, MD. She considers herself fortunate because of the financial opportunities and promotional opportunities available in the city.

I was in North Carolina working between the seven years of 1999 and 2005 and my salary was $\$ 28,000$ - $\$ 30,000$ in 2000 . When I came to work for the federal credit union here in 2005 , I got $\$ 35,000$. Then, when I came to work for the federal government in August of that year, my salary went to $\$ 37,000$ and by February I went up to $\$ 42,000$. — Deidre, December 23, 2016

Deidre recalls her rapid pay increases in the DC area that were not possible in her hometown in North Carolina. She appreciated the ability to move around and to move up within departments. Today, her salary is close to $\$ 65,000$ and she feels stable because of the federal governments annual raises and GS-level scale system.

The long-lasting legacy of the Great Migration continues today. It is the reason I have so many women to interview, as several of them have southern roots, with parents or grandparents who participated in the great migration north. My research participants also benefitted and struggled with many of the characteristics of living in a Mid-Atlantic federal city. They admit to benefitting immensely from the opportunities available as a result of the migration, but also recognize the harsh realities of higher costs of living. 


\section{Chocolate City at Its Height}

The Great Migration led to the formation of several black cities in the North, many of which have been referred to as a black metropolis. The US Census defines a metropolis as generally a "core area containing a large population nucleus, together with adjacent communities that have a high degree of economic and social integration with that core" (US Census 2010). Washington, DC was able to rise as a black metropolis throughout the $20^{\text {th }}$ century. The placement of Howard University as the city's black educational institution, the accessibility of the federal government for employment opportunities, the impressive public school system, and the abundance of black owned businesses in the city allowed for DC to grow in size and significance, eventually becoming the majority black city, Chocolate City.

The Great Migration formed several highly populated black communities across the country - but only one became known as "Chocolate City" and that was Washington, DC. By 1900, Washington, DC had the largest percentage of black people than any other city in the nation (McQuirter 2003). By 1957, with a population over $50 \%$ black, it had become the first predominately black city in the county and began to set to set the example for other black metropolises. In 1980, Washington DC's population was $80 \%$ black (Urban Institute 2017). Over the years, it had become the most densely populated black city per capita in the United States. Unlike other cities where blacks were restricted to certain neighborhoods and ghettos, blacks lived and work all over the nation's capital. During the first migration, neighborhoods like Georgetown, Anacostia, and Shaw attracted African American families because of its affordable housing opportunities.

As the first city in the nation to abolish slavery with the District of Columbia Emancipation Act of 1862, DC has long been a place of hope for African Americans. 
In 1800 , the city's black population was $25 \%$, and it only continued to rise as African Americans gained more societal freedoms. Washington, DC rose to fame as "Chocolate City" after several decades of offering opportunities to black communities. It was home to important institutions such as the federal government, Howard University, and its public school system. Additionally, the city was well known for its thriving arts and culture community, which included popular writers and musicians like Ella Fitzgerald and Langston Hughes.

\section{Howard University}

Howard University was founded in 1867 by Otis Howard, a Civil War general and director of the federal Bureau of Refugees, Freedmen, and Abandoned Lands (Hunter 1994). Before officially becoming the university, the school welcomed students through an open enrollment process that did not restrict students based on race or sex (Lindsey 2017). Over the years, it has become the premier black university, awarding more advanced professional degrees to African Americans than any other university in the country. With its schools of law, medicine, and divinity, it became a school that offered specialized training to African Americans in fields that were unattainable at other colleges and universities in the South. Howard was also the first school in Washington, DC to admit African American women. In Colored No More, Treva Lindsey argues that Howard was the main space that New Negro women created to fight simultaneously again intra- and interracial oppression (Lindsey 2017). The university continues to attract, thousands of African Americans each year who migrate to Washington, DC for the sole purpose of attending Howard. My grandmother, for instance, followed her older brother from Connecticut to Washington, DC to attend Howard and earn a degree in Education. In the 80s, she became first African American student and woman at Howard to obtain a master's 
degree in Early Childhood Education, which she used as a school teacher and principal for DC Public Schools.

In addition to personal family ties, Howard is internationally known and has produced some of the most notable African Americans of our history including: Ralph Bunche, Paul Lawrence Dunbar, Thurgood Marshall, Zora Neale Hurston, Toni Morrison, and several more. In the 1930s, Howard's "programs in the humanities housed the most prominent Black public intellectuals of the day, including economist Abram Harris, sociologist E. Franklin Frazier, political scientist Ralph Bunche, philosopher Alain Locke, literary scholar Sterling Brown, and theologian Howard Thurman (Cooper 2017, pg. 98)." As a result, African Americans migrated from the all points of the country to attend this school, as its opportunities for African Americans were unprecedented. Howard University played a critical role in creating the culture of Washington's Black elite. The university was known to have students from prominent families, and this was reflected in its fraternities, sororities, and social events. As the official photographer for Howard University during most of the $20^{\text {th }}$ century, Addison Scurlock, captured not only the graduation photos of the students, but also the balls and social events that represented the status and high culture of Black Washington. To be photographed by Addison Scurlock was a symbol of status because the photographer was responsible for photographing Washington's black leaders like Dr. Mary McCloud Bethune, Dr. Anna Julia Cooper, and W.E.B. DuBois. His clients, primarily Howard University students and community members of the $U$ Street Corridor area, recognized the significance of being photographed by Scurlock. Throughout history, and as exemplified by Elizabeth Keckly in the Lincoln White House, black Washingtonians have taken a great interest in physical appearance and status. As the Northern-most Southern city, Black Washingtonians have used their 
appearance and access to social groups to distinguish themselves from true Southerners. An emphasis on brand and/or quality clothing, for example, made one more cosmopolitan, but it could also reveal ones social status to others (Wilkerson 2010). Women referred to national black magazines, like Chicago-based Ebony and New York-based JET, to see the most desired names in fashion. Men were also occupied with latest fashions, cars, and other status symbols. For the Black Washington family, the ability to shop and represent high end brands confirmed to themselves and others that they had "made it". This was also present across the university campus, as seen in the image below of six well-dressed women students at a Howard University football game in the 1920s. Upper-middle class families born into the wealth and prestige of Black Washington also set the trends. Shopping and the process of material consumption was common. Participation in black fraternities and sororities, also had implications on a person's social status. 


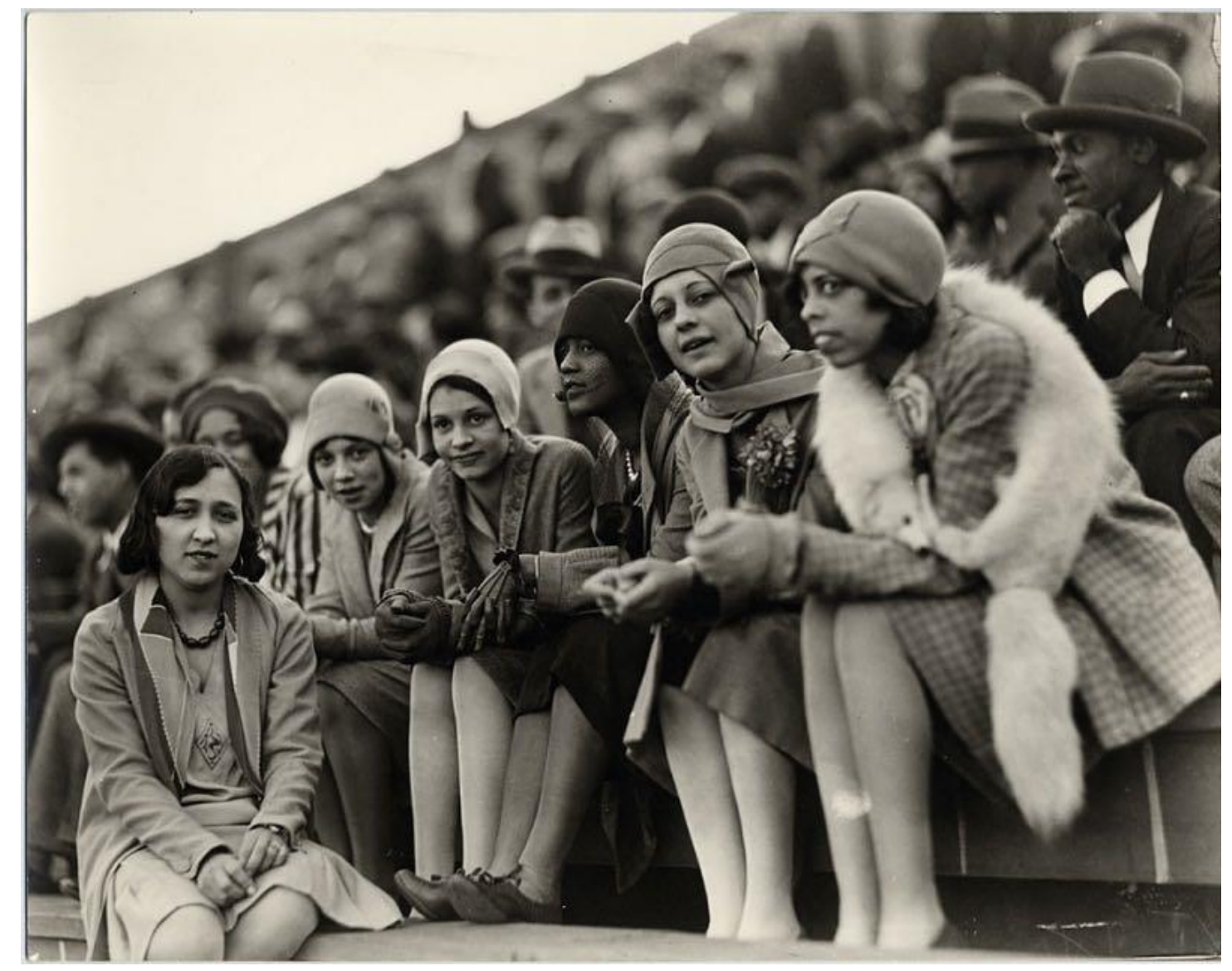

[Young women at outdoor sports event, probably football game at Griffith Stadium: black-and-white photoprint, probably ca. 1920-1930, print ca. 1970.], Photography by Addison N. Scurlock, National Museum of American History, Archives Center

In Liberated Threads, Tanisha Ford describes black women as taking immense pride in their appearance by adorning their "Sunday best" (bright, nicely pressed clothing that were deemed suitable to wear to church) when engaging in political protests and demonstrations (Ford 2015). Black college students consumed and utilized their "Sunday Best" as a way to distinguish themselves from the lower classes and to gain respect as college students while protesting. In the Civil Rights movements, leaders asserted that modest and neat dress was crucial to the movement's success (Ford 2015). Ford explains that "some black women believed that through a public display of respectability they could counter attacks against their character" (Ford 2015). In Washington, DC, and other US cities, black women's 
fashion played a significant role in not only individual expression, but also larger representation in society. Beauty advertisements designed to appeal to African American women through magazines like Ebony, for instance, were used as a way to reinvent African American womanhood as fresh, urban and modern (Lindsey 2017). Although respectability politics has been proven to be ineffective in many cases, there remains a desire to look a certain way in order to gain respect. Through the portraiture of Addison Scurlock and James Van Der Zee, black Americans throughout the $20^{\text {th }}$ century were captured as placing considerable importance in their appearance.

\section{Public School System}

The DC public school system has been very attractive to city residents and beneficial to African American students over the years. Education has played a major role in black communities in this city. In fact, "as early as 1807 , there was evidence that three Black men, recently freed from enslavement, risked their lives to establish the first Black school in DC. George Bell, Moses Liverpool, and Nicholas Franklin, "who knew not a letter of the alphabet" organized this school close to the DC waterfront (Fitzpatrick \& Goodwin, 1999) (Frederick and View 2009)”. Access to education and the formalization of schools for black communities has had a lasting significance in the District.

The M Street High School, founded in 1870, now Dunbar Senior High School, admitted African American students and offered a vigorous college preparatory curriculum in literature, arts, and sciences at a time when most of the country did not. M Street High School was the first public school for African Americans in the city, and one of the first schools for African Americans in the country built with public funding (Stewart 2013). Despite its founding out of Congress' desire to keep schools 
in the district legally segregated, The M Street Public High School benefitted from highly qualified teachers and eager students, who attributed to the success of the school. Washington, DC's public school system continued to grow. Today, the DC Public School system is unlike most in the country because students are allowed to register and attend schools across the city and outside of their neighborhoods. This allows students to attend specialized schools such as Duke Ellington School for the Arts or Benjamin Banneker Academic High School without needing special permissions due to residency. The system allows for access to high-quality education for students without location-based boundaries or transportation limits. Like Howard, the DC Public School system has produced several African American leaders in various fields and has contributed the city's status as a black metropolis. In Treva Lindsey's Colored No More, Lindsey discusses African American women of Washington, DC, many of whom benefitted from the opportunities provided through the DC Public School system as both students and teachers (Lindsey 2017)). Anna Julia Cooper, prominent scholar and activist, taught at the M Street Public High School in NW Washington, DC. Her position as a woman educator at the beginning of the $20^{\text {th }}$ century would have been unlikely in other cities. Cooper was representative of the upward opportunities that were available to many women in DC during her time and beyond. Black women found work as domestics, but also as educators, administrators, office assistants, and business owners.

\section{Federal Government Opportunities}

The phrase "good government job" is very popular in Washington, DC, and perhaps across the country when referring to employment in state and local governments. This phrase was popular, and true in DC because federal government 
positions were plentiful and stable. This applied to Black and White residents, as most residents in the city were eventually employed by the federal government (Prince 2014). Black men and women were often able to enter the federal government at a young age and remain employed through retirement. With federal jobs, significant pay increases are mandatory, the schedules are relaxed in comparison to private sector jobs, and the benefits package is extremely competitive. Brina, a research participant and mother of two, began working for the federal government as a teenager in the $80 \mathrm{~s}$. Her mother found the job for her, and applied. When offered the job, she demanded that her daughter take advantage of the opportunity,

"It was a good job for what I needed it to be. Especially with having kids and a small kid - they [her employer] understood having to be off by this time. They didn't harass or hound me about it, and sometimes I could bring my kids to work with me if need be." - Brina, January 10, 2018

Over 20 years later, Brina still works in the same agency. She earns up to $\$ 85,000$ annually. Most federal employees are able to advance fairly quickly and enter higher pay scales. Those with advanced degrees benefit the most, because their credentials require them to be paid at a higher scale.

\section{Black Owned Businesses}

During its height as "Chocolate City," Washington, DC had hundreds of black owned businesses. African Americans owned their own law practices, doctors' offices, and small shops. Black women specifically thrived in the beauty industry, as salon owners and independent stylists. The high culture in the city allowed photographer, Addison Scurlock, to open a successful photography studio on U Street in NW, Washington, DC. Scurlock became known for his photos of elite black Washington's 
at parties and events, most of them related to Howard University. In my research at the Smithsonian National Museum of American History, I discovered hundreds of family portraits of everyday Washingtonians taken by Addison Scurlock, that presented middle and upper class Black Washingtonians. In the Scurlock' portraits, every black family had a very distinguished look. They primarily wore dark navy, reds, and black colors and were positioned in the family living room of their homes or in the Scurlock studio. It was difficult to tell the occupations, income range, and educational background of the individuals in the photos, but in some cases, the men would wear their military uniforms proudly in their family portraits, which revealed their occupations. Others were a complete mystery. What was most striking about the portraits was that although each of the families had different physical features, they all had a distinct middle-class Black Washingtonian look. Most of the families were dressed in very fine clothing and visible jewelry. Posing in their homes, the portraits captured luxury furniture and neat homes. Scurlock was very meticulous in posing his subjects, so it is likely that the family portraits resemble one another because of his distinct portraiture style. However, their choice of clothing, hair styles, and visible material household goods without a doubt casted the families as members of the middle and upper middle classes of Washington. Addison Scurlock's legacy prevailed with his sons, George and Robert, who took over the studio and continued photographing black Washington through its decline.

Just a few blocks down from the Scurlock Studio, remains one of the most famous black owned businesses in the city. This popular business, which has expanded to additional locations across the city, is Ben's Chili Bowl. Ben's, a small hot dog and chili restaurant located on U Street in NW, DC, embodied the heart and culture of the city. The restaurant opened in 1958 by husband and wife couple, Ben and Virginia Ali, 
and has since served thousands of famous, local, and tourists' patrons. Ben's came to symbolize the tenacity of Black Washington during the 1968 riots. After Martin Luther King was assassinated in Memphis, TN, African Americans across the country took to the streets. Many Black-owned established were saved or untouched, with identifying markers such as "Soul Brother" signs in the front windows. Other establishments were completely burned down. Much of Washington, and especially U St, was destroyed in the riots that lasted over 6-days.

Washington thrived as a black community because of its black available institutions. In the early to mid-twentieth century, one could easily find black banks, schools, movie theaters, and the esteemed Howard Theater. There were institutions in place that allowed for blacks to establish themselves as upwardly mobile individuals as well as places of entertainment. Although a "Southern city," Washington, DC operated differently because its segregation in institutions benefitted the majority black city. These institutions helped DC rise as a black metropolis that served as a model for other cities with large black urban populations.

"Washington, DC, is the only city beneath the Mason-Dixon Line that is a Black Metropolis with respect to the representation of blacks in three of the entrepreneurial occupations. This border city was a Black Metropolis with respect to the representation of black men in banking and barbering and the representation of black women in beauty culture" (R. Boyd 2013). The city's black cultural hub was H Street, in NE Washington, which offered shopping, dining, and entertainment. This area employed and attracted the black community during times when the downtown markets and shops did not cater to African Americans. Small family run businesses, by Italian, African American, and Greek Washingtonians lined H Street and served diverse groups of consumers. Businesses like the Atlas theater remained segregated 
until outlawed in 1953, but H Street mostly welcomed all shoppers. Popular stores such as Mortons, Ourismans, and Garfinkels allowed African Americans to purchase the latest fashions and cars to stay-up-to-date on the trends and develop their image.

As DC's black population continued to rise and establish the district as "Chocolate City," its residents formed tight knit neighborhoods and communities. Communities like Anacostia, Shaw, Petworth, and Brookland became densely populated predominately black areas of the city. The U Street Corridor, where many black businesses were located was once known as "Black Broadway" because of its concentration of theaters, clubs, and music halls. Although DC was a city, in many ways it operated as a small town. Black people across the city knew each other and proudly supported each other's businesses. With the exception of some historic signs, little remains on U Street that showcases the history of Black Washington. In the other neighborhoods mentioned, new single family developments and high rental prices are fiercely driving lower and middle-income black populations out and far away from their familiar neighborhoods.

Black Washington was at its height in the 1960s and 1970s, during the Black Power Movement and prior to the issues that led to its decline in the 80 s and 90s. The city's population was majority black and thriving. As the seat of the federal government, Washington, DC produced and attracted several black leaders in the fight for civil rights. Stokely Carmichael, head of the Black Panther Party, attended Howard University and became heavily involved in local DC community activism. The city became a breeding ground for incubator for progressive, radical thought, that emerged out of the DC's university campuses. Because of its recognition and location, the national mall, served as the site for marches and protests that gained national attention. As the Civil Rights era gained momentum, the city began to decline. 
Drugs, Politics, and Scandals - The Great Decline

In 1984, the National Broadcasting Company (NBC) aired The Cosby Show and for the first time, America had a front seat view of life in a Black upper middle class household. The Huxtables, the family whom the show revolved around, included a father who was a doctor, a mother who was a lawyer, and five privileged children growing up in a large brownstone in Brooklyn, NY. Coincidentally, The Cosby Show aired at the beginning of the decline of previously discussed black metropolises. As the show represented black progress and American equality (there were rarely, if ever any incidences where the children were discriminated against because of their race, or any mention of it), urban areas across the US were dealing with new crimes, drug wars, and continued racial discrimination which contributed to poverty, poor health, and unsatisfactory education for people of color. Surprisingly, gentrification, was never discussed on the The Cosby Show, although it took place in a changing Brooklyn, NY. Spike Lee's Do the Right Thing (1989), however, tackled the issue of gentrification head on. As black families across the country praised the show for its positive representative of black urban families, it failed to address the declining urban areas, like Brooklyn and Washington, DC, that faced new challenges during this time period.

Washington, DC has been a city of constant change. "After the tremendous staying power and lasting sacrifices of so many, the African American population showed a decrease between 1970 and 1980 for the first time (Prince 2014; U.S. Census Bureau, 2008).” In the 1980s, the city was drastically different than the city than many migrants first arrived in during the beginnings of the Great Migration. Crime dominated the city, earning it the new nickname "murder capital," as it 
unfortunately had the highest homicide rate in the country (Fenston 2014, Price 1989). Much of the crime, including the all-time high of 83,000 felonies reported in 1969, were drug related and lead to soaring rates of mass incarceration (Alexander 2012). With crime at its highest rates in decades, those who were financially able moved their families in to nearby suburbs in Maryland and Virginia to offer a safer environment away from the violence of the city. White residents began fleeing the city in the 1950s, just as African American migrants entered, and the city's black population grew. By1980, DC's White population had plunged to under 200,000 residents (Urban Institute 2017). African Americans also began to leave the city in order to benefit from the lifestyles that suburban towns could offer. Additionally, because Washington, DC is tucked in between the two states, travel back and forth is quite easy, perhaps making the decision to relocate easier for certain families.

The city's demographics began to shift in response to President Richard Nixon's 1971 declaration of "the war on drugs," as an attempt to get drugs out of suburban middle class white neighborhoods. Leading up to this declaration, marijuana and heroin were being heavily used in white hippie anti-war and black communities. However, it was not until the mid 1980s that crack/cocaine were understood as a highly dangerous and addictive substances infiltrating the inner cities. Washington, $\mathrm{DC}$ and its residents fell victim to the crack era, with it in the hands of everyone from the poor to middle class to the mayor of the city. The Metropolitan Police Department widely ignored the requests by locals to fight the excessive drug use in the city. In neighborhoods like Columbia Heights, for instance, "Black residents felt their concerns were not taken seriously enough by the MPD until the percentage of White residents grew in the community, at which time, according to these residents, a police presence increased" (Prince 2014). By 1989, President George H.W. Bush decided to 
use Washington, DC as the face of the country's war on drugs. Placing a prop of crack cocaine on the desk in his office oval and addressing the nation, Bush announced the renewal of Nixon's war on drugs. This time the poor and urban cities were the focus. Bush's first priority would be cleaning up the streets of the capital city, Washington, DC. During this time, the DC police force grew, and black men were arrested and incarcerated for drug charges, homicides, and even non-violent petty crimes. The federal government became more involved with local Washington policing, by placing FBI and DEA agents throughout the city.

In 1975, Congress determined that the District of Columbia would be administered by a mayor. Prior to that decision, Washington was locally governed by governors, presidents of the board of commissioners, and formerly in 1802 Mayors of Washington. Since Congress's most recent decision to organize DC's local government through a mayorship, African Americans have exclusively held the position. Beginning with Walter E. Washington to current mayor, Muriel Bowser, the DC mayoral seat represents Washington as progressive, electing black men and women to the esteemed post. Unfortunately, Washington's political arena has not been safe guarded from corruption. While Washington, DC struggled with high crimes rates and drugs taking over the city, it also struggled with a corrupt local government. In 1983 Mayor Marion Barry, a migrant from Mississippi who became heavily involved in local community organizing in the District, was under fire for his drug involvement and illegal actions by members of his staff. Mayor Barry, who was celebrated for successful programs like the DC Summer Youth Employment Program (SYEP), one in which I personally benefitted as it provided me with my first job and experience in an office setting at the young age of 15 , was also rejected for his contribution to the drugs and violence in the city. His actions lead to an arrest in 1990 for possession of 
crack cocaine, and a sentence of six months in prison. Many Washingtonians overlooked his personal character flaw as a drug addict and instead focused on his massive improvements to Black and poor communities in the city, but other residents lost complete trust. As a result, local residents continued to slowly strain out of DC.

It is no surprise that high levels of crime, drugs, and mass incarceration contributed to and were a result of higher levels of poverty. Notoriously impoverished neighborhoods like Sursum Corda in NW, and Barry Road Projects and Anacostia in SE, felt the grunt of these factors. On average, black families in these areas made the lowest salaries, were headed by single women on some form of government assistance and lacked resources and neighborhood development. These neighborhoods became representative of a poor and disenfranchised city in ruin - a picture that totally opposed the view of Washington as the city of promise that was represented a few decades earlier. The city also became a place of refuge for Latin communities from primarily El Salvador, Bolivia, and Guatemala. DC's Latino community formed in the NW areas of the city, in and around Columbia Heights and Mount Pleasant. Today, Latinos comprise roughly $10 \%$ of the city's total population (US Census Bureau 2016).

The greatest and most recent factor leading to the decline of Washington as a black metropolis has been gentrification. In just 8 years since leaving the city to attend college and graduate school out-of-state, the city I recognized as DC has undergone dramatic changes. My local metro station now has a Starbucks and a Barnes and Noble, along with an artist market and late night restaurants and pubs - all clear markers of gentrification. For the first time, my grandmother has several new white neighbors, who bike around the neighborhood in the early hours of the morning and tend to their backyard gardens. And finally, my plan interview black women for 
this research who lived in the city became a major challenge, as most of the women whom I was able to connect with had roots in the city but had since moved away due to the high and rising cost of housing.

Gentrification in Washington has been underway for several decades but has made rapid changes in recent years. Families with roots in Washington, DC for generations suddenly found the increased cost of rent and lack of options for safe and affordable housing in the city to be overwhelming and unattainable. My mother, a native Washingtonian, often tells me stories about how the city has flipped. In these conversations, she refers to areas of the cities that are now known for its large white demographic, that were historically black and underprivileged. Areas like Georgetown, for example, are extremely popular to all Washingtonians and to tourists, as it is now the premier shopping destination in the city. Washington, DC does not have a typical "shopping mall" in the way that most other cities have. Instead, Georgetown's M Street has individual stores (ranging from moderately priced Urban Outfitters to small boutiques that sell exclusive luxury brands), which has led to a surrounding area of million-dollar row homes. The history behind the neighborhood has been erased and many locals and tourists do not know that it was once a predominately black area.

In the 1800 s, African Americans lived in Georgetown as the enslaved property of wealthy slave holders. In tracing my family history, I discovered that my greatgreat maternal grandfather, Alfred Clarke, was enslaved by Eleanor R. Lang, of Georgetown. Alfred was emancipated in Washington, DC in 1862 at the age of 12. Blacks and whites originally lived side by side in the Grace Street-Cherry Hill-Cissell Alley neighborhood west of Wisconsin Avenue and south of M Street, an area with many dilapidated houses and poor city services. By 1910, however, most of that 
neighborhood had become predominantly black as whites abandoned its narrow, crowded streets for better housing and employment elsewhere in the city" (Lesko, Babbs, Gibbs, 1991, p. 41).

Following emancipation, whites fled the Georgetown area, leaving the tobacco and shipping port area to freed slaves and their families. In the center of the neighborhood exists the oldest black church in Washington, Mount Zion United Methodist Church, and its adjacent predominately black cemetery. Hundreds of enslaved people, and freed men, women, and children post-emancipation are buried here. This church has become the center of black history in Georgetown and employs a knowledgeable church historian who leads tours of the church, its heritage center, and its cemetery. Today, blacks have been strategically excluded from the residential demographics of Georgetown — as million dollar homes supported by luxury shopping, fine dining experiences, and waterfront viewing has made the area out of reach both financially and culturally.

With the average income steadily rising in DC (and the metropolitan area), affordable housing has become a major issue. When I use the phrase 'affordable housing,' I am referring to housing that can be afforded by the lower to middleincome resident. This does not mean low-income housing, or public housing. When I returned to DC to embark on this research journey, I found myself unable to find any decent housing — apartment or sublet, within my budget of $\$ 1200 /$ month. It was a major difference from the luxuries I had been afforded, with a one-bedroom apartment for the same price in Miami Beach, FL. In DC, and all across the cities close to metro stations, I could not find anything decent within this price range. After a while, I attended an Inclusionary Zoning and Affordable Dwellings Unit (IZ/AD) Orientation hosted by Lydia's House, a non-profit organization in SE Washington that works 
towards housing equality and home-ownership for residents in the city. It took over 3 months to get on a list for one of these orientations. They filled up very quickly, were at inconvenient times in the middle of weekdays, and were only offered through 6 other organizations across the city. Also, in my particular orientation, individuals were not allowed to bring children, which I prevented several adults from receiving this beneficial information. The orientation was a workshop that taught low to middleincome residents how to find affordable housing in the city. In this workshop, I was surprised to learn that the official median income in Washington, DC for a family of four was $\$ 102,000$ (as of 2016). As an average, this salary pulled from the salaries of top government officials, CEOs, doctors, lawyers, and other high earning professionals in the city. With this as the average salary, it is no surprise that individuals and families with incomes significantly less than the average, are unable to afford to live in the same area.

The rapid pace of gentrification in Washington, DC has caught the attention of many sociologists, demographers, geographers, and historians. It has been associated with the "back to the city movement" occurring in several cities across the US (Hyra 2015). Derek Hyra, author of Cappuccino City and American University professor, argues that as gentrification changes the physical landscape of the city, it also leads to major social consequences for residents who are able to remain in the city alongside wealthy newcomers (Hyra 2015). These long-term residents tend to lose their decision making power in local and community level politics, as upper-income residents begin to outnumber. Similar to other cities, gentrification in Washington, DC has also led to cultural displacement, where the long-term norms and preferences of the city's residents begin to change causing long-term residents to no longer identify with their home (Hyra 2015). 
The rapid pace of gentrification in Washington, DC really surprised me as a researcher. I expected to use my personal and social networks to connect with middle class single mothers who lived in DC as well as those who lived in the greater metropolitan area. Unfortunately, my expectations were off due to the lack of black women that I could locate who lived in the area. I interviewed 30 women, and only 4 lived in the city. Most of my respondents were connected to DC in some way; they may have been born and raised in the city, attended college there, or spent most of their time there for work. Yet, today, they called Maryland suburban neighborhoods home. The high cost of living in the DC area came up quite often in my interactions with respondents. Because my research was not specifically about gentrification or the changing demographic in DC, this observation and trend became relevant through discussions of finances, neighborhood selection, and work commutes.

Today, DC is approximately $47 \%$ black (US Census Bureau 2016). While black residents are no longer a majority of the population, they still exist in specific neighborhoods of the city. Throughout my field research, I struggled with my inability to gain access with more black single mothers in DC. I began to realize that the areas of high black population in the city were typically not middle or upper-class areas that my research sought out. Black single mothers must live in Washington, DC, I was sure of it, but today, the majority of black single mothers who remain in DC are lowincome long-term residents. In the Washington, DC metropolitan area, black single middle class mothers may not be able to afford to live in DC, but black single lowincome mothers are able to remain in the city by benefitting from low-income housing programs, like Lydia's House, and other initiatives that cater to the economically disadvantaged. In this instance, it is the middle class - those mothers and individuals who make too much to qualify for assistance, but too little to afford the high rents or 
mortgages in the city - who have been forced to flee the city and establish middle class homes and communities outside of the beltway.

Prince George's County and Nearby Suburbs

When driving South along Pennsylvania Ave in Washington, DC, one will eventually reach Southern Avenue. There a sign reads, "Welcome to Prince George's County, Maryland" as drivers and pedestrians cross the invisible border that lies between Maryland and the Nation's Capital. These signs, which were revamped in January 2018 to encourage tourism and business in the county, are littered across the border in areas like Capital Heights, MD, Mt. Rainier, MD, and Cheverly, MD - all Maryland cities that are just a few footsteps away from DC. Prince George's County is close to DC, and its proximity can be confusing to tourists who unknowingly cross city/state lines. My grandparent's home, for instance, is in NE Washington, DC, but they have a large backyard that extends to the Maryland border. Still, there are several pronounced differences between the two places including demographics, neighborhood style and design, and governance. Throughout my experiences as a native Washingtonian and PG County girl, I have witnessed first-hand how critical it is to get the city correct when discussing someone's origin. I have also witnessed, through my life and my research, the intermingling of people, who have continued the migration story back and forth across the District line.

There is a long running joke about being from Washington, DC or from nearby cities in Maryland. Washington, DC is truly a city, with Prince Georges and Montgomery Counties as its nearby suburban sisters. In fact, there are a number of neighborhoods in DC that border Maryland, and the neighborhood name remains on either side of the invisible border. Without the faint marker of "Welcome to 
Washington, DC," at times it is unclear whether or not you are in the capital city or in Maryland. For instance, Takoma Park, Capital Heights, and Friendship Heights exists in Maryland and DC. In these cases, you may find people asking, "the DC side or Maryland side?" when referring to living or being in one of these neighborhoods. Still, those from Washington, DC are proud of it and do not typically claim or associate Maryland as their homes, and rightfully so. In the same regard, those from Maryland suburbs do not always claim Washington, DC. What makes this area unique is that many people, especially today, once lived in DC and now live in Maryland, making their sense of home a mix between the two places, and thus creating the “DMV (DC, Maryland, Virginia).

Prince George's County, or PG County as it is affectionately called by local residents and nearby Washingtonians, is the second-most-populous county in Maryland (Hernandez 2018). During the summer of 1997, when I turned six, my mom - a 28-year-old single mother of one at the time, purchased her first home in PG County, MD. We uprooted our lives from DC, where I could no longer hear the sounds of the metro at night, to a single-family home in the suburbs complete with tree-lined streets, driveways with children's toys, and an unusual quiet. I remember being excited about the new space: five bedrooms, 3 baths, and two-floors, but nervous about this strange place where I did not have any friends and were not close to the rest of my family who lived in DC. I recently asked my mother about her decision to purchase a home in Maryland. Her answer was simple: "The closets were bigger." In other words, the homes in PG were bigger with a much smaller price tag, especially in the 90s. My mother, like several other women who provided insight for my research, decided to purchase homes in PG County because of the space and affordable price that it offered. We continued to move back-and-forth across the 
city/state line. Five years later as I was preparing to begin middle school, my mother decided to use the Maryland home as an income property and moved the three of us (herself, my brother, and me) back to Washington, DC - this time because "the schools were better."

My experiences in DC and PG are not uncommon. The nation's capital and an affluent black suburbia both offer distinct opportunities for their residents. In my middle school and DC high school, I knew people who once lived in PG or had a parent who lived in PG. As black people migrated out of the city, they typically selected PG County as their new homes. Still, like my family, they kept their ties to the city - and found that the benefits and experiences offered in PG County just did not compare to DC. On the other hand, PG County offered desired suburban living shopping malls, large schools, and gated communities, which DC never had. I remember my experience being a constant tug-of-war between the two places, because they each offered something different and better or worse than the other place.

The county is unique in its own right because of its high-profile residents and reputation as the most affluent Black community in the country. PG County spans the Eastern border of Washington, DC from Montgomery County to Northern Virginia, and as of the 2010 Census, was comprised of 860,000 residents. The county is divided into several cities, with a number of them having gained national attention because of its prestige. Fort Washington, Bowie, and Upper Marlboro, for instance have been the subject of scholarly research on the black middle class (Lacy 2007). In these areas, black middle class families have been secluded from poor and low-income black families and individuals. I am most familiar with Upper Marlboro. My father lives at 
one edge of this city, and my mother's home is at the other. Their proximity to Upper Marlboro allowed me to enroll in the county's newest public high school, Dr. Henry A. Wise, Jr., High School (referenced in the following image), which opened my sophomore year in 2007.

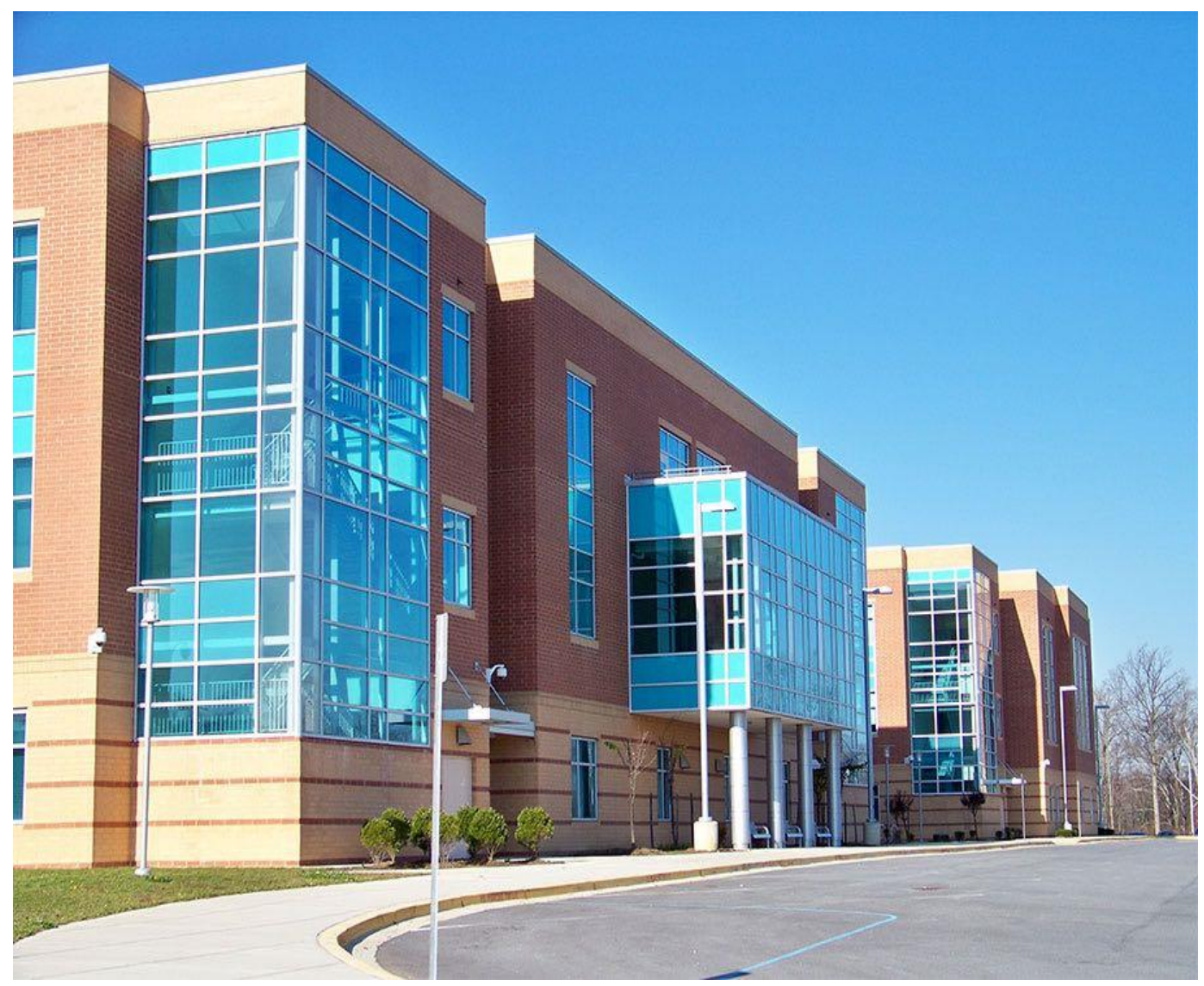

Dr. Henry A. Wise, Jr. High School, Upper Marlboro, MD (Prince George's County Public Schools)

The school was constructed to alleviate crowding in PG County high schools. As a student at Wise, I was introduced to students who lived in extremely large homes — some in gated communities — and most with their own cars and other luxuries not typically associated with black teenagers in a predominately black area.

Several of my research participants lived in Upper Marlboro, or at least mentioned it as the quintessential black middle class neighborhood. The interactions of individuals who live in these established middle and upper-middle class 
neighborhoods with those from less-privileged areas were limited, with the exception of community-service based projects. Lisa, a mother of two toddlers, who recently purchased a single-family home in Upper Marlboro reflected on her childhood experiences going into underprivileged communities and witnessing first-hand how others lived. She expressed interest in teaching her own children about money and responsibility by using the same tactics:

"I fed the homeless and stuff like that when I was in high school. I had to do community service, and I volunteered at a homeless shelter. I was like 'Wow! These children are going to school and coming home and living in a shelter,' so I think you have to make them [children] do community outreach in order for them to understand how privileged they are." — Lisa, 38, September 23, 2016

In a 1997 study of a black middle class suburb in Chicago, Mary Patillo found that the black middle class served as a spatial "buffer" between black ghettos of lowincome residents and wealthy white residents in the city. Other studies have found that the black middle class lives in closer proximity to lower-class blacks than whites of similar class status (Rich, Cox, and Bloch 2016). DC has lost its reputation as the black middle class mecca; the black population who have remained in the city are mostly low-income. If and when this group of people move out of the city, they will likely move to the closest PG County cities that border the DC line. Today, these cities; Capitol Heights, Seat Pleasant, and Landover, are considered the ghettos of PG County to locals and as referenced by the women in this study. While these areas contribute to the overall high income of the county, they are not recognized locally as desired areas to live. As DC's population increases, white transplants have also begun 
to move to these neighborhoods because of their proximity to the city and lower price tag. Unlike the black middle class residents in Pattillo's study, the black middle class of the DC metropolitan area moves far away to isolated areas not accessible by public transportation, thus truly creating an isolated area of middle class residents and customs.

In recent years, the demographics of these well-known middle and uppermiddle class neighborhoods in Maryland has shifted. An influx of out-migrants from DC, has prompted changes to the socioeconomic demographics in the once uppermiddle class areas of the Maryland suburbs. Those who sell their homes in DC to move to Maryland, often make a profit that allows them to buy in a once unattainable or undesirable area in Maryland. Amira, a film producer and mother one teenage daughter has watched her Upper Marlboro neighborhood change in recent years. Originally from DC, Amira moved to Maryland to provide her daughter with a nice, suburban home and quiet neighborhood.

"I would say I live in a middle class neighborhood, it's nice... although there have been some recent people moving in... ratchets...they were not there were the homes are built in '95." - Amira, September 28, 2017 Amira expressed disdain for her changing community. As a young single mother, she was proud to have left DC and moved to a nicer, quieter neighborhood. The influx of "recent" people frustrates her and causes her to rethink her neighborhood's association with the middle class.

So, you definitely see more teenage activities with a few of the neighbors that have come in, in recent years. They throw parties, got nonsense going on the neighborhood was so quiet, and it still is quiet and ideal, but I would say 
the last couple of years has gotten a little weird. I mean, on this street behind us there was like some shooting! So, I don't know what is middle class now. Yeah it's changing. - Amira, September 28, 2017

Prince George's County resembles the stereotypical representation of any other middle class neighborhood; without being told, one may not know off-hand that the area is predominately black. According to the 2010 US Census, the county is $65 \%$ Black or African American, which is highly unusual for an American suburb of this socioeconomic level. In this county, the average household income is $\$ 92,000$ (the median income is also high, at \$76,000) (US Census 2010). Here, African American children attend both public and private schools, are involved in enriching and competitive extra-curricular activities, and live in community-focused neighborhoods. These resources are especially important to the black community because of the history of segregation in this country, which prevented African Americans from having access to these simple 'luxuries,' that whites were able to offer their children.

Black people across socioeconomic lines face challenges in job searches, promotions, securing home loans, and other necessities for them to escape and afford residences in middle and upper-middle class neighborhoods. Because of these factors, blacks are not always able to live in exclusive middle class neighborhoods, and are kept in "lower-opportunity neighborhoods, often with underperforming schools, increasing the difficulty of passing on hard-earned privileges to their children" (Brown 2016). Prince George's County is diverse in that black people across incomes live and work in the area. In this county and nearby, certain consumption practices may lead to better opportunities for status attainment and wealth increase in the lives of black middle class single mothers and their children. Here, black middle class 
single mothers face personal and economic decisions that could increase the educational opportunities for their children. Education is extremely important, as it has historically been the building block for blacks to access and secure their position in the middle class. Students in Prince Georges County, Maryland, the "nation's highest-income majority black county," are disadvantaged by an underachieving school system. According to a Stanford University Center for Education Policy Analysis 2016 study, PG County students underperform at 0.9 grade level below the national average (Belt 2016). Black single mothers in the Washington, DC metropolitan areas have decided to send their children to private schools, enrolled their children in other school districts, and when possible have moved altogether for better educational opportunities that will offer their children greater overall chances at success.

PG County is often compared to Atlanta, GA because of the county's plentiful black professional communities. Atlanta, often referred to as the "Black Mecca," and Washington, DC, formerly "Chocolate City," are both historic hubs that have afforded blacks upward social mobility. Both cities have large black communities of various socioeconomic backgrounds. They each have numerous colleges and universities in their urban centers that are accessible for blacks (both HBCUs and PWIs) to gain education and capital. Also, both cities have job opportunities for blacks to make incomes that allow them to form middle class lifestyles. Washington's booming, but competitive job market has created positions with higher-than-average salaries, which have created a stable and expansive black middle class that competes with Atlanta. Atlanta has a lower cost of living and affordable single family homes. Like DC, several black residents have abandoned the city for suburbs like Lithonia for similar 
reasons as those in DC. Today, Lithonia barely makes the list of the most affluent black areas. Instead, wealthy areas in California (Ladera Heights, Baldwin Hills, for example) take the lead as the most affluent black communities in the country.

The majority of my research participants are current residents of PG County. Few are residents of other Maryland counties, each with their own reputations. I connected with women who lived in Montgomery, Howard, Charles, and Anne Arundel Counties. Montgomery County $(\mathrm{MoCo})$ is the wealthiest county in Maryland. It is also extremely diverse. In the cities closest to the DC border (Silver Spring, Takoma Park, etc.) exists a large Latino population. Montgomery County also consists of the extremely wealthy Potomac, MD, which in 2016 gained national attention with Bravo network's hit show "The Real Housewives of Potomac.” In the show, the camera captures the exaggerated lives of affluent black women and their relationships in the wealthy suburb. The show is criticized by local black women as a false representation of the black middle and upper middle class area in the DMV, particularly because some cast members of the show do not actually live in Potomac: "That is just not real" says Lisa, while laughing after watching a clip of the reality show during our focus group, “most of us don't have loads of money to just sit around gossiping. A lot of women in DC work for what they have." In addition to Potomac, MD, MoCo includes popular cities like Silver Spring (which has a financially booming downtown area and is the home of Discovery Channel), Chevy Chase, Bethesda, and Rockville. These cities are close to Washington, and the last two can be accessed along Wisconsin Avenue - which extends from the Georgetown area of DC into these prominent MD suburbs. These areas are predominately white and because of proximity, contribute to the overall high median income of the DC metropolitan area. 


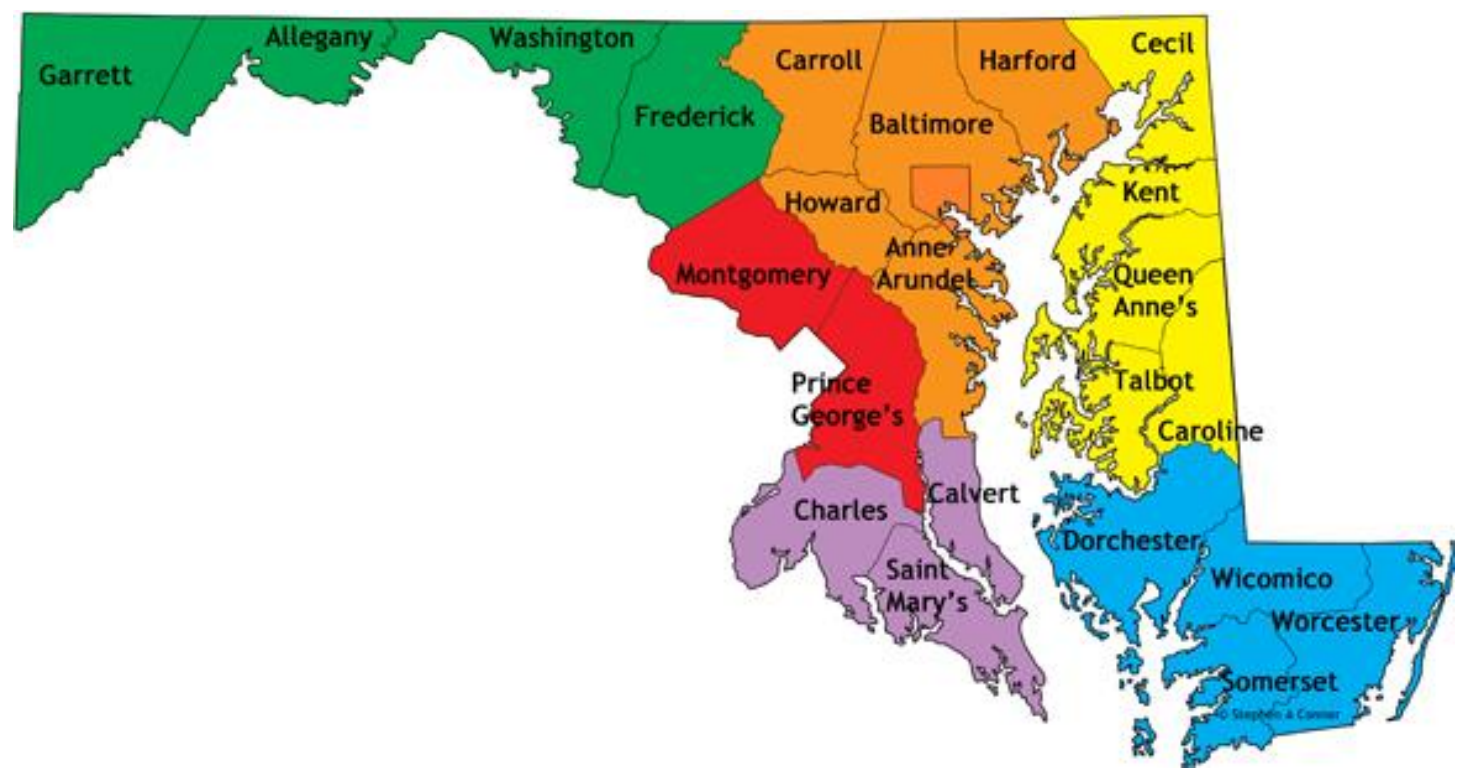

Map of Maryland Counties, Baltimore County Genealogical Society

Charles, Howard, and Anne Arundel County are lesser known counties in the area and are further away from the city. The map above shows the counties in blue and orange that made up my research site. In counties like Charles, where two of my research participants reside, the homes are much larger for a smaller price tag. Charles County, which also has a large black population, is located in Southern Maryland and has become the county that blacks relocate to after wanting more than PG can offer. Large homes in distinguished neighborhoods in PG, such as Woodmore, exceed \$1 million. Those who purchase similar homes in Charles County can spend half of the amount, but sacrifice a shorter drive into DC (Charles County is about 25 minutes outside of DC):

"I am out the door by 6 [am], at work by 7 [am]" says Tyra, a recently separated single mother of three (ages: 20, 16, and 10). Tyra was one of my participants who lived the farthest, and deepest in Southern, MD, in the city of 
Waldorf: "I carpool. I pick-up a co-worker and they pay for the parking, then I drop them off. So, I'm saving \$12 a day." — Tyra, 40, April 21, 2017

Tyra, like so many other mothers in this study live in Maryland and work in the District. Because public transportation and parking rates are extremely high in the area, some people who work in the city strategize to save money by carpooling.

Howard and Anne Arundel Counties are in the direction of Baltimore, MD, which is about an hour away from the DC border. It can take up to 30 minutes to reach each of these counties. Howard and Anne Arundel are also made up of suburban cities and towns, complete with parks, shopping, and gated communities. These counties are best known for their outstanding school systems, which is important for parents. The DMV suburbs are so interconnected, in fact, one city, Laurel, MD overlaps the four Maryland counties as previously discussed - Montgomery, Prince George's, Howard, and Anne Arundel. Laurel, MD is a recently revitalized multicultural city, and is where I lived when I returned to complete my field research in the area. Each of my parents own separate income properties in this city, on the Prince George’s County side.

Laurel's division is a perfect example of how the counties vary and offer different benefits to residents. Patricia, a single mother of one young boy, lives in Laurel - on the sought after Anne Arundel side. She lives with her parents and explains:

The school systems are so much better there [Anne Arundel], like, it's just across the street from PG, but the system is much better. My son participates in all of these school activities that I know PG schools wouldn't be able to offer. That's why I'm this age and still with my parents. They are able to help 
me out with him and I can have him in better school district. — Vera, 37, December 16, 2016

On the contrary, others find the complete city of Laurel to be a desirable and safe suburb to raise their families, regardless of the county. Another Laurel resident, Vera, a 37-year-old widow and single mother of a 5-year-old daughter describes her neighborhood:

The neighborhood is "quiet for the most part. I want to be in an area where there isn't a whole lot of crime. I want my child to be in a decent school - like now she's in a private school."

Vera is referring to a Christian private school a few miles outside of Laurel, that she has sent her daughter to so that she can be rooted in Christian teachings. Vera currently lives in a two-bedroom apartment in a complex where two-bedrooms range from $\$ 1300$ - $\$ 1800$. She had the opportunity to purchase a home but decided to wait because of her high expectations for the neighborhood and primary education options.

"When I was looking to buy a home earlier this year, I was very selective which you can see I am still here [in the apartment] because I have her in private school, which I love. It's more so I want her in Christian private school. You know, I want her to have that foundation." - Vera, 37, December 16,2017

Vera's interest in home ownership was consistent with several other women in the research. Although she ultimately decided to stay in her apartment until she found a home in her desired area, home ownership was clearly a priority for her. A majority 
(over 3/4) of the women in this research were homeowners. At least 3 of them owned multiple homes or other properties.

\section{Conclusion}

Washington, DC has experienced several demographic shifts over the years. From the end of the nineteenth century, the city has offered African Americans unprecedented opportunities for work and education. The progressive nature of the city prompted several thousand more to relocate over the course of the Great Migration. Blacks thrived in federal government positions and were able to purchase homes in predominately black neighborhoods surrounded by a strong black professional and working class. Howard University served as the hub for black intellectual thought, and the organizations that grew out of this university set the trends for the black bourgeoisie. When the city was confronted with drugs and violence in the 1980s, black residents sought new opportunities in nearby Maryland suburbs. The black middle class was redistributed but continued to embrace specific desires and expectations for their lifestyles and neighborhoods. As represented by the participants of this study, Maryland suburbs offer a certain neighborhood aesthetic, financial stability, and amenities. As the black population of long-time residents of Washington, DC has continuously moved into Maryland as a result of gentrification, I found my research primarily focusing on these areas. Without the booming economy and opportunities available in Washington, from the period of the great migration until today, the black utopia of Prince George's County and well-off black residents in other suburbs, would not exist. The diverse experiences of the research participants of this study are in the context of DC and its promise as a backdrop to black single women's present success and future possibilities. 
Meet Lisa

“Do you think you can be my live-in nanny?" Lisa joked with me as I entered her home to assume overnight babysitting duties. Lisa was scheduled to work on Saturday morning at $7 \mathrm{am}$ and did not have anyone else to watch her children. She contacted me and asked me to stay over so that I would be present when the kids woke up early the next day. Lisa laughed as she mentioned her need for a nanny, but it was not out of reach. She recently purchased a newly built home in a desired neighborhood of Prince George's County. Her home was located on a cul-de-sac street, a feature she sought after for the safety of her young children.

Lisa's single-family home was three stories, featured four bedrooms, five bathrooms, and a spacious backyard. It was obvious that she moved in recently because boxes were still unpacked and tucked in corners and key furniture pieces were not yet in place. The house was white and bare, without pictures or artwork. It still felt new. I had visited Lisa's home a few times before. On the first visit, she proudly gave me a tour of the property, and explained her design intentions for the space. She had a large basement, which was perfect for an in-law suite, and was being used at the time of my field research as a one-bedroom apartment for a friend in need. This was Lisa's second home purchase and it provided ample space for her small family of three.

"Patricia is going out with me. Her kids will be here, but they won't be any bother" she says to me. Lisa was going out to celebrate her birthday after a long week of work. Her friend, Patricia, who was renting her basement for herself and three children, was also going out. Both women, dressed in cocktail dresses and heels, were excited to go to the local jazz bar for a night of fun. Recently, they alternated in their 
caregiving duties or were so busy working that they could not go out with other friends.

Lisa's children began to cry as they realized their mother was leaving them for the evening. They were most comfortable with their mother and were not use to having babysitters. "Most times I'm just too tired to even go out" Lisa says, as she tries to calm her son down from crying. The children were not used to others, which made it hard for Lisa to want to leave without her kids. She expressed guilt for leaving the children after seeing them for so little time throughout the week. Her friend, Patricia, encouraged her that it was only one night and that she was deserving of this personal time.

A few years ago, Lisa's mother was diagnosed with cancer. Her mother, who was her primary support as a child and as an adult, now needed additional assistance from her daughter. Lisa moved her mother in to live with her. At the time, her two children were very young - a newborn and a one- year-old. Together, and with her children's father, they lived in Lisa's townhome. When her mother passed, she purchased the new home and continued to use the townhome as an income property. Lisa was proud to have purchased a home in her desirable neighborhood.

Lisa's ended her relationship with her children's father shortly after her second child was born. Her boyfriend became uncomfortable with her financial success and did not appreciate Lisa's control over the home and other expenses. He moved to a nearby city and has limited contact with his children. Lisa blames his insecurities on his inability to provide for the children and serve as a constant presence in their lives. 
CHAPTER FOUR | It's Not Can I do it, But How Can I Do It?: Black Women, Work, and Single Motherhood

"You kept us off the street. Put clothes on our back, food on the table. When you didn't eat, you made sure we ate. You went to sleep hungry. You sacrificed for us. You the real MVP.” - Kevin Durant, 2014

During an emotional MVP acceptance speech, Kevin Durant, then NBA small forward for the Oklahoma City Thunder, called out his mother for her remarkable sacrifices to his family. Durant called his mother, Wanda Durant, or "Mama Durant" as she became known after this speech, the true most-valuable-player in his life. This heartfelt speech became a national representation of the struggles and joys of black single motherhood - and how a single mother's dedication can produce a successful NBA star. Durant's open appreciation for his mother led to Lifetime television network producing a television movie in her honor, titled The Real MVP: The Wanda Durant Story. In his speech, Durant recalls his experiences growing up in modest apartments across PG County, Maryland, moving around a lot, and the basic living conditions that his mother was able to provide. His recollection of his childhood in this speech and in the Lifetime movie, expressed common understandings about black single motherhood. While Durant's experience is his own truth, his story supported over-representations of black single mothers as poor, struggling, and overly sacrificial. Durant's speech has been viewed over 2 million times on YouTube, and at the time of its airing, was the talk of all of the sports networks and local, and national news. Unknowingly, Kevin Durant, and his mother, became symbols of overcoming adversity. Like any other group, black single mothers are extremely diverse and 
complex. Wanda Durant has become a national hero in some regards, and she deserves the recognition. However, there are countless other women, who are also black, single mothers, and living in the same area, who do not share this story and would be misrepresented if they accepted Kevin's speech as representative of all single mothers. The evidence collected throughout my research challenges representations of black single mothers like this one and aims to provide a more nuanced and complete understanding of these women as women and mothers. Black single mothers are often assumed to fit within constrained stereotypes of poverty, lowincome, and a number of other negative character traits, without taking into consideration the differences among them or factors that have impacted their lives as single women who are mothers. Black middle class single mothers employ a combination of things and experiences to embrace some stereotypes and fiercely reject others. These things are used to form black middle class single mothers' identities as single women and mothers, and to craft the lifestyles that they want their children to experience.

Representations of black single mothers as welfare queens concentrated in low-income urban areas is a stereotype that has existed for generations. Kevin Durant's speech about his upbringing and his mother were not new to the conversations and understanding of black family dynamics, but it did bring black single mothers to the national stage, if for a short period of time. Durant is a wildly successful basketball player, whom many would consider an underdog who has succeeded 'against all odds'. Despite his professional successes, his family structure echoes the criticized family structures of the infamous Moynihan Report. In 1965, Daniel P. Moynihan, sociologist and former Senator, and Assistant Secretary of Labor published a comprehensive report on the African American family in urban settings 
titled "The Negro Family: The Case for National Action" also known as The Moynihan Report to the United States Department of Labor. In this report, Moynihan argued that the African American family was in a crisis — of poverty, lack of education, and crime - which severely impacted African Americans from attaining social mobility. He blamed much of these social issues on the state of the black family, calling it a "tangle of pathology," meaning that it's untraditional mother-led households led to the deterioration of the family and the lack of black males in positions of authority. Moynihan believed that the black family was incapable of upward social and economic mobility without the traditional patriarchal nuclear family structure (Moynihan 1965). Consistent with the arguments of prominent black sociologist, E. Franklin Frazier, he believed that black men must develop their skills and social capital in order to elevate their socio-economic status as to take leadership roles within the black community (Frazier 1939, Hunter 2006). Although women in black families often fulfill multiple responsibilities, in many instances successfully, it was still widely accepted and expected for a man to act as the cure to a troubled family unit. This report faced backlash from other politicians and academic scholars, who disagreed with Moynihan's findings, creating an opportunity for scholars to revisit older scholarship and develop new dedicated research on the black family, and specifically for research on single motherhood, to emerge.

The black American family is a highly complex entity with a loaded history that has evolved out of the harsh conditions of slavery. The insecure position of black males within the home (Clarke 1966) and displacement of black males outside of the home and in search of work positioned black women as primary heads of households (Frazier 1939). Unlike Melville Herskovits and Wade Nobles, who previously argued that this unique family organization was of African origin, Frazier argued that black 
families were dynamic and flexible institutions that formed out of cultural adaptation during slavery (Herskovits 1941; Frazier 1939; Nobles 1974). Enslaved people were often forced to breed for the benefit of the slave master (Dill 1988). Enslaved mothers and young children formed close bonds because slave masters understood the importance of children having mothers present to fed and take care of their children, as they would later become forced working, producing members of the plantation. Enslaved families, mother, father, and children, as well as extended family members were often violently disrupted by the sale of black men, murder, or attempts to run away from their inhumane conditions. Although many symbolically "married" (it was not legal for slaves to officially marry), slaves quickly learned that they had limited control over the maintenance of their marriages and physically in-tact families. As black men could not support themselves and families through work, black women took on additional responsibilities in the home. Enslaved women typically became "single mothers" and grew to rely on other women and extended family members to assist in the raising and protection of their children. This tradition has carried on as extended family and friend networks have strengthened black communities and provided help and emotional, social, and financial support to single parent households (Hill 2003, 1977; Billingsley 1993; Stack 1974). The physical and psychological impacts of such forbidden families have had lasting effects within black communities. Due to these circumstances among others, the black American family has historically been denied the ability to form the traditional nuclear family structure, and instead have been matrifocal units wherein women often take leadership roles as economic providers, caregivers, and role models (Collins 1987).

Social scientists have debated the concepts of matriarchy and matrifocality within black communities across socioeconomic levels. They have investigated the 
roles of parents and extended kinship networks in alternative family structures such as single mothers and lesbian families. Anthropologist Raymond T. Smith, in his studies of British Guiana and West Indian family life, used the term 'matrifocal' to emphasize the woman's role of mothers as the focus of familial relationships instead of as heads of households (R. T. Smith 1996). Nancy Tanner defined the concept as mothers who head households, and who hold "economic and political power within the kin group" or family (1974: 132). Black families have often been categorized as consisting of a dominant matriarchal figure, however some scholars disagree. Robert Staples has called the over-representation of dominant black females (in the family) a myth that is not conclusive of all family units. Instead, he argues that both black and white middle class continue to move towards equalitarian gender roles within the family unit and home. These scholars disagreed with the conclusions of Daniel Patrick Moynihan. In showcasing the inconsistencies of Moynihan's arguments, Staples and others have proven that the private patriarchal nuclear family structure has declined for not only black families, but also white families in the United States, as more partners enter cohabiting relationships, single-parenthood, and other family formations (Staples 1985; Garrison 2007; Nock 2005; Furstenberg 2007). In fact, sociologist Bart Landry refers to this redistribution of power within the family, as more women (of all races) continue to enter the workforce, as the "American Family Revolution" (Landry 2002). Black middle class women's participation in the labor force and their decisions to enter motherhood as single women have motivated others, including white women, to also take on multiple roles within the family and escape domesticity (Landry 2002). This finding discredits Moynihan's argument that matrifocal structures are the worst possible scenario for families. 
Despite matrifocal families and the "American Family Revolution," the nuclear family continues to be the most romanticized family structure in the United States. Dorothy Smith refers to this conventional structure as the Standard North American Family (SNAF) (1993). This monolithic family type had been defined as consisting of a father head of household, a mother, and their children typically in a single home wherein the mother is the main caregiver to the husband, children, and the household in general (Holder et al. 1991; Baca Zinn 2000; Smith 1993). The nuclear family is celebrated and encouraged through propaganda in churches, popular culture, and by the government, thus diminishing other family formations. The nuclear family is upheld in black churches as "theological conservatism pushes the church to look with concern at marked increases in single parenthood, fatherlessness, and divorce in the African-American family, and to hold forth a vision that is largely in keeping with traditional Christian morality" (Wilcox, Chaves, and Franz 2004). The nuclear family is eclipsed by other family formations in the United States including single parent families, blended or step-parent families, gay and lesbian families, and unmarried cohabiting unions. These alternative families directly challenge the concept of nuclear family as the traditional middle class family structure. Even though these other family structures violate respected gender norms, they have fully functioned as operational structures for the individuals involved (Lehr 1999).

Feminist and black feminist scholarship specifically, has illuminated family structures that do not fit the heteronormative patriarchal family structure, such as single mothers. Linda Nicholson argues that families who "look" traditional on the surface "reinforce ideas about the pervasiveness of the "traditional family" although they may be related in untraditional ways as co-parents, cohabiting parents, or gay 
men/ lesbian women who socialize with each other (Nicholson 1997: 37). Family structures, thus, are not always correctly categorized. Among my research participants, few women hesitated to refer to themselves as single mothers or nuclear families because they shared responsibilities with the father of the children and operated a co-parents. Additionally, modern medical technology (in vitro fertilization, for example) and newly acquired rights to parenthood and marriage have made 'family' a complex concept. As individuals and couples more frequently enter contract pregnancies, commonly referred to as surrogacy, the common structure of parenting and family becomes a unit of deliberate choice. Just as black women have decided to adopt, seek surrogates, or have their own biological children, the family structure among gay and lesbian couples, single men and women, and others is one of conscious reproductive decision-making, choice, and freedom (Lehr 1999: 128).

\section{Defining Single Motherhood}

Single mother is a contemporary phrase that has grown out of generations of lived experiences of women who lead households and raise children without the assistance of a partner or father, and especially applies to women who are unmarried. The phrase "single mother" has evolved into a convoluted term primarily used to describe women of color who have children outside of traditionally accepted nuclear family structure. A single mother is typically defined as a woman who assumes the primary care and responsibility of a child. She is often responsible for securing housing, education, and other necessities for the child. In the United States, single mothers have grown to be representative of black families. Before Moynihan's report, sociologists such as E. Franklin Frazier, described the black family with pronounced focus on the roles and responsibilities of the "female dominant" mother, who served 
as primary parent and at times, breadwinner for the family. Today's women, however, have the option to economically thrive as "single mothers ."

Feminists have adopted the term "single mother by choice" to describe women who purposefully enter single motherhood. These women have made the conscious decision to become primary parents, assuming full responsibility for their children and thus adding a new level of independence to matrifocality. This phrase is used in ways to distinguish mothers who knowingly enter this family structure from other single mothers who may have become single mothers as a result of abandonment, divorce, or death. The phrase "single mother by choice" is used to proudly describe white women as independent and progressive, while "single mother" continues to be negatively associated with black women. The phrase single mother by choice gives the woman, the mother, agency in her decision to start a family outside of the traditional norms.

Gabrielle, a 44-year old new mom is a solid example of a participant making the tough decision to become a single mother. Gabrielle, like many other black educated women, graduated college and focused much of her time and energy into advancing in her career. She relocated often to have access to the best opportunities available, and made herself fully available to current and potential employers. Gabrielle reflected on what led to her decision to become a single mother:

“It really didn't become a serious consideration for me until really my late 30 s when I got to the point that I realized that I wasn't at a point where I was going to get married. I have the biological clock ticking, so it became apparent to me that I had to consider other options." - Gabrielle, 44, March 3, 2017 
Gabrielle decided to become a single mother because she felt she was running out of time to become a mother. Instead of waiting for marriage or even finding a suitable partner, Gabrielle decided to adopt. A few years ago, she adopted a newborn baby girl.

"I still wanted to be a mom," she says as we sit across from each other in an upscale coffee-shop. "That's what I decided. You know? I can do this on my own. So I considered adoption." — Gabrielle, 44, March 3, 2017

While her work remains time-consuming, she has adopted a work-life balance that allows her to work from home and care for her daughter and remain involved in the workplace. Gabrielle is a striking example and her experiences do not mimic any other women represented in this research. As a top executive in her company, Gabrielle has an annual salary of over $\$ 200,000$. Even with her high salary, Gabrielle considered herself within the upper-middle class, because the expenses for her daughter, taking care of her elderly mother, and household expenses caused her to relate to others within the middle class, especially since the average incomes in the area were so high. Unlike most others in this study, she was able to consciously make the decision to have a child on her own because she had the financial backing and job security to do so. After achieving her professional goals, Gabrielle put a lot of thought into her personal goals. Still, in addition to the economic independence the area has afforded Gabrielle, like other women who become a 'single mother by choice,' continues to prefer marriage, desire the well-respected nuclear family structure, and prefer to maintain traditional gender roles in the home (Staples 1985; Broderick 1965; Kulesky and Obordo 1972). Financial success and socioeconomic mobility is sought after for many educated and motivated black women, even when it alters their family 
plans. In this case, Gabrielle, like other women in this research, found alternative ways to become mothers while having a desired career.

The definitions and expectations of single motherhood varied by the participants in this research, but they each shared one major characteristic: assuming the primary responsibility of the child. Renee describes her single motherhood in an interview at her office in Virginia,

"So I'm not your typical single mother, and that is just me, but he makes a contribution towards her tuition and that's it. And he gets her every other weekend, most times, so I'm not in your true sense single mother, meaning I'm trying to figure this all out. But based on his participation, I still feel like I'm a single mother. So I run her to soccer, I run her to stem classes, I run her to church, I run her here and there, so if I had to define what is a single mother, it's me. It is any one person, whether single mother single father, who has to do the daily management of a child's life." — Renee, 38, November 14, 2016

Others defined single motherhood as the absence of another adult in the home. "Yeah, single mother to me is there's no husband boyfriend in the household helping you raise your children," says Brina, a single mom of two teenagers.

Few women in this research preferred to use the term "unmarried" when referencing their marital status. Aside from it not being used often within the community, most women felt that unmarried placed too much emphasis on marriage. To say one was "un"married, suggested that the absence of marriage was negative. Others, like Issa preferred "unmarried," as it did not suggest loneliness. Issa explained: 
"I just say I'm unmarried because I don't feel single. I think that people say single when they feel alone, and when they are looking for something to complete them. I'm a whole person. I don't feel alone, I'm just not married. And thats okay."- Issa, March 7, 2017

Ultimately, single motherhood was defined by all based on the amount of mother's responsibilities. The marital status was determined to not be as important as the amount of help — financially, physically, and emotionally — the mother received from the other parent. In this chapter, I explore the ways black women and black single mothers are portrayed in the media, and the ways their realities go against negative stereotypes and misrepresentations. Black mothers are unique in that they perform double duty — work in the home and in the workplace, to provide for their households. As they maintain their careers and motherhood, these women are changing the dominant narrative of what it means to be black and a single mother.

\section{Black Women's Representations}

Media representations of social groups has received much scholarly attention. The consistent reinforcement of certain themes push narratives, stereotypes, and representations, which inaccurately shapes viewers perceptions of the social world (Brown Givens and Monahan 2005, Potter 1999, Shapiro 1991).

Television and film is important to discuss because of its role in perpetating stereotypes. Nina Cartier opined: "As viewers of American popular media representations, we scour the screens searching for images that both reflect our lived experiences and offer new possibilities to free ourselves from the confining humdrum (and sometimes stifling racism) of our daily existences" (Cartier 2014). Popular media allows black audiences to see/seek alternate representations, sometimes in roles of 
heroism, like Olivia Pope's character, in ways that are desired in real-life, but often unattainable due to varied circumstances resulting from racism, class status, education, etc. Studies have found that blacks watch more television than other demographics, and place a higher degree of confidence in its programs (Inniss and Feagin 1995). It is important to explore the impacts on-screen representations of black people, and black women specifically, have on black individuals in real life.

On screen, black characters are often over-exaggerated for entertainment purposes; we are rarely portrayed as regular or ordinary people with realistic or relatable narratives. An emerging group of Black professional writers and show runners, including Shonda Rhimes, Issa Rae, Ava Duvernay, and Kenya Barris are working to produce more complex representations of black characters, but we have a long way to go.

In television, film, and the news media, I find that Black women characters are typically described as one of three types: independent and successful, family-focused, or poor and unstable. Black women, like Mary Jane Paul on BET's Being Mary Jane, Olivia Pope on the hit-show Scandal or Annaliese Keating on ABC's How to Get Away From Murder, would fit into the first category, as they are immensely successful women in their respective high-paying professions. In such representations, they are upper-middle class career women "afflicted with disastrous personal lives," estranged from family and community, and whose plot involves 'finding a man' (Harley 2002). They, like other professional women on air, are unmarried, without children, and in a number of unstable relationships. Classic kinship theory (Blackwood 2005) supports such plots, as it reveals that men should have control of women and children, forcefully placing the family into the heteronormative dominant culture that feminists have worked so hard to disrupt. In her anthropological research, Evelyn Blackwood 
has found that society presumes men should be present and have dominant roles within the family (Blackwood 2006: 77), and this is represented throughout cable and network television programming. Other main characters, including ABC's Black-ish's Rainbow Johnson or Beth Pierson of NBC's This Is US, represents the family-focused mother, who is married, working in their chosen careers, and living the suburban “American dream." Fewer, less popular representations of women on television today portray black women as poor and unstable, Deja's biological mother on This is Us who struggled in numerous relationships with men and eventually abandoned her daughter with strangers. In these examples, and many others, black women in the media do not cross or overlap in these imaginary categories as they frequently do off screen. In most cases, black women are understood to be extremely successful professionally, but not mothers (unless they are married), or poor mothers who are unable to take care of their children.

\section{Dominant Stereotypes}

Past and present media representations tend to focus on four major controlling stereotypes associated with black women: the Mammy figure, the strong black woman, the jezebel, and the welfare queen. These stereotypes influence people's judgments of black women in social settings (Brown Givens and Monahan 2005). Throughout this research, black middle class single mothers argued that "strong," "bossy," "unavailable," and "uneducated" were common stereotypes they frequently faced. The significance of such stereotypes has also grown to have major implications in the lives of black women. To combat these misrepresentations, black women actively respond to stereotypes and present counter-narratives in their everyday interactions with others. 
Mammy

The Mammy stereotype garnered national attention in 1940 when Hattie McDaniel became the first black woman to win an Oscar for her portrayal of the racialized cultural icon, "Mammy" in Gone With The Wind (1939). McDaniel played the role of Mammy, an enslaved woman and loyal, maternal figure on the Tara plantation. Here, black women are portrayed to be dominant, often overweight figures with sass who take charge of situations and care for those around them without any resistance. Despite it's offensive and demeaning presentation of black women, it has continued to be reintroduced in mainstream media through films like Tyler Perry's Madea series and The Help. In 2012, Octavia Spencer was awarded the Oscar for her supporting role in the fictional drama, The Help, a film where black women served as nannies and maids to middle class white families set in the 50s. These representations continue to degrade black women as humble, devoted servants who are always present. Audrey Edwards, editor of black women's magazine, Essence, from 1981 to 1986 argued that the mammy figure is one of the "the most persistent images of black women in the media" (p. 216) and is perpetuated through television, advertising, music videos, and the press (Edwards 1993, "From Aunt Jemima to Anita Hill, Media Studies Journal). Edwards relates the image of the mammy figure to Oprah Winfrey's success as a talk show host to her presentation as a comforting, maternal figure to all of her show's guests and audiences.

\section{Strong Black Woman}

The Strong Black Woman stereotype, which can be understood positively as a characteristic of praise (Beauboeuf-Lafontant 2009) and negatively as a controlling image (Collins 2000) asserts that black women are able to overcome all obstacles and 
emerge as strong and independent women who serve their families, workplaces, and communities (Barnes 2016). On the other hand, this praise and expectation of black women as superheroes create massive amounts of pressure and the expectancy of black women to be "everything to everybody" at all times (Barnes 2016). Popular media representations of this stereotype include Cookie Lyons from Empire, who despite serving 17 years in prison to save her husband's career and consistently suffering through infidelity and heartbreak, continues to have the attitude that nothing can hurt her, and that she is invincible. The character and idea of black women as able to endure insurmountable pain without any vulnerability is unrealistic. Although black women are strong, we should not be expected to take on all burdens at all times. In Raising the Race (2015), married black women consciously work to refute this stereotype, but many black single mothers may not have this option. Black single mothers, by nature of being the primary income earners and primary caregivers, do not always have the privilege of deciding to focus on family over careers. Furthermore, black single women may take their responsibilities as full-time mothers and full-time career women as a source of pride and a testament to their independence.

Ava Duvernay works to complicate the narrative of black single motherhood and nuclear family expectations through the character of Charley Bordelon on OWN's Queen Sugar. Charley presents a ‘strong black woman' who endures a lot of emotional abuse, but uses her career as a distraction to overcome her pain. This character takes on a lot of responsibility, for her son, her family, elders in the community, and more. Unlike many other representations of black woman in the 'strong black woman' trope, Duvernay intimately shows how the pressure to provide and take on divorce, infidelity, and more takes a major toll on the character. 
Charley Bordelon interests me as she is one of the few mainstream representations of single mothers on television today. She has a lot of power on the show as the owner of the first black-owned sugar mill in her town in Louisiana. She is also, struggling to navigate life as a single woman and mother after her famous, and wealthy pro-basketball player husband was caught in a affair that gained national public attention. Charlie's character is exciting, and entertaining, but she is far from average. While Queen Sugar's representation of single motherhood is unlike most others on television and in film today, it is an exaggerated portrayal of this character as a mother and soon-to-be ex-wife. Charley is not outwardly faced with the burdens of negative stereotypes surrounding black single motherhood specifically because she has a lot of money. As a businesswoman and former wife of an NBA player, Charley is not concerned with finances, and her character, instead focuses mainly on the embarrassment and betrayal of her husband. The introduction of Charley as a single mother character adds depth to the played-out and overused representations of black women as poor, uneducated, young irresponsible mothers on television and in film. However, the introduction of this character creates two extreme representations that do not quite represent the average black middle class single mother that is present offscreen. While this representation adds another layer to black womanhood, success, and family life to black television and film, it fails to create a representation of normal, average life for black mothers.

Black middle class single mothers in this research identify with the expectations to constantly provide and adopt the "never let "em see you sweat" mentality. Hope, a single mother of two that I spoke with, refers to herself as "obnoxiously independent" and embraces the strong black woman stereotype head on. 
Hope is used to taking care of everything on her own and finds it difficult to ask for help. She often does not realize she has taken on too much until someone else offers to help her with tasks related to her children. Many women are independent, but as an 'obnoxiously independent' woman and mother, she says, it is hard to consider or ever ask for help from others.

Hope suffered through a car accident when she was 18 years old and in her first semester of college. Her injuries resulted in her having a hip relocation and having to relearn how to walk. She also fractured a bone in her face and had other small injuries. At the time, Hope did not realize that the accident would change her life forever. It took her several months to learn how to walk with a cane, which she still uses today. She took an extended leave of absence from university and was never able to fully return to complete her studies. Hope changed her goals for motherhood and family structure after her accident. She assumed that a partner having to care for her and take on children would be too much for any one person.

Although physically disabled, Hope is extremely independent. She is able to drive, live on her own, and take care of things without the help of others. She learned to be independent with her new challenges from the accident. Since then she has prided herself in being able to do most things without help -- but motherhood was different. When Hope realized she was pregnant, with twins, she was nervous and overwhelmed. Hope was not married and did not live with her partner. She would have to learn how to care for two children with her own physical challenges, and she did. She found ways to carry both children and her cane and purchased unique baby equipment to assist. 
To Hope, any and everything is possible. As a single mother who is physically challenged she had to find creative ways to take care of her responsibilities. In a statement that fit perfectly with the experiences of most other women in this research, Hope draws attention to strategizing and finding solutions instead of questioning if something is possible. "It's not 'can I do it', but 'how can I get it done?, she says of herself when entering planning mode to make sure that all things are taken care of for the teenage twins.

Even among black women who are physically disabled, full-time workers, and single parents, the consistent expectation for black women to be strong and resilient through all adversities has been internalized, making it difficult for black women to prioritize their own needs before others.

Jezebel

The Jezebel stereotype grew out of slavery and was heavily broadcasted in blaxploitation films. This stereotype suggests that black women are hypersexual, and this behavior is the cause of their unfortunate circumstances, which may result in rape or other mistreatments. Patricia Hill Collins describes this character as an African American woman with an uncontrollably "excessive sexual appetites" (1991). She updates this character-type as "gold-digging hoochies [who] often aim to snare a highly paid athlete and can do so by becoming pregnant" (Collins 2000). The assumption is that women who represent the Jezebel stereotype, use their bodies for financial, social, and material gains. Amira recognizes this negative stereotype for black single mothers as "having to have a man around" and "jumping from man to man”. Black middle class single mothers who do not rely on welfare or public assistance programs to maintain their households or raise children, continue to face 
racist and sexist stereotypes that assume that black women are successful only by means of manipulating others. Instead of abusing the welfare system, the belief is that a black middle class woman may abuse a husband or romantic partner, or enter a relationship for the sole purpose of their financial gain.

One of the most successful series of reality television is Bravo's The Real Housewives. The Real Housewives began over 10 years ago, documenting the everyday drama of wealthy white housewives of Orange County. It has since expanded to include its most popular franchises, The Real Housewives of Atlanta and The Real Housewives of Potomac, which feature full black women casts who both reject and support the jezebel stereotype.

Despite its title and unlike the casts of the other predominately white franchises, the black casts of The Real Housewives of Atlanta (RHOA) and The Real Housewives of Potomac (RHOP), are not actually housewives. Many of them are unmarried/ were never married, or divorced at some point in the show, and most of them are working women - not "housewives" in the sense that their only responsibility is tending to the home. These two franchises show a stark contrast from the other Bravo's Housewives franchises. The women, who are mostly upper-middle class professionals work in the entertainment, philanthropic, and even restaurant fields. The series generally documents the drama that exists between groups of friends, some lesser known celebrities of the same circle in each of these cities. For the women of The Real Housewives of Atlanta, I would argue that class and upward mobility is the largest concern, as the women are constantly seeking new hustles to increase their net worth. On this franchise, most of the women (Sheree Whitfield, Kenya Moore, NeNe Leakes, Kandi Burruss, and Cynthia Bailey) spend a great amount of time without husbands. They are called "housewives," but they are not 
wives, and primarily take care of household responsibilities on their own. Bailey and Burress, specifically, were raising their teenage daughters as rich single mothers, with very little on-screen interaction with the girl's fathers. RHOA better presents the getahead and "work hard" attitudes present in many of the personalities of my research participants. Many of my participants cannot identify with the fame or fortune that these women have, but handle responsibilities in similar ways. The jezebel trope is deeply offensive and inaccurate for the black middle in the middle class. As single mothers and working professionals, they work hard to provide stability without the need to use men and sex to reach their financial goals.

\section{Welfare Queen}

"I think people assume single mothers are uneducated, that they are high utilizers of the system, and are somewhat lazy." -Brina

Brina, a mother of two young adults, says society views black single mothers as "lazy" and expecting for others to take care of them. This statement supports stereotypes and representations of black single mothers as the "welfare queen." The "welfare queen", a dramatic representation of black mothers who took full advantage of government assistance rose to prominence in 1976, when President Ronald Reagan criticized single mothers in Chicago for abusing government assistance. Like President Franklin D. Roosevelt's New Deal policies that sought to regulate and amend the supposed poor behaviors of black inner-city women (Sandlin and Maudlin 2012), President Ronald Reagan set to control how black mothers used funds while raising their children. These racist policies targeted poor black women and attempted to strip them of their agency in childbearing and childrearing. The welfare queen has remained a common, identifiable stereotype for black women, which as Sandlin and 
Maudlin argues, suggests that black women are reckless, promiscuous, and manipulative (2012). The "welfare queen" profits off of the government by having multiple children and requiring public assistance. She is perceived to be lazy and weak because she is comfortable sitting at home instead of physically going to work outside of the home (Collins 2009). The "welfare queen" then spends public assistance on material goods that do not provide any direct benefits to her home or children, thus resulting in what is considered reckless behavior. A welfare queen is a controversial figure because despite her lack of earned income, she is able to live a lavish lifestyle using other methods of income (Neubeck and Cazenave 2001).

The women included in this research were aware of this stereotype and most took measures to distance themselves from it. The women surrounded themselves by other women with children, and those without, who were shared their socioeconomic status. Although I did not specifically ask about these women's relationships and interactions with poor or working class women, their silence spoke volumes. The research participants mainly referenced poor women when speaking about welfare and how they did not fit that description.

As successful business women and professionals, some of these women interacted with working class women in their families. Georgia recalled being raised by a poor single mother in Los Angeles and used her mother's and her childhood experience as motivation in effort to separate herself from the working class. Other women, like Amira recognized her financial stability as a privilege and understood that family members, like cousins, may come to rely on her for financial assistance. Instead of distancing herself from the working class women in her family, she explained to her daughter that the lifestyles of some relatives may not mimic her own and that was okay. She did not want her daughter to feel uncomfortable or look down upon other 
family members because of their neighborhood, style of dress, or lifestyle. The interaction with other family members who were working class, if not on welfare, was normal, especially among women who were not raised in the middle class.

Because black single mothers are over-represented as poor and on welfare, I asked my research participants directly about their finances. In addition to asking their annual salaries and sources of income, I specifically asked about child-support. Child support is a payment provided to the primary parent to assist in the financial responsibilities of child-rearing. Child support can be regulated by the court or can be an unofficial agreement between parents outside of the court system. My experiences as an intern with the New York County Family Court and as a child who saw firsthand the benefits of child-support, I understand the significance of this type of payment and the intense problems that it can cause. During my interactions with the mothers, financial responsibilities appeared as women discussed the need to work, sometimes long hours, to provide for their children. Those who received child-support complained that it helped a little, but did not really factor into the daily operation of the household. Those who did not receive child-support either proclaimed that they did not need it or that they would like to receive child-support if it were consistent. Their experiences as working women rejected the presumption that single mothers did not work. Instead the argued that they overworked to make up for the lack of financial support that should be provided by the other parent.

"It is very important for me to have multiple streams of income," urges Tyra, "Look, I have a full time job, that's okay, but I need more than just that, because anything can happen. When I telework and on the weekends, I am also making sure that my other businesses are running smoothly. I have an income property, own vending machines, and just began a new luxury car 
service business with a friend. Constant cash flow is necessary." - Tyra, 40 , April 21, 2017

In an effort to remain in the middle class, while simultaneously embracing some stereotypes and rejecting others, Tyra works long hours in her full-time jobs and create other streams of income so that she can maintain their positions in society. While joking about Caribbean ingenuity and determination, Tyra acknowledges her business acumen as a part of her Caribbean culture and as a result of seeing her parents hustle to live middle class lifestyles in New York. While accepting this stereotype, by working multiple jobs, Tyra ensures that another stereotype, the "welfare queen" is not associated with the way she maintains her household.

Black single mothers are expected to be poor and welfare-dependent. Women in this research have been mistreated as a result of race and assumed class status. The assumption that all or most black single mothers are 'welfare queens' affects the ways these women are treated within society. Because they are assumed to have lower incomes, they have had withstand people's rude comments, blatant disrespect, or lack of service. Cassandra recalls a time when her son, who suffers from asthma, became ill at school, and she was dismissed and mistreated because of her single mother status.

"He [Cassandra's son] was about 10 months old, and was breathing funny. $\mathrm{He}$ had always been on a breathing machine, so I called his pediatrician, and told him that he just didn't sound right. And so he said, 'okay Cassie, just go ahead and take him into the ER. One of the doctors is on call. Take him there.' So, I said okay. But I drove far because I wanted him to see a pediatrician. I needed him to go to a pediatric ER. I'm a snob when it comes to my son, so I only want him seen by pediatricians unless its a life threatening emergency - I believe that pediatricians know kid's 
bodies best. So, I took him to pediatric ER and when we walked in, I had a Louis Vuitton bag at that time (I got a push gift of a Louis Vuitton bag) and my son is dressed in his Polo Ralph Lauren sweat suit and his brand new Nikes and he couldn't walk, so I was carrying him. And I get to the counter and the white guy behind the desk says, 'Do you have your medical card?' And I am in an affluent neighborhood. So I told him yes and to hold on for a second while I looked through my bag. And, as I'm digging, he says, 'well what is it Medicaid?” - Cassandra, February 22, 2017

She was offended because of she traveled a long distance, only to receive the best possible care for her son, only to be immediately disrespected upon entry. She took her complaints up with the hospital, and wrote a letter explaining the situation to the hospital's management offices. In that moment, Cassandra felt that her hard work as a working mother was dismissed and overlooked. Cassandra was married, and wearing a wedding ring at the time of the incident, but felt stereotyped as a poor black single mom. Cassandra, and other mothers in this research, actively tried to distance themselves from poor single mothers. As educated, professional women, they did not want to be mistaken for poor or treated as women who were incapable of providing for their children.

The women in this research are not dependent on a husband, spouse, or partner to bring in the household income, nor are they unable to have or raise children without this additional financial backing. Although additional financial assistance is welcomed and preferred by nearly all of the women in this study, the lack of additional financial assistance does not result in the women or children being forced to depend on government aid, change of lifestyle, or any other drastic changes. The father's involvement in the child's life, physically and financially, does impact the relationship between the mother, child, and father. In my conversations with women who receive 
help from the father overall had positive things to say. Despite not being in a relationship, they felt that their children were the priority of both parents. Amira's daughter June's father was very involved - he was consistent with child support, took their daughter for weekends and long vacations in the summer, and participated in all school related activities. Amira's daughter was respectful of her stepmother and could see that although her parents did not live together or were not married, she was important to the both of them. When fathers are unable or unwilling to assist, the children often pick up on it and it causes a strain in the relationship.

When Felicity's daughter turned three this past year, she was upset that her daughter's father did not show up to the birthday party. Felicity worked hard to organize a party that her daughter would be proud of, and hopefully remember for many years to come. Instead, when her daughter's dad did not show up, her daughter asked if her dad was still her dad. This frustrated Faith and ignited a distrust for her ex-fiance that was far worse than his previous infidelity. At this moment, he lost the trust of his daughter, and this deeply impacted Felicity. "I think he didn't show up because he was embarrassed," she says. Felicity admitted to handling all responsibilities related to her daughter. Since she ended the relationship with her daughter's father over a year ago, he was largely out of the picture. "He stopped calling her and never wants to pick her up on the weekends." Felicity believes that her daughter's dad's embarrassment prevented him from showing up to the birthday party. This public spectacle, full of friends and family, who are aware of the lack of presence he has had over the year would have been uncomfortable for him. Felicity does not see this an excuse for his action, but uses it to make sense of why he would not show up. Felicity's daughter understands that her dad has another, younger child, but questions if that means he is still her dad because he is not around. Of all things 
related to childrearing, Felicity emphasized the importance of her daughter's safety. It was imperative for her daughter to know that she is loved by those who surround and support her.

Faith witnessed black fathers criticize the need to support their children through child support. Although she could take care of her financial responsibilities, Felicity shared the sentiment of many women who felt it was unfair and disturbing that men could so easily get out of their childrearing responsibilities. In an emotional response, she argues:

"You know, its funny 'cause I see on Facebook a lot of guys whining about money - like they want a motherfucking breakdown of money, you know? And its funny to me, because my daughter's father only gives me $\$ 500$ every two weeks, and I told you how much money I make. I mean, my checks are clearing almost $\$ 4,000$ a week, so well my [translate], I have given him a motherfucking right back, you know what I mean? Like, so that's when I get offended. When I see that the guys feeling like ...So, in addition to having another job or taking care of his human being, and running her stuff and this child's schedule, and their health care, and now we have to be your secretary and tally everything up for you?" - Faith, 38, May 15, 2017

The Welfare Queen representation is by far the most overused stereotype specifically among black single mothers. The participants of this research were aware of this and actively presented themselves as women who did not fit in with this description of womanhood or motherhood. Women relied on combinations of their earned incomes, child support, and family assistance to provide for the household. As middle class professionals, they do not qualify for welfare benefits, but still understood that the welfare queen stereotype is often associated with single mothers. 
The four dominant stereotypes discussed above contribute to the representations of black women in the media. Black mothers, who are portrayed in as forms of these dominant stereotypes are portrayed in television programming, film, and news media. These representations, which can be both positive and negative, have real-life impacts on black women, and has influenced black women's expectations of family formation, gender roles, and class.

No One Wants to be a Single Mother

Black women are often conditioned to adopt nuclear family ideals. These ideals are ingrained through television, religion, within the home and society at large. In addition to black women's pressures to obtain a higher education and land a wellpaying job, we are also expected to marry and produce nuclear families. The high expectations for black women to simultaneously achieve these ideals can fall short. In the experiences of many women in this research, it is extremely difficult to be all of these things at once, and those who achieve these ideals are viewed as the anomaly. Single motherhood, therefore, is most often viewed as the "last result" and certainly not the preferred state of motherhood. Still, the gendered roles of women as wives and mothers in the media, religion, and society continue to influence black women's expectations.

Nuclear Family Ideals on TV

Claire Huxtable of The Cosby Show remains to be one of the most recognizable black woman-mother characters in TV history. She was a smart, beautiful, and charismatic career woman who endured the everyday joys and 
challenges of marriage and family life with children. Set in Brooklyn, NY, The Cosby Show, represented African American family desires and ideals, but Claire represented a woman who was capable to achieving it all. She became known for her poise, class, and style, and became a role model for many young women and girls who desired to be a successful businesswoman, mother, and wife. This fictional character has had significant impacts on black women, and continues to shape the ways black women plan for family.

"I wanted to be the Cosby family. I know that sounds bad, but I wanted to be the Huxtables" says Lisa, a single mother of two children under 5, "I just knew that I would have a husband first. My whole life was planned out. I was gonna get married at this age - children at this age - and I wanted a husband."

The Cosby Show became known for its near perfect characters. The children were generally well-behaved, and the family did not ever face major pitfalls. The parents were able to provide the family with unconditional love, desired material goods, and a large well-maintained home. There were never things out of place on the show. The Cosby Show showed the world that a black family could resemble a nuclear family structure, and do so flawlessly. Lisa agreed:

"It [ the Cosby family] was two loving professional parents who did the best to raise their children. They were middle class, and it was opposite of what America thought black people were. It was nice to see a lawyer and a doctor and their children. They're both raising them [the children]. They all have different needs. They were not perfect - one dropped out of college... like they [the family] dealt with every situation that every parent deals with, but I thought it was the ideal situation because they handle it together and may have 
had their differences but at the end of the day they still had a loving relationship." — Lisa, 38, September 23, 2016

Although many recognized the family to be unrealistically perfect, it continued to influence the way black women saw their future families. This fictional family was a personification of the family structure that had been preached about and encouraged by society for so long. For women in and aspiring to enter the middle class, The Cosby Show was often used as a marker of success. It served as a modern update to the 1950 s version of the nuclear family, permitting the mother to take action alongside her husband, work, and operate as a contributing member of society outside of the home. Inniss and Feagin's 1995 study on black American's reactions to The Cosby Family found that while a majority of black middle-class viewers enjoy the show, they deemed it fake or an unrealistic representation of the average black middle or upper-middle class family, mainly because they do not face any major tragedies, are not confronted by racism, and have a doctor-lawyer headed household (Inniss and Feagin 1995). Despite The Cosby Family being presented as "fantasy," many women in this research continued to desire this family structure and lifestyle, by using the Huxtables as a primary example.

Other factors have influenced black women's expectations for family structures, including their own families, the church, and society-at-large. The representation and acceptance of nuclear families as ideal has led many black women to desire this family structure, even when they found it difficult to attain or did not have examples of it as they grew up. For black women, the nuclear family is often presented as a way to attain upward mobility and status, except the black mother is still expected to work outside of the home. 
"I think I had hang ups in the past where I wanted the same thing I had growing up, where if, you know, when I came in the house from school, then my dad came home [to help]. My parents were married, and they had seven children. So, I wanted that for her [her daughter].”- Amira, September 28, 2017

Amira compared her current experiences as a single mother to her experiences as a child growing up in a two-parent household. She longed for her daughter to have a similar experience, but has come to accept that although things did not work out between herself and her daughter's father, it may have been the best overall decision for her daughter.

Nuclear family representations in religion

Religion also played a major role in women's desire to model the two-parent nuclear family structure. Several women referred to Christianity and the role it played in their upbringing as a key influence in their desire to marry.

Issa was married for 14 years before divorcing her husband. After her divorce, she understood herself to be unmarried. "I'm a Christian, okay. From all that I have learned in Christianity, you are either married or you're not. And I'm don't have a spouse, so that's just a personal preference for me."

Vera, who has a 5-year-old enrolled in a private Christian academy, relies on family principles in the Bible as a primary example of how family life should be.

“Christianity also plays the part, too. As I'm learning more about the Bible and understanding that God has an order for how we should be, and I'm seeing it now that I'm a single parent. It makes sense that you get married first, before 
having a child because of all of the responsibilities and the pressures of life, you know? It can be difficult at times, especially if you don't have the other parent." - Vera, 37, December 16, 2016

Yvette, another participant who places high emphasis on religion, has become more focused in the teachings of Christianity over the years. Yvette's daughter is now out of the home and has started college in another state. With less physical responsibility for her daughter, she is able to focus on her career and romantic relationships, in ways that she was unable to with a young child. Yvette is currently in a serious long-term relationship with a man. Recent religious teachings and understandings have encouraged her to find love and to most importantly put her partner and potential husband first:

"The Bible says that the women should (cater to) the husband, not the child. I have realized that that is our problem." - Yvette, October 16, 2017

Yvette's understanding of the Bible and the religious principles of Christianity directly contradicts the ways most other women (and herself until recently) in this research have approached single motherhood.

Entering Single Motherhood

Black middle class women's decisions to marry or not as they become mothers in the $21^{\text {st }}$ century is the result of several social and economic factors. Moynihan (1965) argued that the black family did not resemble the traditional nuclear family, yet several studies have shown that the nuclear family structure is in fact desired by black women. Black family sociologist Robert Staples argues that although the "traditional" family structure was important and the goal, black women did not enter marriage 
because the social and economic benefits available from marriage to eligible black men did not contribute to their social mobility (Staples 1985). A large majority of women in this research did not actively choose to become single mothers, unlike the "single mothers by choice" discussed earlier. Instead, they understood single motherhood as a position they found themselves in after wanting and fiercely searching for their version of "The Cosby Family". Growing up, these women were encouraged by their mothers (some who were also unmarried) and families to form a nuclear family structure. At the same time, they were expected to attend university and find a stable, well-paying career (Collins 1994a). Women who were raised in middle-class and upper-middle class households felt extreme pressures to maintain their lifestyles as adults. Balancing single motherhood intensified these pressures. Single motherhood was therefore mostly unplanned, as women worked to enter the middle class and reach their professional goals.

Single motherhood is a circumstance that women find themselves in as a result of varying mishaps. Women in this study represented a wide range of predicaments that created single mother households, but most did not willingly enter single motherhood. They experienced domestic abuse in their relationships, death, and infidelity. One relationship ended after child's father was incarcerated. Others were in long term relationships with men, or with the father of the child(ren), but were not married and still considered themselves single parents. A majority of them entered their pregnancies as they were engaged, married, or in long-term relationships with the fathers of their children. They did not plan to be single mothers, nor did they ever expect to ever become one. Throughout our conversations, my participants reflected on their expectations for family and motherhood pre-parenthood. Their expectations 
were all closely related, and drew upon the examples they witnessed in their parent's households while growing up and from the romantic (and unrealistic) examples of parenthood on shows like Cosby Show. Although their lives has not up to this point, resembled the family structures that they hoped for, the women did not dismiss their expectations as unrealistic or mythical. For these women, they understood their circumstance as it was, while not losing faith for the traditional family.

The majority of women in this research became single mothers because their relationships ended. In Promises I can keep: Why poor women put motherhood before marriage, Edin and Kefalas argue that low-income women actively seek to become mothers and prioritize motherhood over marriage (2005). For the women Edin and Kefalas' work, motherhood marked a major accomplishment that could be easily attained. The women in this research, however, had different views and goals towards motherhood. While they saw it as an accomplishment to be able to single parent successfully, most still preferred to have marriage if it circumstances had worked out. Break-ups are very common, and do not differ for black women. For the women in this study, they decided to not stay with the father of their children for reasons such as infidelity, lack of responsibility, and change of heart. When Felicity discovered that her long-term boyfriend, and father of her child cheated on her, she immediately kicked him out of the home she purchased and decided that single motherhood was the better option. Issa accepted single motherhood as she witnessed the father of her children abandon his responsibilities and place an egregious amount of work on her. Brina decided to remain a single mother after her daughter's father proposed.

"With my daughter," she says over coffee at a shop near Union Station, "her father had posed the "thing" of marriage but I knew that wasn't gonna work out so 
that was that. It was a done deal after that, you know. The untimely proposal deterred Brina from wanting marriage and even continuing a relationship.

Faith decided to have her child and live as a single mother after her partner, and the father of her child, became physically abusive. After years of being in a relationship, and with plans to marry, she gave it all up to move in with family as she prepared to have her child. Faith quickly realized that an abusive relationship was not what she wanted or the type of household she could ever bring a child into. In an instant, Faith chose to become a single mother, because raising a child on her own mattered more than succumbing to violence by a man. For Faith, and other women who experience domestic abuse and violence in the relationship, single motherhood is the smarter, most responsible decision they can make. Despite the negative associations society places with single mothers, their stories are so varied that plumping them into one category is a missed opportunity to understand this type of motherhood.

Three women in this study are widowed. Two of them lost their husbands and were catapulted into single motherhood when their children were very young. One mother became a widow just one year after marrying, and before she became pregnant with her child. The widows' perspective on single motherhood was very similar to the single mothers who had never been married, or who had divorced. They shared the same responsibilities and stereotypes. One mother mentioned that people would look at her and make assumptions based on her single mother status, without knowing that she was married to her child's father and only became a single mother when he was young. She recognized a slight difference in that she was married and did take the traditional route in motherhood, but it did not matter once she was left with the full responsibility. Outsiders, or society at large, would not see her as such, but just as 
another black single mother who did not make smart decisions and was now left alone to raise a child.

Fewer women in this study were in relationships, with the father of their children, or with other men, throughout the field research. Jamie was in a long-term relationship with the father of her 8-year-old child. Her boyfriend lived with her and her son, and to most, the family resembled a nuclear family. Jamie, because she was not married but desired to be married in the future, considered herself a single mother. She also recognized that she was the breadwinner of the household and was responsible for most things related to the child. Although she had another physical body, an adult and father, in the household, she still associated with single motherhood. This lifestyle was something that came up often in my conversations with other women. They would argue that marriage does not make a partnership. Zora experienced this first hand in her first marriage. She describes the lack of shared responsibilities as it related to her first son who had a physical disability, "My idea was that we share and the responsibility for him, but it just didn't turn out that way, so it kind of forced me in a position to have to take on the role as the sole provider for him and, back then, I wasn't receiving any financial support from him.”

While Jamie was not married, she was in two-parent household and also that she felt had uneven duties. The women who were not married, and not eager for marriage at the time, criticized the unfair treatment of women in the household. "We are supposed to go to work all day and come home to cook and clean? It's like having another kid in the house," says Marianne. Jamie, and others, preferred marriage and to not be single mothers, but only if the partnership was equal to close to it.

As an alternative to marriage, Black women have benefitted from entering cohabitating unions, as these units provide pleasure, companionship, and - in certain 
relationships - economic support. While marriage may offer these things, its permanency has proven to be too great of a risk for black middle class women's stability. Staples argued that black women "will not remain in a relationship where the services provided seem relatively meager compared with what the person knows about other" relationships (Staples 1985: 1005). Here, marriage is not recognized as a devalued institution. Instead, black middle class women marry at lower rates because of limited options of "marriageable" partners who can fulfill roles as economic providers (Parsons 1942; Staples 1985; Haller 1981). As a result, black middle class women support the institution of marriage, but do not marry if the union will not be beneficial to them. Patricia Hill Collins argues:

Black daughters are raised to expect to work, to strive for an education so they can support themselves, and to anticipate carrying heavy responsibilities in their families and communities because their skills are essential for their own survival as well as for the survival of those for whom they will eventually be responsible (Collins 1987: 7).

Therefore, from an early age, black women are conditioned to live in matrifocal family structures, but due to societal pressures and personal goals, continue to desire some form of the nuclear family. For example, Renee, entered single motherhood with the expectation that her family would continue to evolve, and that she would marry her child's father. In an interview, she reflected on her experience growing up:

"My mom and my dad were together until I was about 11, and then my dad disappeared for 18 years. Because of that, I have both perspectives in terms of what like to have dad present versus the mom having to do it all alone. My mom is my superhero.” - Renee, 38, November 14, 2017 
Renee expresses discontent with her daughter, Grace, also experiencing similar childhoods. Renee and Grace's father ended a long-term relationship, causing Renee to become a single mother and Grace to become a child, like her mother, with a father outside of the home. Although Renee understands that the decision was best for herself and her daughter, due to the irreconcilable differences between herself and Grace's dad, she wishes that the story would have ended differently to resemble her expectations for family and motherhood.

Only two women in this research decided to have children with the full understanding of entering a life of single motherhood - Gabrielle, an adoptive single mother and Georgia. Georgia, who is business owner, and graduate student, explained that she would always be a single mother because the children are always her responsibility, solely. "Even when I'm married, I will still be a single mom. I learned that with my own mother, because, even if someone comes into the picture, they can always leave. The kids are mine, and I'm okay with that." Georgia is in a long-term relationship with a woman, and plans to get married soon. Although she recognizes her children's father, and her partner, as positive role models in the children's lives, she only sees herself as the parent because of the responsibility she has for them. Like her own mother, Georgia says that she learned that single parenthood is to be expected, as women take on most of the work.

\section{Marriage}

Overall, marriage was overwhelmingly the goal for most of the participants included in this study. These women aspired for marriage despite issues of dating and relationships, in general, among the broader demographic of black women. Statistics show that women across demographics are getting married later in life, but black 
women overall have the lowest rates of marriage and marriage success. Scholars have cited several reasons for black women's disparities in dating and eventually marriage. A number of theories including higher mortality rates, high rates of incarceration, higher education level, and a sex-ratio imbalance are all evidenced to have influenced the low black marriage rates in the United States (Cherlin 1998, Dixon 2009, Charleston 2014). As a result of these disparities, Black women have the lowest mate availability pool (Holland 2009), and thus, may decide to start a family prior to marriage or without ever expecting marriage.

Black women are also disadvantaged in mate availability because they prefer to date and marry men in their own race (Catanzarite and Ortiz 2002; A. E. O. King and Allen 2007). Studies have found that both African American men and women highly value the institution of marriage as an act of commitment and love (Curran, Utley, Muraco, Curran, et al. 2016; Staples 1985), but several factors, including mate availability prevent them from marrying. Studies have revealed that African American women overwhelmingly prefer African American men as mates, whereas African American men prefer to date women outside of their race. In fact, Staples reported that black men enter interracial marriages at a rate twice as high as black women (Staples 1985). This creates an imbalance of available marriage partners for African American women, aside from other factors such as requiring similar class backgrounds, education, and employment. Recently, reporters and scholars have addressed this imbalance in online dating. Dating apps such as OkCupid, Tinder, and Match.com, have revealed lower success rates for black users. In 2014, OKCupid cofounder, Christian Rudd, reported that user data showed that "most men on the site rated black women as less attractive than women of other races" (Brown 2018). 
Online, the negative stereotypes of black women extend to the internet, making it even more difficult for black women to date and enter consistent long-term relationships. The challenges related to dating postpones or disables women from realistically approaching marriage, causing middle class women especially to move forward with motherhood, regardless of marital status. Although "for many African Americans, success is achieved through marriage" (Dixon 2009), which results in fewer poor families, black women remain the least likely group to marry and the most likely to have children.

Research shows that marriage benefits African Americans economically, socially, and psychologically, but Marsh found that a rapidly growing portion of the black middle class consists of never-married singles (Marsh, Darity, Cohen, Casper, et al. 2007). One theory, as argued by Robert Staples, is that black women can receive all the benefits (companionship, pleasure, economic and emotional support, etc.) of marriage through cohabitating unions so they opt out of/delay marriage because the benefits outweigh the costs (Staples 1985). Here, the women I interviewed desired marriage but only if the union would be fair and equal. They were not interested in marrying for "the sake of the children," or to fit an ideal black middle class representation. Instead, they acknowledged that single motherhood would be tough physically, emotionally, and financially, but they would prefer it over committing themselves to someone who would not put in equal effort or would make motherhood more difficult.

Roles and Responsibilities

The women discussed their responsibilities as mothers and as single parents. Those with younger children expressed their exhaustion, tight schedules, and lack of 
interaction with other adults. The concept of being "on duty" prevailed throughout the research, as the women felt that their children required their constant presence and attention because they were the only parent available. Single motherhood required the women to commit their time and to be physically available. Instead of focusing on the financial obligations involved in raising children, the women often focused on their time. Several of them recognized their time as the most precious and valuable asset in childrearing.

Women who did not receive sufficient physical support from their children's father found this to be extremely problematic for their children and themselves. As black middle class single mothers, the women in this study were not overly concerned about having enough money to pay the bills or to take care of the family's necessities. They were, however, concerned about the physical presence of fathers in their children's lives. A large majority of the women interviewed maintained some level of communication with the fathers and were able to have a working co-parenting relationship. Others expressed frustration as they had to provide for the child(ren) financially and consistently be present in the child's lives.

Although these women self-identified as single mothers, most of them felt they were not truly alone in raising their children. Lisa began to rely on me for frequent babysitting. She did not have many family members in the area and could not depend on her children's dad to assist when she needed to work late nights or weekends. Lisa, and a few of the other mothers in this study, mimicked the responses of women in Carol Stack's All Our Kin, who were low-income black women in Chicago (1999). Fictive kin and community relationships had long been categorized as a survival strategy for African Americans. If mothers, and children especially, need additional assistance, the community often step in to help. These women relied on relatives and 
fictive kin networks to handle the responsibilities of motherhood. Parenthood is no easy feat and one person, man or woman would struggle immensely by attempting to handle everything without any assistance from others. For mothers, regardless of financial stability, a little help is always needed.

Over a light dinner at a restaurant not far from her home, Issa expressed her frustrations with her teenage child's father. The father had been inconsistent over the years which created tensions in the relationship. Issa held a managerial position within a telecommunications company in Maryland. She earned well over the median income for her area, and purchased a brand new luxury townhome, complete with an elevator, in a popular Maryland suburb. Issa was not concerned with finances when it came to her children, but she did acknowledge the rage she experienced from not being able to provide her child with two consistent parents.

“This is how I feel about both of my daughter's father - you see, I am a daddy's girl. Both of my parents were never married, but my father was very present up until he went to jail. My father would come and pick me up from school every day and we would go have lunch, all of those little things. Nothing is more important to a little girl than her dad. The finances? That's on me. But spending time with them... If you give me no money, that's the most important thing to them. They don't care about your money."- Issa, March 7, 2017

Issa felt that it was important for her girls to have their father present even if he was not in the home. She was hurt and frustrated when her daughter's father was inconsistent and did not set a good example. To make up for his absence, Issa relied on other men in her network, including male relatives to assist in providing her 
daughters acceptable examples of men and man/woman relationships. She reflected on her childhood and the positive feelings she had about her father and wanted that same experience for her daughters.

On the other side, some women, especially those with teenage sons, emphasized the importance of male-figures for different reasons. As one mother, Cassandra, summed up during our conversation, "I am a woman. It takes a man to teach a boy how to be a man, and I can't do that." They wanted their sons to have successful men to look up to and potentially model themselves off of. These men, sometimes fathers and sometimes not, stepped in to provide guidance as needed and examples that the women felt that they could not provide. Single motherhood was difficult for mothers of both girls and boys for many reasons, but it was stated that those with sons required extra attention. A physical and consistent presence in the children's lives was important to the mothers for the overall betterment of the children. It also allowed the mother to have support in areas of childrearing where she felt unqualified.

The physical presence combined with financial assistance provided a benefit to the children and the mother. Single mothers looked forward to taking a break when possible, and child support and consistent child care would assist with that. Without these securities, the women found that they would have to work more in their professions or side gigs, and also work harder to find childcare. Additionally, the women maintained that they wanted their children to have strong, solid relationships with both parents - regardless of their parent's marital status.

Lisa's financial stability and personal time were taken for granted by her children's dad. She often worked on weekends or late evenings, and because of the father's absence, she was forced to hire a babysitter or risk losing her job. Although 
the kids father lived nearby and was technically available, he chose to not help out in the everyday caregiving as needed. This inconvenience left Lisa constantly in search of on-call babysitters to assist her whenever she were running late or in a pinch. With two young children, aged 3 and 4 at the time of this research, she spent large amounts on childcare. Additionally, because of her own absence — due to working to provide for the children — she inherited an immense guilt for leaving her children for long periods. Sometimes, Lisa worked 7 days straight for over 10 hours, as mandated by her employer. She enjoyed the financial benefits of the work but resented the time she missed with her children. Lisa would have preferred for her children to spend time with their father on weekends instead of a sitter.

Women like Lisa have to rely on family and fictive kin networks to assist in child rearing. Of the 30 women participants of this research, 23 were natives to the Washington, DC area. Many of these women had families and friend networks easily accessible to them. In some instances, the grandmothers retired and moved into their daughter's homes in order to provide full-time assistance. As professional working mothers, these networks were important to the successful upbringing of the children. When work related duties required travel or late evenings, many women looked to their extended networks for help. As this research progressed, I found myself a designated member of the extended networks of five of the women. When available, I assisted in childcare and pick-ups and drop-offs, when no one else was available to help. For these women, additional reliable members of such networks, better known as "the village" were often welcome regardless of the women's socioeconomic status. There is a saying quite popular in the black community: "it takes a village to raise a child." 
Felicity was extremely dependent on this village, which she called "The Team" in caring for her four-year-old daughter, Jade. As a symbol of her appreciation, she shared that she planned to make t-shirts that read "Jade's Team" for each of the people in her support system who have helped make single motherhood manageable and give these shirts out as a Christmas gifts. She was aware of the help she received and visibly appreciative of the support. Felicity's high income did not exclude her from needing assistance. Black single mothers across economic statuses depend on networks of people in the community and within their families to care for the children.

Single mothers also formed networks amongst themselves to rely on one another to assist in the children's upbringing. In this study, three mothers shared that they lived with other single mothers as a method of group support and shared responsibility. As homeowners, these women allowed other single mothers, friends with children, to move into their homes. Together, the mothers were able to act as a blended family with the mothers taking turns with domestic duties, being available to "babysit" while the other mother went out, and sharing the cost of the household. Lisa's brand new three-floor single family home far exceeded the amount of space she and her two young children actually needed. To make additional income and to support a fellow mother in need, she rented out her basement to a friend and former co-worker, a single mother with three children, including a newborn. Together these women alternated their duties for a fixed period, which assisted them both in the burdens of being "on-duty" at all times as single mother. I was surprised to learn that this practice was not uncommon among single mothers. I was reminded of my own childhood, when my mother allowed friends to move in with us in our basement. These friends and extended family members were able to help my mother with my 
brother and I as needed, and most importantly, help with payments towards the mortgage or other bills. Finding alternative ways to bring in additional income and securing on-call babysitters is important and necessary for single mothers, particularly those with young children.

Felicity recently allowed a coworker to move into her home as she worked to save for a new home. While this coworker did not have children, the reasonable rent Felicity charged benefitted both women. Several of the women in this research used their homes and additional properties as a source of income. Whether they allowed friends or family to move for low rental fees or rented out entire properties, they understood that their home ownership in high priced DC and Southern Maryland could provide them with extra money.

Lastly, the mothers in the research depended heavily on their parents to assist with children. Grandparents who lived nearby were often available to assist in pickups, aftercare, weekend babysitting, and vacations. When Hope fell ill, her mother moved in with her for the second time. Her mother also moved in when the twins were newborns to provide full-time assistance and peace of mind for her daughter. It is important to note that these single middle class mothers came from diverse, single mother and two-parent households themselves, but were mostly raised in the middle class. As their parents aged as senior citizens in the middle class, they were available retirees who could physically and financially assist with child-rearing. These women are fortunate in that their own mothers are not continuing to work and have the free-time to lend a helping hand where capable. Any extra help was appreciated by the mothers. Help by those who were trusted and close to the family was preferred, and at times, the only help what was accepted. 
The single working professional mothers presented in this research shared similar levels of exhaustion to welfare-dependent mothers who worked low-paying jobs outside of the home. Both groups of women worked, often 8 or more hours a day, and returned home to the responsibilities of motherhood. When asked if she ever gets a break, Zora, mother of two boys who I spoke with, responded "No, I am always tired." Zora's son is physically disabled and requires $24 / 7$ attention. Zora and other moms took on the full responsibilities of the household and, at times, refused help from others due to lack of trust. They were extremely protective of their children and did not allow others outside of close family members to step in to assist. "I just don't trust anyone else with her," explains Vera as she discusses the challenges of motherhood and her new work schedule. Vera recently returned to college to obtain her Master's degree in Finance. In addition to school, she works full-time and is raising her 5-year old daughter. In order to complete all of the tasks at hand, she cares for her daughter immediately after work and is only able to complete her schoolwork after midnight. She only accepts assistance from close family families who she trusts, and this assistance is rare during the weekdays. She explained that most nights, she does not get to sleep until about 3am, before waking up at $6 \mathrm{am}$ for the next day. Vera is exhausted.

As single mothers, the challenges related to motherhood — including exhaustion - cannot prevent them from achieving their professional goals. Without the option of marriage or the nuclear family structure, full time work is a requirement. These women have established schedules and systems in place to manage their responsibilities and help them achieve their goals. 
The Working Mother

Black women are the most educated group of people in the United States. According to a recent study by the National Center for Education Statistics, black women have a higher percentage of college degrees (associates and bachelors) than any other group in the US (2016). Formal education is by far the most important factor in obtaining and maintaining black middle class and upper middle-class status. Black women have benefitted from education as a way to gain access to their desired careers and to maintain their independence. As more black women earn advanced degrees, the black middle class continues to expand, while marriage and motherhood among this group is delayed. Black women who want to utilize their education in their career of choice while also having a family, must make difficult, conflicting decisions in their strategies to work and parent. Ultimately, despite their educational attainment, Black women continue to have the lowest mate availability pool (black men have high incarceration rates, less college degrees, and enter interracial marriages at greater rates than black women) (Holland 2009), and may decide to start a family without a husband. To compensate, they use their financial resources (for services such as childcare) and extended kin and community networks to aid in childrearing (Higginbotham and Weber 1992; Jackson 1992; Christopher 2012; Barnes 2016).

Black women college graduates are fully expected to seek careers and dedicate their time and efforts to work post-graduation. As symbols of success, black women face societal pressures from their families, the black community, and the greater community to use their degrees in meaningful professions (Barnes 2016). Black women, with advanced degrees especially, are encouraged to not "waste" their education and success as a mere wife or stay-at-home mother. Unlike white middle 
class women, work within the home and hands-on childrearing has not been allowed to be priority for black women. Instead, black women across socioeconomics statuses are socialized that work-family conflict is normal and to be expected (Ammons et al. 2017). As black women continue to make strides in the professional arena, they are further removed from the possibility of staying at home. For black single mothers, this work-family conflict becomes a challenge to maximize income and time spent with family using creative and, often exhausting, tactics.

In Sharon Harley's Sister Circle: Black Women and Work, contributors explore black women and work throughout history, including the choices and decisions black women make to enter executive and professional positions (Harley 2002). At the end of the twentieth century, the majority of jobs open to black women "were limited in mobility, earnings, and benefits (such as health plans and retirement insurance)" (Woody 1992). While black women still face challenges regarding equal pay and benefits in the workplace, their educational attainment and experience have placed them in better positions than before. All of the women in my research worked in corporate or white-collar environments. Few of them were in positions of authority, and recognized their responsibilities to their employees in addition to their responsibilities at home.

The high levels of education among Black women have led to high levels of employment, and preferred career options. Faith, a mother of one 11-year-old daughter, recently became a manager at a popular national news station after many years of working towards this career goal. During a lunch-hour interview that took place at a sandwich shop near her office, Faith explained, "[This job] doubled my salary and made me a manager. They basically made me an offer that I couldn't 
refuse." Faith was introduced to television news programming during an undergraduate internship and at the time, decided she would become a television personality.

"I went to get my Masters degree in television still with the idea of being on air, and I got down there [to her university] and one of our professors, a real good, gracious, old white guy... taught me that we needed to learn the technical side of everything if we wanted to be on air because we needed to know all the components that it took to make something come together. So that's how I fell in love with the technical side. "

Since then, she has worked in several television and film offices across the city. As a graduate student completing her internship requirements, Faith recalled working harsh 100-hour work weeks without pay. She accepted the long hours as a necessary step to build experience in order to get where she is today. "Before, in my old job, I was reporting to a bunch of white dogs that didn't even have my resume or my skillset. They were like 12!," she says sarcastically. In her previous position, Faith's experience and expertise was undermined. After several years with the company, she was forced to work for white men who were significantly younger and less experienced. She was offered a new position with her current company, which offered her a $\$ 150,000$ annual salary.

Black women have employed various strategies to negotiate motherhood, marriage, and careers. Strategic mothering is a framework developed by cultural anthropologist, Riché J. Daniel Barnes, that explores the many tactics black mothers use to redefine the responsibilities of professional careers to fit the needs of their 
families and communities (Barnes 2016). Most of the women of Barnes' research, Raising the Race: Black Career Women Redefine Marriage, Motherhood, and Community were married professional women, but their trajectory to professional success resembled women, like Faith, presented in this research. The doctors, lawyers, and other professional women in Barnes' study recognize these better positions as affording them the opportunity to balance their work-family life. In this research, single mothers engaged in strategic mothering my seeking opportunities that provided them with financial stability, flexibility, and upward mobility. Several women expressed the need for their careers to work with their family life. Amira, a full-time producer and editor and mother of one teenager, for instance, worked from $11 \mathrm{am}$ $7 \mathrm{pm}$ at the television station because it worked better with her parental responsibilities. With these work hours, she is able to attend morning meetings and programs at her daughters school, take her to school, and run other errands before work. Other mothers appreciated their jobs in the government because of the ability to telework at least one day a week. On these days, the women scheduled tasks like doctors appointments or school meetings so they could make the most of their time.

Barnes recognizes the contradictions to strategic mothering to be, what she refers to as the neo-politics of respectability and constrained choice. The neo-politics of respectability is the contemporary reworking of the politics of respectability, by which black women of the early twentieth-century responded to negative stereotypes and conceptions that deemed black women as unworthy of protection (Barnes 2016). To combat these misconceptions, black women adopted a framework to convince others of their respectability, just as today's black women continue to combat negative stereotypes of black women as unmarriageable and bad parents (Barnes 2016). 
Constrained choice exists for black middle class women as a result of their raced and classed identities, which allows them to choose to pursue social and economic advantages (such as housing choices, leisure choices, educational choices, etc.) or to pursue them selectively (Barnes 2016). Choices are constrained by economic and political structures and tend to impact the opportunities available to black women, but "give the appearance of having been motivated by the actor's free rational will" (Barnes 2016, 14). For example, Jamie, a mother of one middle-school aged son, expressed serious distaste for her neighborhood and home. She would prefer to live in a more affluent area that reflects her income, but because of her responsibilities as a single mother, she is unable to afford a better neighborhood, close to work with her salary. She has enrolled her son in extra-curricular activities in more affluent communities, but is embarrassed by her options for schooling and neighborhood for her family. In Jamie's situation, she may speak openly her neighborhood as a "preference" because of its proximity to work, but if given a larger salary and more support from her son's father, she would quickly decide to move to a more acceptable and desirable neighborhood which reflects her middle class status as she truly prefers. In other words, with constrained choices, black women make the best out of the situations and opportunities they have access to. Jamie compensates for her constrained options in affordable neighborhoods by purposefully exposing her son to children in activities across town. The women in Barnes' research have made the constrained choice to make their roles as mothers and wives first priorities (to ensure the well-being of the entire family unit), just as the black single women in my research may have made the constrained choice to become mothers without the support of a husband (to ensure that their goals of motherhood were fulfilled). 
With the high costs of living in the Washington, DC area, it is imperative that one work either a professional job and/or long hours in order to generate the income to maintain a middle-class lifestyle. Unlike the relatively low black median income of $\$ 35,600$ in Barnes' study on Atlanta's Fulton County, the 2014 median income in one of my research areas, predominately black Prince George's County, MD was much higher at $\$ 73,856$ (which is more than double Fulton's average) (Census 2015) and in the Washington, DC metro area overall, the black median income $\$ 64,896$. These average incomes have continued to rise over the years. For black single mothers, they have to navigate working in important government and corporate fields and tending to their children. The black middle class single mothers of focus in my work have developed a way to meet the priorities of both and earn approximately the high median income for the area. Each woman in this research project worked, and was employed full-time at the time the research was conducted. The research participants represented various professional fields, including television and film, federal/local government agencies, education, real estate and housing, and communications. In addition to their full-time careers, few of the women also managed independent entrepreneurial ventures which included, income properties, consulting firms, and websites.

The careers that the women had mostly offered the work hours and flexibility required in order to single parent. They each worked standard hours, such as 9am 5pm, or $8 \mathrm{am}-4 \mathrm{pm}$, which allowed the women to take care of their children. Many of the jobs offered start and end times that worked best for the women and their commutes. Few women worked late hours in their regular full-time jobs, past $6 \mathrm{pm}$. None of the women worked overnight jobs, as this would be extremely difficult for their home responsibilities. With the exception of Gabrielle, none of the women were 
required to travel often in their positions. Gabrielle, however, traveled once a week to her company's headquarters in New England. She traveled each week for one day, but was able to work from home, or work remotely for the rest of the week. Gabrielle is a new adoptive mother of an infant girl, and this schedule worked well for her, allowing her to spend time with her daughter and work. Other jobs, like Deidre's and Patti's, offered flexibility in other ways such as allowing children to come to the office. During the holidays, when school was not in session, but offices had not yet taken breaks, their offices allowed children to come to work, dedicating a conference area or other common space for children of employees. Two of the women in this research, Georgia and Carmen, were full-time graduate students. Their flexible class and writing schedules seemed ideal for single motherhood. Both women expressed fatigue in graduate school responsibilities and motherhood, but acknowledged that their student status allowed them to be present for their children.

I would argue that the occupations of women of this research were considered acceptable positions for their circumstances. The careers offered flexibility, stable incomes, and opportunities for advancement. Several of the women had been in their companies, or fields, for several years and had climbed the career ladder to settle in their current positions. Many of them continued to seek opportunities that would increase their annual salary and place them in positions of leaderships. As single parents, the women required careers that offered basic benefits like healthcare, sick and vacation leave, and retirement plans. None of the women in this research held positions that did not guarantee payouts on a consistent basis (such as operating exclusively as a real estate agent). Although no work is guaranteed, I would consider all of the careers presented in this research to be safe, stable careers. Here, the women 
were focused on earnings as consistent pay with gradual increases was necessary to take care of their households.

There are many challenges for black women and work, and specifically for black single mothers with young children. Black women are faced with issues related to equal pay, career advancement, and stress. As professional working women, they are also expected to meet the demands of "ideal mothers." Oddenwaller recognized the ideal mother as a women who practices "intensive mothering" (Hays, 1996), of which the highest standard was the stay-at-home mother . The stay-at-home mother characteristic does not apply, however, to single mothers of women of color. Instead, single mothers and women of color must justify and reframe their decisions to become stay-at-home mothers to the greater society (Wall 2013). As highly educated single mothers and/or women of color, the women fall into the supermom stereotype, "which celebrates working mothers ability to achieve family, work, and life success (Oddenwaller et al. 2017). The supermom stereotype, although presented positively, ignores the high levels of stress associated with the overworking of supermoms.

"They are expected to shift effortlessly from hardworking and determined career women to the patient, involved, and family-oriented mother - without sacrificing time or quality in wither domain (Dillwat and Pare 2008). In reality, the supermom profile represents a trade off for working mothers who despite having more competence than stay-at-home mothers, are perceived as less committed and effective than stay-at-home mothers and less likable on the job than men and working fathers (Cuddy et al., 2004; Gorman \& Fritzsche, 2002; Okimoto \& Heilman, 2012). Adjacent to the ideal mother and supermom profiles, are the "mompreneurs" (Ekinsmyth, 2014), SAHMs who coordinate work (e.g., online businesses, blogs) 
around caregiving priorities and, as a result, acquire nontraditional characteristics such as executives of the home, balancing work, family, and life, and work focused. Although these stereotypes may represent feminist progress, the blurred lines between mothering and work continue to elevate SAHMs' social value and disparage WMs. This is especially true of those who work outside the home for career advancement and personal fulfillment (versus financial necessity).

Several women in this research identified with the Strong Black Woman depiction, as "supermoms" who rarely display their vulnerabilities and speak and behave as they were in control of all decisions made in their lives regarding work and family. Sharde' Davis' developing theoretical framework, The Strong Black Woman Collective (SBWC) advances the idea that black women assert their strength and fortitude through communal communication practices (Davis 2000). This was witnessed throughout my field research, but was most noticeable during the focus group. These women, who shared similar experiences of single motherhood, spoke very candidly and firmly about their experiences. They called out their primary responsibilities, and did not hesitate to place the blame on their children's fathers for their shortcomings. In declaring that they were the primary caregivers, and the parent who put in the most work, they asserted their importance to their children, and their self-awareness of strength and responsibility among themselves.

Finally, in the black community, the need to be successful, educated career women role models is often more important than being full-time mothers and wives in "raising the race" (Barnes 2018). The pressures of black middle class respectability fall on the women, who then internalize their responsibilities to their families and community. The expectation of the Strong Black Woman demands constant attention 
and strategic mothering by black middle class women. The expectation for black middle class women to serve as role models is particularly important because studies have shown that blacks are less likely to retain their middle and upper-middle class status across generations. Black middle class single mothers must acknowledge each of these expectations and challenges, and decide whether or not to be everything to everyone at once; mother, professional, and community role model.

The obligations of work and family life results in sacrifices and adjustments in single mother households. Women, across racial and socioeconomic divides, face income inequality in the workplace. Women, on average, make 20 percent less than men in the United States, are less likely to advance in their careers. For Black women, the gender pay gap is even larger, with Black women earning an average of $\$ 0.69$ to every dollar for white men in Maryland, and just $\$ 0.54$ to white men in Washington, DC (National Partnership for Women and Families 2018). Research has proven that childbearing also negatively impacts women's wages (sources). This negative effect, called the "motherhood penalty" which includes direct pay, and a change in employment behavior from supervisors that does not benefit the working mother (Budig and England 2001, Lu et al. 2017). The "prime" working age for women is between 25 - 35 (Shah 2014, Miller 2017). Women who have children within that 10 year span are at a greater risk of a widened pay gap, and single mothers have the largest penalties (Shah 2014).

Single mothers, like women across the board, are faced with challenges in the workplace as they decide to start a family. Amira experienced first-hand the motherhood penalty in her office. After working for some time and eventually sharing general information about her home life, Amira, began to realize that certain 
assignments were not given to her because it was known among her supervisors and other employees that she was a single mother. "I had to say, you know, I am a single mom, but what was I supposed to do? It [the schedule] was hard at first, but ended up being the best thing later on" she explained, when discussing her the challenges of working $11 \mathrm{am}-7 \mathrm{pm}$. Amira's colleagues assumed that she would be unavailable to participate in certain activities or produce specific projects because of her responsibilities at home. The unfair, and illegal actions, she recognized, jeopardized her career advancement. Other women work colleagues, with children and those with partners at home, did not face the same judgment based on their home responsibilities. Black single mothers seeking career advancement must have plans in place to navigate the workplace. From hiring babysitters, to relying on family and friend networks for child care, single mothers must make plans for their children's wellbeing while working. At times, these plans must be publicly disclosed in the workplace, in order to show that they are willing and able to take on certain work responsibilities, including working late hours or traveling at the company's request.

Stress is an underlining theme present in research on black women and work (Barnes 2016). Successful, and earned employment in fast-paced careers, as doctors, lawyers, and professional executives, is often an extreme source of both happiness and stress among women. The role of mother and/or wife/partner in addition to the role of career woman, could lead to what is referred to as "role strain." Women are thus required to juggle multiple roles, which have inordinate demands (Jackson 1992), and be equally present in both areas of their lives: home and work. In Barnes' research, the married women of focus made decisions to stay home to help alleviate stress which came from structural, familial, and community pressures (Barnes 
2016).Unlike the women of my research, these women had consistent financial backing from a partner or spouse who was present in the home. Fortunately, these women were able to develop strategies to create less stressful environments.

Recently, several reports have made news headlines detailing the harmful effects of stress on black women and childbearing. A May 2016 Essence magazine article, highlights black women's stress, and discusses the cycle stress causing fibroids issues and fibroids causing stress at home and work (Gray 2016). Black women are three times more likely to develop fibroids (Gray 2016). In December 2017, a NPR story on the staggering rates of postpartum death among black women reignited a national conversation about black women racism and stress and its relation to childbearing in the United States (Martin and Montague 2017). It is important to consider how stress management and the ability to lessen a workload or stop working all together is a privilege for these black married women, that is likely unavailable to black single mothers. Even when or if black single mothers take an extended break from work, it is clear that as primary earners they must return to work eventually if they want to maintain their middle class status, unless of course, other exceptional events have placed them in privileged positions of not requiring full time jobs.

In Daniel-Barnes study, one of her research participants, a marketing executive, stated, "I think Black women make adjustments to their professional goals before they get high enough for there to be an impact. I think it is good for my daughters to see me working and to see me being involved in our family financially..." (Barnes 2016). Black career women, as exhibited here, recognize their earned and privileged professional positions as something that needs to be shared as positive examples for their children and the black community. As single mothers, the 
women of my research were constantly displaying their "get-ahead" attitudes to their children. Children could easily recognize the busy schedules of their single, working mothers, because they were the sole parent in the home. In my experience, doing well in school and staying out of my mothers way was the biggest way my brother and I could support my mother. Because we watched her work long hours, and weekends, it seemed appropriate to at least do as we were told and succeed in school, to not add additional burdens. This became much clearer to me as I grew older, and started to take on additional responsibilities for my brother. My mother's early work schedule, for instance, prevented her from taking us to school in the mornings. As city children, I was responsible for getting myself and brother, who was in Pre-K, on the public metro bus and to school each morning. Growing up in a single mother household, I was always aware of my mother's professional responsibilities and its impact on the household. Throughout the research, the women were open about their duties at work and school. They shared these duties with their children so that they could step up to assist or adjust their schedules as needed. It seemed that it is would be virtually impossible to hide work and professional goals from children in single mother households.

Black women have historically had a long history with work outside of the home. Black women have had to balance work and family roles for generations, and continued to do so by entering creative and flexible professional fields. At least six mothers in this research study considered themselves entrepreneurs. Each of them had regular, full-time positions, but in addition to those jobs, they found time to tend to their personal and entrepreneurial interests. These women practiced entrepreneurship for different reasons, including additional income and personal fulfillment. 
Entrepreneurship allowed the women to be in control, and to apply their skills in various ways. A majority (about $75 \%$ ) of the women who were involved in entrepreneurial ventures had children who were at minimum, teenagers. As their children grew older and became more self-sufficient, these mothers were able to find additional time to start and/or grow their businesses. Here, the "mompreneurs" have not necessarily coordinated their work around caregiving needs, because their children were older. Instead, they coordinated their entrepreneurial work to fit within their already busy schedules, including their full-time jobs and family responsibilities. During the holidays and for special occasions, Wanda operates a small bakery and catering business outside of her home. Her products are popular among her professional colleagues, family, and friends. While she admits that she does not want to run her business as a full-time job because of its lack of benefits and the incredible amount of work it requires, she continues to bake because she enjoys doing it. She sells her products because her numerous requests demanded that she at least make a profit for her time. Wanda's daughters, both in their teenage years, are unofficial employees of the business. Wanda is able to pay them for their help in prepping the kitchen, assisting the process, and packaging and sorting the final products. She uses the in-home work experience to teach her daughters valuable skills in baking, money management, and entrepreneurship. Additionally, she is able to use this time to bond with her daughters over their common interests.

Two of the women, Zora and Cassandra, operated businesses that were specifically targeted to single mothers and families. The goals in their businesses were strikingly similar, and stemmed from online platforms. Zora is a published author, who writes about finding balance in managing life as a single mother. She uses her 
platform to attract women in the Washington metropolitan area to come together in fellowship, to discuss their worries, joys, and challenges related to single motherhood. Zora is committed to encouraging single mothers to find their own personal time to do things that bring them joy, including finding better suited careers, seeking higher education, and just having fun. Zora also manages a non-profit charity organization, which provides support to families with children who have certain diseases. Cassandra, like Zora, also uses writing to encourage other single mothers, but does so on an online platform. She is the primary contributor to a personal blog that has garnished over 3,000 active followers. She openly writes about dating, co-parenting, and divorce. While I do not believe Cassandra generates an income from the blog, I recognized it as an entrepreneurial venture because it has led to her work being featured in other publications, and participating in speaking engagements.

Tyra recently separated from her husband of 10 years. To generate additional income, she opened a car service company alongside a friend and business partner. The company owns several cars, including a Bentley that was proudly displayed on Facebook. During the individual interview, this mother stressed the importance of having money coming in from various places. She managed to designate time to this "new venture" as she called it, in addition to her full-time job. She also owns vending machines.

The careers and professions available to black women in the DC metro area have provided them with competitive salaries, but some black single mothers take on these additional side gigs to earn extra cash and to provide a more stable base for their household. The middle class was once a class of people with savings to support their lifestyles and any emergencies that may appear. However with the cost of living rising 
and wages staying more or less the same, the middle class is unable to keep up. Young professionals, particularly those in the millennial generation are not purchasing homes or having children, despite desiring home ownership and wanting to start families, because they struggle to enter and maintain the middle class lifestyles promised through hard work and education (Coughline 2018). The Great Recession of the late 2000s was nearly a decade ago, but it has long lasting impacts on the millennial generation, as we entered college and accepted our first jobs that offered salaries far less than living wages in most instances.

Black single women in the middle class also experience the challenges of middle class life. Despite earning college degrees and gaining advanced technical skills at higher rates than men, the National Women's Law Center reports that black women makeup $1 / 3$ of the low-wage jobs available and will grow the most over the next decade (National Women's Law Center 2016, Connley 2018). Black single women who are also mothers must work hard to receive promotions in their fields that position them comfortably in the middle class. As these women enter or remain in the middle class, they are unable to apply for any financial assistance from the state or federal government, although, at times they could use additional help. For instance, Hope, a single mother of twins, was recently diagnosed with cancer. Shortly after her diagnosis, she underwent a costly surgery to remove the cancer, and was out of work for several weeks. As the sole provider of her children, with no financial help and little contact from the children's father, her sudden illness took a toll of her family. As a single middle class mother, Hope is unable to receive financial assistance because her salary is too high.

As a result of unforeseen circumstances like Hope's, and other costly including providing for their children into adulthood, black single mothers find 
themselves in a tough bind financially. Although their salaries must support themselves and the children, aid is often based on income and does not take into account women who make, for example $\$ 65,000$ annually but also owns a home with three children. This woman, despite a decent earned wage, may feel less apart of the middle class because her expenses supersede her savings and comfort level. Black middle class single mothers do not want to have to depend on public assistance, but the high costs of living and increasing expenses for the household make them feel like they are drowning in their debts and unable to maintain the middle class status they worked so hard to reach and maintain.

As middle-class and/or high earning professionals, these women are often unable to benefit from any or most forms of public assistance. Welfare, which was introduced in The Social Security At of 1935 was created for dependent (white) mother and children, as well as senior citizens, individuals with physical disabilities, and workers. Over the years, it has become a negative characteristic associated with black never married low-income women. For decades, low-income black women who rely on welfare to provide financial aid to them to support themselves and their children have been criticized for taking advantage of the system. In an effort to thwart welfare aid dependency, the federal government created a series of rules and regulations targeted at black women. Women were required to be single, unmarried and not live with their partners (particular other male adults). This system forced women to live lifestyles that did not support marriage. Christina Gibson-Davis explains that the Aid to Families with Dependent Children program which in the 1960s began accepting unwed mothers, "discouraged marriage by greatly restricting eligibility for two-parent married households and by counting the resources of any nonbiological cohabiting man against the mother's cash grant (Moffitt 2002)" 
(Gibson-Davis 2011). Additionally, women received increased welfare benefits as more children were born and entering the home. As a result, when black married couples were assumed to be middle class, and not welfare-dependent because the system would not allow black women to be both wives and welfare recipients. It became expected for welfare dependent families to consist of low-income singlemother-led homes.

In addition to the cash assistance that welfare recipients benefit from, some women referred to the institutions in place that provide help to low income single mothers as desired. As the mother of twins, Hope was nervous about returning to work when her children reached school age. Fortunately, she was able to enroll her children in a HeadStart program -- an early childhood education program offered primarily to low-income families -- because the school had low enrollment. With this, Hope was able to benefit from a free education and childcare for her children and was able to return to work without having to ask for others to babysit or most importantly, to have to pay a before or after-care facility to care for her children. In the HeadStart program, her twins were able to attend school for the full day and their grandmother picked them up until Hope made it home from work.

Programs like these would provide a benefit to most single middle class mothers, but government agencies restrict middle class women from gaining access to these benefits. As they work towards professional goals including promotions and salary increases, these women give up their ability to receive any form of aid. While their salary increases are helpful, they often feel like their household and child rearing responsibilities account for most of their income. Benefits such as food stamps or daycare vouchers would work to secure single middle class women's positions in the middle class. Their incomes could go toward further advancements instead of basic, 
but expensive, necessities for the household. This causes resentment between single middle class mothers and mothers with low-income jobs. Although their annual incomes may be less, the middle class mothers recognize the major benefits of receiving public assistance. They are recognized as high incoming earning individuals -- with their (often) full responsibilities for the children disregarded or overlooked.

When asked about her ideal salary, one mother said, "I would like to make $\$ 99,000$ and that's it. I wouldn't want to hit a hundred [thousand] because then I'd be in another tax bracket". These women are conscious of how "the system" works, taxing the middle and upper-middle class the highest to the point where they actually are not making comfortable living salaries for the area in which they live. As single mothers, they work to maintain their incomes and status so that additional benefits, like a private school education or access to paid extra-curricular activities, are not taken away from their children. Things like first-time homebuyers programs are not available for individuals who make over the capped amount. Even with the high cost of living in the DC metropolitan area, most of the women in this study far exceeded the income levels for federal and state issued benefits.

\section{Conclusion}

Despite negative representations of black women in the media, many black women have come to embrace their single motherhood as the best decision under their presented circumstances. They have provided counter-narratives to criticism of single motherhood through their actions and behaviors, as consumers and as educated working professionals. Working to provide better lives for themselves and their children, black single mothers have used various strategies to enter, maintain, and build upon their middle class status. As "strong women" they have learned to roll with 
the punches and create the best environment they can in their positions. Overall, black single mothers did not seek out single motherhood. They desired marriage and consistent financial, emotional, and physical support from a partner who would help in child-rearing. But as relationships ended these women decided single motherhood was the best alternative. The women have continued to work in the home, as mothers to their children and managers of their households, while also working outside of the home. Black single mothers have accepted and sought positions that allow them the flexibility between work and motherhood. Extended family and friend networks play vital roles in these women's ability to manage work and parenting as the networks provide a support system. The financial opportunities available and the assistance of trusted networks allow black single mothers to provide middle class lifestyles for their children. 


\section{Meet Gabrielle}

Gabrielle followed the steps to success in the most traditional way a woman could. She attended college, excelled in internships, and participated in extra-curricular activities that would make her resume and experiences stand out in the crowd. Today, at 44 , she is a top executive in a health related organization. Gabrielle works primarily from home, but travels out of state one day of each week to commute to work.

"I wasn't really focused on finding love" Gabrielle says over coffee. We meet at an upscale coffee shop not far from her home. "This is where I work most days" she says as she puts her laptop aside so that we can begin the interview. Gabrielle's flexible work schedule allows her to work anywhere, while also being available for her daughter. One year ago, she adopted a newborn girl on her own. Gabrielle has never been married, and admits that she did not prioritize personal relationships over her lifetime.

Like many women, Gabrielle was focused on attaining success outside of the family. She wanted to use her degree and skillset to make a difference in the world and make money. As Gabrielle climbed the corporate ladder, she overlooked her personal needs. "I would love to get married one day, but it came to the point that I had to realize that that may not happen for me, and that's okay — but I did not want to sacrifice motherhood because of it." As women make strides in the professional arena, they are often forced to decide on advancing their career or advancing their personal life. It can be difficult to always be available at work, while gunning for that promotion, while also going on dates in the hopes of meeting the perfect partner. Gabrielle felt that her career would provide her the most fulfillment in life.

Although she desired marriage, she understood that it was not guaranteed and would not have the same impact on her life as her professional success. To Gabrielle, 
marriage was always optional but motherhood was not. She wanted to become a mother, but saw financial freedom as the key to being an available mother. She worked long hard hours to get where she is today, but now had the freedom to work remotely, while living in a large, newly constructed home in one of the most esteemed communities in the Washington metro area. She decided to adopt to fulfill her desires of being a mother. Her financial status allowed her to adopt a child without the support of a husband or father. Gabrielle's mother lives in her home and acts as her live-in nanny, helping to care for her daughter when Gabrielle travels or has work obligations hat pull her away. 
CHAPTER FIVE | Material Culture and Class in the DMV

The Black Middle Class

The American middle class is most appropriately defined as a mindset, a culture (Moskowitz 2004). Although annual income is typically the determinant of economic class in America (Samuel 2014), a concrete definition has varied among scholars, particularly because of the multitude of criteria used to identify the middle class - criteria that changes based on race, location, and other factors. While the middle class was once strictly defined by income (Belli 2007; Samuel 2014; Strobel 1993), other shared cultural markers have also been used to define it, such as good acquisition, residential neighborhoods, and educational degrees (Samuel 2014; Frazier 1957; Goloboy 2005; Lacy 2007). Sociologist Max Weber used occupation as an indicator of class (1978), while economist Frank Levy identified education as middle class' key indicator (1988). In his 2012 State of the Union Address, President Barack Obama suggested that the middle class is a population of people who are able to work towards the American dream and promise of "rais[ing] a family, own[ing] a home, send[ing] your kids to college, and put[ting] a little away for retirement" (Obama, 2012). The middle class is, therefore, a heterogeneous group of individuals from diverse backgrounds working towards a comfortable life and 'success'. As there has been no consensus on a definition for the middle class in the United States, I am using a combination of objective (income, education, and occupation) and subjective (lifestyle, luxuries) criteria that together support the idea of the attaining the American Dream.

The US black middle class has emerged three times: during Reconstruction, Jim Crow segregation, and the Civil Rights era. This population has grown 
tremendously (doubling in size) since the 1960s as a result of the Civil Rights movement and a stable economy (Moore 2008). Its formation has been hotly debated and analyzed in academia by W.E.B. DuBois and Booker T. Washington. DuBois argued for the "Talented Tenth," the top ten percent of educated African Americans, which at the time of his writing was a mere 2,300 black college graduates, to lead the race to economic security and progress through formal education (1903). Washington, on the other hand, argued for blacks to become masters of skilled trades in order to secure middle class status. The black middle class was originally comprised of those in low paying public sector positions such as primary and secondary education instructors, social workers, and postal service employees. Towards the end of the nineteenth century, the black middle class adopted new roles as leaders whose responsibility was to "advance the Negro race and create conditions under which lower-class Negroes could elevate themselves” (Durant and Louden 1986). In 1987, Bart Landry sweepingly categorized any white collar employees or sales occupations, police, and firefighters as members of the black middle class. Today, increased job and career diversity has positioned blacks from several fields within the middle class. This class increased due to industrialization, urbanization, increased occupational opportunities in the labor force, educational attainment, entrepreneurship, and collective resources from organized social groups (Durant and Louden 1986). As members in this class, blacks have been afforded opportunities for upward social mobility and increased access to better residential options, higher education, and public services.

Most scholars have agreed to identify education as the most important building block for the black middle class (DuBois 1903; Frazier 1957; Holloway 
2002; Lacy 2007; Marsh and Landry 2011). They emphasize that its members value education as a sine qua non condition for middle class reproduction (Jewell 2007; Collins 1990; Giddings 2001; Savage 2001). Many black middle class parents get involved in their children's education as they are convinced that it creates the conditions for one to take advantage of opportunities (Strmic-Pawl and Leffler 2011). Black churches, as social institutions, also support and initiate educational programs within their walls and in the communities they serve (Strmic-Paul and Leffler 2011). Education provides necessary professional skills and allows students to build personal and professional networks that often lead to stable employment. It is also the driving force that allows the black middle class to adopt a leadership role in institutions, churches and other organizations as ways to maintain their class status (DuBois 1903; Evans 1993; Holloway 2002).

In comparison to white Americans, however, it is more difficult for blacks to maintain their middle class status and pass this or higher status levels onto their children. Specifically, after the economic recession of 2007, the black middle class has continued to face its challenges. It is becoming increasingly difficult for black men and women to maintain middle class incomes, lifestyles, and status. This trend exists as a result of institutional racism and discrimination which effectively keeps blacks at an economic disadvantage. Although blacks (especially black women) are attending and graduating from colleges and universities at record numbers, the few available jobs and high costs of living are making it harder for blacks to enter and remain in the middle class. The economy is expanding and individuals have higher earnings, yet it is predicted that "black children will make less than 80 percent of what their parents did" (Brown 2016). These findings, in comparison to whites, determine 
that it is more difficult for black families to retain middle class status across generations. Black middle class parents are thus faced with the responsibility of not only sustaining their own status but also building strong financial foundations that will allow for their children to remain in the middle class. In addition to being able to afford opportunities to better assist their children, black middle class parents have to strategize to assist their children in preparing for acceptance or rejection in certain spaces. Riche J. Daniels-Barnes' argues that in her study, “middle-class and uppermiddle class families had to consider how their children would be perceived in Black and white social and educational settings (Barnes 2016). For black parents in the middle class, the level of effort employed to ensure children's opportunities and success is far greater (Maylor and Williams 2011).

Race and class categories are socially constructed and are determined and understood based on a group's relative social and economic position to other groups (Moore 2008; Bourdieu, 1984; Cornell and Hartman 1998). Like the wider American middle class, the black middle class also prioritizes higher education, good work ethic, and a desirable income. The middle class places "emphasis upon respectable patterns of behavior that differentiate them from the lower classes" (R. T. Smith 1996). There are unwritten sets of rules and behaviors one must adopt in order to be respected within middle class communities. In order to distinguish themselves from the lower classes, members have adopted a set of moral codes, certain practices, and affiliations that must be preserved. Members of the black middle class have adopted specific attitudes and embrace a particular habitus that makes their group dynamic and unique. Sociologist Karyn Lacy argues that blacks use several strategies to create the idea of "middle class Black" (Lacy 2007). While the attitudes are not harmonious for 
every individual within the black middle class, its members generally perform their class identity by placing emphasis on the same material things, family values, and way of life (Moore 2008). Through purchases of homes, luxury cars, high-fashion brands, and private education, members of the black middle class, including black single mothers, can display wealth and worth.

Status Symbols in the Black Middle Class

In 2009, the National Harbor officially opened for business in Oxon Hill, MD. The National Harbor, "a 350-acre resort destination” opened with a large pier, restaurants, hotels, and a ferris wheel that could be seen from the Potomac River shores of Washington, DC and Northern Virginia. During the time of the Harbor's opening, residents cheered (and scoffed) at the attention it would bring the area. The National Harbor is not located in the Nation's Capital at all. It was strategically placed at the southern end of the Woodrow Wilson Bridge (which connects Maryland to Virginia), in a popular Prince George's County city. Prince George's County residents expressed great satisfaction as the new harbor would bring new jobs and taxes to benefit to the community. Locals were surprised and overall pleased to see that such a prominent attraction was built in Prince George's County. The National Harbor, which has since expanded to include a nearby Tanger Outlets and recently opened a massive MGM Grand Casino and Hotel, attracts Washington, DC tourists to an area that would likely not have been sought after without this attraction. Oxon Hill is known for its predominately African American middle and upper middle class neighborhoods. Karyn Lacy explored wealthy neighborhoods in the Oxon Hill/Fort Washington area in her book Blue Chip Black: Race, Class, and Status, in the New Black Middle Class (2007), prior to the building of the National Harbor. 
Prince George's County has gained prominence as the wealthiest African American county in the United States. The most popular cities in PG County known for its concentration of wealth are Upper Marlboro, Bowie, Mitchellville, and Fort Washington. Upper Marlboro, where my former high school is located, is home to local celebrities and features massive homes in a very suburban area. Bowie and Mitchellville are nearby, to the Northeast and contain similar homes and exclusive neighborhoods. These areas are remote in that they are not accessible by Washington, DC's WMATA public transportation services. Although only located about 30 minutes outside of the city, these areas operate as small cities of their own, complete with shopping plazas, colleges (Bowie State University and Prince George's Community College), and other attractions.

In the Washington, DC area, I have noticed that status is important to many of its residents. Status symbols, according to Goffman, are "the cues which select for a person the status that is to be imputed to him and the way in which others are to treat him" (Goffman 1959). These symbols, sometimes subtle or grand, can be used by individuals to associate class, income, and status. They are highly effective in dividing the social world into categories, although not always the best test of status. It its important to note that status symbols can be both tangible and intangible, and can for instance, be expressed through everyday objects or symbolic possessions (degrees, vacations, etc.).

Black middle class families are concerned with home ownership and community. Black middle class families live both in suburban areas (i.e. Prince George's County, Maryland or Lithonia, GA) and in inner city urban areas (i.e. Washington, DC or Chicago). In predominately black Prince George's County, MD, a county where some homes well exceed \$1 million, “it's residents have lost far more 
wealth than families in neighboring, majority-white suburbs" (Fletcher 2015), because blacks put their money into homes that suffered during the economic recession. Although the county remains the highest-income earning county for blacks, it also has the highest foreclosure rate in the Washington, DC metro area. Here, blacks continue to earn high wages, but economic security and wealth retention remains a struggle. Home ownership, once the biggest asset and greatest source of wealth, has become the black middle class' biggest financial burden. Members of the black middle class prefer to live in neighborhoods surrounded by like-minded upwardly mobile blacks, in order to provide their children with opportunities to advance and socialize with other middle class families (Patillo 1999; Lacy 2007). However, because blacks of all classes face challenges in job searches, promotions, securing home loans, and other basic needs required for them to afford residences in middle and upper-middle class neighborhoods they are not always able to live in exclusive middle class neighborhoods, and are kept in "lower-opportunity neighborhoods, often with underperforming schools, increasing the difficulty of passing on hard-earned privileges to their children" (Brown 2016). For black middle class families who live in predominately white or middle class neighborhoods, parents often actively engage their children in extra-curricular activities and in schools where they can be around other black children and explore black culture. For black middle class families who live in urban areas, they may decide to send their children to schools in better districts, or invest in private educations because of the disadvantages present in predominately black and lower-income schools. Thus, families use consumption to facilitate and form and their middle class identities. 
Home ownership was one of the most discussed material status symbols in this research. When asked about the factors that placed the women in the middle class, they often proudly mentioned that they owned their homes. Homes as a status symbol, is interesting, because living in a nice home does not always equate home ownership. One can rent a large home, and to outsiders the home can serve as a status symbol regardless. For the women included in this research, the emphasis on ownership was important, likely because of the high costs of living in the area. In Prince George's and Montgomery counties combined, the average cost of a single family home was $\$ 312,345$ in 2017 (Lerner 2017). Black single mothers who are able to afford to purchase a home and provide such stability for their children is remarkable, and for them, brings about a sense of pride. In comparison to other predominately black areas in the country, such as Atlanta, Charlotte, and Chicago, the cost of homes in DC are much higher. These cities are also facing gentrification, but suburbs outside of the cities are still affordable, whereas DC suburbs compete in the high costs of living. In the city of Atlanta, for instance, my mother purchased a 3-bedroom townhome in 2007 for less than $\$ 100,000$ as an income property. In DC, then and now $\$ 100,000$ may allow you to purchase a one-bedroom condo in the undesired parts of the city, or outside of the city completely. It is more expensive to own homes in the DC metropolitan area, so single black women who manage to do so, are proud of their accomplishments, and rightfully so.

As a status symbol, a home's style can inform others about your taste, its size can inform others about your income, and its neighborhood can reveal one's status. Most new developments in these Maryland counties have homes starting in the high $\$ 500,000$ s. Communities like Marlboro Ridge, in Upper Marlboro, and Woodmore in Mitchellville, include horse stables, pools, recreational areas, golf clubs, and gated 
entries. Neighborhood selection and home ownership go hand-in-hand as status symbols. A nice home in a desired, or popular well established community evokes a greater importance as a symbol. The neighborhood or community amenities can be used intentionally or not to establish one's position in the middle, or upper middle class. In mixed communities like Marlboro Ridge, for instance, which includes single family and townhomes, the size of the home may not matter as much for status, because the community speaks volumes.

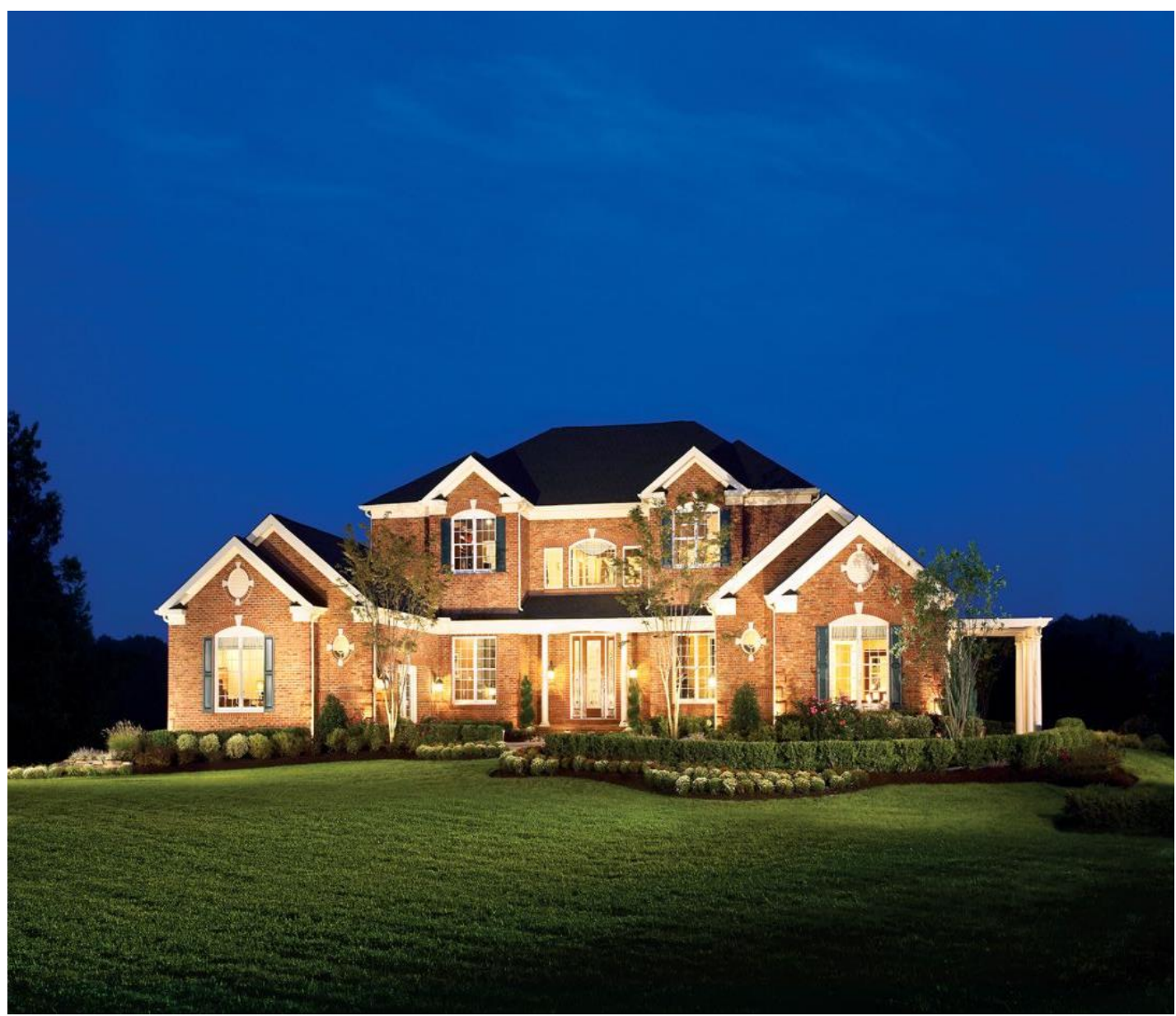

Marlboro Ridg Community, “The Estates,” TollHouse Brothers

None of the women interviewed for this research lived in any of these "premier" communities in the area like the one in the image above, but they effectively served as the marker of status and middle and upper-middle class living. 
Marlboro Ridge, for example, in located off a main road in Upper Marlboro and its grand entrance is easily recognizable and known by many locals. The gated community, at the time of its opening had large images of homes like the one above to entice buyers. While my research participants did not live in this community, they did live in similar communities nearby, sometimes less than a mile away from new development neighborhoods. Several women questioned their status as middle class, because they did not own homes in these communities. Lisa, recently purchased a home in an Upper Marlboro community not far from Marlboro Ridge. Her new home was built upon purchase, and features 5 spacious bedrooms, 5 bathrooms, and a large backyard. Her community is currently under development, and she is one of the first to build and own on her street. She also noted that she is the only single parent that she is aware of on her street. Lisa's house, which is on a street that ends in a cul-desac is everything she envisioned in order to raise her children in a middle class neighborhood.

"I wanted them to grow up around kids like them." She says. In other words, Lisa wanted her children to be surrounded by other children and families who shared their socioeconomic status. Their neighborhood and homes were used as status symbols, not only for Lisa to associate herself with the middle class, but as a way to ensure that those she would call neighbors were also of a certain class and shared similar values.

The importance of home as a status symbol was very clear throughout this research. Women preferred to live farther away from the city, so that they could afford mini mansions and acquire the best of what that their middle class salaries could afford. They also expressed discontentment over having homes in neighborhoods that they felt was not representative of their social status. In an eye-opening interview with 
Jamie, a single mother of one middle school-aged son, she admitted to being completely ashamed of her home. For this interview, we met at my family home, using my mother's dining room as the interview site, while my family were out for the day. Jamie, who knows my mother, insisted that the interview take place a local cafe or at my home. She was vocal about not wanting me to visit her at her home, although, I assumed it would be more convenient for her. After all, for most of my interviews, I traveled to the women to make the interview as easy and accessible as possible for the working, single mothers. Jamie, however, did not want me to come to her, and in the interviews it became clear that she often hid her home out of shame or embarrassment because of its size. She compared her home and lifestyle to that of other parents in her son's friend group.

Like his some of the friends, his closest friends in school, they come from married families that live in like Fort Washington. And so, we go over there because he'll go and spend the afternoon over there or something. He'll be at their house and I... once, I had to come and pick him up and I'm like... I walk in the front door like "wow, this house is huge!"

Jamie, who is originally from the Midwest, recognized the size of one's home in the DC metropolitan area to be a marker of their status. Unlike in the Midwest, where she was raised in a nice home with both parents, she adjusted to the pressures of DMV living after moving to Washington to attend university. The idea of a nice sized home that she was used to when growing up was equivalent to what she believed to be low-income living in the DC metro area.

In our interview, she recalled a recent occurrence between herself and the parent's of her son's friend: 
He [Jamie's son] has this one friend, whose dad will take my son home sometimes if I'm running late and I will go over there to pick up my son. So, I said okay, you know what, they do this... they've done this pretty frequently, I need to pay them back somehow. So I say, okay, you know, I'll take their child out for the day or for the evening and let them have a break as my show of appreciation. And so they were like, “oh, okay! Sure that's great. Fabulous. Fabulous. We'll bring him over to you." And I was like 'no no no no i'll come pick him up.' So that was like my moment where I was feeling embarrassed that like I live in this little hut compared to their house in their neighborhood.

Jamie's son attends a private school in Prince George's County. There, he is surrounded by black children from diverse backgrounds, who live in both single and married parent households, with a range of incomes. Jamie has found it important for her son to participate in school activities and extracurricular activities outside of school. Although she cannot provide him with a large home at this time, she makes it clear that she wants the best for him. Exposing him to various activities and groups of people is one way that she is able to support this goal. Despite the positive results she hopes this exposure for her son will bring, the wealthier families have placed Jamie in an uncomfortable position. She continued:

I could tell that when the family came over that day to drop off their son, I could tell that when they first walked in... 'cause you know as soon as you walk in my house, it's like, it's just it's open space but it's just not big. Their house? You could probably fit my whole house in their lower level. So when they walked in and they realized that -- like, I think the mom made a, well I don't know if she made a comment or just her response like, "oh nice house". 
And, I'm like, really? Like, come on. You're just saying that because you have to.

I asked Jamie if she felt the comment was genuine, but she did not believe so. The pressures to compete with others regarding material goods is very present in the Prince George's County. Because most middle class black people have 'nice things,' there is a sense of drive for others to attain the same, or similar things to position oneself as someone of a certain status. Even if the taste varies, the ability to purchase nice things can both encourage and taunt black people in the area. It can also create an atmosphere of judgment, or presumed judgment as it did for Jamie.

I guess because I feel a certain way about my home compared to where I feel I should or want to be at this point in my life, anything anyone says especially if I know your circumstances - if I know that you have a fabulous, \$5-67,000,000 dollar home or more I mean, that is, you know, huge, compared to mine then you come to my home. Then anything you say I'm probably gonna take out of context because of the way I feel about my own situation.

I am very familiar with the status symbols of PG County, and the pressures to uphold them. As a high school student at my public high school, Dr. Henry A. Wise High School, which is located not far from Lisa or Jamie, I experienced first-hand the pressures of upper-middle class/elite lifestyles in a mostly middle class community. I was in the second graduating class of Wise, attending the school during its opening year. Wise was built as more families moved outside of DC into the Maryland suburbs, forcing a change in demographic in Prince George's County communities. The schools were filling up quickly and the nearby cities continued to grow. At Wise, 
students drove to schools in luxury cars, some their parents, some gifts from their parents for doing well in school or for learning to drive. Although we were mandated to wear uniforms, students wore the latest and most expensive shoes and handbags to compliment our dull uniforms. Thousand dollar Louis Vuitton and MCM book bags were a real thing at my high school. For students like me, who were either uninterested in spending that kind of money on things, or whose parents could not afford to or refused to, material goods became something to be sought after. Class and status was literally worn on these students sleeves, even if it were not their income we did not have jobs. Marlboro Ridge, the community mentioned and photographed above, was built during my tenure at Wise. It was located a stone's throw away from the school, and it quickly became known who lived in or was moving to the premier community. Even as teenagers, students in the predominately black high school were hyper-aware of money, class, and status symbols. I did not grow up or live in Upper Marlboro. I attended Wise because of proximity and zoning, and for the first year, until my mother purchased my first car, I rode the school school bus each day. Like Jamie's son, who visited his friend's homes, I often felt the financial disadvantages of my single-mother upbringing when I visited friends in their homes. Most of my close friends at Wise came from two-parent families. Their large homes, cars, and backyards, showcased their parent's dual incomes. In these moments, I felt proud of my mother's accomplishments on her own, but also realized that we would likely have more if she had a partner or at least, consistent financial help. In this area, the average is understood as if it is the bare minimum. Because of frequent exposure to images of black professionals with the most extremes, the average is just no longer quite enough. 
Social stratification serves as a mechanism which establishes boundaries on social interaction (Heller 1981). Here, Jamie is consumed by her perceived social status and her status of the other family, which negatively impacts her interaction with them. She does not accept their kind comments as truth, and is constantly comparing herself to them, which has created a social distance. "Social distance emerges between acting units with different degrees of participation in, or possession of, social goods" (Krauss 1976) insofar as these goods to "macro social properties (Shils1969) are the basis for the formation of interaction patterns and identity. Social distance is thus seen as emerging because particular groups have distinct life experiences and develop specific views of themselves and their society" (Heller 1981).

\section{Presentation of Self}

In The Presentation of Self in Everyday Life, Erving Goffman emphasizes the role of performance in forming social identities. Individuals behave as actors on a social stage, be it at a dinner party, a graduation, or the office - people act in ways they want to be perceived by their immediate audience and themselves. In this performance, specific objects assist in selling the idea, or the presentation, or oneself. Jamie felt as if she was unable to identify as truly middle class and was instead outside of her social class because of her lack of one particular status symbol - a large home. Despite the fact that she earns a high income, or that her son attends a private school, without the marker of the large home Jamie suffers an imposter syndrome in her own social class. People in the same social class tend to possess a similar pattern of behavior (Goffman 1951), but Jamie's emphasis on the home discredited her wellpaying job and higher education as factors that related her to others in the middle class in PG County. 
In this area, people present themselves through their material objects, professional affiliations, and more. This presentation primarily occurs in person, on various social stages, but today, social media and other online platforms have become another social stage on which individuals can perform their identities. Facebook, the popular social networking site, serves as a social stage for individuals. I began to think about Facebook as an on stage experience, where people can curate their posts and positive things to share with others. I became friends with several participants on Facebook, and at times, the information revealed on FB contradicted the in person discussions we had. It made me wonder, were they "performing" in our conversation, or are they performing on FB? The use of social media as additional platform to share ones experiences and opportunity to present oneself can be used as both an on-stage and backstage area. Social media is used by diverse demographics for job hunting, staying in communication with long-time friends and distant family members, and for entertainment purposes. The participants of this research were no different. They ranged from ages 25 to 55, and each of them were familiar with social media.

Social media plays a significant role in users' lives as platforms of selfpresentation. Today, social media is used to share and promote the daily and important activities in our lives. People often over-share on social media, and use it to spark conversations, debates, and inform the public about what is going on individual's lives. Ultimately, social media is like a stage, in which users perform their identities — often carefully curated versions of themselves — to the world.

No one would admit to using social media as a tool to brag, but it has been used in this way - either intentionally or unintentionally. I found that some women shared their material goods on social media despite sharing with me, personally, that they were not interesting in "keeping up" or sharing with others what they did or did 
not have. This struck me as both interesting and contradictory, because online social media platforms are often the complete opposite of private. Generally, people post on social media when they want the public (their "friends" or the greater online community) to know something. It is not as private as making a phone call directly to a friend, or sharing a message via email.

In our conversations, the women participants would suggest that they were not concerned about how others viewed them or that they did not do anything for show, but social media suggested otherwise. I became Facebook friends with a few of my participants after meeting to conduct this research. I was also friends with a number of other women participants who I knew prior to field research.

Tyra, mother of three, has a huge personality, but I noticed that her personality was larger-than-life on social media. She constantly posted images to social media of her exotic vacations to Europe or the Caribbean Islands, and photos of her new luxury cars. Despite sharing with me that she was rather modest and unconcerned about her perception by others, her Facebook profile showed the opposite. There is an inherent pressure in this community to look and behave a certain way and each of the women responded to that pressure differently.

It was difficult to know whether Tyra, and other mothers used Facebook as their "on-stage" or "backstage" platform. Our in-person interactions through interviews and observations added another layer of performance, as I, the researcher, conducted a study. Were the comments shared with me in private representative of Tyra's on-stage presentation of self or was Facebook, or both? These women also performed when speaking with me directly. The methods of present were not same, and the content share conflicted. In these instances, I understood social media to be the more exaggerated presentation of the status symbol she possesses, compared to 
our personal conversations which expressed similar sentiments, but without the elaborate showcasing.

Renee uses social media in one of the most resourceful ways I have noticed among the women. Her social media posts mostly contain questions for her wider networks regarding parenting and opportunities for her daughter. Questions related to finding the best dance studio, a tutor, or weekend cultural opportunities are common on her page. In a recent post, she shared that her young daughter has decided on a future career in the STEM fields. Renee used the platform to ask for other black women in the field to come forward to speak with her daughter so that she could have an example. Representation for young black girls is extremely important, and Renee's posts reveal her awareness of this. In addition to sharing photos and communicating with friends, she uses the platform to build her social networks to create opportunities for herself and her daughter, particularly in areas where here knowledge and access is limited.

They are aware of themselves and make specific decisions to represent themselves the way they do both online and in person. In a performance of identity online, Renee's Renee's Facebook posts shows that she is her as highly engaged, motivated single mother. Through her posts, she shows the public that her marital status does not negatively impact her daughters ability to succeed. If anything, her dedication to her child's exposure may be more pronounced because of her single status. In addition to genuinely wanting to parent well, she works hard to show that she is fully committed independently of raising a young woman who is fearless and goal-oriented. 


\section{Self-Presentation in a Consumer Society}

We live in a consumer society, where we are driven to purchase and consume. Advertisements take over our television screens and infiltrate our social media platforms. Objects are no longer needed exclusively out of necessity. We purchase more shoes than are needed because of style and comfort, and purchase new versions of technology whenever the latest version hits the stores. Black Friday, the day after Thanksgiving, that once marked the start of holiday shopping season, has become Black Thursday, as stores open earlier and earlier each year, affirming America’s obsession with consumption.

In this society, people are often associated with their things, and objects and individuals come to coexist. It is only humans, however, who can speak and use these things to reflect themselves (Heidegger 1927 [2001], Aspers 2010). Material objects are essential for understanding humans. People, like brands (Louis Vuitton, H\&M, Chevrolet), have identities which are used to tell others who and what they are and represent. Together, brands and people, have agendas to get others to see them the way they want to be seen. Patrick Aspers calls this level of identity reflexive identity. Aspers argues that reflexive identity explains how actors behave in relation to who they think they are and what they want to become, which is inseparable form their interpretation of their current world (Aspers 2010). In other words, what the actor wants to see in ourselves becomes our reality. In an example, he explains that advertisements of clothing brands often display young, beautiful models even when the target audience, in reality, are older women and women (Aspers 2010). It is the idea that the consumer wants to see themselves as the younger, more beautiful model, which would entice them to make the purchase or develop a relationship with a particular brand. Aspers explains, "Reflexive identity refers to actors' desire for an 
identity, which can be different from how they perceive their current identity (cf. Goffman [1963] 1968: 129)." It is wrong to see this level as non-social, however; reflexive identity and the process of thinking about one's identity only become meaningful in relation to the identities of others (Quante 2007)" (Aspers 2010). With clothing, individual scan compare style, fashion choices, and brand loyalty to make meaning of their own identities.

As consumers, we buy into the pressure to purchase because of what the material goods do for us. These objects can make us look good, feel good, and can be required objects to fit in with a certain crowd. Our consumer choices tell the world who we are without us having to say a word. The choices we make as consumers create and reflect on how we view ourselves and the ways in which we want others to view us. Alan Warde explains how people use things to share who they are:

People define themselves through the messages they transmit to others through the goods and practices that they possess and display. They manipulate or manage appearances and thereby create and sustain "selfidentity". In a world where there is an increasing number of commodities available to act as props in this process, identity becomes more than ever a matter of the personal selection of self-image. Increasingly, individuals are obliged to choose their identities. (Warde 1994).

Fashion, and clothing specifically, is the most visible material object of consumption that is used to represent oneself. Although other things, like cars, jewelry, and technology can also be purchased at high rates, clothing is always seen and is always available. Veblen makes that point that fashion, unlike other things, "affords an indication of our pecuniary standing to all observers at first glance" (Veblen 1899). A 
group of work colleagues can generally know of a co-workers style or closet inventory but may never see the car they drive into work. Furthermore, they may never see the home they live in or the jewelry that is reserved for special occasions, but their clothing is visible and therefore, is most likely used to define the individual.

Of all material goods, fashion is one way of generating, maintaining, and expressing collective identities (Aspers 2010). In the book Orderly Fashion: The Sociology of Markets, Patrik Aspers discusses subcultures, like Goths and Mods, and how they embrace a style, or uniform, which is used to signal people's group membership to those who may not know them personally. Through clothing, people can show others what they want them to see, in hopes of others seeing them as intended.

Clothing is particularly important in the scheme of material goods up for consumption, because of its vast choices and varieties. Through the consumption of clothing, individuals can express various looks which are used to control and manage one's identity. Fashion is a tool. Clothes, and other specific material goods, are used to get closer to or maintain one's reflexive identity. The clothes that are selected for purchase and worn in public affirm the desires of the actor/consumer in how they have formed their identities. Of course, these ability to purchase certain items and have diverse clothing of choice depends on one's socio-economic status. Some luxury brands may not be affordable to the middle class consumer, even though the clothing they sell best represents how the consumer wants to display themselves. Other fashion items may be exclusive, in that it is sold in limited quantities online, or only available at specific stores out of reach to those of lower incomes. Take for instance, the streetwear brand, Supreme. Although the brand mimics the fashion styles of inner city black young men, the brand only releases a limited number of items each week and 
only has six physical stores, with only three of them in the United States (New York and LA). This literal inability to access the fashions exclude low-income demographics who may be unable to purchase the clothing online at the moment it is released, or unable to travel far distances to stand in line to enter a store. Because of these limitations, the brand is adorned by celebrities with social and economic capital, and affluent white suburban boys who have the financial means to acquire such items, which in turn has bestowed a high value in the brand. The selections of fashion choices is therefore related to power, which may be a result of status, financial capital, the resources of political associations, and violence (Aspers 2010).

Studies in consumerism and consumption have often overlooked differences presented by race, and has focused on gender and different consumption practices. Chimamanda Adichie observed that Western women, regardless of race, "who wanted to be taken seriously were supposed to substantiate their seriousness with a studied indifference to appearance" (Adichie 2014). To be serious meant to dress in a masculine uniform - in dull, dark suits, no accessories. She furthered her critique of Western women's appearance in the workplace and applied it to her career, stating "for serous women writers in particular, it was better not to dress well at all, and if you did, then it was best to pretend that you had not put much thought into it" (Adichie 2014). For Adichie, this process of conforming to biased gender expectations by way of constrained consumption limited her individuality and self-expression. This process of conforming completely rejects the description of consumption by Anne Friedberg, who suggests that consumption was supposed to facilitate expressing individual identity (Friedberg 1994). Adichie did not feel like herself in clothes she was uncomfortable in, but for many black women comfort is not an option. Black women, at times, have been robbed the ability to use consumption solely as a way to 
present themselves as they truly would like to express themselves. Instead, consumption has been used to conform to expectations of class, gender, and race, even when the individual would prefer otherwise.

Black women have had to conform and change their appearance in various majority-white and/or majority-male work settings, as further explained in Cassie Pittman's dissertation, “Race, Social Context, and Consumption” (Pittman 2012). Pittman's research revealed that black women conformed, by “ton[ing] down their distinctiveness" and attempting to blend in with their fashion choices since their race already made them stand out. In situations like these, conformity through consumption and appearance is not welcomed but it is necessary for black women's survival. Pittman, Adichie, Ford, and Craig have each exhibited how women in 'serious' professions, as activists, scholars, and business professionals, become concerned with consumption and appearance to appear respectable. In these examples, women consumed fashion and hair styles for acceptance by their "masters", who in this case was the society-at-large, their university, or their work environment. Veblen's discussion of women consuming to represent their husband's status and wealth is similar to these women's consuming to represent their race, gender, and class status (Veblen 1899). As serious professionals appearance dictated how they were responded to as black women.

There is an immense amount of pressure on black women to be ideal representations of the black middle class. In Ain't I A Beauty Queen, Maxine Leeds Craig argues that black women "had responded to calls from within their own communities to be upstanding representatives of the race by con-forming to middleclass standards of behavior and appearance" (Craig 2002). As college students and as beauty contestants, black women were and continue to hold the image of the middle 
class on their shoulders. To be a black woman and a member of the middle class is to be a representative of the black community. Just as Robert Stearns correlates consumerism with life goals, black women's consumption patterns contribute to their overall goals as best possible representations of middle-class women.

Respectability Politics in the Black Middle Class

David Crockett defines the politics of respectability as a "strategy of action that mobilizes a diffuse array of constantly shifting display-oriented (consumption) objects and tactics to generate a counter narrative to stigma" (Crockett 2017). Black respectability politics is a highly complex process of presenting oneself or a group in a carefully crafted, curated way to evoke a specific response, gain respect, or acceptance from a larger community. Used as an anti-racist strategy, black respectability has interpreted individuals actions, appearances, and behaviors to propel and justify racial uplift. "Racial uplift emphasized black people's social and cultural fitness for full citizenship, premised on the essentialized behavior norms of elite whites" (Crockett 2017). Respectability politics was first theorized by Evelyn Higginbotham in 1993, and has been discussed ever since. Treva Lindsey takes a critical look at respectability politics among Washington's prominent New Negro women in the later nineteenth-early twentieth century, and how women in Washington have both challenged ideas surrounding respectability politics for black women and fully invested in these ideas to appear more politically significant (Lindsey 2017). Today, respectability politics continues to have an impact on black communities through expectations set in the media and pressures within the black community to uphold a certain image.

Consumption has longed been used by African Americans to assert themselves, as citizens, into American society. As an accessible thing, African 
Americans sought objects to combat racism through appearance. With limited political or economic power, African Americans believed that they could "manage stigma through self-reform" (Crockett 2017). If nothing else could change around them, the one thing African Americans had power over was their appearance. The act of purchasing items, has served as acts of resistance, conformity, and solidarity. For black women who participated in the Civil Rights Movement, as described in Tanisha Ford's, Liberated Threads and Maxine Leeds Craig's Ain't I a Beauty Queen, consumption supported the performance of middle class respectability and expectations of femininity. Particular objects and things could be used as symbols of resistance, to facilitate conformity, or express solidarity. At times, these objects and things overlapped and served multiple purposes. Discussions of objects serving political purposes and purposes beyond self-expression have been largely ignored in texts of consumerism and material culture such as Bourdieu's Distinction and Veblen's The Theory of the Leisure Class, which mainly focus on how objects are used to distinguish individuals based on class. Studies by Daniel Miller, such as "Making Love in Supermarkets" and Consumption and its Consequences, however, offer alternative uses and understandings of material culture and consumption practices. Works that reframe black women's consumerism adds intersectional analysis to class-based studies on consumerism. They also add other uses and motivations for consumption, just as love is described as a motive for consumption by Miller.

In Liberated Threads, Ford offers an alternative understanding of black women's consumption practices. In one example, she describes black women as taking immense pride in their appearance by adorning their "Sunday best" (bright, nicely pressed clothing that were deemed suitable to wear to church) when engaging 
in political protests and demonstrations (Ford 2015). Black college students consumed and utilized their "Sunday Best" as a way to distinguish themselves from the lower classes and to gain respect as college student protesters. In the Civil Rights movements, leaders asserted that modest and neat dress was crucial to the movement's success (Ford 2015). Ford explains that "some black women believed that through a public display of respectability they could counter attacks against their character" (Ford 2015). The past studies on women and consumerism have failed to recognize how consumption has served for reasons beyond beauty and taste for women of color. Consumption preferences for black women, for instance, could be the deciding factor between safety and danger, life and death.

In Evelyn Higginbotham's pioneering study of black respectability in the United States, black middle and upper middle class Baptist church women set the rules for decorum and "respectable" behavior among black women in a strategy to combat gendered and radicalized violence. These women established strict manner and moral codes, rigorously modeled off of the ideals of elite Victorian women. The black Baptist women held classes in public community spaces, such as churches, community halls, and schools to teach other black women how to dress, behave, style their hair, and eat, with the goal of never allowing the public to see black women as objects or individuals less worthy of respect by both black and white people. The established codes were presented at the annual Women's Conventions. In an effort to change the way black women were perceived, these black Baptist women teachers "envisioned themselves as sorely needed missionaries for America," who had the ability to reform the structural system of American race relations (Higginbotham 1993). By reinforcing the values of white America among black women, the black Baptist women attempted to subvert black women's subordination. 
David Crockett further explains the ways objects have been used as tools to combat racism among black people.

"Racial uplift may not prescribe specific action, but it is accompanied by respectability as a strategy of action. Respectability specifies (and mobilizes) the objects and tactics necessary to enact a counternarrative to white supremacist domination — namely, Christian piety, well-mannered dignity, thrift, and temperance (Gaines 1996; Williams 2009). To give this counternarrative a material and behavioral presence, blacks relied heavily on the goods that became increasingly available as the culture of mass consumption emerged in the late-19th-century United States (Mullins 1999b)" (Crockett 2017).

It was believed that black women's ability to give respect, would in turn, result in their right to be respected. The highly self-conscious concession to dominant white values in manners and morals “served to reinforce their [Baptist women's] sense of moral superiority over whites," and was used as a tool to garner sympathy. The 1915 executive board of the Women's Convention best conveyed their strategy for combating racism and injustice with this declaration:

"Fight segregation through the courts is an unlawful act? Yes. But fight it with soap and water, hoes, spades, shovels and paint, to remove any reasonable excuse for it, is the fight that we will win."

The concept of respectability has gone beyond black women's fight for racial justice and quality. The manners and moral codes established by the Baptist women in the early twentieth century preceded the women's magazine and lifestyle guides published in the fifties, just as the Baptist women's codes mimicked the Victorian 
ideals of the late nineteenth century. Although today, expectations for behavior may not be written so explicitly as they once were, there continues to be unspoken guidelines for behavior and presentation within specific social groups. In the 1940s and 50s, mainstream magazines such as Ladies' Home Journal and Good Housekeeping advised society — and women especially — on their roles and behavior in domestic life. Complete with advertisements of acceptable clothing, desired appliances, and advice columns, these periodicals played an important role in shaping women's expectations. These magazines were specifically targeted to white women, who represented the American ideal.

Higginbotham noted that the concept of respectability signified self-esteem, racial pride, and a search for common ground. As black Americans worked to figure out what was "common ground" that could be adapted by both blacks and whites to live as Americans collectively, this concept was applied to other areas of social life in relation to race and gender. The idea of class and class status also adopt strict rules of governance and acceptance that have carried on today. For instance, members of the middle class are expected to be home owners, married, own a car, and typically residents of suburbia. The women who have participated in this research explained that this expectation is common knowledge and is sought after by most in order to maintain their middle class status.

In addition to class based expectations, Black women continue to face expectations of a domestic life, as evidenced by self-help manuals and films that advise women on the steps towards marriage. The expectation of a woman to be an educated professional, but also a submissive mother and wife, continues to be presented as the ideal character. Comedian Steve Harvey's Act Like A Lady, Think Like a Man: What Men Really Think about Love, Relationships, Intimacy, and 
Commitment (2009) is one of the best recent examples of how contemporary media reinforces the notions of respectability for black women. This book gained national attention as it became a New York Bestsellers list and went on to become a major blockbuster with two films. In this story, Harvey provides his unsolicited advice to women on how to find — and keep — a man. Instead of offering a counternarrative to outdated expectations of women's roles in the home, this work reinforces the ideas old ideas regarding women's pleas for a nuclear family.

Keeping Up With the Joneses: Conspicuous Consumption in the BMC

For the past few years, Helly Hansen has been a popular brand of outerwear among Washington, DC's black youth. Helly Hansen brand clothing is easily identifiable by its double $\mathrm{H} \log$ and sleek design. The brand is designed for skiers and snowboarders, because of its ability to withstand extreme weather conditions. Washington, DC's winters are moderately cold and not known for its extreme winter weather, but the brand has made its way into the hands of several DC black youth. Young black men's loyalty to the brand, whose coats range from $\$ 175$ (for a very thin jacket) to upwards of $\$ 1000$ (for a down coat), shows how brand loyalty can create a collective identity within a community. These young men save their money to purchase expensive coats and ski pants because they are in style and a symbol of trendiness. The purchase is a sign of accomplishment. They could purchase coats at a lower cost elsewhere, but have continued to spend high amounts on specific brand clothing. As a student in DC and PG County public schools, I witnessed outerwear brand loyalty often. At the time, the top brands were Spyder, North Face, and Columbia, brands that each have distinct logos. These brands served as function (they kept us warm) and fashionable, and both were important. To own and wear these 
brands also meant that you would be spared of ridicule for wearing "off-brand" apparel. Bonus points were issued for having multiple brand coats or for wearing more than one style per season. Although we did not have jobs or our own source of income, we experienced this social pressure to have a lot of stuff and change our styles often. Over the course of my field research, I noticed that younger black residents of DC and Maryland still engage in this type of brand loyalty and hyperawareness of fashion and style.

In 1899, Thorstein Veblen termed 'conspicuous consumption' and defined it as "specialized consumption of goods as an evidence of pecuniary strength (Veblen $1899,43)$. He wrote about consumption and its relation to the 'leisure class', arguing that when consumption is used as evidence of wealth it results in derivative growth of the individual (Veblen 1899). During this time, Veblen wrote almost exclusively about the men of the leisure class as the consumers, with women in society as producers. When women consume, he argued, it is a continuation of their work in the home or in society - not for mere adornment or "fullness of life" (Veblen 1899). Veblen believed that women and the industrious class, or today's low-income or middle classes, should only consume what was necessary for subsistence, leaving the luxuries and objects of comfort to the deserving leisure (upper and elite) classes. Consumption and access to luxury goods works quite differently in 2018 capitalist America. The availability of luxury brands in mainstream stores like Nordstrom, Neiman Marcus, and Saks makes the process of consumption much easier for individuals across socioeconomic class. Access is still limited by funds availability, but it is not often limited in physical accessibility. A blue-collar worker with a modest income can technically walk into a Porsche dealership and leave with a very expensive car if he or 
she has saved enough money or was able to finance the vehicle through a bank or other source - regardless of his or her 'class'.

When Veblen wrote about consumption and the leisure class, the lines of class were much more rigid and defined. Today, consumed objects cross invisible class boundaries. With the rise of social media and popular culture on television and the internet, celebrities often define and lead trends in consumption patterns among the youth and other individuals. Black urban youth style and culture has been commodified globally and is highly marketable (Collins 2004). Although most celebrities are considered members of the elite class, they draw from and build upon the styles of urban youth to influence audiences of low and middle-classes (and upper and elite classes) to engage in certain activities and consume certain, often expensive, products. When Pharrell Williams, a rapper and music producer turned entrepreneur established the Billionaires Boys Club in 2005, the high price tag polo shirts, graphic tees, and sneakers attracted young men shoppers of all socioeconomic and racial backgrounds. The name of the brand was exclusive, Billionaires, which explicitly states that the brand was intended for young men of high income communities. Regardless of title or costs, popular culture pushed the brand into all communities, making mostly young men from low-income or middle class communities desire and work towards acquiring an object from the brand. Similar patterns have occurred among African American women. For instance, high heeled shoes worn by the upper class such as Christian Louboutins are highly visible in everyday middle class neighborhoods. The shoes, which are worn often on reality television shows of the rich and famous or on red carpets, retails for around $\$ 700$ and have a distinct red bottom of the surface. They have been referred to in several songs and have become known as "red bottoms" in black communities. In todays culture, where personal style 
is constantly judged and displayed to the world on social media platforms, brand recognition and loyalty is important. In this example, these specific shoes have come to symbolize wealth, success, and style. For interested women who are not in the upper class or do not make extremely high incomes, the act of purchasing these shoes can be viewed as both overspending and commitment to style and trendiness.

For generations, the black middle class has been criticized as a group of conspicuous consumers. Conspicuous consumption is oversimplified as the "display of expensive consumer goods" (Frijters and Leigh 2008). It blends material culture and hyper consumerism to create a self-expression based on purchasing expensive things. To Bourdieu, conspicuous consumption is "gratuitous luxury" (Bourdieu 1984). Conspicuous consumption has been researched at great lengths in individuals of the leisure class as well as in individuals of low income and underprivileged socioeconomic backgrounds by sociologists, anthropologists, marketing specialists, and economists (Veblen 1899; Bourdieu 1984; Frazier 1957). Particular items generally fall under the category of conspicuous consumption, such as luxury goods, vintage items, and oversized homes (Frijters and Leigh 2008; Podoshen, Andrzejewski, and Hunt 2014; Lamont and Molnar 2001; Friedman and Ostrov 2008). Thorstein Veblen, who in 1899 popularized the concept of conspicuous consumption in his book, Theory of the Leisure Class, also included interior decorations and lavish parties as goods that fell under conspicuous consumption as they were mainly obtained to impress other people (Veblen 1899). E. Franklin Frazier elaborated on this idea and applied it directly in his critique of the US black middle class. Frazier, who believed that one of the biggest problems of the black middle class was their obsession of material goods, expanded on Veblen's concept of conspicuous consumption by arguing that blacks were only interested in consuming as a way to 
rank themselves in relation to blacks of a lower or similar socioeconomic class (Frazier 1957). Conspicuous consumption "signals an high income, which in turn signals high quality goods" and also becomes prevalent as a "status seeking motive" (Friedman and Ostrov 2008). It has two motives, and when done well, it reveals both high income and high status among individuals.

Conspicuous consumption supports the "keeping up with the Joneses" motto, which suggests that one must keep up with the latest products of the upper classes, conspicuous consumption, "postulates that people care about the average level of consumption as well as their own personal level" (Friedman and Ostrov 2008). Conspicuous consumption is a major focus of various sociological and anthropological studies, and is especially discussed in studies surrounding African Americans of all socioeconomic classes beyond Frazier's Black Bourgeoisie. Studies on hip hop culture and the urban aesthetic reveal low-income African Americans as a group of people extremely interested in flashy, expensive products often seen on television in music videos or reality shows (Mukherjee 2006; Podoshen, Andrzejewski, and Hunt 2014; Dominguez 2015). The general rule is that the more exclusive an item, the higher value it has in creating the sense of higher social status and income. Individuals engaged in conspicuous consumption become uninterested in “ownership of traditional status symbols - automobiles, fashion clothes, furniture, jewelry" since these basic commodities no longer serve as status signifiers, and instead come to desire "the relative status value of individual brands within commodity groups" (Mason 1998). Frazier condemned middle class African Americans for imitating the wealthy whites and blacks because the practice of conspicuous consumption was like living in a "world of delusion" and a "world of 
make-believe" (Frazier 1957). By engaging in conspicuous consumption, this group not only attempts to "keep up with the Joneses", but they attempt to exceed or become the new Joneses - the new definition of status - even if that means consuming outside of their means. In doing so, they create a false reality in such that the high priced goods cannot be maintained, and also the luxury goods are no longer exclusive. The availability of luxury goods, in turn, makes class identification based on material goods alone very difficult. Someone with a low paying job can have a high priced, luxury handbag, while someone in a well-paying stable career may only shop at discount or wholesale chains. As luxury brand items become more mainstream and available to everyone, material objects cannot be individually used to understand one's social class. These things must be put into context with other characteristics of individual's lives.

In the 1930s study of the black life in Chicago, Drake and Cayton criticized the black upper class as being "organized around a cult of clothes" (1945). Fashion and style continues to be important in many black communities. In addition to showing one's individuality, it can also reveal a great deal about ones family background, values, interests, and status. In photos of middle class and elite Black Washingtonians captured by photographer, Addison Scurlock and sons throughout the 20th century, one can quite easily spot the uniform of decorum expected of black middle class and elite families. In these photos, men both young and old almost always wear suits while women wear dresses. The family photos in the collection at the National Museum of American History Archives Center reveal a time where status was defined and showcased through attire. These middle class families adorned uniforms, of dresses and suits, to fit in within black elite Washington. 
Today, the black middle class's uniform varies widely, but the overall sentiment of showing one's best is still in place. The mothers in this study were concerned about their own image and their children's image. They were not all preoccupied with brand names or luxury items, but each of them embraced the basic principles of cleanliness and looking "put together," which included hair, manicured nails, and other personal grooming. In other words, to them, the uniform required their children and themselves to pay attention to what they put on out of self-respect when projecting one's self-image.

Black Americans have adopted a uniform of sorts, to encourage acceptance by society as 'normal', non-threatening individuals. Although clothes alone cannot combat racism or other forms of discrimination., many believe that one's physical presentation of self can change the way others treat and perceive people of color.

Wanda, a mother of two teenage girls, stressed the importance of her daughters keeping their hair and nails done. Leading by example, Wanda had a standing weekly hair appointment and bi-weekly nail appointment. Hair styling and grooming holds a particular weight in the lives of black women. Black hair is recognized as a marker of class and femininity to black women (Pittman 2012; Author and Tompkins Bates 2012; Craig 2002)(Pittman 2012, Ford 2015, Craig 2011) In order to look "presentable" to others, black women must engage in a number of consumption practices and behaviors to attain the desired look. In the 1960s, black women increasingly embraced and adorned the "natural" afro-style as a form of resistance, a symbol of self-love, and as a notion of solidarity with black communities. Today, many black women wear weaves and hair extensions out of preference, or in some instances, to get the desired work-acceptable look. Outward appearance is extremely important to Wanda as a federal government employee and 
self-proclaimed fashionista. In addition to having style, Wanda's concern for having her daughters neatly dressed and with styled hair is important because of the impressions it leaves and the way she is then portrayed as a mother. In Wanda's life, she works hard to keep hidden the backstage to her home life — rarely revealing a less than perfect version of herself to the public.

The idea of children's actions and behaviors being a "reflection of me" is something that I have heard from black mothers for many years. In the experiences of black single mothers, as found in this research, the sense of children's actions and appearance being a reflection of single mother's ability to parent effectively is consistent. If a child from a two-parent suburban household wears dingy clothes, others may assume that it is the child's style, or that they are hippies or alternative. For children of black parents, and black single mothers specifically, a dingy outfit could suggest to others that the children were not in stable homes or were poor. The implications could be dangerous for the household.

The clothing and material goods purchased by some mothers in this study were simply a means to an end and did not support common ideas relation to consumption in the black community. Cassandra, a single mother of one and a writer, dressed her 9 year old son in khaki pants and a polo style button up shirt for school on most days. Her son did not require a uniform at school, but Cassandra placed a major emphasis on her sons clothing with the hope that his attire would make teachers treat him respectfully, without the assumption that baggy clothes or streetwear made him any less than eager to learn. Young black men in and around urban metropoles are often associated with rap and hip hop culture. Since its origin, this style of music had been criticized as representative of violence and rebellion (Dyson 2004). Over the years, black and white audiences have responded negatively to the music, and it has 
been used to further divide black communities. In most instances, rap music's themes "continue to be drawn from the conflicts and contradictions of black urban life" (Dyson 2004). As rap and hip hop culture has grown to influence the fashion industry and those outside of urban low-income neighborhoods, there are concerns about how young black men's rap influence in style may cause stereotypical assumptions.

Black males, specifically in urban communities, are often targeted as threats and a disturbance to society by social authority figures. In the news and other media, black men are identified as "endangered," “dangerous," or “in crisis" (Dancy II 2011). Young black men are physically harmed or detained for simply being, and when found guilty of a crime face harsher punishments than any other demographic (Carll 2017; Alexander 2013). In 2007, the Children's Defense Fund found that black men were more harshly punished than white men for the same offenses, which has led to the over-representation of black men in the juvenile justice system, and black men growing up to have a 1 in 3 chance of being imprisoned in their lifetime (Children's Defense Fund 2000, 2007; Stevenson 2004). Among black youth, the path to social delinquency beings in the classroom. Black students are punished with more out of school suspensions, which decreases the time spent in school learning (Huang 2018). Anne Ferguson argues that black boys are criminalized at very young ages, and the negative stereotypes and expectations of black men as criminals comes from within the school system, from teachers to guidance counselors, and administrators.

"African American males are often targeted as threats and menaces to society by social authority figures ranging from police to school teachers, and this social construction of black males as "menace" has both public health and economic marketing implications" (Gibbs 1988, McIntyre and 
Pernell 1985, Potts 1997, Rowan, Pernell and Akers 1996, Sampson and Laub 1993) Stevenson 2004.

Black mothers, single or otherwise, are forced to take into consideration that their young black sons may be targeted at school or in public when they are out of their care. In an effort to combat discrimination on the basis of race, class, and gender, some mothers depend on material culture -- and specifically fashion choices -- to deter any punishments such as detention, expulsion, or worse. African American men are the most vilified and misunderstood group of students (Johnson III and Rivera 2015), and anything that could potentially save or protect them is often done by women in the black community. Black mothers employ several strategies including material consumption, to save and protect their young men.

"People constantly think that because I am a single mother I am uneducated. I told my son's last principal the she was classist and egregious... and that I just really don't like you. She was shocked. We went into a meeting, I invited my mother and I said, as the only one at this table with a $\mathrm{PhD}$ in Education (my mother), I figured she could give you some suggestions of what you could do. You are a white woman. As a black mother, you have to understand that we are constantly inundated with studies that show that you all just don't care about our black boys or black girls. This is being fed to us everyday." Cassandra's involvement in her son's school, and consumption of education materials for her son were used to combat the negative stereotypes related to single motherhood and to protect her son against an education system that she felt did not have her son's best interest at heart. In addition to dressing him in preppy, dark clothing (she stressed that she did not like bright colors and felt that dark colors 
presented a more polished look), she purchased the latest computer technology and books to help her son succeed in school.

Drawing from their personal experience and research, authors Greggory Johnson and III and Mario Antonio Rivera discuss the importance of clothing in racial profiling, and how clothing can dramatically impact a black man's outcome:

"It is assumed that a young African American man who wears a hoodie (sweatshirt with hood pulled over his head) and "sagging" pants poses a threat to others. Sagging refers to a manner in which persons wear their trousers or shorts below their waist to expose their underwear. The history of sagging may go back to prisoners -- often men of color -- who were not allowed to wear a belt (Jenkins 2013), mainly to make escape difficult. Therefore, their pants sagged below their waists. Other accounts, according to Jenkins, suggest that sagging isa fashion statement in rebellion against the exaggeratedly buttoned-down images seen in television characters of "nerds"...Regardless of the reason that Black men "sag," the authors propose in the classroom that sagging should not be judged by anyone who does not understand Black youth and their expression of rebellion through choice and manner of clothing." (Johnson and Rivera 2015).

Cassandra has skillfully limited her son's choice of dress. Because Cassandra is aware of the stereotypes and perceptions of young black men, she uses her son's clothing as a shield --- even though her son, at this tender age, may be unaware of such threats and consequences. By taking such choices regarding her son's appearance, in this uniform, Cassandra is attempting to ensure the physical and emotional safety of her son. 
Cassandra's focus was on her son's style — not to fit in or keep up with the trends — but as a strategy of respectability. Cassandra was aware of the stereotypes associated with rap music and urban life and how these assumptions lead to dismissal, or worse - physical harm to young black men. Despite her attention to details regarding her son's clothing, punctuality, and preparedness, she realized that her son was still treated unfairly at his school by his teachers. As an educated woman and concerned parent, she confronted the school about the mistreatment.

Shopping, Spending, and Budgeting

With the abundance of things in the DC metropolitan areas, it can be difficult to resist the temptation to consume. Shopping malls are in every corner of the city, and new restaurants and shopping centers seem to appear every other week. These shopping destinations are driven by the dollars of the black middle class. When the MGM Grand Casino opened at the National Harbor in 2017, Prince George's County residents rejoiced because for the first time it seemed that finally they were given something that would bring tourism and income to the county. Unlike small strip malls full of sneaker stores (Prince George's Plaza and the Boulevard at Capital Gallery), the National Harbor and MGM Casino would attract big dollars to the predominately black county. Black residents were pleased that after years of traveling to entertainment destinations in nearby counties in Virginia and other counties in Maryland, finally something of significance had made it to their backyard.

Black women's buying power is monumental in the consumer industry, but has been overlooked for many years. By 1919, Madame C.J. Walker had become the first black millionaire. Walker manufactured and sold beauty products designed for black women and showed the world that black women were avid consumers who would purchase things that they liked or that addressed their unique concerns. Black 
women supported her business because no other hair brand had developed products specifically for Black women's hair. Recently, singer and actress, Rihanna, followed a similar business model when she released a makeup line, "Fenty," which included forty shades of foundation for women of color that was rarely stocked by other makeup brands. Her products sold out in stores nationwide within hours upon first launch. Black and brown women everywhere expressed via social media and among personal networks how important it was for them to finally have a makeup brand that represented their skin tone. As one of the first brand's to focus on black women of darker shades, black women supported it wholeheartedly for their own benefit and for the brand's success. Forbes values the makeup industry at $\$ 445$ billion (Sorvino 2017). Black women, who were typically shut out of the makeup industry, were not viewed as viable consumers. Recently, Rihanna and her brand changed that.

In Beauty Shop Politics: African American Women's Activism in the Beauty Industry, Tiffany Gill addresses the importance of beauty to black women and the ways in which their consumerism in the beauty industry has been in response to their society (Gill 2010). For generations, black women have used their physical appearance to convey specific messages about themselves, while contributing financially to a growing industry focused on beauty. In addition to beauty, black women have served as major contributors to other major industries, including fashion, real estate, and automobile, and more. Although Black women are not emphasized as major contributors in consumerism reports, their buying power is monumental. As high income earners, the participants in this research were serious shoppers, who enjoyed buying new things without spending more than their budgets allowed. Jamie earned an annual salary of over $\$ 90,000$, but expressed little interest in spending. She admitted to infrequently purchasing things for herself, and was most 
concerned with taking care of primary financial responsibilities before spending on any luxuries. When she did spend on luxuries, they were actually simple necessities for herself, such as new shoes or clothes for work. She did not spend large amounts on material things for herself, but preferred to spend on things that would support her son and serve as an investment into his future.

"I feel very conscious about money. I haven't really had the resources to shop in the last few years. Whenever I do shop, I always have to make sure that everything else is taken care of first." - Jamie

A majority of the women in this research shared similar sentiments. They liked to shop but they did not like the act of spending. In several conversations, discount retail stores like Marshalls and TJ Maxx were introduced. These stores are known for their designer brands and dramatically low bargain pricing. At these stores, which I too am I frequent shopper, one can purchase a $\$ 3000$ designer purse for $\$ 850$, or $\$ 200$ designer jeans for $\$ 75$.

In "Why Cant a Smart Woman Love Fashion," author and feminist Chimamanda Adichie expresses her resistance to sexist expectations of women's dress in professional settings. She explains that some women, including herself, love to shop and enjoy fashion (Adichie 2014). Conspicuous consumption, however, suggests that women who take much joy in shopping, are not forward-thinking, financiallyresponsible individuals (Mason 1998; Mukherjee 2006). It allows for a stereotype of (black) women prioritizing their looks over all else. For Adichie, fashion consumption should not be a source of shame, but a source of individuality and pride. Her argument supports Daniel Miller's claims that fashion choices become clear signals of "specific taste, personality, and presence in the world" that cannot be replicated 
(Miller 2012, 55). Adichie argues that women should be allowed to express themselves through fashion without fear of being judged for being overly feminine or not serious.

Wanda, a participant in this study admitted that she loves to shop, but is very strict with her spending. She is extremely fashion-forward, and is known for her style. She almost exclusively shops at the discount chains for her own fashions, as well as her daughters. If the clothing items her teenage daughters want are not at the stores she prefers, she expects them to purchase the item using their allowance or savings.

“They always get new clothes for school because they don't wear uniforms. And a few weeks ago, Tasha said she wanted these shoes. I found the shoes at one store and she said they weren't the right ones! She wanted to have this one kind of shoe that was only at the Nike store. I told her to go buy it herself, or I'd buy the ones I found at DSW, where it is cheaper." - Wanda

Wanda teaches her daughters smart spending habits using the discount stores mentioned above. She explains to her daughters that the high fashion items that are popular in their high schools are attainable, but not from the retailer directly. She encourages them to shop around before spending anything. She has taught them how to compare prices at competing stores to make the best purchase.

Tyra, like Wanda, also has a stable career in the federal government, and takes great pride in her fashion choices. However, unlike Wanda, she is most interested in style outside of the workplace. Tyra relocated to the Washington, DC area almost 20 years ago, as a young 20 -something from New York City. She recognized the DC metro area as a place of opportunity for a young woman to grow and establish herself. She accepted a position that provided her with technical training, a competitive 
income, and educational benefits. Tyra still closely associates with New York City; she visits her family and friends at least once a month, and invites them to come and stay in her large home in Maryland. She carries New York with her at all times through her style.

“In New York, you don't want to look like everyone else," she says, "that's what makes you stand out. Your style is your individuality." Tyra's desire to embrace her own sense of style supports the ideas of today's society as a society of individuals, who are able to make decisions independent of others (Bauman 2000). Compared to other women who participated in this research, Tyra's display of luxury brands is the most pronounced. When asked if she has a favorite brand, she yells "Gucci!" and laughs. Gucci is known as a high end luxury brand. The items are expensive and can be difficult to access. Tyra sports a Gucci purse, Gucci tee shirts, and belts to regular everyday outings, although most people in the DMV area are not as outgoing in their brand loyalty.

Tyra is a 40-year-old single, recently separated mother of three children. She owns a massive home, a luxury SUV, and high-end brands with her stable government salary. She revealed that she loved to shop, but did not like to spend, admitting to her bargain ways. Tyra called herself an 'eBay fanatic' because it was her primary method of material consumption.

"I am an eBay fanatic! If I want anything, clothes, clothing, these jeans, those jeans, I mean anything you can think, I buy on eBay." And she does not use the bidding feature to compete with other buyers.

"I just buy it now. Yeah, that's just fine. Now shoes, all of my shoes in my closet are from eBay. Sweaters... I've learned what designers look good on 
me because I'm small and I'm tall and I just run with it. Literally I will go on eBay and say BCBG sweater extra small - buy now - line it up lowest to highest and then I just do my search. I don't have to rummage through racks, I don't have to wait on line. You know you go into T.J. Maxx or something and you see all of this stuff. I just like if there's different things. So if I'm like right now I need a particular candle from Bath and Body Works that is out of season. I'll go on eBay and people are selling that candle, so I buy a candle, and I'm like let me see if anybody's uploaded some new G-Star jeans or some BCBG shoes or whatever? And I might pick up one two or three four items and then out and then sometimes it's funny because I'll do all this major shopping and then I'll just delete it and that satisfies my shopping urge literally.

Tyra represents what Roopali Mukherjee calls the 'ghetto fabulous aesthetic' (2006). Mukherjee calls on the ghetto fabulous aesthetic as a genre that rose from black film, music, and popular culture in the nineties. Tyra adorns high end fashion, without the exorbitant price tags. She likes to wear flashy things and key status symbols for the upper class. "Revealing a particular class trajectory, often a meteoric rise from rags to riches, bling encapsulates key aesthetic signifiers - luxury cars, designer labels, fur coats gold, and diamond jewelry" (Mukherjee 2006). The ghetto black aesthetic culminates urban black experiences, desires, and socioeconomic status. While many embrace this style without the income to support it, it is most relevant amongst black individuals who have worked to "come up" on some money and be able to buy these highly visible things, which shows the world that they have "made it". It does not have the same weight for individuals who attain the "bling" without putting in the 
work, or with the ability to maintain and sustain it. For this individuals, the consumption of bling can be recognized as a front.

The women's connection with brand-names and/or luxury items differed based on origin. The research participants who were not originally from the DC metropolitan area placed the most distinct emphasis on material goods. These women, who were from New York City, Upstate New York, Los Angeles, Detroit, and North Carolina, identified with things differently than the women born and raised in and around the city. The popular representation of this area as a black well-established metropolis, encouraged women to consume things in order to fit in. These women identified specific preferred brands and placed an emphasis on brand as well as style. The participants from the DC area tended to shy away from directly calling out brands, and instead urged quality over anything - regardless of whether or not the item was brand name.

Georgia, who relocated to Maryland from the West Coast, placed a big emphasis on luxury brands. Coincidentally, she also appreciated the Gucci brand. Georgia grew up in a low-income single parent household. Her father emphasized the importance of fashion and style. She says, "He's the guy who only wears Gucci shoes. He's like upper middle class because he military career really took him far. He's a fine dresser. "Today, as a mother of two, and both a full-time student and full-time professional, Georgia ensures that she makes space in the budget to reward herself accordingly. She does so through her style choices and vacations. She openly shares that she owns a number of luxury brand purses. She is attracted to their high, longlasting quality and the image that it represents. As a child growing up in poverty, Georgia set early goals to have financial freedom and one day be able to offer her children luxuries that she was not afforded as a child. She is a proud homeowner and 
entrepreneur and has found a way to bring in a stable income while completing her graduate studies. Georgia explains how her financial success has influenced the wants and desires of her children, who have been raised in her middle class household with access to specific brands and items.

I'm only mentioning it because I'm not sure if it's a middle-class thing or if it's the fact that I come from poverty. Now I can do it because I don't know if my daughter will have those same experiences because she meets my standards. She gets what she needs, right? So she may not aim for material things like a Louis Vuitton bag because it probably doesn't mean this much to her — it's common for her. 'Mommy has a Louis Vuitton bag' and she knows that my girlfriend - her potential stepmom — is a Gucci person, like my Dad. So this stuff is so common to her, it may not be something she aims for. - Georgia

Georgia exposes her children to luxury brand items because it is her preference, and because it is present among other family members. As a single mother, however, Georgia is still cognizant of her spending and where she shops. She strategically purchases (luxury) things from places where she can get the best price and other added amenities:

I was just in Geneva and I bought a Louis Vuitton bag there, and if all goes the way I want every time I go to Europe I will buy a bag. It's cheaper to buy it there than it is to buy it here. So luggage and stuff like that... I'm all Louis Vuitton. I like Nordstrom for shoes and stuff and that's because of the return policy - like if something happens and it needs to get fixed they don't have a problem fixing their stuff. 
Fashion choices can reveal a lot about a person, from their taste in music, to their profession, to their income or status. With the numerous options available in our consumer society, clothing choices can vary drastically amongst buyers. Elise van der Laan and Olav Velthius recognize post-modern consumers as engaging in a paradigm they have termed as construction-through-consumption. In this, individual's self selection of material goods have replaced traditional sources of identity, and class (2016). Individuals are no longer attributed to specific classes based exclusively on family wealth or name. The purchasing of specific material goods is an act of socioeconomic class. In her brand new, newly constructed single family home, Lisa desired and planned to purchase a $\$ 7,000$ dining room set. She explained the table as elegant and colorful, and from a high end furniture shop 40 miles away, in Baltimore. This dining set, which would be placed in the grand dining room near the front door of her home, would immediately show Lisa's guests her taste and style. Even if guests are not familiar with the specific brand, they may be able to tell that the furniture is expensive and that Lisa has prioritized aesthetic over function.

Consumer marketing and economy scholars have found African Americans are among the most "materialistic" groups of Americans (Podoshen et al 2014). African Americans are major consumers and proudly display their purchases. It has not been proven that African Americans shop or consume more than other groups of Americans, but they are more materialistic, and engage in conspicuous consumption. Lamont and Molnar found that despite their lower median household income and lower household expenditures in a lot of product categories, black households spend more than while households on object of status consumption (2001).

Dyson argues that through hip hop culture, African Americans "learn to place an inordinate amount of value on material wealth and "getting rich" (Kitwana 2002, 
Podoshen 2014). While I agree that hip hop culture does emphasize wealth and the showcase of wealth, I do not believe this is the only or even driving force behind the extreme materialism of African Americans. In this research, my participants were mostly middle aged (35-55) and rarely referred hip hop, specifically, as an influence in their consumer choices. They did, however, discuss the idea of looking the part, or appearing the way they wanted to be treated. In other words, I would argue that African Americans use material consumption as a coping mechanism to ensure their safety, job security, physical security, and/or respect. There are distinct connections between consumption and respectability politics that have existed among African Americans over time. While being "materialistic" is often discussed and represented as a negative characteristic among African Americans, it largely ignores the reasons African Americans are interested in high levels of material consumption in the first place. Those in low-income and underserved communities are able to see other communities flourish with nice, luxurious things in popular culture and in real life on the other side of town. When they are able to make a certain amount of money, they may purchase material goods that represent themselves to others in their own community as having a good income. For those, like the women in this research, who are middle and upper-middle class professionals, they may become "materialistic" to fit in, or compete with the individuals in their social circles, including white men and women in the workplace. Here, materialism and consumption is used to demand these women are treated as equal, by showing that they too, can afford the same things and "look" the part.

Felicity, mother of one, spoke about her desires to purchase more luxury items in the next few years as she becomes more grounded in the upper middle class. She worked hard to purchase her home at the young age of 26 , and continued to set goals 
for herself as she grew professionally. She expressed a sense of pride as she discussed purchasing a luxury brand item at the mall.

"I remember the first time I bought one, I was just so happy. I walked into the galleria and went to the Louis Vuitton store and picked out the bag that I liked. And I paid for it with my debit card - just like that." - Felicity, 28, November 15,2016

Since purchasing her first Louis bag, she has purchased a few more. These material goods serve as a reminder to herself that she has done well and has worked hard. They also compliment her personal style. Unfortunately, because of her race and age (Felicity is 28), she will likely be perceived as a frivolous spender consuming objects that she actually "cannot afford." She earns about $\$ 120,000$ annually, through her full-time government position and part-time job. Felicity vowed to herself that she would purchase herself a Porsche Cayenne SUV in a few years. The Porsche, a luxury brand recognizable across the world, was the ultimate symbol that Felicity had made it. With the job, the income, and a nice home, she felt that the car was the last thing she wanted off of her bucket list. Cars, unlike other material goods, like homes or luxury bags, was unique in that they depreciated in value almost immediately after purchase. They serve as the ultimate status symbol because the consumption of luxury cars is primarily for visibility. While cars, of course, are functional, luxury brand cars typically have the same amount of seats (or less) and do not do things that other cars cannot. Also, for the most part they cannot be resold at a higher price, in ways that vintage bags or homes can.

Felicity desired and set a plan to purchase a Porsche for no other reason than she liked it. It was a clean high-end buy that would bring about admiration from 
others and a sense of pride in herself. To Felicity, the ability to work towards purchasing a Porsche was a privilege in itself. The car, which latest basic models start at $\$ 65,700$ (Porsche 2018), would serve as both a symbol of status and a symbol of perseverance. Felicity owned two cars already, but still had her eyes set on a luxury vehicle for herself and her daughter, showing that function is not the only thing that matters. As single mothers, black women still have preferences, and want the best if they are able to attain it. For those who can afford the things they desire, the ability to purchase specific material goods without entering debt is a major achievement. In this instance, Felicity was not looking to keep up with others in her community - very few people in her circle were homeowners, let alone Porsche car owners — but instead, she wanted to set the bar by owning things that made her happy. She was not searching for validation from others, but recognized that the consumption of these things would show the world that she was stable.

"People are always going to have something to say regardless, but if anyone knows me they know that I handle my business before anything else. I want a Porsche because I deserve it. I don't care if someone thinks I can or cannot afford something. It's the car that I have saved up for with my money. I want a blacked out Cayenne. It's like, a sports car but also a soccer mom car, so I can do both. And I'll keep my old car, too, just for everyday driving or if I need to switch cars or something. ." - Felicity, 28, November 15, 2016.

For some of the participants in this study, the ability to purchase such items cars and handbags — signified success. Vern Baxter explains that among African Americans (male youth specifically), "Style expressed through bodily adornment is a sign of material success that demonstrates strength and celebrates the self in ways that are essential for recognition in the subculture. The absence of this display is a sign of 
weakness" (Baxter and Marina 2008). To be able to purchase a $\$ 2000$ handbag at a retail store with cash is a measure of success and a big deal for someone like Felicity, who was raised in a low-income community and worked extremely hard to make a better life for herself and her daughter.

'Now for Jade (Felicity's daughter), she doesn't have any brands like that. She's too young and she grows too fast. I mostly dress her in things that will last, but is also cute, but I won't waste money on expensive items for her. She doesn't even know what she is wearing half the time." - Felicity, 28, November 15, 2016.

Felicity was aware of luxury brand names, and purchased some of these things though not exclusively. She also shopped at average stores for herself and for her daughter. A large majority of participants affirmed that they were more generous with spending on their children. As single mothers, these women were trained to put their children's needs before their own. They had become accustomed to making sure that their children had certain things before they purchased additional, somewhat unnecessary items for themselves. Because children grow at a much faster speed, many women found themselves shopping for their children's clothing frequently. Because of this, the women were mostly interested in purchasing items that fit well and were good quality, regardless of the brand of the item. For their children, especially those of younger children, the mothers spoke about having things of decent quality, but understood that because kids grow so quickly it was a waste of money to buy very expensive things for their kids when they would just outgrow. Felicity is not concerned with luxury consumption for her three-year-old daughter, Jade, because she is too young to take care of the items and will certainly outgrow them quickly. 
As popular culture and access to the main brands become more easily accessible to the masses, the black middle class constantly seeks to find new trends and brands to sport. Some may be lesser known in the black community, but from my experiences, that can make the brand more valuable to the consumer. For instance, a black consumer who purchases a luxury brand item for the look and feel of the item, without the loud or gaudy logos suggests the person's class and taste. It is perceived that lower class individuals who consume luxury brands wants society to clearly recognize the brands, while those who are of upper classes are not concerned with showing off logos.

Others, like Faith, were not motivated by brands that were "in style" or most popular in society. During our meeting, Faith's hair was a bright pink and blue, she had on high black boots, and a fishnet top. She stepped out of her office to have lunch with me during our interview. "That's why I don't fit in," she says. "Everyone looks like Beyonce or Kim Kardashian. They have bundles [hair weaves] and they have all of this makeup on, and they have these outfits. But I just don't care - its not impressive to me."

At 38, Faith is one of the younger mothers in this research, but has a clear understanding of herself and her style. Faith is extremely vocal and direct, and is raising her daughter to share the same values of owning her individuality.

"I see these women, and they are excited about looking like other people, and there's no substance. I feel for them. I'm eclectic. I'm in Takoma Park, you know, so there's a lot of hippies and hipsters, and there's some legacy black people that have been there for years. So there's a mix. And it's funny because 
the black people in my neighborhood are the one's with the government jobs and all."

Faith attributes her neighborhood to her style influences. Takoma Park is known as the liberal hippie area of the city. Bordering Silver Spring, MD, this area of DC is exposed to a lot of traffic in and out of the city. It has large older single family homes, tree-lined streets, and farmer's markets. It is away from the bustle of downtown DC, and feels more like a suburb than a city. Today, the area is mostly white, with few families who resemble Faith's three generational household. She is one of the few black families left in the neighborhood.

Contrary to research which suggests that the Black middle class is a class of conspicuous consumers, the majority of women in this research were not consumed by designer and luxury brands that were out of their price range or budget for livelihood. Most of them lived in average sized homes (for the area), drove typical cars, and wore clothes that could be found in any average American shopping mall. Few expressed interest in sporting specific designers, but nearly all of them stressed the importance of quality and fit. The participants were strategic with their saving, spending, and budgeting as consumers. As shoppers and hard working women, they often enjoyed shopping, but found ways to purchase desired high end items without high price tags or without sacrificing their financial stability.

Immaterial Consumption and the Importance of Experiences

The black middle class has been categorized over the years as conspicuous consumers who purchase objects that showcase their positions in society. But what happens when the consumption occurs in the absence of things? The women in this 
research identified their consumption patterns outside of typical material goods. Many of them suggested that they spent far more on services, and that alone made them members of the middle class. The participation in extra-curricular activities, for instance, or international travel with the family can costs more significant than the consumption of material goods.

Tyra prioritized material goods and travel. She often traveled outside of Maryland to visit her parents in the Northeast, or took her children on vacation to places in Florida. In addition to family vacations, Tyra frequently took "girls trips" with her friends to international destinations in Europe. Several mothers, like Tyra, stressed the importance of providing worldly experiences to their children. The mothers wanted to offer their children the opportunity to be exposed to a new culture, or to see something outside of their neighborhoods. As single mothers, the women combined their personal interests with their desire to provide their children with new opportunities. Instead of finding a babysitter, many women would bring their children along for the travel experience.

"We travel annually. The kids just started traveling internationally in September. We went to Chichen Itza in Mexico because my kids are bilingual; they study Spanish and they study Mayan history." - Georgia Travel is used as a vacation and a learning tool. The ability to provide children with new experiences is something that many research participants took great pride in. The engagement of travel, particularly to international destinations, presented additional opportunities to consume foreign goods and shop as tourists. Like Georgia, who not only owned a Louis Vuitton purse, but felt it was important to note that that bag was purchased while vacationing in Geneva, these women emphasize the glamorous and atypical experiences to distinguish themselves as middle class. After all, many, many 
people have LV bags, but in this area, Georgia's experience seemed elevated because it was an international purchase. When traveling with children, these women continued to consume in the areas of things like watersports, cultural tours, shopping in an effort to provide the full experience. Because of negative stereotypes surrounding black single motherhood, women who were able to offer their children "middle class opportunities" did so often.

Faith exposes her daughter to new foods as a way to prepare her for life as an adult. 'I take my daughter to really nice restaurants. We don't do like Olive Garden and Outback and Apple Bees. You know, we go to steakhouses, we go to Japanese restaurants. And, you know, my daughter wants to order Thai iced tea and edamame and shit like that and I think that's really neat for a kid to experience. She's challenged to try new things."

Faith's desire to expose her daughter to new cultures is more important to her than material goods, though she admits that material goods are present in their lives. "We do like to shop, and travel, and we like nice cars...fast cars, but you know, that feels like a facade to me. Like the material stuff. The experiences of traveling and eating really good food... I think that's more desirable to me. More so than having a McMansion in Mitchellville [Mitchellville is one of the popular black upper middle class communities in PG County], Or riding in a [Volkswagen] bug — something like that everybody else has, or to say 'yeah, I have a $\$ 5,000$ pocketbook — I mean that's stupid to me!" Faith's interest in experiences and services over material goods aligned with several women in this research.

"Can you help me find tickets to Paris?," Renee asks during our interview. Renee knows that I am a budget travel enthusiast, and is looking to take her daughter to Europe. 
"Maya is taking French in school. I want to show her France. I want her to be able to practice in a natural environment. She needs to practice with people who speak the language, and to experience the culture, so I'm planning to take her to Paris." - Renee, 38, November 14, 2016

Renee's daughter attends a private elementary school about 45 minutes away from her home. Renee pays for her daughter to attend the school and sacrifices early mornings to get Maya prepared for school and transportation on the school bus. The school offers advanced science, technology, and language courses for the students. In Renee's case, her consumption is somewhat intangible, because she cannot physically display her daughter's school. She spends a significant amount on a private school education, travel, and her daughter's extra-curricular traveling dance group.

Extra-curricular activities and out-of-school learning were important to the mothers and their children. Some of the activities included basketball, cheerleading, dance, and soccer. Mothers spent on these activities to provide their children with opportunities outside of the classroom. In a 2012 study of Black Caribbean middle class families in the UK, Vincent argues that extra-curricular activities are "for the parent respondents, a key mechanism through which they support the development of their middle-class Black children" (Vincent, Rollock, Ball, and Gillborn 2012). In my research the single mothers agreed, speaking about extra-curricular activities as important to their children's social, creative, and physical development. The activities also allowed some mothers to enroll their children in activities outside of their community, exposing them to different neighborhoods, activities, and people. Participation in activities outside of school, and in more diverse communities would, in hopes, better prepare the children for navigating key institutions in their futures. 
Annette Lareau calls this acquired knowledge as knowing the "rules of the game" (Lareau 2015).

Wanda's daughter, a high school sophomore at the time of this research, was committed to the cheerleading squad at her school. She participated in cheerleading everyday after school and on Saturdays. She also practiced with the team on evenings throughout the summer. Her daughter did not have a part-time job during the school year, which allowed her to devote large amounts of time to the sport. With cheerleading, Wanda was able to support her daughter in traveling to out-of-state competition sites. She was required to purchase competition uniforms ( $\$ 224$ each year), help fundraise for travel, and pay for dues. For this family, cheerleading was understood as an example of commitment that could be used to push Wanda's daughter to persevere in future endeavors. After longs days of practice or arguments with her coach or teammate, Wanda's daughter would threaten to quit the team. Wanda used the extra-curricular activity as a learning opportunity to show her daughter that one cannot give up when things get tough.

The extra-curricular activities that the children participated in often required time, energy, and money. The activities both allowed the mothers to take a break, by allowing them to get out of the house and spend time with friends. On the other hand, for those with younger children, the extra-curricular activities required the mothers to be more involved and was approached as yet another tasks that would be added to the to-do list. For this reason, few mothers did not allow their children to engage in these additional activities because they did not have the time.

Conclusion

E. Franklin Frazier criticized consumption by African Americans as a means to imitate the wealthy class, and a form of self-hate or denial of blackness (Frazier 
1957). These claims largely ignore the genuine interest in middle class blacks purchasing nice things in which they deserve. "A benefit of reaching the middle class is having the resources for improved consumption of goods and services" (Landry and Marsh, 2011). Here, the women who purchased the luxury brand items or engaged in seemingly elite class activities such as international travel or fine dining, did so not because of their desire to imitate others, but as a way to reward themselves for the hard work they do as single, working mothers. Luxury brand items, though expensive, should not be reserved for the elite class. Additionally, these items are not always purchased through discount stores.

The participants in this research exhibited diverse feelings and attitudes towards consumption. Some openly adhered to consuming luxury and comfort items, while others fiercely rejected the need or interests in luxury items, calling it out as a waste of money. The black middle class is extremely diverse, but they are united in their ability to work and earn the luxuries that are afforded to them. The negative associations with conspicuous consumption had resulted in middle class African American mothers, and arguably middle class African Americans in general, being ashamed of the things they have. Many middle class African Americans desire and adorn certain things and specialty brands, but the negative associations of conspicuous consumption urges some to have justifications for their shopping patterns or to go without purchasing certain brands. Most of the women in this research take offense to being called 'bougie', a term used in the black community for modern bourgeoise that is used to describe black people who have expensive taste, luxury items or experiences, have a higher education, high-paying jobs, or a combination and use things as a justification to act better than others or treat others without these things as second-class. The negative associations with this term encouraged women like Hillary 
to focus away from the term. As an example to show that she is not bougie or a conspicuous consumer, Hillary says, "Do you see my old Lexus [outside]? That's the only car that I have. And I haven't had a car note since 2009. I focus on other things." In this statement, she makes a point to mention the brand of her car, Lexus, which is typically on the higher end, but simultaneously negates its significance by calling it old. Hillary and several other women in this research do this constantly in our discussions. They acknowledge specific luxury brands but also deemphasize their ownership by describing the items as standard, old, or typical. In Others, as the women have explained in this research, take pride in their ability to consume for themselves and their household. Consumption has acted as a form of power for black single mothers, who are otherwise dismissed as unfortunate, poor, or non-contributing members of society. Black women, and black single mothers are major consumers who decide how to spend their available funds to serve the best interests of their household - whether that comes in the form of fashion, automobiles, education, or travel. 


\section{CHAPTER SIX | Conclusion}

I began this research with one major goal in mind — to share the complex experiences of black women who were both single mothers and middle class professionals. After one year of field research and 27 years of personal experience with the demographic, I felt prepared and compelled to share their diverse stories in the form of this dissertation.

Black single women have always represented the middle class for me, as a young black woman growing up in Washington, DC. Prior to college, it did not occur to me that the greater society would think vastly differently of these women. I grew up surrounded by strong, vulnerable, dependable, complicated black women. I have watched my mother, play aunts, and family friends take on single motherhood and succeed. My friends were mostly children of single mothers, and the few friends from two parent households mostly depended on their mothers when it came to parenting responsibilities. To me, black mothers were always the ones in control, and the ones who could make miracles happen. I've since learned that there are no miracles without hard work and dedication, and this research has shown the efforts made by black single women who manage being moms and working professionals. In the first two chapters of this dissertation, I identified the problem, provided background to the research, and laid out my methods for conducting the research project.

In Chapter 3, I contextualized Washington, DC as the site of this research. I traced the history of the city to show the importance that it has had for the African American community for generations. Washington, DC is similar to other metropolitan areas, regarding its high cost of living and accessible jobs, but it is unique because it is the center of the US government with more federal work opportunities than any other place in the country. This has provided a major advantage 
to DC residents, who have historically been African Americans and other people of color. Other minority groups, including women, have been able to benefit from this access. Since 1862, when thousands of freed black people became eligible to earn wages for their work, federal and private sector work opportunities have supported the emergence of a black middle class, and ultimately led to the development of Prince George's County — right over the southeastern border of DC — to flourish and eventually become the wealthiest African American community in the US. Today, Washington, DC's local black community struggles to survive in a city that is rapidly gentrifying, with the high cost of living making residence in the city nearly impossible for its long-term residents. As black students continue to inhabit the DC area to attend top-tier universities like Howard, Georgetown University, and American University, the realities of living in DC are slim, although the professional opportunities of the city remain. The desire to continue a tradition of a black majority and a strong black middle class visibility in DC is the priority of local community organizers and most recently, Aristotle Theresa, a black Civil Rights lawyer from the historically black Anacostia neighborhood. Theresa has sued the DC government for discriminating against long-standing African American residents with the city's new urban renewal efforts, in hopes to bring attention to the displacement of DC's African American residents, and potentially slow down the gentrification for the future.

Chapter 4 defined black women and black motherhood by exploring stereotypes and expectations presented in popular culture through television, film, and the media. Using popular fictional black middle class families, such as the Cosbys (The Cosby Show, 1980) and the Johnsons (Black-ish, 2015), I presented black single mothers in the middle class as being influenced by but not wholly representative of that version of the black middle class. Black single mothers, as professionals, have to 
engage in various strategies, including strategic mothering (Barnes 2016) and dependency on established networks for childcare, in order to manage motherhood and careers. Black women are faced with challenges in the workplace as they work to earn salaries that compete with white women and men within their fields. As single mothers, they must do so by establishing alternative work schedules so that they can keep up with the demands of work while tending to their children's needs. Single motherhood was not the preferred parenting model set forth by the women in this study, but overall, they each argued that it was the most logical structure for their circumstances. Black women are uninterested in entering a marriage or remaining in a marriage or long-tern relationship where the responsibilities are not equal or they feel unfulfilled. Black middle class women are aware of their value and have actively decided to not succumb to the dated ideal that women should be married prior to childbirth or that the middle class exists exclusively with married couples.

The black middle class, like the greater American middle class, is largely defined by things. Our society has come to distinguish people's class and other characteristics based on individual's possessions. We assume that some people are wealthy based on the number of cars they have, or that others are poor based on the neighborhood they live in. Things, or material objects, help us to make sense of our own positions in society, and have been used to compare experiences to others. Without material things, it is more difficult to distinguish the backgrounds of others, since things are consumed for both functionality and aesthetic. In Chapter 5, I explored the black middle class' relationship with material things. The black middle class is identified using specific status symbols that affirm to others and themselves that they are members of the middle class. Most important among these symbols is one's home, with home ownership being a key signal of middle class success in the 
Washington, DC area. Other intangible things, such as vacations and paid extracurricular activities for children are used to identify members of the middle class. Black middle class single mothers mostly see their interests in these things as preference of things aligned with the brands they are used to or believe to be the best representation of their styles and positions in society. The shopping and consumption habits of the black middle class are examined in this chapter. Black single mothers, like any demographic or others within the middle class like nice things. They, too, understand that material things are used to define people. They also take pride in the ability to afford the modern luxuries they desire. From high-end fashion brand clothing to household decor, black middle class women have worked hard to be able to afford the things they have without shame.

\section{Analysis and Major Findings}

The American middle class is a highly complex, multi-dimensional entity, which includes people and family structures of varying degrees. The black middle class, nestled within the larger American middle class, is composed of individuals and families of various makeups. From multi-generational families living under one roof, to same-sex families, to single parent families, the black middle class family is as diverse as the American middle class itself. Using qualitative research methods employed in the fields of anthropology and sociology, in this research I have worked to present a more complex, intersectional narrative of the black middle class family by exploring the specific experiences of black middle class single women, I conducted this research with four main objectives related to identity-making in the black middle class: 
1. Assess the ways in which black middle class women have entered single motherhood and identify the ways they work to maintain or disrupt their current family structures

2. Understand the ways black single mothers acknowledge and respond to their controversial positions within black middle class traditional expectations and perceived norms

3. Verify the status symbols black middle class single mothers consume and acquire to affirm their middle class status

4. Identify the challenges black middle class single mothers face and specific ways they address such challenges

\section{Objective \#1}

This research has shown that black women have become single mothers for a range of reasons both in and out of their control. Very few women admitted to being single by choice through adoption (1) or preference (1); others argued that they were single mothers as a result of unfortunate and/or unwanted circumstances, including divorce (5), death of a spouse (3), or infidelity. A majority of women argued that they were positioned somewhat between more choice and chance. Dating while raising a child (multiple children at times) is difficult for my respondents. These women have to juggle demanding workplace responsibilities and manage a household. When they do find the time to date, they may place high expectations on their romantic interests or avoid "getting too serious" with someone due to lack of time. Overall, these women are single because they have consciously decided to choose themselves first without agreeing to marry or remain in a long-term relationship with a partner that is insufficient for the sake of fulfilling a class-based expectation or representing a negative stereotype. 
Black single mothers have made the tough choices to become mothers, despite their initial desires for the traditional family structure. As a result of several circumstances, many out of the women's control, a two-parent married family structure may have been out of reach. The women in this research, like many women, expressed a sincere interest in marriage and motherhood. However, as they grew older or became pregnant, they prioritized their interest in motherhood over marriage. It was understood that motherhood could operate successfully in the absence of marriage.

Women are not faced with a shortage of men, but they are faced with a shortage of men who are the ideal candidates for marriage. Several of the women in this study were in long-term relationships but have decided not to, or not yet marry their partners. Black single middle class mothers are strategic in their approach to marriage. As mothers and, up until they enter serious relationships, they are the sole provider for their household. In an effort to protect their children and their assets, they give serious consideration for marriage, weighing the pros and cons of the union. Aside from love, which can be expressed without a marriage certificate, black women consider marriage as a business partnership, with black middle class women fully expecting their partners uphold their end of the arrangement.

The unofficial network of black women and extended family and friends make single motherhood possible for single black mothers across socioeconomic backgrounds. "Single" was a term used loosely throughout this research. While all were single by marital status, few expressed dissatisfaction with the word because they understood that others were always available to assist in household. Very few women received adequate assistance from the fathers of the children. Assistance required more than time or money, but required a combination of physical and 
financial child support. Several mothers received little to no help from the children's fathers and were forced to take on every responsibility. They were always present, but depended on their parents, grandparents, extended family, and friends to help care for the responsibilities of the children when needed. Even those women who were adamantly single, and clearly stated that they took on all of the responsibilities from everyday care to doctor appointments to soccer games - felt they had a community of people available to help if ever needed. This strong sense of community allowed for the single mothers to confidently mother while pursuing their careers in hopes of providing their children with the best experiences available.

Black single mothers reject stereotypes while in the workplace by showing up and exceeding in their careers. They stretch their boundaries and over-extend themselves to take on additional tasks at work. The women reject the stereotypes of black single mothers as lazy or dependent on government assistance by working hard, often harder than others in their professional networks.

Black mothers, generally, see their children as reflections of themselves and of the communities that raised them. We are products of our environments. Black single mothers strive to raise their children with specific values in education, appearance, and behavior as they grow up to represent their household. Although they are products of single mother households, these women work hard to show that a single mother household does not equate to dysfunction, lack of care on beheld of the parents, or low-income.

\section{Objective \#2}

Black middle class single mothers have understood through media representations, television and film, and everyday interactions, that single motherhood 
in the black community is highly criticized and stereotyped. In most cases, the women have found ways to respond to the general view of black single motherhood. Black women are vocal in their communities, through blogging, conferences, support groups, and in the workplace about the realities of single motherhood. They also use alternative methods to convey their points, such as behavior and appearance to dispel negative stereotypes. Through both material and immaterial things, black middle class single mothers have challenged domineering/well-known/pertinent stereotypes.

Black middle class single mothers have fully engaged in middle class life. They encourage their children to travel, participate in extra-curricular activities outside of school, and pursue higher education. Through these actions, black middle class single mothers acknowledge their place within the black middle class and participate accordingly. Instead of verbally revealing their class status, these women use their actions to present their status. Additionally, their children act as representatives of their mothers, through behavior and appearance. Black single mothers are aware of the traditional expectations of the middle class, but have realized that they do not need to marry in order to provide themselves or their children with the same available opportunities. Black single middle class mother's actions and positions in the workplace and in the community is their most powerful response to criticism about black single motherhood.

\section{Objective \#3}

Just as the American middle class has been characterized as an individual or family attaining the "American dream" and owning a "house with a white picket fence," the black middle class has come to be identified with specific status symbols. The pursuance of a higher education has long been identified with the black middle 
class. Black people have used higher education to enter the middle class and maintain one's entry.

Black middle class women are consumers. They are homeowners, fashionistas, vacationers, and learners, and so much more. Homeownership is extremely important among this demographic. It was the key symbol used to signify middle class status. Owning a home in the suburbs, and more importantly in highly desired neighborhoods was the goal of most of the women. As reports suggest that home ownership is on the decline, these women, mostly homeowners themselves, have shown that home ownership is still very much important to the middle class - even if affording a home has become more challenging, and to themselves as mothers and providers for their families.

Material objects, such as fashion (clothes, purses, shoes) and cars are also used to affirm socioeconomic status among black middle class single mothers. These objects, which have dual functions as utilitarian objects and as preferred objects of taste, are important to the community. Black women understand their ability to consume certain items as a sign of success. They are mostly proud that they can buy the things they desire and share these things with their children. In addition to showing others that these women are members of the middle class, these objects serve as reminders to the women themselves that they are succeeding in their professions and are combatting negative stereotypes of black single motherhood.

Black single mothers attribute their status to immaterial things, like vacation and education. All things cannot be seen or touched, but are the most prized possessions among them. The women in this research study stressed the importance of life experiences for their children. It is through life experiences, in and outside of the DC metropolitan areas that will beet position their children as middle class members 
of society, and will best support their efforts to maintain their middle class status as they grow older. Black middle class single mothers invest in their children's education through public and private school, tutoring, and educational opportunities and extracurricular activities to give their children a competing edge. Although extra-curricular activities, including sports, are physically and financially on the women, they continue to support their children in these activities in hopes of a better future. Additionally, certain extracurriculars, with hard work and dedication may offer scholarships to college. As single parents, these women are relying on financial aid to support their children through college — something that was expected by every mother in this research.

The concept of a conspicuous consumer discredits black people, and black women who work hard to earn the things they have. This research has revealed that yes, black women do like to spend. They spend on clothes, shoes, homes, and vacations among other things. Black women spend because they can and because they use things to applaud themselves for the hard work it takes to achieve such things. Throughout history, black people have been identified as conspicuous consumers who do not spend wisely, by spending exorbitant amounts of money on things they cannot afford. The women in this research have shown that with hard work, long work hours and countless promotions, spending a little extra on luxury items is well-deserved. As single mothers, the ability to take care of the household and also purchase things the women desire, is an honor, and a sign that they are doing well in society. There is very little credit given for black women who hold stable positions and can, in fact, afford the things that are often regarded as extraneous. 
Objective \#4

Black single women, who juggle careers and motherhood, are one-of-a-kind. They are skilled time-management experts who find ways to manage responsibilities in the workplace and the home. They are victims of the Strong Black Woman trope, which suggests that black women care unfazed by stress, discomfort, and unhappiness. Black women are strong and powerful, the leaders in the community and ... But, black women, like anyone else are not all-powerful super-human beings, and need help sometimes.

Black middle class single mothers are faced with similar challenges of motherhood, as are women and mothers of various racial and socioeconomic backgrounds. They struggle to manage their personal time, are not always taken seriously in the workplace, and have trouble dating. These women have figured out ways to maintain their lifestyles, and their sanity, by co-living with others, forming strong networks of support systems, and modify their work schedules to be present in the home. All of these efforts have made the challenging task of single motherhood possible for these women.

Black single mothers, especially those in the middle class, could benefit from some form of aid. The mothers in this study often felt overcome with the high cost of living in the DC metropolitan area. Although they could technically "afford" their lifestyles, they expressed an interest in qualifying for some form of government aid to assist them in the everyday expenses. It was not taken into account, they felt, by the government that although their incomes may seem to be above average, as the single providing parent of more than one child, a homeowner, and responsible for other bills, they often felt like they were struggling to get by. The women's income level was used to determine if they could enroll their children in free or subsidized after care 
programs or if they could receive food assistance. As much as they worked to be in the middle class, they often felt like they were lower-middle class or just a catastrophe away from low-income. Aid available to single mothers, particularly parents who do not receive any or adequate child support from the other parent, would tremendously assist the mothers in maintaining their class status and securing the future for their children.

Black middle class single mothers are strategic in the workplace (DanielBarnes 2015). They work hard to earn promotions with better titles and higher salaries, while prioritizing their household duties. They set up their schedules so that they could telework certain days throughout the week or modified their work days to report and leave earlier so that they could spend more time at home, all while working to meet their goals in their career. Professional development is important to financial stability and is highly desired among these women. To achieve their professional goals, black middle class single mothers have used their resources and networks to find time to return to school for additional degrees or certifications to support their careers. Career advancement, without children, can be a challenge for women and especially women of color across the country. For black single mothers, the stakes are higher and the goals may be out of further reach.

The concept of personal time is virtually nonexistent among black single mothers with younger children. When they are not at work physically, they are often with their children or doing something on behalf of their children. Many women felt that they were consumed by their parenting and work responsibilities and had no time to take care of themselves. Dating was a challenge or not even considered for some women because they felt they did not have time to add another responsibility or chore to their plates at the moment. Black women suffer from chronic stress (Wilson 2014) 
from managing all of their responsibilities and having little or no personal time for self-care, solitude, or social gathering with friends. As women who identified with the 'strong black woman' trope, these black single mothers did not always have the privilege of taking an extended break from work or leaving their children to go on long vacations.

\section{Connections to Larger Contemporary Issues}

Evolving Families

Today's economy has prompted women to delay motherhood and marriage until professional goals have been reached or until specific financial goals have been met. Recent news reports have brought attention to the decline in childbirth in the United States. Millennials have found that children are far too expensive, and the job market is not profitable enough at present to become a parent. Many young professionals are working positions in which they are unpaid and overworked, and thus, are avoiding parenthood in their mid to early 30s. Some women, however, have decided to become parents despite emerging careers or unstable partnerships. They have considered the impairments that motherhood would likely have on their careers and have decided to become mothers without married partners. To these women, motherhood is a priority - marriage is not.

Single mothers are becoming more common among American women as they work to advance in their professional careers without giving up the opportunity to become mothers. With the societal and biological pressures to become mothers by a certain age, many have decided to become mothers outside of class and family expectations. Black women have combined two competing notions of womanhood: 
mothers and workers. As working professionals, black women have successfully entered the middle class and managed to maintain their households as single mothers outside of the general expectation of the black or American middle class being a twoparent nuclear family structure.

Black families have historically formed alternative family structures that best serve their interests and needs. Black women have had to focus on family and work for generations. During slavery, the institution of marriage was not legally observed for African Americans, but still families formed. Shirley Hill argued that post-slavery, newly freed African Americans were most interested in reconstructing their families, which was not limited to or defined by marriage. Today, black women continue to prioritize family without entering or remaining in unfulfilling marriages or long-term relationships.

Pay Equality

In 2018, Women's Equal Pay Day in the United States was April 10 ${ }^{\text {th }}$. This date represents that number of days needed to work in order to make the same amount paid to white men. Statistics have shown that women make 80 cents to every dollar paid to men. The pay gap is even larger for Black, Latina, and Asian women. Black women are reported to make 66 cents to every dollar, and thus, recognized Black Women's Equal Pay Day four months later, on August $8^{\text {th }}$. Women hold important positions in the workplace. They are contributors of workplace success, leaders, and dedicated employees. Women must be paid fair and comparable wages for their work. Without equal pay, women will never be able to truly compete with men for positions, 
status, and title in the workplace, and they may continue to depend on men or partners for additional income.

Equal pay would allow women, including single mothers, to not struggle as much in their household responsibilities. In other places, where women are not afforded as many opportunities as major metropolitan areas, they may marry out of a combination of emotional connection and need for survival. In DC, and other major cities, women are able to find work opportunities that utilize their skills outside of domestic work and other low-wage fields. Still, their salaries are not comparable to men, and single mothers may have more challenges when attempting to climb the corporate ladder. With higher salaries and salaries equal to their male colleagues, single mothers would be able to afford childcare and stress less about bills and other finances that arise.

Equal pay for black women, especially in the DMV, would allow women heads of households to actually feel comfortable with their incomes. Many women in this research felt that they were just barely in the middle class. They wanted larger homes, bigger savings accounts, and to feel secure in case of emergency. Because of this, some women expressed interests in some form of financial aid. Whether the aid come in the form of college scholarships or need based grants, childcare cost assistance, or food, they identified the ways aid could benefit their families. In general, families must be extremely poor in order to receive any type of government aid. The federal poverty level is $\$ 12,140$ for an individual and $\$ 25,100$ for a family of four (Healthcare.gov 2018). These figures are unrealistic in major cities facing gentrification across this country. Even with incomes double these amounts, families would struggle to find adequate housing, pay bills, and live comfortably. Families should not have to be in poverty in order to receive aid. Single mothers, who have 
decided to take care of their responsibilities and parent without the consistent assistance from the other parent should not be punished for their moderate incomes. In this research, the single mothers fought hard to maintain their middle class lifestyle and provide their children with opportunities that would better position them in the future. Their "high" incomes, however, prevented them from qualifying for various forms of government assistance, including Federal Student Aid when their children entered college. Because of this, black single mothers had to make the tough decision to pay for their children's college educations outright or allow their children to take out student loans, which would ultimately be a hindrance to their own entrance into the middle class. Without aid for all single mothers, the wealth gap will continue to widen as single mothers spend more of their income on their children without additional financial help.

\section{Gentrification}

Gentrification has had major negative impacts on inner city communities. In the context of Washington, DC, it has prevented native Washingtonians from remaining in the communities they grew up in or has made living outside of the city far more affordable and accessible. The processes in play that promote gentrification make middle class living impossible or an extreme challenge in the city. It dramatically affects African Americans and communities of color who are native to the city. In Washington, the black median income is less than a third of that of white median incomes according to the latest US Census data (Giambrone 2017). As black women strive to follow the rules and stay on track to enter and maintain middle class status, the finish line is constantly moving and out of reach. As a result, black 
professionals have been forced to move out of the city in order to afford the middle class lifestyles that they want and deserve.

Gentrification has truly changed the dynamic of our cities. The people and cultures historically represented in inner cities are becoming harder to find. As Washington, DC is white-washed with transplant Capitol Hill interns, federal job seekers and wealthy recent college graduates, the hard work of black professionals who do not have the supportive financial backing of their families is not enough to keep them in the city. Howard University remains to be a major attractant for black students from across the country. Many enroll in Howard University because of its reputation of training highly skilled blacks in various fields, and preparing them to enter the middle and upper middle class. Additionally, Washington, DC's prior reputation as a booming black metropolis with nearby predominately black suburbs, has made the area desirable and inviting for young black professionals. However, wage disparities and high rents make living in the city expensive for native black residents as well as new black migrants, causing them to relocate to areas in PG County or to move away from the DMV area completely.

\section{Black buying power}

We cannot continue to ignore the influences of black Americans in key industries in the US economy and globally. Black people have been excluded from the marketing efforts of major brands including luxury brands and high end designers, but continue to support these brands through their own consumption practices.

Furthermore, these actions encourage others to find interest in specific material goods, bringing more fame, notoriety, and profits to the companies, although the products were typically not designed with black people in mind. Young Black Americans 
especially contribute to and set trends in popular culture, which encourage others to mimic and experiment with alternative styles and materials. We have watched black dollars at work as they help to bring attention to our favorite musicians, Nike Air Jordan's, beauty care and more. Black consumerism, as a major force in the US economy, needs the appropriate attention from researchers and cultural critics. Black buying power is discussed in silos, such as Black Twitter or specific college classes, but not typically in the mainstream. Additional research must be produced and shared so that the needs and wants of black consumers are introduced across all industries and not just fashion and entertainment.

Black single mothers consume products and experiences in the best needs of their households. These women invest in educational opportunities, travel, and specific products that support their household's middle class lifestyle and prepares their children for the future. Black middle class consumption is not limited to fashion and other objects typically categorized within conspicuous consumption. Meaningful objects and experiences as well as luxury items each provide black single mothers with the power to present themselves in the ways they want to be presented. Black single mother's buying power provides them with a way to combat stereotypes and misrepresentations of black single motherhood and diversifies the often monolithic representations of the black middle class.

\section{Recommendations for Future Research}

Black Americans play a major role in the United States and global economy as consumers. It is imperative for researchers to continue to explore the experiences of black individuals as consumers. Black consumers impact major industries including technology, fashion, automobile, and more, but there is limited research dedicated to 
our decisions in consumerism, brand loyalty, or interests. This research only scratches the surface of the potential of research surrounding black consumers. This research has built upon the work of Michele Lamont and Virag Molnar (2001) Roopali Mukherjee (2006), who have identified some ways material objects and consumptions work to represent African Americans in contemporary Black and American culture. While these texts have guided this present research, additional research on the specific experiences of black consumers, including but not limited to, their impacts on specific markets, and the ways in which black consumers are recruited or come to identify with specific brands, would be useful. Black consumers impact on popular culture and trendsetting is often discussed in the media and popular culture, but lacks in-depth well-supported academic research. I would recommend for researchers in the fields of anthropology, sociology, economics, and consumer studies to interact with black consumers to understand more about their processes, instead of simply learning ways to market to this demographic.

This research was limited in its time, funding, and available resources. With a dedicated team and additional funding, this research should be expanded to a larger sample size of black middle class women who are single mothers. In this research, I connected with 30 women over a period of one year. Single mothers, as I learned while in the field, are extremely busy women who have strict schedules to meet the demands of work, motherhood, and if possible, a personal life. The women's schedules required me to be patient when scheduling interviews, and to be open to changing dates and times frequently to meet their needs. A larger sample size of participants would likely bring about new findings for the study, including a more diverse background of women from different professional fields and neighborhoods within the DC metropolitan area. The focus group conducted for this research 
provided very useful information, and created a social dynamic between women of similar backgrounds that was not present in any other research method employed. I would have preferred additional focus groups to gather more information but was unable to do so as a result of my limited sample size and the women's limited availability.

It would be beneficial to administer this research project in different cities across the United States. As stated throughout the research, Washington, DC is an extremely unique city because it is home to the federal government where federal work opportunities are plentiful. Several women in this study were government employees at the time of the research or at some point throughout their careers. By expanding this research to additional research sites, researchers would be able to compare the experiences of black single middle class mothers and the factors that contribute to their identity making within the middle class. In many ways, this research both responds to the findings of black middle class mothers presented in Riche J. Daniels-Barnes' Raising the Race (2016). Daniels-Barnes research took place in and around Atlanta, Georgia, a Southern metropolis with a cost of living significantly less than that of Washington, DC. By completing this particular research project in Atlanta, for instance, researchers may find that women do not have as many professional opportunities, or that they find marriage to be imperative to maintaining a middle class household (just as the women in Daniels-Barnes study represented). An expanded research project which takes place in metropolitan areas across the United States would diversify the research findings and provide a more well-rounded understanding of the challenges, expectations, and lifestyle decisions of black middle class mothers. 
Finally, a larger research staff and more time would allow for more conversations with the women over time. I am aware that some of my participant's experiences have changed throughout my field research and the writing of this dissertation - including change/loss of jobs, pregnancy, and marriage. A longer study that allows for follow-ups on the participants to document change of opinions and experiences over time would benefit the study.

Conclusion

This dissertation has presented the ways in which black middle class single mothers position themselves as members of the middle class using material culture and consumption practices. I have combined two demographics that are typically researched and represented as sharp dichotomies: black single mothers and the black middle class. For many generations, black women have worked and managed their households successfully, but recent opportunities have allowed black women's work in the professional arena to earn livable middle class wages. Through this work I have provided an opportunity for black middle class single mothers in the Washington, DC area to share their experiences. I am honored to have been allowed the opportunity to develop relationships with this phenomenal group of women, and hope that this research brings to light some of their strengths and challenges as they complicate the general understanding of the black middle class. 


\section{References}

Adichie, Chimamanda. 2014. "Why Can't a Smart Woman Love Fashion ?" Elle. http://www.elle.com/fashion/personal-style/a12670/personal-essay-on-style-bychimamanda-ngozi-adichie/.

Alexander, Michelle. 2013. "The Zimmerman Mind-Set.” TIME Magazine.

Allen, Douglas E, and Paul F Anderson. 1994. "Consumption and Social Stratification : Bourdieu's Distinction." Advances in Consumer Research 21: 70-74.

Appadurai, Arjun. 1990. "Disjuncture and Difference in the Global Cultural Economy." Theory Culture \& Society 7 (2): 295-310. doi:0803973233.

_. 2006. "The Thing Itself." Public Culture 18 (1): 15-21. doi:10.1215/08992363-18-1-15.

Archer, Melanie, and Judith R. Blau. 1993. "Class Formation in Nineteenth-Century America: The Case of the Middle Class." Annual Review of Sociology 19 (1993): 17-41. doi:10.1146/annurev.so.19.080193.000313.

Aspers, Patrik. 2010. “Affordable Fashion.” In Orderly Fashion: A Sociology of Markets. Princeton University Press. http://www.jstor.org/stable/j.ctt7sgtm.6\%0AJSTOR.

Author, Book, and Beth Tompkins Bates. 2012. "Chapter Title: Henry Ford Ushers in a New Era for Black Workers Book Title: The Making of Black Detroit in the Age of Henry Ford." University of North Carolina Press. doi:10.5149/9780807837450_bates.7.

Barnes, Riche J. Daniel. 2016. Raising The Race. New Brunswick: Rutgers University Press.

Bauman, Z. 2000. Liquid Modernity. Cambridge: Polity.

Baxter, Vern Kenneth, and Peter Marina. 2008. "Cultural Meaning and Hip-Hop Fashion in the African-American Male Youth Subculture of New Orleans." Journal of Youth Studies 11 (2): 93-113. doi:10.1080/13676260701800761.

Belt, Deb. 2016. "How Income Gaps Affect Prince George 's Schools Students." Bowie Patch, May 2. http://patch.com/maryland/bowie/how-income-gaps-affectprince-georges-schools-students-0.

Bernstein, R. 2009. "Dances with Things: Material Culture and the Performance of Race.” Social Text 27 (4 101): 67-94. doi:10.1215/01642472-2009-055.

Boehm, Lisa Krissoff. 2009. Making a Way Out of No Way: African American Women and the Second Great Migration. Jackson: University Press of Mississippi. 
Botterill, Katherine. 2018. "“ We Don't See Things as They Are, We See Things as We Are ": Questioning the " Outsider " in Polish Migration Research S Ea r Ch." Forum Qualitative Social Research 16 (2): 1-13.

Bourdieu, Pierre. 1977. Outline of a Theory of Practice. Edited by Jack Goody. Cambridge Studies in Social Anthropology. Vol. 16. Cambridge Studies in Social Anthropology. Cambridge University Press. doi:10.1590/S010320702013000100001.

1984. Distinction: A Social Critique of the Judgement of Taste. Cambridge: Harvard University Press. doi:10.1017/CBO9781107415324.004.

Boyd, Robert. 2013. “THE ‘ BLACK METROPOLIS ' IN THE AMERICAN URBAN SYSTEM OF THE EARLY TWENTIETH CENTURY : Harlem, Bronzeville and Beyond," no. 1899: 129-44. doi:10.1111/1468-2427.12048.

Boyd, Robert L. 2009. "Urban Locations of Eminent Black Entrepreneurs in the United States." Urban Studies 46 (10): 2061-78. doi:10.1177/0042098009339434.

Bozkurt, Aras, and Chih-Hsiung Tu. 2016. "Digital Identity Formation: Socially Being Real and Present on Digital Networks Digital Identity Formation: Socially Being Real and Present on Digital Networks." Educational MEdia IntErnational 53 (3): 153-67. doi:10.1080/09523987.2016.1236885.

Brodesser-Akner, Claude. 2008. "Toyota: No One 's Targeted Black Women Like This." Advertising Age.

Brown Givens, Sonja M., and Jennifer L. Monahan. 2005. "Priming Mammies, Jezebels, and Other Controlling Images: An Examination of the Influence of Mediated Stereotypes on Perceptions of an African American Woman." Media Psychology 7 (1): 87-106. doi:10.1207/S1532785XMEP0701_5.

Brown, Steven. 2016. "The Stalled, Struggling Black Middle Class.” Urban Wire: Race, Ethnicity, and Gender. Urban Institute.

Brumfiel, Elizabeth, and John K. Millhauser. 2014. "Representing Tenochtitlan: Understanding Urban Life by Collecting Material Culture." Museum Anthropology 37 (1): 6-16. doi:10.1111/muan.12046.

Carll, Erin. 2017. "Disparate Vantage Points: Race, Gender, County Context, and Attitudes about Harsh Punishments in the US." Social Science Research 64. Elsevier Ltd: 137-53. doi:10.1016/j.ssresearch.2016.10.008.

Cartier, Nina. 2014. "Black Women On-Screen as Future Texts: A New Look at Black Pop Culture Representations." Cinema Journal: The Journal of the Society for Cinema \& Media Studies 53 (4): 150-57. doi:10.1353/cj.2014.0050.

Catanzarite, Lisa, and Vilma Ortiz. 2002. "Too Few Good Men? Available Partners and Single Motherhood among Latinas, African Americans, and Whites.” 
Hispanic Journal of Behavioral Sciences 24 (3): 278-95.

doi:10.1177/0739986302024003002.

Center, Scribe Video. 2018. "The Great Migration: A City Transformed." https://greatmigrationphl.org/node/24.

Chambers, Anthony L., and Aliza Kravitz. 2011. "Understanding the

Disproportionately Low Marriage Rate among African Americans: An Amalgam of Sociological and Psychological Constraints." Family Relations 60 (5): 64860. doi:10.1111/j.1741-3729.2011.00673.x.

Chaney, C. 2011. "The Character of Womanhood: How African American Women's Perceptions of Womanhood Influence Marriage and Motherhood." Ethnicities 11 (4): 512-35. doi:10.1177/1468796811415764.

Chattopadhyay, Sutapa. 2013. "Getting Personal While Narrating the 'Field': A Researcher's Journey to the Villages of the Narmada Valley." Gender, Place and Culture 20 (2): 137-59. doi:10.1080/0966369X.2011.649348.

Cherlin, Andrew. 1992. Marriage, Divorce, Remarriage. Cambridge: Harvard University Press.

Christopher, K. 2012. "Extensive Mothering: Employed Mothers' Constructions of the Good Mother." Gender \& Society qqqqqqqqqq (a): 73-96. doi:10.1177/0891243211427700.

Clarke, Alison J. 2001. "The Aesthetics of Social Aspiration." In Home Possessions: Material Culture Behind Closed Doors, edited by Daniel Miller. Oxford.

Clarke, Edith. 1957. My Mother Who Fathered Me: A Study of the Families in Three Selected Communities of Jamaica. Kingston: The Press University of the West Indies.

Collins, Patricia Hill. 1994a. Shifting the Center: Race, Class, and Feminist Theorizing about Motherhood. Edited by Donna Bassin, Margaret Honey, and Meryle Mahrer Kaplan. Representations of Motherhood. Binghamton: Yale University Press.

1994b. "The Meaning of Motherhood in Black Culture." In The Black Family. Belmont: Wadsworth Publishing.

2000. Black Feminist Thought. New York: Routledge.

Compton, Josette. 2005. "Pantene: Redefining Black Beauty." The New Amsterdam News.

Conroy, Marianne. 2003. "Discount Dreams: Facrory Outlet Malls, Consumption, and the Perfromance of Middle-Class Identity."

Cooper, Brittney. 199AD. "A'n t I a Lady ?: Race Women, Michelle Obama, and the Ever-Expanding Democratic Imagination” 35 (4): 39-57. 
Cosmides, Leda, John Tooby, and Robert Kurzban. 2003. "Perceptions of Race." Trends in Cognitive Sciences 7 (4): 173-79. doi:10.1016/S1364-6613(03)000573.

Craig, Maxine. 2002. Ain't I a Beauty Queen?: Black Women, Beauty, and the Politics of Race. Ain't I a Beauty Queen?: Black Women, Beauty, and the Politics of Race. Oxford: Oxford University Press. doi:10.1093/acprof:oso/9780195152623.001.0001.

Crockett, David. 2017. "Paths to Respectability: Consumption and Stigma Management in the Contemporary Black Middle Class." Journal of Consumer Research 44 (3): 554-81. doi:10.1093/jcr/ucx049.

Crowder, Kyle, and Scott J. South. 2008. "Spatial Dynamics of White Flight: The Effects of Local and Extralocal Racial Conditions on Neighborhood outMigration.” American Sociological Review 73 (5): 792-812. doi:10.1177/000312240807300505.

Curran, Melissa A, Ebony A Utley, Joel A Muraco, Melissa A Curran, Ebony A Utley, Joel A Muraco, An Exploratory, and Ebony A Utley. 2016. “An Exploratory Study of the Meaning of Marriage for African Americans An Exploratory Study of the Meaning of Marriage for African Americans" 4929 (January). doi:10.1080/01494929.2010.528314.

Dancy II, T. Elon. 2011. "Becoming Men in Burning Sands." In Black Greek Letter Organizations 2.0 New Directions in the Study of African American Fraternities and Sororities. University Press of Mississippi.

Darity Jr., William, and Samuel L Myers Jr. 1983. "Changes in Black Family Structure: Implications for Welfare Dependency." American Economic Review 73 (2): 59-64.

http://search.ebscohost.com/login.aspx ?direct=true $\& d b=b t h \& A N=4507249 \&$ site $=$ ehost-live \&scope $=$ site.

Dill, Bonnie Thornton. 1988. “OUR MOTHERS'GRIEF: Racial Ethnic Women and the Maintenance of Families." Journal of Family History 13 (1): 415-31. doi:10.1177/036319908801300125.

Dixon, Patricia. 2009. "Marriage among African Americans: What Does the Research Reveal?” Journal of African American Studies 13 (1): 29-46. doi:10.1007/s12111-008-9062-5.

Djafarova, Elmira, and Oxana Trofimenko. 2017. "Exploring the Relationships between Self-Presentation and Self-Esteem of Mothers in Social Media in Russia." Computers in Human Behavior 73: 20-27. doi:10.1016/j.chb.2017.03.021.

Dominguez, Pier. 2015. "I'm Very Rich, Bitch!': The Melodramatic Money Shot and the Excess of Racialized Gendered Affect in the Real Housewives Docusoaps. Camera Obscura: Feminism, Culture, and Media Studies. Vol. 30. 
doi:10.1215/02705346-2885486.

Drake, St. Clair, and Horace Cayton. 1945. Black Metropolis. Chicago: University of Chicago Press.

DuBois, W.E.B. 1915. The Negro. New York: Cosimo Classics.

Durant Jr., Thomas J and Joyce S Louden. 1986. "The Black Middle Class in America: Historical and Contemporary Perspectives." Phylon 47 (4): 253-63.

Edin, Kathryn. 2000. "What Do Low-Income Single Mothers Say about Marriage?" Social Problems 47 (1): 112-33. doi:10.1525/sp.2000.47.1.03x0282v.

Eichenlaub, Suzanne C, Stewart E Tolnay, and J Trent Alexander. 2010. "Moving Out but Not Up : Economic Outcomes in the Great Migration" 75 (1): 101-25. doi:10.1177/0003122409357047.

Fisher, Christy. 1996. "Black, Hip, and Primed (to Shop)." American Demographics 18 (9): 52.

Fletcher, Michael. 2015. "A Shattered Foundation." The Washington Post, January 24. http://patch.com/maryland/bowie/how-income-gaps-affect-prince-georgesschools-students- 0 .

Ford, Tanisha. 2015. Liberated Threads: Black Women, Style, and the Global Politics of Soul. Chapel Hill: University of North Carolina Press.

http://www.jstor.org/stable/2579018.

Forsey, Martin Gerard. 2010. "Ethnography as Participant Listening." Ethnography 11 (4): 558-72.

Francis, Jacqueline. 2009. "To Be Real: Figuring Blackness in Modern and Contemporary African Diaspora Visual Cultures." Radical History Review, no. 103. doi:10.1215/01636545-2008-040.

Frazier, E. 1957. Black Bourgeoisie. Glencoe: Free Press Paperbacks.

Frazier, E Franklin. 1948. "Ethnic Family Patterns : The Negro Family in the United States Author ( s ): E . Franklin Frazier Source : American Journal of Sociology, Vol . 53, No . 6 ( May, 1948 ), Pp . 435-438 Published by: The University of Chicago Press Stable URL : Http://Ww." American Journal of Sociology 53 (6): 435-38.

Frederick, Rona M, and Jenice L. View. 2009. "Facing the Rising Sun." Urban Education 44 (5): 571-607.

Freeman, Tim. 2006. “"Best Practice' in Focus Group Research: Making Sense of Different Views.” Journal of Advanced Nursing 56 (5): 491-97. doi:10.1111/j.1365-2648.2006.04043.x.

Friedberg, Anne. 1994. Window Shopping: Cinema and the Postmodern. Oakland: 
University of California Press.

Friedman, Daniel, and Daniel N. Ostrov. 2008. "Conspicuous Consumption Dynamics." Games and Economic Behavior 64 (1): 121-45. doi:10.1016/j.geb.2007.12.008.

Frijters, Paul, and Andrew Leigh. 2008. "Materialism on the March: From Conspicuous Leisure to Conspicuous Consumption?” Journal of SocioEconomics 37 (5): 1937-45. doi:10.1016/j.socec.2008.07.004.

Furstenberg, Frank F. 2007. "The Making of the Black Family: Race and Class in Qualitative Studies in the Twentieth Century." Annual Review of Sociology 33: 429-48. doi:10.1146/annurev.soc.33.040406.131727.

Garrison, Marsha. 2007. "The Decline of Formal Marriage : Inevitable or Reversible?" Family Law Quarterly 41 (3): 491-520.

Gibson-Davis, Christina. 2011. "Mothers but Not Wives: The Increasing Lag between Nonmarital Births and Marriage." Journal of Marriage and Family 73 (1): 26478. doi:10.1111/j.1741-3737.2010.00803.x.

Glass, Ruth. 1964. "London: Aspects of Change."

Glick, Paul C., and Lin Sung-Ling. 1987. "Remarriage after Divorce: Recent Changes and Demographic Variations." Sociological Perspectives 30 (2): 162-79. https://doi.org/10.2307/1388997.

Goffman, Erving. 1959. The Presentation of Self in Everyday Life. Edited by Edinburgh University Of. Teacher. Vol. 21. Anchor Books. Doubleday. doi:10.2307/2089106.

Graham, Lawrence Otis. 1999. Our Kind of People: Inside America's Black Upper Class. New York: HarperCollins Publishers.

Gray, Gina Roberts. 2016. "Feelings Behind Out Fibroids.” Essence, May. http://www.essence.com/2016/05/17/feelings-behind-out-fibroids?iid=sr-link1.

Gregory, James N. 2009. "The Second Great Migration: A Historical Overview." In African American Urban History: The Dynamics of Race, Class, and Gender since WWII.

Harley, Sharon. 2002. Sister Circle: Black Women and Work. New Brunswick: Rutgers University Press.

Heller, Laurie. n.d. "Predictors of Parenting among African American Single Mothers: Personal and Contextual Factors." Journal of Marriage and Family.

Henare, Amiria, Martin Holbraad, and Sari Wastell. 2006. "Thinking Through Things.” In Thinking Through Things: Theorising Artefacts Ethnographically, 137. 
Higginbotham, E., and L. Weber. 1992. "MOVING UP WITH KIN AND

COMMUNITY:: Upward Social Mobility for Black and White Women." Gender \& Society 6 (3): 416-40. doi:10.1177/089124392006003005.

Higginbotham, Evelyn Brooks. 1994. Righteous Discontent: The Women's Movement in the Black Baptist Church, 1880-1920. Cambridge: Harvard University Press.

Hill, Shirley A. 2006. "Marriage among African American Women : A Gender Perspective." Journal of Comparative Family Studies 37 (3): 421-40.

Hintzen, Percy Claude, and Jean Muteba Rahier. 2003. "From Structural Politics to the Politics of Deconstruction: Self-Ethnographies Problematizing Blackness." In Problematizing Blackness: Self-Ethnographies by Black Immigrants to the United States, 1-20. London: Routledge. doi:10.1016/B978-0-12-3969590.00001-X.

Holland, Rochelle. 2009. "Perceptions of Mate Selection for Marriage Among African American, College-Educated, Single Mothers." Journal of Counseling \& Development 87 (2): 170-78. doi:10.1002/j.1556-6678.2009.tb00564.x.

Hollway, Wendy, and Tony Jefferson. 2000. Doing Qualitative Research Differently. doi:http://dx.doi.org/10.4135/9781849209007.

Hooks, Bell. 1984. Feminist Theory: From Margin to Center. London: Pluto Press.

Huang, Francis L. 2018. "Do Black Students Misbehave More? Investigating the Differential Involvement Hypothesis and out-of-School Suspensions." Journal of Educational Research 111 (3). Taylor \& Francis: 284-94. doi:10.1080/00220671.2016.1253538.

Hull, Glorida T., Patricia Bell Scott, and Barbara Smith. 1982. All the Women Are White, All the Blacks Are Men, but Some of Us Are Brave. New York: Feminist Press at the City University of New York.

Hunt, M. O., and R. Ray. 2012. "Social Class Identification Among Black Americans: Trends and Determinants, 1974-2010." American Behavioral Scientist 56 (11): 1462-80. doi:10.1177/0002764212458275.

Ibrahim, Yasmin. 2016. "Coalescing the Mirror and the Screen : Consuming the 'Self ' Online." Continuum 4312. Routledge: 1-10. doi:10.1080/10304312.2016.1239066.

Inniss, Leslie B, and Joe R. Feagin. 1995. "The Cosby Show: The View From the Black Middle Class.” Journal of Black Studies 25 (6): 692-711.

Jackson, Aurora P. 1992. "Well-Being among Single, Black, Employed Mothers." Source: Social Service Review 66 (3): 399-409. http://www.jstor.org.

King, A. E. O., and T. T. Allen. 2007. "Personal Characteristics of the Ideal African American Marriage Partner: A Survey of Adult Black Men and Women." 
Journal of Black Studies 39 (4): 570-88. doi:10.1177/0021934707299637.

King, Desmond. 1995. Separate and Unequal: Black Americans and the US Federal Government. Oxford: Oxford University Press.

Laan, E. V. D., and O. Velthuis. 2016. "Inconspicuous Dressing: A Critique of the Construction-through-Consumption Paradigm in the Sociology of Clothing." Journal of Consumer Culture 16 (1): 22-42. doi:10.1177/1469540513505609.

Lacy, Karyn. 2007. Blue-Chip Black: Race, Class, and Status in the New Black Middle Class. Berkeley: University of California Press.

LaFont, Suzanne, and Deborah Pruitt. 1997. "The Colonial Legacy: Gendered Laws in Jamaica." In Daughters of Caliban: Caribbean Women in the Twentieth Century, edited by Consuelo Lopez Springfield, 215-28. Bloomington: Indiana University Press.

Lamont, M., and V. Molnar. 2001. "How Blacks Use Consumption to Shape Their Collective Identity: Evidence from Marketing Specialists." Journal of Consumer Culture 1 (1): 31-45. doi:10.1177/146954050100100103.

Landry, Bart. 2002. Black Working Wives: Pioneers of the American Family Revolution. Berkeley: University of California Press.

Lareau, Annette. 2015. "Cultural Knowledge and Social Inequality." American Sociological Review 80 (1): 1-27. doi:10.1177/0003122414565814.

Lemann, Nicholas. 1999. The Promised Land: The Great Black Migration and How It Changed America. New York: Vintage Books.

Lemke-Santangelo, Gretchen. 1996. "Abiding Courage: African American Migrant Women and the East Bay Community." Chapel Hill: University of North Carolina Press.

Lin, Ken-Hou, and Jennifer Lundquist. 2013. "Mate Selection in Cyberspace: The Intersection of Race, Gender, and Education." American Journal of Sociology 119 (1): 183-215. doi:10.1086/673129.

Lindsey, Treva. 2017. Colored No More: Reinventing Black Womanhood in Washington, DC. Urbana and Chicago: University of Illinois Press.

Mandara, Jelani, Jamie S. Johnston, Carolyn B. Murray, and Fatima Varner. 2008. "Marriage, Money, and African American Mothers '." Journal of Marriage and Family 70 (December): 1188-99.

Mannis, Valerie. 1999. "Single Mothers by Choice." Family Relations 48 (2): 12128.

Marsh, Kris, William a Darity, Philip N Cohen, Lynne M Casper, Danielle Salters, William a Darity Jr, North Carolina, and Southern California. 2007. "The Emerging Black Middle Class : Single and Living Alone The Emerging Black 
Middle Class : Single and Living Alone.” Social Forces 86 (2): 735-62.

Mason, Roger. 1998. The Economics of Conspicuous Consumption: Theory and Thought since 1700. Cheltenham: Edward Elga.

Maylor, Uvanney, and Katya Williams. 2011. "Challenges in Theorising Black Middle Class Authenticity” 23 (3): 345-56. doi:10.1080/09540253.2010.490203.

Mclafferty, Sara L. 1995. “Counting for Women.Pdf." Professional Geographer. doi:10.1111/j.0033-0124.1995.00436.x.

McLanahan, Sara, and Christine Percheski. 2008. "Family Structure and the Reproduction of Inequalities." Annual Review of Sociology 34: 257-76. doi:10.1146/annurev.soc.34.040507.134549.

McQuirter, Marya Annette. 2003. "A Brief History Of African Americans In Washington, DC - Www.Culturaltourism.Org." In African American Heritage Trail. Washington: Cultural Tourism DC.

https://www.culturaltourismdc.org/portal/a-brief-history-of-african-americans-inwashington-dc.

Mechaneck, Ruth, Elizabeth Klein, and Judith Kuppersmith. 1987. "Single Mothers by Choice." Women \& Therapy 6 (2): 263-81. doi:10.1300/J015V06N01_21.

Mendenhall, Ruby, Phillip J. Bowman, and Libin Zhang. 2013. "Single Black Mothers' Role Strain and Adaptation across the Life Course." Journal of African American Studies 17 (1): 74-98. doi:10.1007/s12111-012-9220-7.

Miller-Cribbs, Julie E, and Naomi B Farber. 2008. "Kin Networks and Poverty among African Americans: Past and Present." The Social Worker 53: 43-51. doi:10.1093/sw/53.1.43.

Miller, Daniel. 1998. Material Cultures: Why Some Things Matter. Chicago: University of Chicago Press.

-2012. Consumption and Its Consequences. Cambridge: Polity.

Moffitt, Robert. 2002. "Incentive Effects of the U.S. Welfare System: A Review." Journal of Economic Literature 30: 1-61.

Moller, S. 2002. "Supporting Poor Single Mothers: Gender and Race in the U.S. Welfare State." Gender \& Society 16 (4): 465-84. doi:10.1177/0891243202016004004.

Moore, K. S. 2008. "Class Formations: Competing Forms of Black Middle-Class Identity.” Ethnicities. doi:10.1177/1468796808097075.

Morello, Carol, and Dan Keating. 2011. "Number of Black D.C. Residents Plummets as Majority Status Slips Away." The Washington Post, March 24. https://www.washingtonpost.com/local/black-dc-residents-plummet-barely-amajority/2011/03/24/ABtIgJQB_story.html?utm_term=.f237a231b5bb. 
Morgan, David L. 1998. The Focus Group Guidebook. Thousand Oaks: Sage Publications.

Moynihan, Daniel Patrick. 1965. "The Negro Family: The Case For National Action." Daedalus. doi:10.1017/CBO9781107415324.004.

Mukherjee, Roopali. 2006. "The Ghetto Fabulous Aesthetic in Contemporary Black Culture: Class and Consumption in Barbershop Films." Cultural Studies 20 (6): 599-629. doi:10.1080/09502380600973978.

Murphy, Keith M. 2016. "Design and Anthropology.” Annual Review of Anthropology 23 (2): 1-11. doi:10.1111/gena.12013.

Nobles, WadeW. 1974. "Africanity: Its Role in Black Familes." The Black Scholar 5 (9): 10-17.

Nock, Steven L. 2005. "Marriage as a Public Issue." The Future of Children 15 (2): $13-32$.

Onwuegbuzie, Anthony J., Wendy B. Dickinson, Nancy L. Leech, and Annmarie G. Zoran. 2009. "A Qualitative Framework for Collecting and Analyzing Data in Focus Group Research." International Journal of Qualitative Methods 8: 1-21. doi:10.1177/160940690900800301.

Patillo-McCoy, Mary. 2000. "The Limits of Out-Migration for the Black Middle Class." Journal of Urban Affairs 22 (3): 225-41.

Patillo, Mary. 1999. Black Picket Fences: Privilege and Peril among the Black Middle Class. Chicago: University of Chicago Press.

Perry, a. R. 2013. “African American Men's Attitudes Toward Marriage.” Journal of Black Studies 44: 182-202. doi:10.1177/0021934712472506.

Petrov, Julia. 2012. "Cross-Purposes: Museum Display and Material Culture." CrossCurrents, 219-34. doi:10.1111/j.1939-3881.2012.00231.x.

Phinney, Jean S. 1990. "Ethnic Identity in Adolescents and Adults: Review of Research.” Psychological Bulletin 108 (3): 499-514.

Pierre, Jemima. 2004. "Black Immigrants in the United States and the 'Cultural Narratives' of Ethnicity." Identities 11 (2): 141-70. doi:10.1080/10702890490451929.

Pittman, Cassi Louise. 2012. "Race, Social Context, and Consumption: How Race Structures the Consumption Preferences and Practices of Middle and WorkingClass Blacks.” Harvard University.

Podoshen, Jeffrey S., Susan A. Andrzejewski, and James M. Hunt. 2014. "Materialism, Conspicuous Consumption, and American Hip-Hop Subculture." Journal of International Consumer Marketing 26: 271-83. doi:10.1080/08961530.2014.900469. 
Prince, Sabiyha. 2014. African Americans and Gentrification in DC: Race, Class and Social Justice in the Nations Capital. Burlington: Ashgate.

Reeves, Richard V., and Katherine Guyot. 2017. "Black Women Are Earning More College Degrees, but That Alone Won't Close Race Gaps.” The Brookings Institution: Social Mobility Memos, December 4.

https://www.brookings.edu/blog/social-mobility-memos/2017/12/04/blackwomen-are-earning-more-college-degrees-but-that-alone-wont-close-race-gaps/.

Rich, Motoko, Amanda Cox, and Matthew Bloch. 2016. "Money, Race, and Success: How Your School District Compares." The New York Times, April 29. http://www.nytimes.com/interactive/2016/04/29/upshot/money-race-andsuccess-how-your-school-district-compares.html?_r=0.

Roberts, Dorothy E. 1997. "Unshackling Black Motherhood." Michigan Law Review 95 (4): 938-64.

Rose, G. 1997. "Situating Knowledges: Positionalities, Refelxivities and Other Tactics." Progress in Human Geography 21 (3): 305-20.

Sabia, Joseph J. 2008. "Minimum Wages and the Economic Well-Being of Single Mothers." Journal of Policy Analysis and Management 27 (4): 848-66. doi:10.1002/pam.20379.

Sandlin, Jennifer A., and Julie G. Maudlin. 2012. "Consuming Pedagogies: Controlling Images of Women as Consumers in Popular Culture.” Journal of Consumer Culture 12 (2): 175-94. doi:10.1177/1469540512446877.

Sasso, Nadia. 2015. Am I: Too African to Be American? Too American to Be African? Sierra Leone/ Ghana/ USA.

Saukko, Paula. 2003. Doing Research in Cultural Studies: An Introduction to Classical and New Methodological Approaches. doi:10.4135/9781849209021.

Schwartz, Matthew. 2016. "Why Is There Such A Large Ethiopian Population in the Washington Region?" WAMU, April 21. https://wamu.org/story/16/04/21/how_did_the_dc_region_become_home_to_the _largest_population_of_ethiopians_in_the_us/.

Scott, Graham G, and Kirsty Ravenscroft. 2017. "Bragging on Facebook : And Focus in Online Impression Formation” 20 (1): 58-64. doi:10.1089/cyber.2016.0311.

Silverman, David, and A Marvasti. 2008. Doing Qualitative Research: A Comprehensive Guide. Vol. 44. Thousand Oaks: SAGE Publications. doi:10.1097/00006199-199507000-00011.

Smith, Raymond T. 1996. The Matrifocal Family: Power, Pluralism, and Politics. New York: Routledge.

Smith, Stephanie D. 2009. "Essence Panel Explores Beauty Purchasing." Women's 
Wear Daily. http://www.wwd.com/beauty-industry-news/marketingtrends/essence-panel-explores-beauty-purchasing-2139829.

Stack, Carol B. 1975. All Our Kin: Strategies for Survival in a Black Community. New York: Basic Books.

Staples, Robert. 1985. "Changes in Black Family Structure: The Conflict Between Family Ideology and Structural Conditions." Journal of Marriage and the Family 47 (4): 1005-13.

Stearns, Peter N. 2006. Consumerism in World History: The Global Transformation of Desire. New York: Routledge. doi:10.2307/30041171.

Stewart, Ashley. 2013. First Class: The Legacy of Dunbar, America's First Black Public High School. Chicago: Lawrence Hill Books.

Strmic-Pawl, Hephzibah V., and Phyllis K. Leffler. 2011. "Black Families and Fostering of Leadership.” Ethnicities 11 (2): 139-62. doi:10.1177/1468796811398825.

Sudarkasa, Niara. 2007. “African American Female-Headed Households: Some Neglected Dimension.” In Black Families, 172-83. Thousand Oaks: Sage Publications.

Svensson, Ylva, Jesper Berne, and Moin Syed. 2018. "A Narrative Approach to the Role of Others in Ethnic Identity Formation." Cultural Diversity and Ethnic Minority Psychology 24 (2): 187-95. doi:10.1037/cdp0000182.

Tavernise, Sabrina. 2011. "Washington, D.C., Loses Black Majority - The New York Times.” New York Times. https://www.nytimes.com/2011/07/18/us/18dc.html.

Thomas, Brian. 2014. "Invisibility, Multiculturalism, and Black Canadians." Constellations 21 (4): 589-607. doi:10.1111/1467-8675.12109.

Timseena, Bhanu. 2009. "Participant Observation in Field Research: An Overview." Nepalese Journal of Qualitative Research Methods, 75-86.

Tompkins Bates, Beth. 2012. The Making of Black Detroit in the Age of Henry Ford. Chapel Hill: University of North Carolina Press.

Trentmann, Frank. 2004. "Beyond Consumerism: New Historical Perspectives on Consumption.” Journal of Contemporary History Copyright 39 (3): 373-401. doi:10.1.

U.S. Census Bureau. 2016. "American Community Survey: 1-Year Estimates." https://factfinder.census.gov/faces/tableservices/jsf/pages/productview.xhtml?pid

Veblen, Thorstein. 1899. "The Theory of the Leisure Class." A Penn State Electronic Classics Series Publication 7 (4): 425. doi:10.1086/250610. 
Vincent, C., N. Rollock, S. Ball, and D. Gillborn. 2012. "Raising Middle-Class Black Children: Parenting Priorities, Actions and Strategies." Sociology 47 (3): $427-$ 42. doi:10.1177/0038038512454244.

Warner, Kristen J. 2015. “They Gon' Think You Loud Regardless: Ratchetness, Reality Television, and Black Womanhood." Camera Obscura: Feminism, Culture, and Media Studies 30 (1): 129-53. doi:10.1215/02705346-2885475.

Waymer, Damion. 2011. "Hip Hop and Capitalist Interests." In From Bourgeois to Boojie: Black Middle Class Performances, 159-73.

Wilcox, W Bradford, Mark Chaves, and David Franz. 2004. "Focused on the Family? Religious Traditions, Family Discourse, and Pastoral Practice." Source Journal for the Scientific Study of Religion 43 (4): 491-504. http://www.jstor.org.

Wilkerson, Isabel. 2010. The Warmth of Other Suns: The Epic Story of America's Great Migration. New York: Random House.

Wilson, Angie D. 2014. "The Lived Experiences of Resilient Single Mothers Who Raised Successful Black Men.” Adultspan Journal 13 (2): 90-108. doi:10.1002/j.2161-0029.2014.00029.x.

Wilson, William Julius. 2011. "The Declining Significance of Race: Revisted and Revised.” Daedalus 140 (2): 55-69. doi:10.1162/DAED.

Wood, Margaret C. 2014. "One Hundred Percent Americanism: Material Culture and Nationalism, Then and Now." International Journal of Historical Archaeology 18: 272-83. doi:10.1007/s10761-014-0257-2.

Woody, Bette. 1992. Black Women in the Workplace: Impacts of Structural Change in the Economy. Westport: Greenwood Press.

Zhao, Yawei. 2017. "Doing Fieldwork the Chinese Way: A Returning Researcher's Insider/Outsider Status in Her Home Town.” Area 49 (2): 185-91. doi:10.1111/area.12314.

Zinn, Maxine Baca. 2000. "Feminism and Family Studies for a New Century." The ANNALS of the American Academy of Political and Social Science 571 (1): 4256. doi:10.1177/000271620057100104.

Zou, Manyun. 2016. "The DC Area Has the Highest Median Income in the US Again.” Washingtonian. https://www.washingtonian.com/2016/09/21/the-dcarea-has-the-highest-median-income-in-the-us-again/. 
VITA

AYSHA PRESTON

Born, Washington, DC

2009-2013

B.A., English

B.A., Government and Politics

St. John's University

Queens, New York

2013-2015

M.A., African and African Diaspora Studies

Florida International University

Miami, FL

Teaching Assistant

Florida International University

Miami, FL

2015-present

Doctoral Candidate

Florida International University

Miami, FL

2016

Smithsonian Institution

I received the Smithsonian Institution Graduate

Research Fellowship to conduct archival research at the National Museum of American History.

\section{PRESENTATIONS/ PUBLICATIONS}

Forthcoming. David McKenzie, Colleen Prior, Aysha Preston, Sarah Jencks, Kenneth Foote. 2019. "Memorializing Lincoln's Life Where He Died" in Affective Architectures. Routledge.

The \#BlackLivesMatter Movement: The Critical Role of Black Women, Black Mothers, and Social Media. Digital Blackness Conference, Rutgers University. April 22, 2016. 